\title{
Loss of Spent Fuel Pool Cooling PRA: Model and Results
}

\author{
N. Siu \\ S. Khericha \\ S. Conroy \\ S. Beck \\ H. Blackman
}

Published September 1996

Lockheed-Martin Idaho Technologies Co.

Idaho National Engineering Laboratory Idaho Falls, ID $\mathbf{8 3 4 1 5}$

Prepared for the U.S. Nuclear Regulatory Commission Office for the Analysis and Evaluation of Operational Data under JCN E8238

Technical Monitor: J. Ibarra 


\section{DISCLAIMER}

This report was prepared as an account of work sponsored by an agency of the United States Government. Neither the United States Government nor any agency thereof, nor any of their employees, makes any warranty, express or implied, or assumes any legal liability or responsibility for the accuracy, completeness, or usefulness of any information, apparatus, product, or process disclosed, or represents that its use would not infringe privately owned rights. Reference herein to any specific commercial product, process, or service by trade name, trademark, manufacturer, or otherwise does not necessarily constitute or imply its endorsement, recommendation, or favoring by the United States Government or any agency thereof. The views and opinions of authors expressed herein do not necessarily state or reflect those of the United States Government or any agency thereof. 


\section{DISCLAIMER}

Portions of this document may be illegible electronic image products. Images are produced from the best available original document. 


\section{ABSTRACT}

This letter report documents models for quantifying the likelihood of loss of spent fuel pool cooling; models for identifying post-boiling scenarios that lead to core damage; qualitative and quantitative results generated for a selected plant that account for plant design and operational practices; a comparison of these results and those generated from earlier studies; and a review of available data on spent fuel pool accidents. The results of this study show that for a representative two-unit boiling water reactor, the annual probability of spent fuel pool boiling is $5 \times 10^{-5}$ and the annual probability of flooding associated with loss of spent fuel pool cooling scenarios is $1 \times 10^{-3}$. Qualitative arguments are provided to show that the likelihood of core damage due to spent fuel pool boiling accidents is low for most U.S. commercial nuclear power plants. It is also shown that, depending on the design characteristics of a given plant, the likelihood of either: a) core damage due to spent fuel pool-associated flooding, or b) spent fuel damage due to pool dryout, may not be negligible. 



\section{ACKNOWLEDGMENTS}

The authors gratefully acknowledge the support and guidance provided by J. Ibarra, H. Ornstein, and W. Jones (U.S. Nuclear Regulatory Commission); and the excellent cooperation provided by C. Kukielka, R. Henry, D. Roth, and numerous other technical staff members of the Pennsylvania Power and Light Company. Support for a number of calculations and in formatting the risk models was provided by C. Smith and D. Judd (INEL), respectively. Helpful comments on this report were provided by T. Leahy and J. Bryce (INEL); J. Bryce also provided valuable project management support. This work was performed under DOE Contract Number DE-AC0794ID13223. 



\section{TABLE OF CONTENTS}

Abstract

Acknowledgments

Table of Contents

1. Introduction

$\begin{array}{llr}1.1 & \text { Background } & 1-1 \\ 1.2 & \text { Objectives } & 1-1 \\ 1.3 & \text { Report Outline } & 1-2 \\ 1.4 & \text { Summary of Results } & 1-3\end{array}$

2. Model Summary 2-1

2.1 Modeling Approach 2-1

2.2 Initiating Events and Cases

2.3 Event Trees $2-3$

2.4 Success Criteria $\quad 2-5$

2.5 Fault Trees $2-5$

2.6 Human Reliability Analysis $2-6$

2.7 Basic Event Quantification $\quad 2-7$

2.8 Key Modeling Simplifications and Limitations $\quad 2-7$

3. Pool Heatup Results $\quad 3-1$

3.1 Pool Heatup: Instantaneous Frequencies

3.2 Pool Heatup: Annual Probability $3-3$

3.3 Comparison with Earlier Studies

3.4 Remarks $3-5$

3.4.1 Caveats $3-5$

3.4.2 Model Capability to Treat Other Plants 3-6

4. Post-Heatup Accident Progression: Discussion 4-1

4.1 Post-Heatup Hazards

4.2 Heat and Steam 4-2

4.2.1 Spatial Isolation $\quad 4-2$

4.2.2 Equipment Vulnerability $\quad 4-4$

4.2.3 Hazard Mitigation $\quad 4-4$

4.2.4 Equipment Recovery 4-5

4.3 Flooding 4-5

4.3.1 Spatial Isolation $4-5$

4.3.2 Equipment Vulnerability 4-5

4.3.3 Hazard Mitigation . 4-5

4.3.4 Equipment Recovery 4-6

4.4 Application to Base Case Plant 4-6

4.4.1 Heat and Steam Hazard $4-6$

4.4.2 Flooding Hazard 4-6 


\section{TABLE OF CONTENTS (CONTINUED)}

5. Risk Assessment Insights from Operational Data $\quad$ 5-1

5.1 Event Data

5.2 Mapping to Risk Model

$5-1$

5.3 On Reductions in Seal Failure Frequency

$5-2$

5.4 Concluding Remarks

$5-3$

$5-4$

6. References

$6-1$

Appendices

A. Model $\quad$ A-1

B. Event Quantification $\quad$ B-1

C. Human Reliability Analysis $\quad$ C-1

D. Key Assumptions $\quad$ D-1 


\section{INTRODUCTION}

\subsection{Background}

In 1975, the risk from spent fuel pools in nuclear power plants was analyzed using simple models and assessed to be very small (orders of magnitude lower in frequency) in comparison with the risk associated with core damage accident scenarios [1]. In the mid-1980's, changes in conditions (the onsite storage of fuel using high density storage racks) and new information concerning the possibility of cladding fires in drained spent fuel pools prompted a re-examination of spent fuel pool risk under Generic Issue 82. Based on value/impact and cost-benefit analyses, it was determined that no actions were required by the U.S. Nuclear Regulatory Commission (USNRC) [2]. In 1992, questions raised concerning a newly postulated accident scenario, in which boiling of the spent fuel pool leads to core damage, led to a new study, performed by the Pacific Northwest Laboratory (PNL) under the sponsorship of the USNRC, of the spent fuel pool risk at the Susquehanna Steam Electric Station (SSES) [3]. In a safety evaluation that referenced some of the results reported in Ref. 3, the USNRC staff concluded that "potential regulatory action based on safety concerns was not justified at the SSES". [4].

More recently, the USNRC Office for Analysis and Evaluation of Operational Data (AEOD) has initiated a broader investigation of safety issues associated with spent fuel pools. The AEOD study involves the collection and analysis of event data and plant-specific information (e.g., on configurations, procedures, and training). As part of this study, the Idaho National Engineering Laboratory (INEL) has been tasked with providing a risk perspective to the investigation ${ }^{1}$. The specific objectives of the INEL work are as follows:

- Assess the likelihood of the loss of spent fuel pool cooling for up to six different configurations.

- Determine if the implications of operating experience are consistent with available risk insights and critically evaluate substantive differences.

- Develop qualitative insights on risk associated with accident scenarios involving the loss of spent fuel pool cooling.

\subsection{Objectives}

The objectives of this letter report are to present:

a) the models used to quantify the likelihood of loss of spent fuel pool cooling;

\footnotetext{
${ }^{1}$ Note that "risk", as defined in Ref. 5, is a generic term treating both the likelihood and consequences of accident scenarios. The consequences (e.g., loss of spent fuel pool cooling) to be addressed in a particular study depend on the underlying purpose for the study.
} 
b) the models used to delineate key post-loss of cooling scenarios and the qualitative impact of plant design and operational features on the likelihood of core damage associated with these scenarios;

c) qualitative and quantitative results generated for a selected plant design; and

d) al comparison of these results and those generated from earlier studies [2,3].

Note that an earlier letter report submitted to the NRC [6] documents a review of the models and results presented in Ref. 3; it also provides initial documentation of the models discussed in this report. This report provides more complete documentation of the models and the results generated from these models.

\subsection{Report Outline}

Section 2 of this report outlines the event tree/fault tree model used to estimate the likelihood of loss of spent fuel pool cooling and to delineate possible accident scenarios following loss of cooling. The purpose of the section is to provide a basis for interpreting the results in the following sections. The detailed model documentation is provided in Appendices A-D of the report.

Section 3 provides the estimated near-boiling frequency (NBF) results for a base case plant (the base case is based upon the Susquehanna plant). The section also discusses how sensitivity analyses treating variations in plant design and operational practices can be performed using the model documented in this report.

Section 4 presents a discussion on the factors that affect post-heatup accident progression. The discussion derives the conditional core damage probability (given a spent fuel pool accident) that must be exceeded for a spent fuel pool accident to be a significant contributor to core damage risk, and qualitatively addresses the effect of plant design features and operational practices which will contribute to this conditional core damage probability.

Finally, Section 5 presents risk assessment insights developed from a review of the AEOD database. These insights concern the degree to which the model documented in this report reflects actual operating experience. Insights concerning earlier spent fuel pool modeling efforts are also drawn.

Appendix A of the report documents the event tree/fault tree model developed in this study. The initiating events, event trees, success criteria, and fault trees are presented. Appendix B presents the approach used to quantify basic events not treated in the human reliability analysis (HRA) and the values obtained. Appendix C presents the HRA, and Appendix D lists the key modeling assumptions. 


\subsection{Summary of Results}

The following conclusions regarding the likelihood of spent fuel pool boiling are based upon the calculations and analysis summarized in Section 3 of the report.

- $\quad$ For the base case plant studied (a 2-unit boiling water reactor), the annual probability of spent fuel pool (SFP) boiling events is $5 \times 10^{-5}$. The dominant contribution (56\%) comes from scenarios initiated by a loss of offsite power (LOOP). The contribution from loss of SFP inventory events is also significant (31\%).

- The instantaneous frequency of SFP boiling events during operation is $4 \times 10^{-5} / \mathrm{yr}$. The instantaneous frequency during refueling is $1 \times 10^{-4} / \mathrm{yr}$. The risk profile during operation is dominated by LOOP (66\%); loss of inventory also contributes $(28 \%)$. During refueling, the largest contribution comes from loss of inventory (45\%). LOOP and loss of coolant accidents (LOCAs) also provide large contributions ( $25 \%$ and $22 \%$, respectively).

- Major contributions to the likelihood of SFP boiling come from initiators involving: a) loss of inventory, and b) non-pipe break LOCAs during refueling. These initiators were not addressed in Ref. 3.

- The annual probability of flooding events associated with the SFP is $1 \times 10^{-3}$. The annual probability of flooding following a large seal failure is around $3 \times 10^{-4}$.

- The annual probability of SFP events involving a large loss of inventory and boiling (but not necessarily boil-off) of the remaining inventory is $6 \times 10^{-6}$. For single unit plants, credit cannot be taken for the operators or makeup systems of the second unit and the probability may be a factor of 7 higher.

Regarding the likelihood of core damage involving spent fuel pool initiators, note first that, assuming a base case (non-SFP associated) core damage frequency (CDF) of $5 \times 10^{-6} / \mathrm{yr}$, the conditional probability of core damage given spent fuel pool boiling needs to be greater than $10^{-3}$ in order for the boiling scenario to be a visible ( $>1 \%$ ) contributor to core damage risk. ${ }^{2}$ Similarly, the conditional probability of core damage due to flooding given an SFP event involving severe flooding needs to be greater than $2 \times 10^{-4}$ in order for the flooding scenario to be a visible contributor to core damage risk. The following conclusions are based upon the discussion presented in Section 4 of this report.

- For most, if not all, nuclear power plants, the conditional probability of core damage given spent fuel pool boiling is likely to be smaller than $10^{-3}$. A small probability value is expected due to: a) the spatial separation of emergency core cooling system (ECCS) equipment (which implies that steam/heat must be carried to several rooms to create a

\footnotetext{
${ }^{2}$ The CDF value used is roughly correct for the Grand Gulf boiling water reactor plant. (The CDF from the Susquehanna individual plant examination - IPE - is not used in this comparison, due to significant differences in methodology and quantification between the IPE and this study.) For plants with a higher core damage frequency, spent fuel pool accidents must have an even higher conditional core damage probability to be risk significant.
} 
serious challenge to core cooling), b) the spatial separation of the spent fuel pool area from the ECCS equipment areas, $c$ ) the robustness of most nuclear power plant components with respect to the temperatures associated with spent fuel pool boiling, and d) the length of time available to the operators to mitigate SFP boiling (e.g., by diverting the resulting steam). This conclusion may not be valid for plants with potentially sensitive equipment (e.g., solid-state protection cabinets).

- For plants with spent fuel pools housed in the same building (and above) the ECCS equipment areas, as is the situation in the base case plant, the conditional probability of core damage given SFP-associated flooding may be high enough to warrant additional investigation. In this case: a) the spatial separation may not be as effective as for the heat/steam transport scenario (the elevation boundaries may not be watertight), b) ECCS equipment are generally assumed to be vulnerable to immersion, c) the flooding times can be relatively rapid, especially in the case of large seal failures during refueling.

The above conclusions are the result of a limited scope study. Key modeling simplifications are listed in Section 2; these include the simplified treatment of seal failures (the model treats only seal failures that lead to a loss of spent fuel pool inventory, but does not distinguish between different seals), the use of a simplified human reliability analysis method and the lack of a recovery analysis for dominant sequences. Key simplifications during quantification are discussed in Section 3. These include the use of generic estimates for initiating event frequencies and basic event probabilities, the use of point-estimate calculations throughout, and the lack of any sensitivity analyses. It should also be noted that a number of initiating event frequency estimates are based on the events included in a June 13, 1996 version of the SFP database being developed by AEOD; events added to the database after this date are not reflected in the analysis. 


\section{MODEL SUMMARY}

This section summarizes the loss of spent fuel pool cooling (SFPC) model developed in this study. The description of the modeling approach and key assumptions is intended to provide a basis for interpreting the results in Sections 3 and 4. The detailed model documentation is provided in Appendices A-D of the report. Note that the model is based largely on the Susquehanna plant, a two-unit boiling water reactor with two spent fuel pools, a SFPC system powered off of a non-safety bus and cooled by non-safety service water, residual heat removal (RHR) assist cooling as backup to the SFPC system, and a safety-related emergency service water system to provide makeup when normal pool makeup is unavailable or inadequate. The event tree models are generic enough to allow analyses of a variety of other plant configurations. (For example, they can treat plants where the fuel pools are not cross-tied, as they are at Susquehanna.) However, the success criteria and the fault trees developed are intended to represent Susquehanna.

\subsection{Modeling Approach}

The premise underlying the analysis is that events involving the loss of spent fuel pool cooling can, under some circumstances, lead to boiling of the pool. Furthermore, in a subset of these events, the consequences of these scenarios (e.g., steam release, water flooding) can affect emergency core cooling system (ECCS) equipment, and eventually lead to core damage. Even if core damage does not result, adverse consequences associated with the spent fuel are also potentially of interest [2].

This section summarizes the event trees and fault trees developed in this study. The starting point for model development was the model presented in Ref. 3. As discussed in Ref. 6, improvements have been made to improve the chronological representation of scenarios, to treat demands on operators and equipment due to core challenges during some scenarios (e.g., loss of offsite power), to increase the detail of the post-boiling analysis, to correct some errors in quantification, and to reflect lessons learned from AEOD's review of operating plant experience with spent fuel pool events.

It is useful to note that, with respect to scenarios that can affect the core, the modeling approach employed is analogous to that used in the analysis of the so-called external events (e.g., internal fires). This approach divides the accident scenario analysis into three portions: a) the quantitative hazard analysis (e.g., the frequency of fires of a given size in a given location), b) the equipment fragility analysis (e.g., the conditional probability of damage to a given set of equipment, given the fire), and c) the plant response analysis (e.g., the conditional probability of core damage, given the loss of the given set of equipment). In simplified mathematical form,

$$
\mathrm{CDF}=\sum_{\mathbf{j}} \lambda_{\mathbf{j}} \phi_{\mathrm{edlj}} \phi_{\mathrm{cdlj}, \mathrm{ed}}
$$

where $\lambda_{\mathrm{j}}$ is the frequency of hazard scenario $\mathrm{j}, \phi_{\text {edj }}$ is the conditional probability of equipment damage, given hazard scenario $j$, and $\phi_{c d j, e d}$ is the conditional probability of core damage, given equipment damage and hazard scenario $j$. 
In this study, it can be seen that $\lambda_{\mathrm{j}}$ corresponds to the near boiling frequency (NBF) associated with a given scenario; this is assessed quantitatively. The term $\phi_{\text {edlj }}$, on the other hand, is not quantified. (This term is highly dependent on the particular geometry, equipment layout, and ventilation conditions for the plant being analyzed. Furthermore, the analysis of heat and mass transport: needed to support quantification is beyond the scope of this limited study.) Instead, qualitative issues affecting the likelihood of equipment damage are discussed. Note that the term $\phi_{c d j, e d}$ can be quantified using the internal events model for the plant in question, as long as the likelihood of operator errors is not drastically affected by the spent fuel pool boiling event.

Regarding the particular analysis approach employed, the SAPHIRE [7] software package is used to implement a fault tree linking approach. The SAPHIRE database produced is not documented in this report.

\subsection{Initiating Events and Cases}

The initiating event categories and specific initiating events (acronyms in parentheses) treated in this study are as follows.

- Loss of Spent Fuel Pool Cooling System (LSFP1, LSFP2, LSFP3)

- $\quad$ Loss of Offsite Power (LP1, LP2, LP3)

- Loss of Spent Fuel Pool Inventory (LINVC, LINCS, LINVR, LINRS)

- $\quad$ Loss of Primary Coolant (PLOCA, PLOCR)

- $\quad$ Seismic Event (EQE)

The LSFP1 initiating event covers a loss of the SFPC system for Case 1 (both units operating, as defined below); LSFP2 and LSFP 3 cover Cases 2 and 3 (also defined below). These events treat system loss due to hardware failures and human errors. They also include system loss due to loss of cooling to the SFPC heat exchangers and due to internal flooding and fires.

Note that in principle, the loss of heat exchanger cooling, internal flooding, and internal fires should be treated as separate initiating events, since these causes for loss of SFPC might also affect other parts of the plant. (At Susquehanna, heat exchanger cooling is normally provided by a non-safety service water system.) These events are intentionally grouped with direct losses of SFPC because of the limited scope of this study, and because the results of Ref. 3 indicate that, at least in the case of Susquehanna, the contributions to risk from the loss of service water and internal flooding initiators are relatively small.

The LP1, LP2, and LP3 initiating events treat loss of offsite power (LOOP) events for Cases 1, 2, and 3 (defined below). Note that unlike the model in Ref. 3, the analysis of station blackout (SBO) events is integrated in the LOOP model. 
The LINVC, LINCS, LINVR, and LINRS events include losses of inventory from leaks/breaks from the piping (including misalignments) or gates/seals. (LINVC and LINCS treat large and small leaks, respectively, when all units are operating - Case 1; LINVR and LINRS treat large and small leaks, respectively, where one unit is refueling - Cases 2 and 3.) Only leaks/breaks for which the outgoing flow rate exceeds the normal makeup flow rate are considered. Losses of inventory due to structural failure of the spent fuel pool boundary (e.g., due to missiles, heavy load drops, thermal stresses) are not treated. This category of events may need to be reexamined, depending on the quantitative results of the models documented in this study.

The PLOCA and PLOCR events respectively cover primary system pipe break loss of coolant accidents (LOCAs) in an operating unit and non-pipe break LOCAs (e.g., maintenanceinduced LOCAs) in a unit undergoing refueling. (PLOCA treats situations when all units are operating - Case 1; PLOCR treats situations where one unit is refueling - Cases 2 and 3.) These events are of potential concern because, depending upon plant design, a LOCA can lead to a trip of the SFPC system, and because it creates a demand for the RHR system, which serves as an alternate cooling system for the spent fuel pool. In the case of LOCAs during refueling, the event also provides a potential means for quickly draining the spent fuel pool down to the bottom of the transfer gate.

The EQE event covers seismically-induced losses of offsite power, SFPC piping integrity, and spent fuel pool boundary integrity. Two classes of earthquakes are treated: those with peak ground acceleration (PGA) between $0.2 \mathrm{~g}$ and $0.6 \mathrm{~g}$, and those with PGA above $0.6 \mathrm{~g}$.

The response of the plant to an initiating event depends on the operational states of the reactor units. The following different plant configurations ("cases") are analyzed in this study:

- $\quad$ Case 1 - Both units operating.

- $\quad$ Case 2 - Unit 2 operating, Unit 1 refueling (1/3 core offload).

- Case 3 - Unit 2 operating, Unit 1 refueling (full core offload).

It should be recognized that although some of the event trees presented in the following section are used for a number of cases (e.g., the PLOCR event tree is common to Cases 2 and 3), a separate analysis may be performed for each initiating event/case combination. This allows for changes in top event success criteria and failure probabilities to represent differences between situations (e.g., reduced time to boil, increased presence of plant personnel on the refueling floor).

\subsection{Event Trees}

Event trees are used to represent the sequence of events following an initiating event. In general, the structure and level of detail of the NBF trees developed in this study (see Appendix A) are similar to those of the event trees presented in Ref. 3. The three key differences are as follows.

1) Those trees that model initiators with potential direct impacts on the core (LOOP, seismic, PLOCA) include a top event (UNREC) indicating if recovery is uncomplicated. Assuming 
that operators are generally more concerned with the core than the spent fuel pool, a complicated recovery can inhibit the operators from devoting sufficient resources to deal with the spent fuel pool in a timely fashion. Appendix B provides the operational definition for complicated scenarios used in this analysis.

2) The trees explicitly allow for the possibility that operators will not respond to the initiating event until pool boiling occurs. This delay can be due to lack of awareness (e.g., failed instrumentation) or distraction (e.g., due to a complicated recovery). Note that the AEOD database includes a number of events in which operator response was delayed for many hours, although none were delayed to such an extent that pool boiling occurred.

3) The LOOP, seismic, and primary LOCA trees represent the possibility of "direct core damage" (i.e., core damage not due to the consequences of a spent fuel pool scenario) for complicated scenarios. The purpose of this treatment is to ensure that any final core damage frequency estimates developed from the results of this study do not double count risk contributing scenarios. (Thus, for example, station blackout scenarios which lead directly to core damage are not included in the NBF estimation, even though they could lead to pool boiling.)

As an example, part of the NBF tree for the LP1 initiator is shown in Figure 2.1. The event progression model underlying Figure 2.1 is presented in Appendix A. In addition to top events representing the success/failure of systems and key operator actions, the figure shows a "flag" (non-probabilistic) top event (FVPWR) used to model the plant design, a top event to represent the current plant status (GSTAT), a top event used to model the fraction of times a given scenario is not complicated (UNREC), and a top event used to model the fraction of times a complicated scenario does not lead directly to core damage (NCD). The top events are defined in success terms; per the usual convention, a "Yes" answer to a given top event question selects the upper path at the corresponding event tree branching point.

The post-heatup event trees (PHETs) are presented in Appendix A. These trees treat the progression of selected accident scenarios past pool heatup; one or more separate trees are developed for each non-successful endstate of the NBF trees. (Multiple trees are required for endstates where steaming and flooding effects are of potential concern.) They address the following issues: the spatial isolation of the spent fuel pool from other safety equipment, the vulnerability of exposed safety equipment to the hazards associated with the scenario (i.e., heat and humidity from pool boiling, water from losses of pool inventory), the ability of operators to divert steam/water away from the safety equipment, and the recoverability of safety equipment affected by the steam/water.

As an example, the FPIS1 event tree, whose entry condition involves the loss of spent fuel pool cooling (from the SFPC system, the RHR system, or any other alternate cooling system) and subsequent pool boiling, is shown in Figure 2.2. As in the LP1 tree, there is a flag event (FSPIS) modeling the plant design (in this case, the degree of isolation of key ECCS equipment with regard to heat and steam from the spent fuel pool). There is also a phenomenological top event (SSNV) which models the vulnerability of ECCS equipment to the heat and steam hazard, and two top events modeling the operator and system response. 
The CDF event tree top events are not intended for fault tree analysis. Rather, they raise key questions whose answers can be used to identify entry states into an internal events tree. (Again, this is analogous to the approach used in the analysis of such external events as fires and floods. For example, a fire in a given location may lead to damage of different sets of components, depending on the result of the competition between growth and suppression processes. A major part of the fire analysis is to define the likelihood of damage of different sets of components; this information is then fed into a conventional event tree model.)

\subsection{Success Criteria}

The hardware success criteria developed for each event tree are presented in Appendix A. The success criteria for operator action top events are implicitly defined; the human reliability analysis (HRA) is described in Appendix C.

An example set of success criteria is shown in Table 2.1. These criteria, which apply to the LOOP scenario, Case 1, are based on the analysis of Ref. 3, and are appropriate to the Susquehanna plant. (In general, alternative success criteria will need to be developed when analyzing other plants.) It can be seen that the success criteria depend on the plant's electric power state during the scenario. While not shown (because the relevant portions of the event tree are not shown in Figure 2.1), the success criteria also depend on the status of the gates separating the two spent fuel pools.

\subsection{Fault Trees}

Fault trees have been developed to describe how each of the top events in the model can occur. (A number of these are trivial - they have only a single basic event.) The complete set of fault trees is provided in Appendix A.

For the non-trivial fault trees, e.g., for treating the unavailability of the SFPC system and the RHR system(s), the models supporting Ref. 3 have been used as a starting point. These trees have been modified using a modeling approach similar in spirit to that used in developing Accident Sequence Precursor (ASP) models (see for example Ref. 8). Using this approach, components on a single pipe segment are generally grouped into super-components. In some cases, entire trains of equipment are treated with a single super-component. Also, a number of low probability failure modes (e.g., normally closed manual valves transferring open during the scenario) are omitted. This simplified approach is judged to be adequate for treating spent fuel pool scenarios whose risk, as shown in Ref. 3, tends to be dominated by human error contributions.

An example fault tree for top event R1 (modeling the failure of the Unit 1 RHR system to start and run during a loss of spent fuel pool cooling system scenario, Case 1) is shown in Figure 2.3. (The simplified system piping and instrumentation diagram showing how the fault tree super-components are developed is shown in Figure 2.4.) It can be seen that the tree includes common cause failure and human error basic events. (The scenario-dependence of human error is treated during the accident sequence analysis; rule sets specifying which human error probability is used under which conditions are developed by the analyst and used by SAPHIRE during quantification.) Note that the tree also includes a number of basic events modeling the closing of 
normally open manual valves. While not generally significant contributors to system unavailability, these failures are typically included in the ASP models.

From the accident sequence perspective, it is important to observe that only a single train of RHR is modeled. This is due to the assumption that one train of RHR is always reserved for standby core cooling.

\subsection{Human Reliability Analysis}

In keeping with the simple modeling approach used in other parts of the analysis, a simple human reliability analysis (HRA) technique is employed. This technique, documented in Ref. 9, is a worksheet-based approach developed for the ASP program. A sample worksheet for a single action is shown in Figure 2.5. The analyst evaluates the following performance shaping factors (PSFs) relevant to a given action and modifies base human error probabilities (HEPs) based on the evaluation.

- Complexity, stress, and workload

- Experience/training

- Procedures

- $\quad$ Ergonomics

- $\quad$ Fitness for duty

- Crew dynamics

The first four PSFs are of special interest to this study, due to the nature of the spent fuel pool accident scenarios hypothesized. For example, some of the modeled actions (e.g., placing RHR in a spent fuel pool assist cooling mode) can be fairly complex and time consuming; variations in scenario timing, e.g., due to different decay heat loads, can affect the time available (which affects workload); procedures may not be well developed for some spent fuel pool scenarics because they have not received as much attention as direct core damage scenarios; and some of the needed accident mitigation equipment may not be accessible during the scenario (e.g., elevated radiation levels near the pool during a severe draining event). (The last problem can be considered, in a broad sense, as an ergonomics issue. Another important ergonomics issue concerns the human-machine interface, as this affects how operators are informed of spent fuel pool conditions and how they manipulate components in response to their indications.)

The likelihood of failure of subsequent actions is treated using a second worksheet (see Figure 2.6). This worksheet addresses issues that could increase the dependency between actions. This study treats multiple unit actions (e.g., failure of operators at Unit 2 to restore spent fuel pool makeup using Unit 2 systems, given that operators at Unit 1 have failed using the Unit 1 systems) using the worksheet. (In general, the result is that there is a moderate level of dependency between actions.)

The base HEPs and the modification factors used in this procedure are derived from the widely used Technique for Human Error Rate Prediction (THERP) [10] methodology. Thus, the approach does not represent a fundamentally different approach to dealing with human errors; 
rather, it is a consistent, psychology- and human factors-based compilation which allows relatively quick (if sometimes conservative) estimates of HEPs under a wide variety of conditions.

\subsection{Basic Event Quantification}

As indicated earlier, the fault trees used in this study are super-component based. The unavailability of a given super-component is approximated as the sum of the unavailabilities of the components contained in the super-component definition. The base component unavailabilities, in turn, are the same generic values used in the ASP models [11,12]. The basic events and associated unavailabilities used in this study (including a breakdown into components where relevant) are listed in Appendix B.

In some cases, the basic event values (e.g., for the relative frequency of SFPC system leaks versus SFP boundary leaks) are derived. The estimation process used for each of these values is presented in Appendix B.

\subsection{Key Modeling Simplifications and Limitations}

Because of the limited scope of this study, a simplified approach has been used in the modeling. Attempts have been made to ensure, where appropriate, that the simplifications have been applied uniformly across the initiating events analyzed, in order to avoid distortion of the computed risk profile. However, some distortion is inevitable.

Some of the key modeling simplifications are as follows. (Caveats due to simplifications in the quantification process are discussed in Section 3.)

- The loss of inventory models distinguish between losses of inventory from the spent fuel pool cooling system and those from the spent fuel pool (via seal failures), but do not treat the precise location of the leak. (For example, if a loss of inventory due to seal failure occurs, the model does not address which seal has failed.)

- $\quad$ Recovery analysis has not been performed for any of the dominant sequences or cutsets. (Such an analysis treats operator actions in restoring unavailable equipment.)

- A simplified HRA method (described in Section 2.6 above) has been used. This method does not require a formal task analysis, and is not sensitive to the detailed characteristics of available operating procedures.

- $\quad$ The same HRA models have been employed for the two refueling cases (Cases 2 and 3). The time windows used are appropriate for Case 3 (full core discharge).

- The PLOCR model, which treats a LOCA during refueling, treats all LOCAs as being relatively large (e.g., the equivalent diameter of an RHR pipe).

- It has been assumed that when plant recovery from a LOCA, LOOP, or earthquake is complicated, the operators will not deal with a loss of spent fuel pool cooling until near 
boiling conditions develop. (A "complicated recovery" is defined as a plant recovery given one or more of the following conditions: offsite power is unavailable and one or more emergency diesel generators are unavailable; one or more relief valves is failed open or closed; high pressure coolant injection is unavailable; RHR is unavailable; an earthquake with peak ground acceleration greater than $0.2 \mathrm{~g}$ has occurred. Details on the modeling of complicated recovery are provided in Appendix B.)

- In sequences where the operator response to a loss of spent fuel pool cooling is greatly delayed, it has been assumed that RHR assist cooling will not be employed because of the length of time required to establish this mode of cooling. This assumption is based on an estimate of 8 hours provided for Susquehanna; for other plants, the time required may be sufficiently less that RHR assist cooling could become a viable option.

It can be seen that some of these simplifying assumptions tend to make the model predictions more conservative. The degree of conservatism cannot be determined without more detailed study or at least some sensitivity studies. Both of these options were not pursued due to the limited scope of the project. 
Table 2.1 - Success Criteria for LP1 (Case 1, Pools Cross-Connected)

\begin{tabular}{|l|l||l|l|l|}
\hline DGs Available & Offsite Power & \multicolumn{1}{|c|}{ SR1O2 } & \multicolumn{1}{c|}{ LS1O2 } & \multicolumn{1}{c|}{ ALT-C } \\
\hline All & Early recovery & $\begin{array}{l}2 \text { of } 6 \text { SFPC pumps or } \\
1 \text { train RHR in any unit }\end{array}$ & 2 of 6 SFPC pumps & $\begin{array}{l}\text { Any available alternate } \\
\text { cooling system }\end{array}$ \\
\hline All & Late recovery & 1 train RHR in any unit & 2 of 6 SFPC pumps & $\begin{array}{l}\text { Any available alternate } \\
\text { cooling system }\end{array}$ \\
\hline All & None & 1 train RHR in any unit & Not modeled & $\begin{array}{l}\text { Any available alternate } \\
\text { cooling system }\end{array}$ \\
\hline Some & Early recovery & $\begin{array}{l}2 \text { of } 6 \text { SFPC pumps or } 1 \\
\text { train RHR in any unit }\end{array}$ & 2 of 6 SFPC pumps & $\begin{array}{l}\text { Any available alternate } \\
\text { cooling system }\end{array}$ \\
\hline Some & Late recovery & Not modeled & 2 of 6 SFPC pumps & $\begin{array}{l}\text { Any available alternate } \\
\text { cooling system }\end{array}$ \\
\hline Some & None & Not modeled & Not modeled & $\begin{array}{l}\text { Any available alternate } \\
\text { cooling system }\end{array}$ \\
\hline None & Early recovery & Not modeled & 2 of 6 SFPC pumps & $\begin{array}{l}\text { Any available alternate } \\
\text { cooling system }\end{array}$ \\
\hline
\end{tabular}




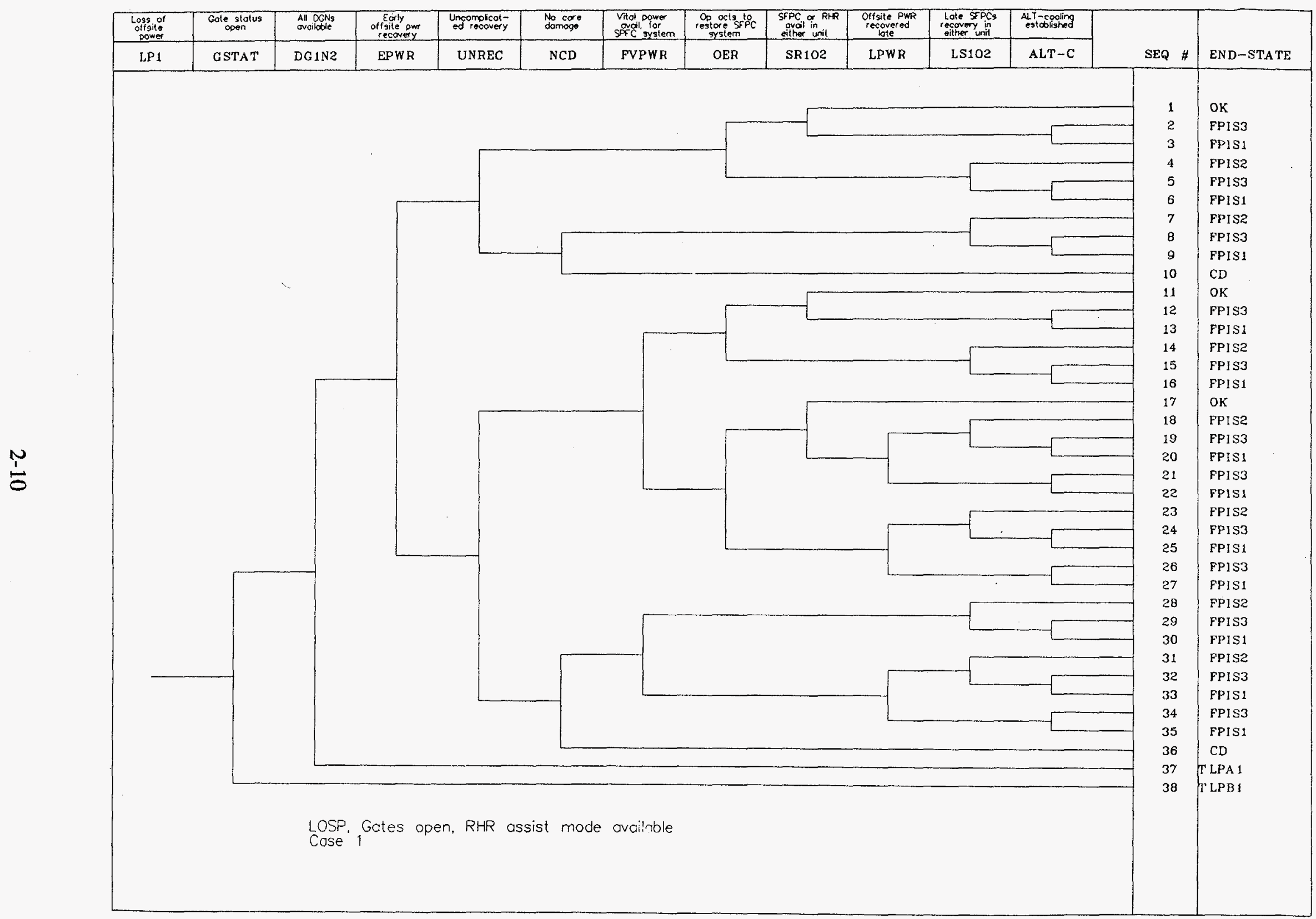

Figure 2.1 - LOOP SFP Heatup Event Tree (Partial) 


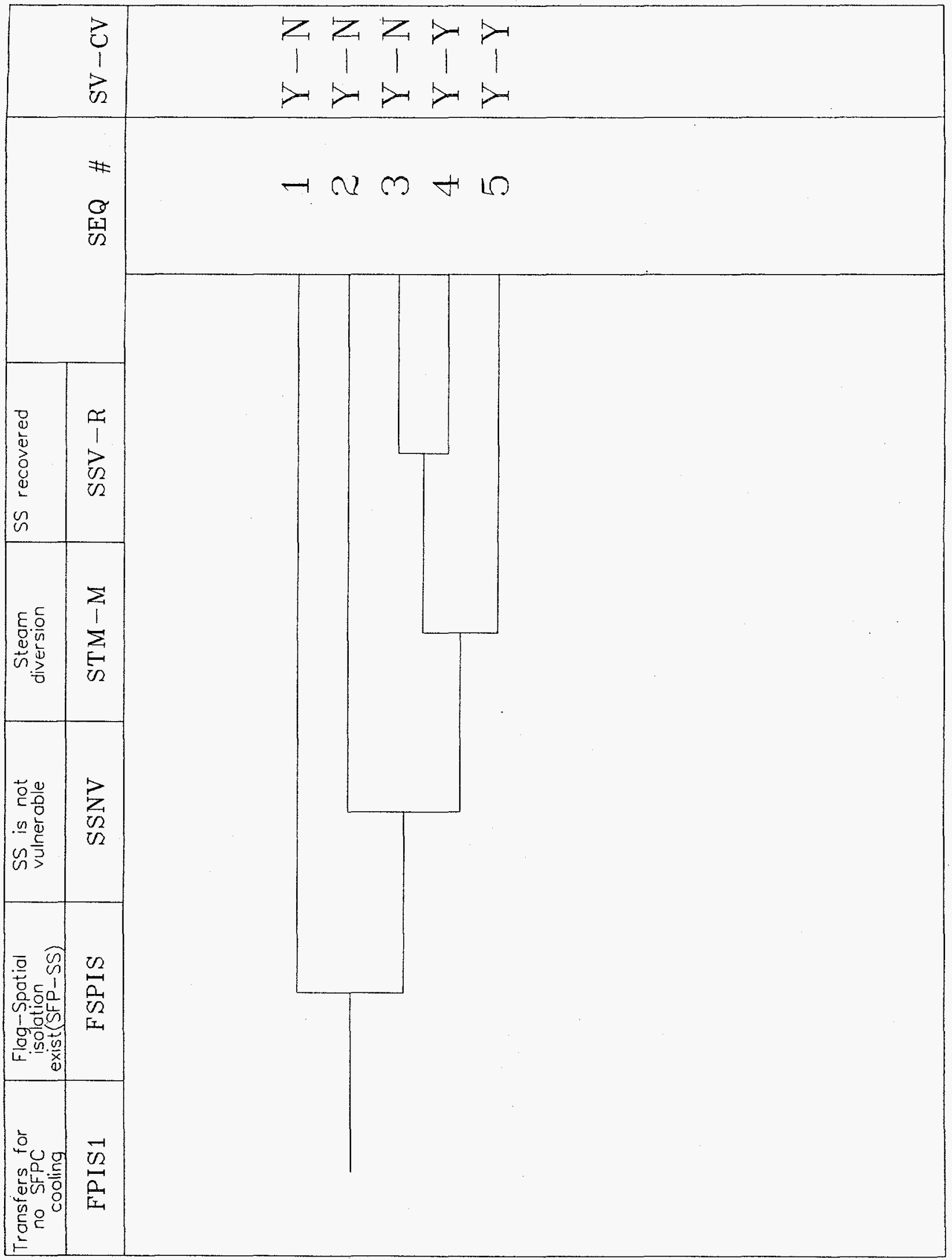

焉 


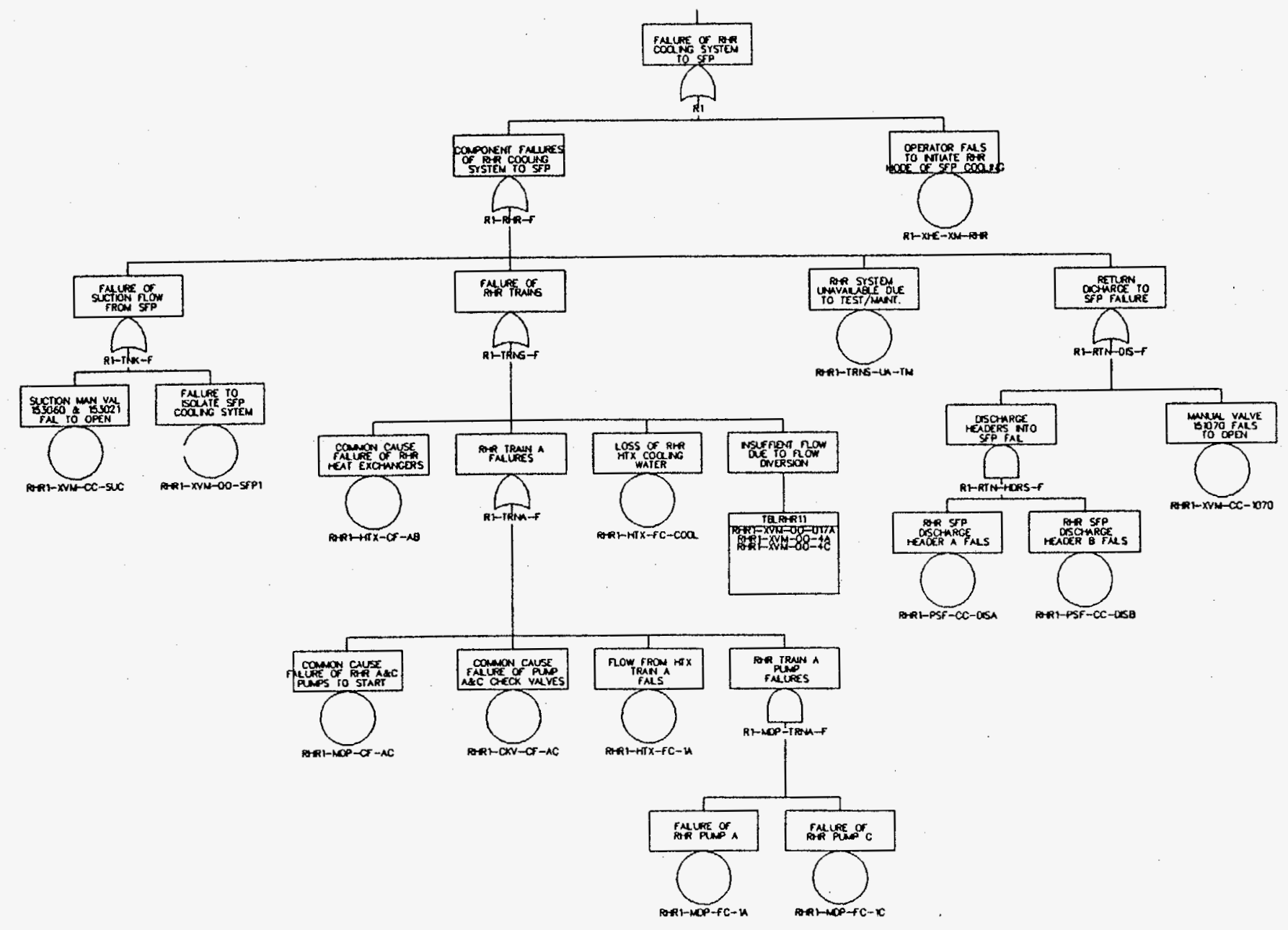

Figure 2.3 - R1 (RHR) Fault Tree 


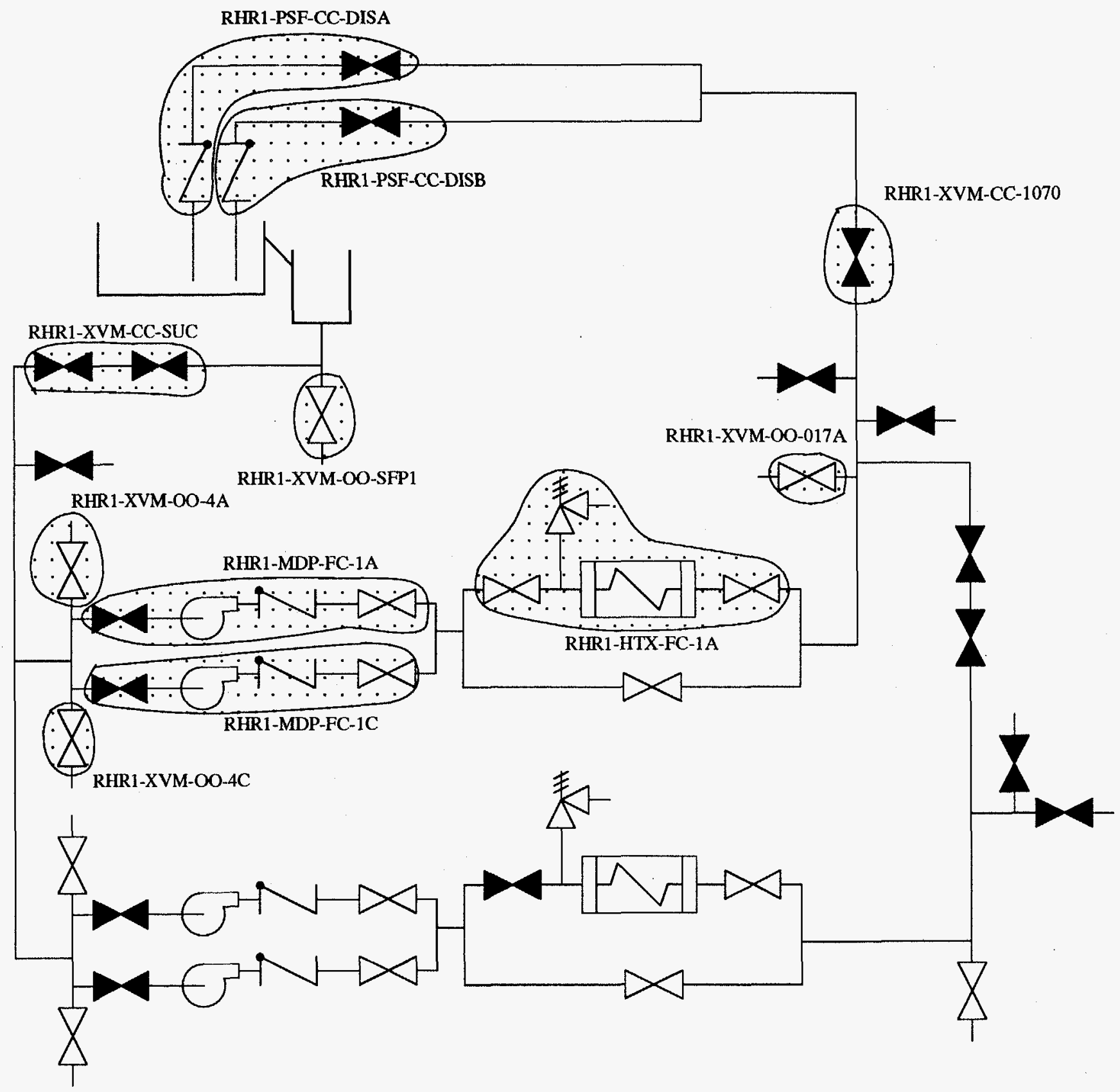

Figure 2.4 - Simplified Piping Diagram, RHR System 
Plant:

Scenario:

Sequence Number:

Cutset:

Task Error Description: and workload

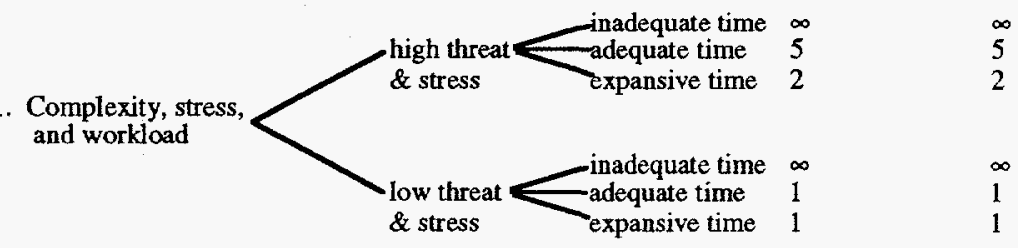

Processing

\section{Response}

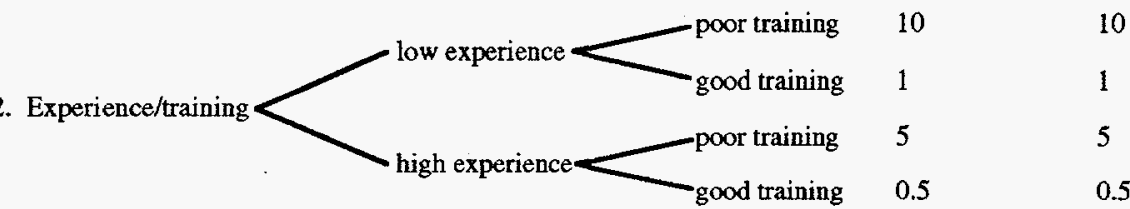

3. Procedures procedures absent $10_{\text {procedures present }}^{10} \underset{\text { poor procedures } 5}{2}$

good procedures 1

4. Ergonomics

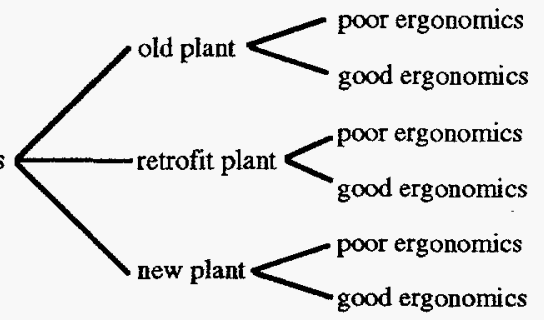

$\begin{array}{ll}5 & 5 \\ 1 & 1 \\ 3 & 3 \\ 0.7 & 0.7 \\ 2 & 2 \\ 0.4 & 0.4\end{array}$

5. Fitness for duty

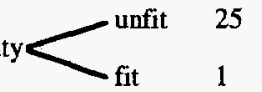

25

1

6. Crew dynamics

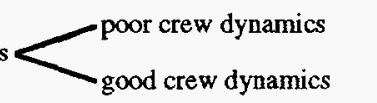

10

10

1

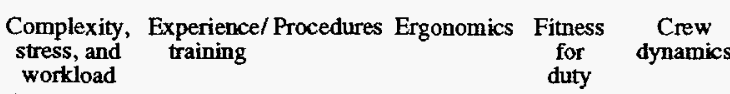

Prosessing: $10 \mathrm{E}-2$ $\mathrm{x}$ $x+x$ $x$ $\mathrm{x}$

Processing Failure Probability

Response: $10 \mathrm{E}-3 \mathrm{x}$ $\mathbf{x}$ $\mathrm{x}$ $\mathbf{x}$ $\mathbf{X}$ $\mathbf{x}$ Response Failure Probability

Figure 2.5 - ASP HRA Worksheet (Sheet 1 of 2) 
DEPENDENCY CONDITION TABLE

\begin{tabular}{|c|c|c|c|c|c|c|c|}
\hline $\begin{array}{l}\text { Condition } \\
\text { Number }\end{array}$ & $\begin{array}{c}\text { Crew } \\
\text { (same or } \\
\text { different) }\end{array}$ & $\begin{array}{l}\text { System } \\
\text { (same or } \\
\text { different) }\end{array}$ & $\begin{array}{l}\text { Location } \\
\text { (same or } \\
\text { different) }\end{array}$ & $\begin{array}{c}\text { Time } \\
\text { (close in } \\
\text { time or not } \\
\text { close in } \\
\text { time }\end{array}$ & $\begin{array}{c}\text { Cues } \\
\text { (additional } \\
\text { or not } \\
\text { additional) }\end{array}$ & Dependency & $\begin{array}{c}\text { Number of } \\
\text { Human Action } \\
\text { Failures }\end{array}$ \\
\hline 1 & $\mathrm{~s}$ & $s$ & $s$ & c & - & complete & \multirow{7}{*}{$\begin{array}{l}\text { if this } \\
\text { error is the }\end{array}$} \\
\hline 2 & $s$ & $s$ & $\mathrm{~s}$ & $\mathrm{nc}$ & na & high & \\
\hline 3 & $s$ & $\mathrm{~s}$ & $\mathrm{~s}$ & $\mathrm{nc}$ & $\mathbf{a}$ & moderate & \\
\hline 4 & $s$ & $s$ & $d$ & $\mathrm{c}$ & - & high & \\
\hline 5 & $\mathrm{~s}$ & $\mathrm{~s}$ & $d$ & nc & na & moderate & \\
\hline 6 & $s$ & $\mathrm{~s}$ & $d$ & nc & a & low & \\
\hline & & & & & & & \\
\hline 7 & $s$ & $d$ & $\mathrm{~s}$ & c & - & moderate & \multirow[t]{2}{*}{ in the } \\
\hline 8 & $s$ & $\mathrm{~d}$ & $\mathrm{~s}$ & $\mathrm{nc}$ & na & low & \\
\hline 9 & $s$ & $\mathrm{~d}$ & $s$ & $\mathrm{nc}$ & $\mathrm{a}$ & low & \multirow[t]{2}{*}{ sequence } \\
\hline 10 & $s$ & $\mathrm{~d}$ & d & c & - & moderate & \\
\hline 11 & $s$ & $d$ & $d$ & $\mathrm{nc}$ & na & low & \multirow[t]{2}{*}{ then the } \\
\hline 12 & $\mathrm{~s}$ & $d$ & $d$ & $\mathrm{nc}$ & $a$ & low & \\
\hline 13 & $d$ & $\mathrm{~s}$ & s & $c$ & - & moderate & \multirow{2}{*}{ dependency } \\
\hline 14 & $\frac{d}{d}$ & $s$ & $\mathrm{~s}$ & $\mathrm{c}$ & na & $\begin{array}{c}\text { Doderate } \\
\text { low }\end{array}$ & \\
\hline 15 & $\mathrm{~d}$ & $s$ & $s$ & $\mathrm{nc}$ & $\mathrm{a}$ & zero & \multirow[t]{2}{*}{ is moderate, } \\
\hline 16 & $\mathrm{~d}$ & $s$ & $d$ & $\mathrm{c}$ & - & zero & \\
\hline 17 & $\mathrm{~d}$ & $s$ & $\mathrm{~d}$ & $\mathrm{nc}$ & na & zero & \multirow{2}{*}{ if it is the } \\
\hline 18 & $d$ & $\mathrm{~s}$ & $\mathrm{~d}$ & $\mathrm{nc}$ & $a$ & zero & \\
\hline 19 & $d$ & $d$ & $\mathbf{s}$ & c & - & low & \multirow[t]{6}{*}{ fourth error } \\
\hline 20 & $d$ & $d$ & $s$ & $\mathrm{nc}$ & na & zero & \\
\hline 21 & $\mathrm{~d}$ & d & $s$ & $\mathrm{nc}$ & $a$ & zero & \\
\hline 22 & $d$ & $d$ & $d$ & $\mathrm{c}$ & - & zero & \\
\hline 23 & d & $d$ & $\mathrm{~d}$ & $\mathrm{nc}$ & na & zero & \\
\hline 24 & d & $\mathrm{d}$ & $\mathrm{d}$ & nc & $\mathrm{a}$ & zero & \\
\hline
\end{tabular}

Using N=Task Failure Probability Without Formal Dependence (calculated on previous page):

For Complete Dependence the probability of failure is 1 .

For High Dependence the probability of failure is $(1+\mathrm{N}) / 2$

For Moderate Dependence the probability of failure is $(1+6 \mathrm{~N}) / 7$

For Low Dependence the probability of failure is $(1+19 \mathrm{~N}) / 20$

For Zero Dependence the probability of failure is $\mathrm{N}$
$\left(1+\left({ }^{*}\right.\right.$ )'
Task Failure Probability With Formal Dependence

Figure 2.6 - ASP HRA Worksheet (page 2 of 2) 


\section{POOL HEATUP RESULTS}

\subsection{Pool Heatup: Instantaneous Frequencies}

As shown in the example LP1 event tree shown in Figure 2.1, a loss of spent fuel pool cooling accident can lead to a number of different endstates, depending on the sequence of events comprising the accident. The endstates defined in this study are:

\begin{tabular}{|c|}
\hline $\begin{array}{l}\text { FPIS1 - Spent fuel pool boiling } \\
\text { FPIS2 - Spent fuel pool heatup (cooling restored late) } \\
\text { FPIS3 - Spent fuel pool steaming (alternate cooling employed in "feed and boil") } \\
\text { FPSF1 - Spent fuel pool boiling; flooding from loss of inventory or LOCA } \\
\text { FPSF2 - Spent fuel pool heatup; flooding from loss of inventory or LOCA } \\
\text { FPSF3 - Spent fuel pool steaming; flooding from loss of inventory or LOCA } \\
\text { CD - Direct core damage (damage not caused by spent fuel pool heatup) } \\
\text { OK - Success state }\end{array}$ \\
\hline
\end{tabular}

FPIS1 and FPSF1 are the most significant spent fuel pool-related endstates from the standpoint of SFP-heatup induced challenges to other plant systems; the other endstates are included in case a plant has a special vulnerability to steam or hot air (e.g., if solid state protection system cabinets can be exposed to the steam/hot air). From the standpoint of flooding following a loss of inventory or LOCA event, the FPSF2 and FPSF3 endstates also are potentially important.

Table 3.1 shows the initiating event frequencies used in this study; Table 3.2 shows the resulting frequencies for each of the endstates for Cases 1, 2, and 3. (Recall that in Case 1, both units are operating; in Case 2, Unit 1 is refueling and has offloaded 1/3 of its core; and in Case 3 , Unit 1 is refueling and has offloaded its entire core.) It is important to note that even though the units of the frequencies shown are per year, these are instantaneous (and not annualized) frequencies. Thus, the Case $\mathrm{j}$ probability of Endstate $\mathrm{i}$ occurring over an arbitrary time interval $[0, t]$ is given by:

$$
\mathrm{P}\{\text { Endstate } \mathrm{i} \text { in }[0, \mathrm{t}] \mid \text { Case } \mathrm{j}\}=1-\mathrm{e}^{-\lambda_{\mathrm{ij}} \mathrm{t}} \approx \lambda_{\mathrm{ij}} \mathrm{t}
$$

where $\lambda_{\mathrm{ij}}$ is the appropriate frequency obtained from Table 3.2. (The approximation on the right hand side of Eq. 3.1 is reasonable as long as $\lambda_{\mathrm{ij}} \mathrm{t}<0.1$.) In order to obtain the annual probability of endstate $i$, the contributions from each case are weighted and summed. The results of this weighting and summing are provided in the next section.

It should also be noted that the direct core damage (CD) endstate frequencies are underestimated for some scenarios. Because this endstate is being treated only to ensure that scenarios which lead to core damage before pool boiling are excluded from the analysis, the CD endstate was not modeled for some sequences where SFP cooling is assured. The CD endstate frequencies are provided for accounting purposes only, and should not be interpreted as representing the total core damage frequency. 
Table 3.2 shows that for Case 1 (both units operating), three initiating events contribute almost $90 \%$ of the frequency of SFP boiling (i.e., endstates FPIS1 and FPSF1); they are loss of offsite power (LP1), small loss of inventory (LINCS), and large loss of inventory (LINVC). These contribute $66 \%, 17 \%$, and $11 \%$, respectively, to the frequency of boiling. For Cases 2 and 3 (one unit refueling), four initiating events contribute over $90 \%$ to the frequency of boiling: loss of offsite power (LP2 and LP3), large loss of inventory (LINVR), primary LOCA during refueling (PLOCR), and small loss of inventory (LINRS). The contributions to the pool boiling frequency from each of these initiators ranges from 20 to $25 \%$. For all cases, the loss of the spent fuel pool cooling system (LSFP1, LSFP2, and LSFP3) initiator and the seismic (EQE) initiator are visible but not large contributors.

It can be seen in Table 3.2 that the relative contribution of LOOP to the pool boiling frequency is significantly higher for Case 1 than for Cases 2 and 3 . This is not because the absolute frequency of LOOP-induced pool boiling changes, but rather because the instantaneous frequencies of the other contributing initiators (loss of inventory, LOCA) are significantly lower during operation than during refueling. (See Table 3.1.)

Note that the earthquake contribution is low because most earthquakes large enough to cause problems with the spent fuel pool are large enough to be a significant hazard to the rest of the plant. (The endstates FPIS1 and FPSF1 only include scenarios involving pool boiling but not direct core damage.) Similarly, a number of important PLOCR-initiated scenarios involve direct core damage, and do not contribute to the FPIS1 and FPSF1 endstates.

Note also that the results for the 1/3 core discharge (Case 2) and the full core discharge (Case 3) are only slightly different. This is due to the dominance of human error as a contributor to failure and a modeling simplification mentioned in Section 2.8: the Case 3 time windows used for the different human actions were employed for Case 2 as well. This simplification was made to reduce modeling effort; a deeper investigation of the different contributions of different refueling strategies should be conducted for this issue.

Tables 3.3a through 3.3d list the Case 1 and Case 3 cutsets for the FPIS1 and FPSF1 endstates which have instantaneous frequencies greater than $1.0 \times 10^{-6} / \mathrm{yr}$. (The results for Case 2 are very similar to those for Case 3.) These tables show the instantaneous cutset frequency, the percent contribution of the cutset to the total endstate instantaneous frequency, the initiating event, the subsequent basic event successes and failures, and some notes on the cutsets.

For both endstates, it can be seen that very few hardware-related basic events are included in the top cutsets. Most of the basic events involve the failure of operators/plant personnel to perform a required action; also included are basic events modeling the failure to recover offsite power.

Table 3.3a lists the dominant FPIS1 cutsets for Case 1. Seven LOOP scenarios contribute over $50 \%$ of the total instantaneous FPIS1 frequency; these scenarios involve situations where the two spent fuel pools are isolated (so SFP cooling must be restored in both units) and where the operators fail to respond early enough to employ RHR in the SFP cooling assist mode. Two loss of inventory scenarios contribute more than $10 \%$ to the FPIS1 frequency. One scenario involves 
the operators failing to respond early and failing to provide makeup late. The other scenario involves failure to provide makeup after the leak has been isolated.

Table 3.3b lists the dominant FPIS1 cutsets for Case 3. Two of the most important cutsets involve a small loss of inventory followed by failure of the operators to provide makeup; they contribute over $25 \%$ of the endstate frequency. The seven LOOP scenarios, which also contribute more than $25 \%$, are similar to the scenarios discussed in Case 1; they involve failure of the operators to respond early.

The single dominant FPSF1 cutset for Case 1 is shown in Table 3.3c. The cutset involves failure to isolate a large leak in SFP cooling system and failure to provide makeup.

The two dominant FPSF1 cutsets for Case 3 are shown in Table 3.3d. Both cutsets involve failure of isolation and failure to provide makeup. It should be noted that, as shown in Appendix C, the human error probability used for these cutsets takes credit for the presence of a second unit and operating crew (the reduction factor is 0.14 , or about $1 / 7$ ). For a single unit plant, or for a multi-unit plant where the spent fuel pools are not cross-connected, such credit may not be taken. The instantaneous frequency of endstate FPSF1 during refueling may then be $2.6 \times 10^{-4} / \mathrm{yr}$. Even after weighting the frequency to account for the fraction of time the plant is undergoing refueling, the resulting annual probability of endstate FPSF1 (which involves boiling in a drained pool) is on the order of $3 \times 10^{-5}$. This is higher than the total probability of pool draining employed in Ref. 2 (around $7 \times 10^{-6}$, as shown in Table 3.7). It therefore appears that for a number of plants, the probability of cladding fires may be higher than the value used in Ref. 2 .

\subsection{Pool Heatup: Annual Probability}

Eq. (3.1) provides the probability of observing a particular endstate in a specified period of time when the plant is in a given configuration (as modeled by Cases 1 through 3). To estimate the probability of observing a particular endstate in one year, the following equation is used:

$$
\mathrm{P}\{\text { Endstate } \mathrm{i} \text { in } 1 \text { year }\} \approx \lambda_{\mathrm{il}}\left(1-\phi_{\mathrm{r}}\right)+\lambda_{\mathrm{ik}} \phi_{\mathrm{r}}
$$

where, as before, $\lambda_{\mathrm{ij}}$ is the frequency of Endstate $\mathrm{i}$ for Case $\mathrm{j}, \mathrm{k}=2$ or 3 (depending on whether the plant performs $1 / 3$ or full core offloads during refueling), and $\phi_{\mathrm{r}}$ is the average fraction of time the plant is in a refueling outage. ${ }^{1}$ Note that this model assumes that one unit is always operating over the year. It therefore does not treat situations when both units are in an outage, nor does it treat situations where one unit is in a non-refueling outage. It is not believed that these simplifications will greatly distort the results, due to the relatively small amount of time multi-unit plants would be undergoing simultaneous outages (under normal circumstances), and due to the lower heat loads associated with outages. However, as implied by the results of recent shutdown risk assessments $[15,16]$, the risk from these situations may not be negligible. Additional analysis is needed to determine the quantitative significance of these simplifications.

\footnotetext{
${ }^{1}$ To make the units consistent, the right hand side of Eq. (3.2) can be multiplied by 1 year.
} 
The results for endstates FPIS1 and FPSF1 (where the SFP is boiling) obtained assuming an 18-month refueling cycle and a 2-month refueling outage are shown in Table 3.4. The results associated with a 1-month refueling outage are shown in Table 3.5. (These latter results assume that the model parameters, e.g., the failure rates, do not change significantly as the outage time decreases.) Not surprisingly, both annualized risk profiles closely resemble the risk profile for Case 1. However, the contribution for primary LOCA has become more important, due to its importance during refueling.

Only three initiators are modeled as being able to lead to flooding: a loss of inventory, a primary LOCA during refueling (i.e., a LOCA in a connected system - a "J LOCA", or a maintenance-induced LOCA - a "K LOCA"), or an earthquake. The annual probabilities for endstates involving flooding (i.e. FPSF1, FPSF2, and FPSF3) are shown in Table 3.6. Both the relatively high total probability (nearly $1 \times 10^{-3}$ ) and the risk profile (a large contribution from primary LOCAs) are notable.

\subsection{Comparison With Earlier Studies}

The results of an earlier NRC report on spent fuel pool risk (which focused on scenarios involving pool drainage and consequent zircaloy cladding fires) [2] and of an NRC-sponsored investigation of the risk at Susquehanna [3] are shown in Tables 3.7 through 3.10. (Table 3.9 provides the annualized frequencies obtained from Ref. 3; Table 3.10 presents the instantaneous frequencies, which can be compared with the results of this study shown in Table 3.2.)

Comparing Table 3.4 (this study) with the BWR "Best-Estimate" column in Table 3.7 (Ref. 2), it can be seen that the results of this study are higher by nearly an order of magnitude. (Note that Table 3.4 addresses spent fuel pool boiling; Table 3.7 addresses a complete loss of spent fuel pool inventory.) Perhaps more importantly, the dominant contributors are quite different.

In Ref. 2, the endstate frequency is dominated by seismic contributions. In this study, the earthquake contribution is relatively unimportant. This difference arises because: a) this study estimates much higher contributions for other initiators, as discussed below, and b) this study excludes the pool boiling contribution due to earthquakes that are severe enough to cause core damage, regardless of their impact on the spent fuel pool. Note that the sum of the combined CD, FPIS1, and FPSF1 frequencies in Table 3.2 is $7.3 \times 10^{-6} / \mathrm{yr}$; this is quite comparable to the value of $6.7 \times 10^{-6} / \mathrm{yr}$ reported in Ref. 2 .

Regarding the contribution from loss of inventory events, Ref. 2 reduces the empirical frequency of pneumatic seal failures (around $0.01 / \mathrm{yr}$ ) by a factor of 1000 to arrive at an estimated frequency of severe pneumatic seal failures. As discussed in Section 5 of this report, there seems to be little evidence to support such a reduction; this report uses empirically estimated generic initiating event frequencies for losses of inventory, which include seal failures. (Details on the initiating event frequencies used in this study are provided in Appendix B.) Note that while this study's predicted annual probability of $4.6 \times 10^{-6}$ for endstate FPSF1 (loss of inventory events only) is comparable to that of Ref. $2\left(6.7 \times 10^{-6}\right)$, the probability of endstate FPSF1 may increase by nearly an order of magnitude for single unit plants (see Section 3.1). 
Regarding the contribution from LOOP events, this initiating event was not modeled explicitly in Ref. 2 .

To compare the results of this study with those of Ref. 3, Table 3.4 can be compared with Table 3.9. It can be seen that the total frequencies of pool boiling differ only by about a factor of 2. Furthermore, the contributions from the different initiators are comparable. (Note that this study treats LOOP, Extended LOOP, and station blackout using a single initiating event; the combined NBF of $1.1 \times 10^{-5} / \mathrm{yr}$ in Table 3.9 compares reasonably well with the pool boiling frequency of $2.7 \times 10^{-5}$ reported in Table 3.4 for LOOP events.) The most significant difference concerns the loss of inventory initiating event; this event is an important contributor in this study, but is not treated in Ref. 3. Another difference concerns the LOCA initiator; Ref. 3 does not treat special LOCAs during shutdown (the " $J$ " LOCAs, i.e., LOCAs in connected systems, and the " $\mathrm{K}$ " LOCAS, i.e., maintenance-induced LOCAs). As a result, Ref. 3 underestimates the LOCA contribution to pool boiling frequency. A third significant difference concerns the LOCA with LOOP initiator. As discussed in Ref. 6, the treatment in Ref. 3 is incorrect and is overly conservative. This study does not treat the LOCA with LOOP initiator explicitly because of its very low probability.

It should be pointed out that while the overall pool boiling frequency results of this study are numerically comparable to those of Ref. 3, the modeling approaches employed are quite different. In Ref. 3, non-conservatisms in initiating event frequency estimates (e.g., for station blackout and for earthquakes) are balanced by quite conservative human error probabilities, by not deducting contributions from "direct core damage scenarios" (i.e., scenarios that lead to core damage directly regardless of the behavior of the spent fuel pool), and by not allowing credit for alternative cooling systems. This study eliminates the non-conservatisms in initiating event frequencies, but also employs more realistic human error probabilities, deducts contributions from direct core damage scenarios, and allows credit for alternative cooling systems. As it turns out, these modeling differences do not lead to significantly different bottom line results for the Susquehanna plant; however, they may lead to different results when applied to a different plant with different systems and operating practices.

It should also be noted that there is significant flooding potential associated with some of the scenarios treated in this study. This hazard is not treated in either Refs. 2 or 3. In principle, SFP-initiated flooding scenarios should be treated in standard internal flooding analyses. However, most of these analyses have been performed for operating units (i.e., for Case 1) only; the results of this study indicate that a significant flooding risk may arise during refueling, due to the higher (instantaneous) frequency of loss of inventory events. Note also that conventional flooding studies are not likely to address scenarios involving a combination of pool boiling and plant flooding (i.e., scenarios leading to endstate FPSF1).

\subsection{Remarks}

\subsubsection{Caveats}

The results presented in the preceding sections should be employed with caution for a number of reasons. First, the initiating event frequencies for loss of the SFPC system and for 
losses of inventory are based on an early version of the AEOD database (dated June 13, 1996). A number of events have been added to the database since that date; the estimates for these initiating event frequencies may therefore be low.

Second, the results are based on generic data which may or may not be applicable to a specific plant being analyzed. In particular, the loss of inventory model employs industry-wide statistics to estimate the frequencies of SFPC system and SFP boundary failures during operation and refueling. However, there are wide variations in seal design; one design may allow large leaks on failure, while another may not. A rigorous, mechanistically based analysis of the severitydependent likelihood of seal failures would be extremely helpful in addressing this issue.

Third, again in regard to the loss of inventory model, the available data for large seal failures are both sparse and uncertain. Different interpretations of the event narratives might lead to large changes in the estimated frequency of pool boiling and, perhaps more importantly, significant changes in the risk rankings of scenarios. A formal sensitivity analysis identifying key risk parameters (beyond basic events) and assumptions and determining the impact of changes in these parameters is outside the bounds of this limited scope study. Such an analysis should be performed before the results of this study are used in any decision support activities.

Finally, as a related point, the calculations performed in this analysis employ point estimates throughout. No attempt has been made to deal with uncertainties. An uncertainty analysis is a valuable tool for placing analysis results in context, as well as for identifying areas where additional modeling efforts may be useful. Again, an uncertainty analysis should be performed before the results of this study are used in any decision support activities.

\subsubsection{Model Capability to Treat Other Plants}

The results reported in Sections 3.1 and 3.2 are appropriate for plants whose design and operational practices are similar to those of the Susquehanna plant. However, the model used to generate these results is more general; with relatively simple changes in event tree top event success criteria, system fault trees, and/or basic event probabilities, a number of different plants can be modeled without a great deal of effort. Some of the different situations that can be treated are as follows.

1) A one-unit plant. Some of the modeling changes involved ensure that: a) the event tree top e:vents modeling the fuel pool gate status are always failed, b) the top events modeling the cooling systems for the second unit are always failed, c) credit is not taken in the human reliability analysis for the actions of the second unit's crew (e.g., in establishing makeup cluring a loss of inventory scenario), and d) the initiating event PLOCA is not analyzed for Case 3 (since there is no fuel in the core).

2) Plants with a two-train SFPC system powered from safety buses. (Susquehanna has 3 trains powered from a non-safety bus.) The modeling changes here would involve: a) using fault trees appropriate for two-train systems, b) using common cause failure models appropriate for two-train systems, and c) ensuring that the event tree top event 
FVPWR (a flag event modeling the availability of vital power to the SFPC system) is set to "true".

3) Plants with different reactor cavity seal designs. As discussed in the preceding section, a generic statistical analysis has been used to estimate the frequency of large seal failures. The results of a design-specific reliability analysis could be used to replace this generic estimate in the fault trees for top event LKSFP.

4) Plants which do not routinely leave their spent fuel pools cross-connected. (Susquehanna currently leaves its pools cross-connected.) Similar to the first sensitivity study, this involves modeling changes that ensure that the event tree top events modeling the fuel pool gate status are always failed.

5) Plants which have different maintenance policies for the diesel generators, SFPC system, and RHR system. For example, some plants may elect to perform all SFPC system maintenance prior to a refueling outage. Such a situation is simply modeled by increasing the maintenance unavailability of the SFPC system for Case 1 and reducing it for Cases 2 and 3.

6) Plants having potential instrumentation problems (e.g., vulnerability to hazards associated with spent fuel pool heatup, lack of redundancy, poor accessibility, poor readout design). This problem can be treated in the fault tree for top event OER by: a) adding basic events for instrumentation failures, and b) modifying the HRA to account for a poor humanmachine interface (poor ergonomics).

7) Plants with different refueling policies (i.e., discharge of $1 / 3$ of the core instead of the full core). As mentioned in Section 3.1, the current HRA model is not sensitive to the differences between the two policies. Case-dependent modifications of the time windows for operator actions are needed to make the human error probabilities case-sensitive. 
Table 3.1 - Initiating Event Frequencies (Instantaneous)

\begin{tabular}{|l|l|c|c|}
\hline Initiating Event & Description & Frequency (/yr) & Source \\
\hline LSFP1 & Loss of SFPC system, Case 1 & $2.4 \mathrm{E}-2$ & Data (see App. B) \\
\hline LSFP2 & Loss of SFPC system, Case 2 & $2.8 \mathrm{E}-1$ & Data (see App. B) \\
\hline LSFP3 & Loss of SFPC system, Case 3 & $2.8 \mathrm{E}-1$ & Data (see App. B) \\
\hline LP1 & Loss of offsite power, Case 1 & $8.0 \mathrm{E}-2$ & Ref. 14 \\
\hline LP2 & Loss of offsite power, Case 2 & $8.0 \mathrm{E}-2$ & Ref. 14 \\
\hline LP3 & Loss of offsite power, Case 3 & $8.0 \mathrm{E}-2$ & Ref. 14 \\
\hline LINVC & Large loss of inventory, Case 1 & $2.0 \mathrm{E}-3$ & Data (see App. B) \\
\hline LINCS & Small loss of inventory, Case 1 & $5.0 \mathrm{E}-3$ & Data (see App. B) \\
\hline LINVR & Large loss of inventory, Cases 2 and 3 & $2.0 \mathrm{E}-2$ & Data (see App. B) \\
\hline LINRS & Small loss of inventory, Cases 2 and 3 & $3.0 \mathrm{E}-2$ & Data (see App. B) \\
\hline PLOCA & Primary LOCA, Case 1 & $1.5 \mathrm{E}-2$ & Ref. 8 \\
\hline PLOCR & Primary LOCA, Cases 2 and 3 & $1.2 \mathrm{E}-1$ & Ref. 15, 16 (see App. B) \\
\hline EQE & Seismic event (0.2g < PGA $\leq 0.6 \mathrm{~g})^{\mathrm{a}}$ & $1.2 \mathrm{E}-4$ & Ref. 17 \\
\hline
\end{tabular}

${ }^{a}$ Earthquakes with PGA $>0.6 \mathrm{~g}$ are for the purposes of this analysis, assumed to lead directly to core damage (with frequency $3.2 \mathrm{E}-6 / \mathrm{yr}$ ). 
Table 3.2 - Instantaneous Frequencies of Endstates (/yr)

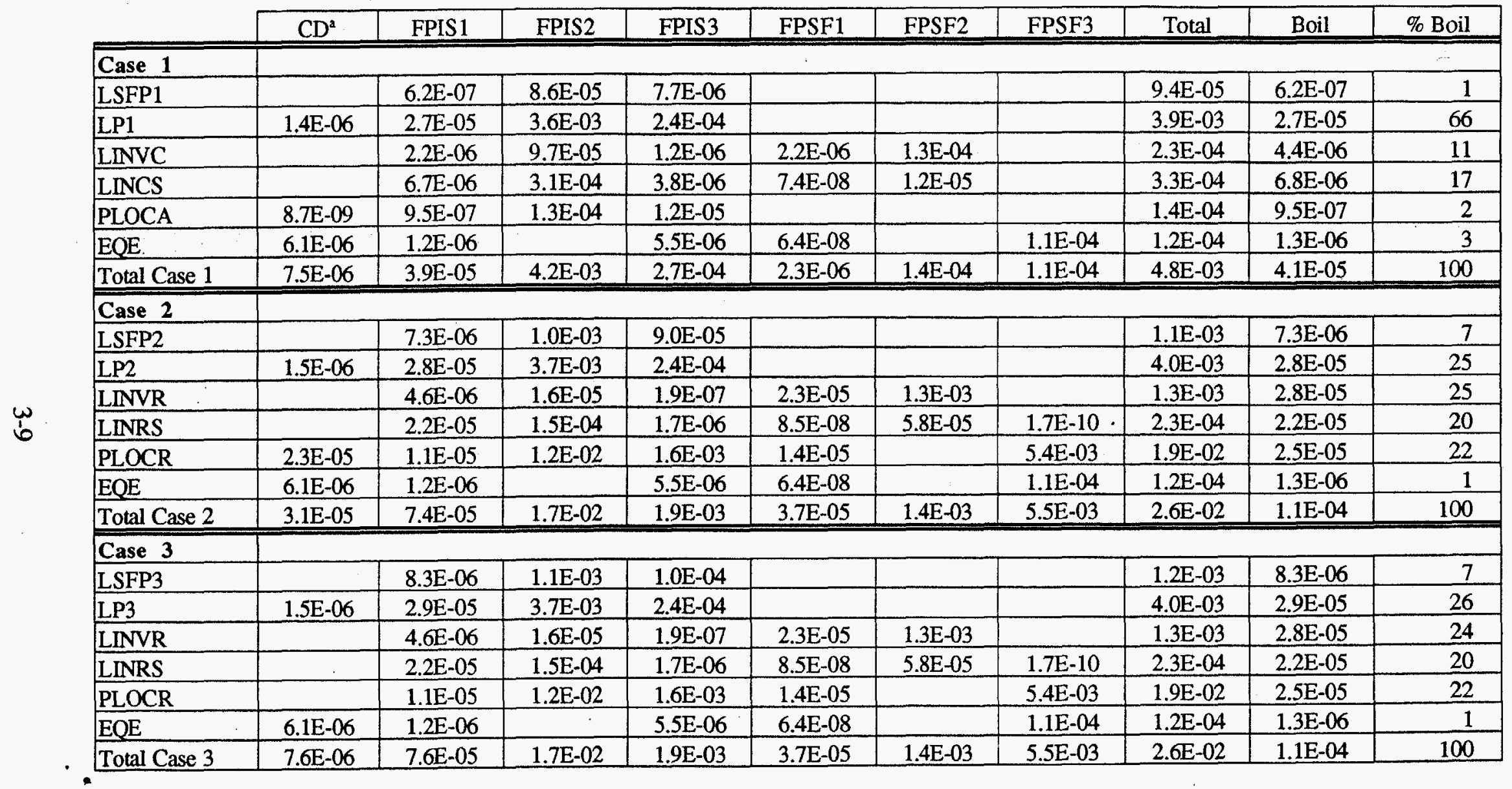

'Endstate provided for accounting purposes only; frequencies listed do not provide total core damage frequency. 
Table 3.3a - Dominant Cutsets, Endstate FPIS1 (SFP Boiling), Case 1

\begin{tabular}{|c|c|c|l|}
\hline$\%$ Total & Frequency & IE & Cutset Elements (Successes and Failures) \\
\hline 8.20 & $3.19 \mathrm{E}-06$ & LP1 & $\begin{array}{l}\text { /DG1N2, /EPWR, ALT-XHE-XM-SFPL, SFP-OPEN-GATE, SFP-XHE- } \\
\text { XE-LP, SFP2-XHE-XM-LSFP, /UNREC01 }\end{array}$ \\
\hline 8.20 & $3.19 \mathrm{E}-06$ & LP1 & $\begin{array}{l}\text { /DG1N2, /EPWR, ALT-XHE-XM-SFPL, SFP-OPEN-GATE, SFP-XHE- } \\
\text { XE-LP, SFP1-XHE-XM-LSFP, /UNREC01 }\end{array}$ \\
\hline 8.15 & $3.17 \mathrm{E}-06$ & LP1 & $\begin{array}{l}\text { /GSTAT, /DG1N2, ALT-XHE-XM-SFPP, EPWR-XHE-EA-REC, LPWR- } \\
\text { XHE-LA-REC, SFP-XHE-XE-LP, /UNREC02 }\end{array}$ \\
\hline 7.92 & $3.08 E-06$ & LINCS & /AISOL, LMKUP-XHE-XA-SFP, SFP-XHE-XE-LINVC, /LKSMC \\
\hline 7.34 & $2.86 E-06$ & LP1 & $\begin{array}{l}\text { /DG1N2, /EPWR, ALT-XHE-XM-SFPL, /NCD-DGAL, SFP-OPEN- } \\
\text { GATE, SFP2-XHE-XM-LSFP, UNREC-XHE-RECV-1 }\end{array}$ \\
\hline 7.34 & $2.86 \mathrm{E}-06$ & LP1 & $\begin{array}{l}\text { IDG1N2, /EPWR, ALT-XHE-XM-SFPL, /NCD-DGAL, SFP-OPEN- } \\
\text { GATE, SFP1-XHE-XM-LSFP, UNREC-XHE-RECV-1 }\end{array}$ \\
\hline 7.30 & $2.84 E-06$ & LP1 & $\begin{array}{l}\text { /GSTAT, /DG1N2, ALT-XHE-XM-SFPP, EPWR-XHE-EA-REC, LPWR- } \\
\text { XHE-LA-REC, /NCD-DGAL, UNREC-XHE-RECV-2 }\end{array}$ \\
\hline 4.78 & $1.86 E-06$ & LINCS & /AISOL, /OERLINVC, MKP-XHE-XA-CSMIS, /LKSMC \\
\hline 4.17 & $1.62 E-06$ & LP1 & $\begin{array}{l}\text { /DG1N2, ALT-XHE-XM-SFPP, EPWR-XHE-EA-REC, LPWR-XHE-LA- } \\
\text { REC, RHR1-TRNS-UA-TM, /OER-LP, SFP-OPEN-GATE, /UNREC02 }\end{array}$ \\
\hline 2.99 & $1.16 E-06$ & EQE & ALT-XHE-XM-SFPL, /NDSFP-EQ, /NLEAK-EQ, /NCD-EQ, R1TRUE \\
\hline 2.77 & $1.08 E-06$ & LINVC & /AISOL, LMKUP-XHE-XA-SFP, SFP-XHE-XE-LINVC, /LKLGC \\
\hline 69.19 & (Total) & &
\end{tabular}


Table 3.3b - Dominant Cutsets, Endstate FPIS1 (SFP Boiling), Case 3

\begin{tabular}{|c|c|c|c|}
\hline$\%$ Total & Frequency & $\mathbb{E}$ & Cutset Elements (Successes and Failures) \\
\hline 20.95 & $1.59 \mathrm{E}-05$ & LINRS & /AISOL, /OERLINVR, MKP-XHE-XA-RSMIS, /LKSMR \\
\hline 9.42 & $7.17 \mathrm{E}-06$ & LSFP3 & $\begin{array}{l}\text { /FGATE, ALT-XHE-XM-SFPL, SFP-OPEN-GATE, SFP-XHE-XE-UR, } \\
\text { SFP1-XHE-XM-LSFP }\end{array}$ \\
\hline 7.88 & $6.00 \mathrm{E}-06$ & PLOCR & $\begin{array}{l}\text { SFP-MKUP-ECCS-F, /NCDPLOCR, TGATE-STAT, MKP-XHE-XA- } \\
\text { CSMIS }\end{array}$ \\
\hline 5.20 & $3.96 \mathrm{E}-06$ & LINRS & MISLSFLE, /OERLINVR, MKP-XHE-XA-RSMIS, LKSMR \\
\hline 4.23 & $3.22 \mathrm{E}-06$ & LP3 & $\begin{array}{l}\text { /EPWR, ALT-XHE-XM-SFPL, SFP-OPEN-GATE, SFP-XHE-XE-LP, } \\
\text { SFP2-XHE-XM-LSFP, /UNRECO1 }\end{array}$ \\
\hline 4.23 & $3.22 \mathrm{E}-06$ & LP3 & $\begin{array}{l}\text { /EPWR, ALT-XHE-XM-SFPL, SFP-OPEN-GATE, SFP-XHE-XE-LP, } \\
\text { SFP1-XHE-XM-LSFP, ,UNREC01 }\end{array}$ \\
\hline 4.21 & $3.20 \mathrm{E}-06$ & LP3 & $\begin{array}{l}\text { /GSTAT, ALT-XHE-XM-SFPP, EPWR-XHE-EA-REC, LPWR-XHE-LA- } \\
\text { REC, SFP-XHE-XE-LP, /UNREC02 }\end{array}$ \\
\hline 3.79 & $2.88 \mathrm{E}-06$ & LP3 & $\begin{array}{l}\text { IEPWR, ALT-XHE-XM-SFPL, NCD-DGAL, SFP-OPEN-GATE, SFP2- } \\
\text { XHE-XM-LSFP, UNREC-XHE-RECV-1 }\end{array}$ \\
\hline 3.79 & $2.88 \mathrm{E}-06$ & LP3 & $\begin{array}{l}\text { /EPWR, ALT-XHE-XM-SFPL, NCD-DGAL, SFP-OPEN-GATE, SFP1- } \\
\text { XHE-XM-LSFP, UNREC-XHE-RECV-1 }\end{array}$ \\
\hline 3.77 & $2.87 \mathrm{E}-06$ & LP3 & $\begin{array}{l}\text { /GSTAT, ALT-XHE-XM-SFPP, EPWR-XHE-EA-REC, LPWR-XHE-LA- } \\
\text { REC, /NCD-DGAL, UNREC-XHE-RECV-2 }\end{array}$ \\
\hline 3.76 & $2.86 \mathrm{E}-06$ & LINVR & /OERLINVR, /MISLLGE, MKP-XHE-XA-RLGIS, LKLGR \\
\hline 2.15 & $1.64 \mathrm{E}-06$ & LP3 & $\begin{array}{l}\text { ALT-XHE-XM-SFPP, EPWR-XHE-EA-REC, LPWR-XHE-LA-REC, } \\
\text { RHR1-TRNS-UA-TM, /OER-LP, SFP-OPEN-GATE, /UNREC02 }\end{array}$ \\
\hline 1.96 & $1.49 \mathrm{E}-06$ & LINVR & /AISOL, /OERLINVR, MKP-XHE-XA-RLGIS, /LKLGR \\
\hline 1.85 & $1.41 \mathrm{E}-06$ & LINRS & IAISOL, MUES-XHE-XA-LSFP, SFP-XHE-XE-LINVR, /LKSMR \\
\hline 1.53 & $1.16 \mathrm{E}-06$ & EQE & ALT-XHE-XM-SFPL, /NDSFP-EQ, /NLEAK-EQ, NCD-EQ, R1TRUE \\
\hline 1.44 & $1.09 \mathrm{E}-06$ & PLOCR & $\begin{array}{l}\text { ALT-XHE-XM-SFP, RHR1-TRNS-UA-TM, SFP1-XHE-XM-SFP, } \\
\text { NCDPLOCR, TGATE-STAT }\end{array}$ \\
\hline
\end{tabular}

80.15 (Total) 
Table 3.3c - Dominant Cutsets, Endstate FPSF1 (SFP Boiling + Flooding), Case 1

\begin{tabular}{|c|c|c|l|}
\hline \% Total & Frequency & $\mathrm{IE}$ & Cutset Elements (Successes and Failures) \\
\hline 76.78 & $1.81 \mathrm{E}-06$ & LINVC & /OERLINVC, MKP-XHA-XA-CLNIB, LKLGC, MISLLGE \\
\hline
\end{tabular}

76.78 (Total)

Table 3.3d - Dominant Cutsets, Endstate FPSF1 (SFP Boiling + Flooding), Case 3

\begin{tabular}{|c|c|c|l|}
\hline$\%$ Total & Frequency & E & Cutset Elements (Successes and Failures) \\
\hline 61.45 & $2.26 \mathrm{E}-05$ & LINVR & /OERLINVR, MISLLGE, MKP-XHE-XA-RLNIB, LKLGR \\
\hline 36.72 & $1.35 \mathrm{E}-05$ & PLOCR & NNCDPLOCR, TGATE-STAT, MKP-XHA-XA-CLGNI, ILOC \\
\hline
\end{tabular}

98.17 (Total) 
Table 3.4 - Annual Probability of Spent Fuel Pool Boiling By Initiator

(18-month refueling cycle, 2-month refueling outage)

\begin{tabular}{|l|c|c|c|c|}
\cline { 2 - 5 } \multicolumn{1}{c|}{} & $\begin{array}{c}\text { Boiling } \\
\text { (FPIS1) }\end{array}$ & $\begin{array}{c}\text { Boiling }+ \\
\text { Flooding } \\
\text { (FPSF1) }\end{array}$ & Total & \% Total \\
\hline Loss of SFP cooling system & $1.4 \mathrm{E}-06$ & $0.0 \mathrm{E}+00$ & $1.4 \mathrm{E}-06$ & 3 \\
\hline Loss of offsite power & $2.7 \mathrm{E}-05$ & $0.0 \mathrm{E}+00$ & $2.7 \mathrm{E}-05$ & 56 \\
\hline Loss of inventory (Large) & $2.5 \mathrm{E}-06$ & $4.5 \mathrm{E}-06$ & $7.0 \mathrm{E}-06$ & 14 \\
\hline Loss of inventory (Small) & $8.4 \mathrm{E}-06$ & $7.5 \mathrm{E}-08$ & $8.5 \mathrm{E}-06$ & 17 \\
\hline Primary LOCA & $2.1 \mathrm{E}-06$ & $1.6 \mathrm{E}-06$ & $3.6 \mathrm{E}-06$ & 7 \\
\hline Earthquake & $1.2 \mathrm{E}-06$ & $6.4 \mathrm{E}-08$ & $1.3 \mathrm{E}-06$ & 3 \\
\hline Total & $4.3 \mathrm{E}-05$ & $6.2 \mathrm{E}-06$ & $4.9 \mathrm{E}-05$ & 100 \\
\hline
\end{tabular}

Table 3.5 - Annual Probability of Spent Fuel Pool Boiling By Initiator

(18-month refueling cycle, 1-month refueling outage)

\begin{tabular}{|l|c|c|c|c|}
\cline { 2 - 5 } \multicolumn{1}{c|}{} & $\begin{array}{c}\text { Boiling } \\
\text { (FPIS1) }\end{array}$ & $\begin{array}{c}\text { Boiling }+ \\
\text { Flooding } \\
\text { (FPSF1) }\end{array}$ & Total & \% Total \\
\hline Loss of SFP cooling system & $9.9 \mathrm{E}-07$ & $0.0 \mathrm{E}+00$ & $9.9 \mathrm{E}-07$ & 2 \\
\hline Loss of offsite power & $2.7 \mathrm{E}-05$ & $0.0 \mathrm{E}+00$ & $2.7 \mathrm{E}-05$ & 60 \\
\hline Loss of inventory (Large) & $2.3 \mathrm{E}-06$ & $3.4 \mathrm{E}-06$ & $5.7 \mathrm{E}-06$ & 13 \\
\hline Loss of inventory (Small) & $7.6 \mathrm{E}-06$ & $7.5 \mathrm{E}-08$ & $7.6 \mathrm{E}-06$ & 17 \\
\hline Primary LOCA & $1.5 \mathrm{E}-06$ & $7.8 \mathrm{E}-07$ & $2.3 \mathrm{E}-06$ & 5 \\
\hline Earthquake & $1.2 \mathrm{E}-06$ & $6.4 \mathrm{E}-08$ & $1.3 \mathrm{E}-06$ & 3 \\
\hline Total & $4.1 \mathrm{E}-05$ & $4.3 \mathrm{E}-06$ & $4.5 \mathrm{E}-05$ & 100 \\
\hline
\end{tabular}


Table 3.6 - Annual Probability of Flooding Associated with SFP By Initiator (18-month refueling cycle, 2-month refueling outage)

\begin{tabular}{|c|c|c|}
\hline & $\begin{array}{c}\text { Flooding } \\
\text { (FPSF1, FPSF2, FPSF3) }\end{array}$ & $\%$ Total \\
\hline Loss of SFP cooling system & $0.0 \mathrm{E}+00$ & 0 \\
\hline Loss of offsite power & $0.0 \mathrm{E}+00$ & 0 \\
\hline Loss of inventory (Large) & $2.6 \mathrm{E}-04$ & 27 \\
\hline Loss of inventory (Small) & $1.7 \mathrm{E}-05$ & 2 \\
\hline Primary LOCA & $6.0 \mathrm{E}-04$ & 60 \\
\hline Earthquake & $1.1 \mathrm{E}-04$ & 11 \\
\hline Total & $9.9 \mathrm{E}-04$ & 100 \\
\hline
\end{tabular}

Table 3.7 - SFP Accident Frequencies, Generic Issue 82 Analysis [2]

\begin{tabular}{|c|c|c|c|c|}
\hline \multirow[b]{2}{*}{ Accident Sequence } & \multicolumn{2}{|c|}{ PWR } & \multicolumn{2}{|c|}{ BWR } \\
\hline & Best Estimate & Upper Bound & Best Estimate & Upper Bound \\
\hline \multicolumn{5}{|l|}{ Structural Failures } \\
\hline Missiles & $1.0 \mathrm{E}-8$ & $1.0 \mathrm{E}-7$ & $1.0 \mathrm{E}-8$ & $1.0 \mathrm{E}-7$ \\
\hline Aircraft crashes & $6.0 \mathrm{E}-9$ & $2.0 \mathrm{E}-8$ & $6.0 \mathrm{E}-9$ & $2.0 \mathrm{E}-8$ \\
\hline Heavy load drop & $3.1 \mathrm{E}-8$ & $3.1 \mathrm{E}-7$ & $3.1 \mathrm{E}-8$ & $3.1 \mathrm{E}-7$ \\
\hline Seismic & $1.8 \mathrm{E}-6$ & & $6.7 \mathrm{E}-6$ & \\
\hline Pneumatic Seal Failures & $3.0 \mathrm{E}-8$ & $5.0 \mathrm{E}-7$ & $3.0 \mathrm{E}-8$ & $5.0 \mathrm{E}-7$ \\
\hline Inadvertent Drainage & $1.2 \mathrm{E}-8$ & $1.0 \mathrm{E}-7$ & $12 \mathrm{E}-8$ & $1.0 \mathrm{E}-7$ \\
\hline Loss of Cooling and Makeup ${ }^{c}$ & $6.0 \mathrm{E}-8$ & $1.4 \mathrm{E}-6$ & $6.0 \mathrm{E}-8$ & $1.4 \mathrm{E}-6$ \\
\hline TOTAL & $1.9 \mathrm{E}-6$ & & $6.8 \mathrm{E}-6$ & \\
\hline Claciding Fire Probability & 1.0 & & 0.25 & \\
\hline
\end{tabular}

${ }^{\mathrm{a}}$ Adapted from Table 4.7.1, Ref. 2.

${ }^{b}$ All frequencies in events/yr.

'Includes beyond design basis seismic induced loss of cooling and makeup. 
Table 3.8 - Susquehanna Annualized Initiating Event Frequencies (Ref. 3)

\begin{tabular}{|l|c|}
\hline \multicolumn{1}{|c|}{ Initiating Event } & Frequency $(/ \mathrm{yr})$ \\
\hline Loss of SFPC & $1.57 \mathrm{E}-4$ \\
\hline LOOP & $7.00 \mathrm{E}-2$ \\
\hline Extended LOOP & $7.00 \mathrm{E}-3$ \\
\hline SBO & $2.73 \mathrm{E}-8$ \\
\hline LOCA & $3.67 \mathrm{E}-3$ \\
\hline Flooding & $3.90 \mathrm{E}-3$ \\
\hline Loss of SWS & $2.00 \mathrm{E}-3$ \\
\hline Pipe Break & $3.40 \mathrm{E}-3$ \\
\hline Seismic $($ PGA $<0.6 \mathrm{~g})$ & $8.55 \mathrm{E}-6$ \\
\hline Seismic PGA $\geq 0.6 \mathrm{~g})$ & $4.20 \mathrm{E}-7$ \\
\hline LOCA w/LOOP & $2.57 \mathrm{E}-4$ \\
\hline
\end{tabular}

Table 3.9 - Susquehanna Annualized NBF, As-Fixed Conditions (Ref. 3)

\begin{tabular}{|c|c|c|c|c|c|c|}
\hline \multirow[b]{2}{*}{ Initiating Event } & \multicolumn{4}{|c|}{ Annualized Frequency $(/ \mathrm{yr})$} & \multirow[b]{2}{*}{ Total } & \multirow[b]{2}{*}{$\%$ Total } \\
\hline & Case 1 & Case 2 & Case 3 & Case 4 & & \\
\hline Loss of SFPC & $1.1 \mathrm{E}-7$ & $1.9 \mathrm{E}-8$ & $5.0 \mathrm{E}-8$ & 4.6E-8 & 2.3E-7 & 1.1 \\
\hline LOOP & $5.5 \mathrm{E}-7$ & $7.9 \mathrm{E}-8$ & $8.5 \mathrm{E}-7$ & 4.6E-7 & $1.9 \mathrm{E}-6$ & 9.3 \\
\hline Extended LOOP & $3.0 \mathrm{E}-6$ & 4.0E-7 & $3.5 \mathrm{E}-6$ & $2.1 \mathrm{E}-6$ & $9.0 \mathrm{E}-6$ & 43.2 \\
\hline SBO & 4.0E-9 & $5.0 \mathrm{E}-10$ & $1.1 \mathrm{E}-9$ & $7.1 \mathrm{E}-10$ & $6.2 \mathrm{E}-9$ & 0.0 \\
\hline LOCA & $1.5 \mathrm{E}-6$ & 1.7E-7 & $1.6 \mathrm{E}-6$ & $1.1 \mathrm{E}-6$ & $4.3 \mathrm{E}-6$ & 20.7 \\
\hline Flooding & $2.8 \mathrm{E}-7$ & $3.8 \mathrm{E}-8$ & $3.8 \mathrm{E}-7$ & $2.3 \mathrm{E}-7$ & $9.3 \mathrm{E}-7$ & 4.5 \\
\hline Loss of SWS & $3.5 \mathrm{E}-8$ & $5.0 \mathrm{E}-9$ & $5.4 \mathrm{E}-8$ & $2.9 \mathrm{E}-8$ & $1.2 \mathrm{E}-7$ & 0.6 \\
\hline Pipe Break & $2.5 \mathrm{E}-7$ & $3.3 \mathrm{E}-8$ & $3.3 \mathrm{E}-7$ & $2.0 \mathrm{E}-7$ & 8.1E-7 & 3.9 \\
\hline Seismic $(\mathrm{PGA}<0.6 \mathrm{~g})$ & $1.2 \mathrm{E}-7$ & $1.6 \mathrm{E}-8$ & $6.9 \mathrm{E}-8$ & $4.4 \mathrm{E}-8$ & $2.5 \mathrm{E}-7$ & 1.2 \\
\hline Seismic (PGA $\geq 0.6 \mathrm{~g}$ ) & $3.1 \mathrm{E}-7$ & $3.8 \mathrm{E}-8$ & $4.6 \mathrm{E}-8$ & $3.1 \mathrm{E}-8$ & $4.2 \mathrm{E}-7$ & 2.0 \\
\hline LOCA w/LOOP & $1.6 \mathrm{E}-6$ & $9.6 \mathrm{E}-8$ & $6.9 \mathrm{E}-7$ & $4.6 \mathrm{E}-7$ & $2.8 \mathrm{E}-6$ & 13.6 \\
\hline Total & $7.7 \mathrm{E}-6$ & $9.0 \mathrm{E}-7$ & $7.6 \mathrm{E}-6$ & $4.7 \mathrm{E}-6$ & $2.1 \mathrm{E}-5$ & 100.0 \\
\hline
\end{tabular}

Case $1=$ Both units operating

Case 2 = One unit operating, one unit shutdown, fuel not completely offloaded, RHR out of service part of the time Case $3=$ One unit operating, one unit refueling, $1 \mathrm{SFPC}$ pump required to maintain $\mathrm{T}<200^{\circ} \mathrm{F}$

Case $4=$ One unit operating, one unit refueling, 2 SFPC pumps required to maintain $\mathrm{T}<200^{\circ} \mathrm{F}$ 
Table 3.10 - Susquehanna Instantaneous NBF, As-Fixed Conditions (Ref. 3)

\begin{tabular}{|l|c|c|c|c|}
\hline \multirow{2}{*}{\multicolumn{1}{|c|}{ Initiating Event }} & \multicolumn{4}{c|}{ Instantaneous Frequency (/yr) } \\
\cline { 2 - 5 } & Case 1 & Case 2 & Case 3 & Case 4 \\
\hline Loss of SFPC & $1.5 \mathrm{E}-07$ & $2.1 \mathrm{E}-07$ & $4.6 \mathrm{E}-07$ & $6.3 \mathrm{E}-07$ \\
\hline LOOP & $7.6 \mathrm{E}-07$ & $8.7 \mathrm{E}-07$ & $7.8 \mathrm{E}-06$ & $6.3 \mathrm{E}-06$ \\
\hline Extended LOOP & $4.1 \mathrm{E}-06$ & $4.4 \mathrm{E}-06$ & $3.2 \mathrm{E}-05$ & $2.9 \mathrm{E}-05$ \\
\hline SBO & $5.5 \mathrm{E}-09$ & $5.5 \mathrm{E}-09$ & $1.0 \mathrm{E}-08$ & $9.7 \mathrm{E}-09$ \\
\hline LOCA & $2.1 \mathrm{E}-06$ & $1.9 \mathrm{E}-06$ & $1.5 \mathrm{E}-05$ & $1.5 \mathrm{E}-05$ \\
\hline Flooding & $3.9 \mathrm{E}-07$ & $4.2 \mathrm{E}-07$ & $3.5 \mathrm{E}-06$ & $3.2 \mathrm{E}-06$ \\
\hline Loss of SWS & $4.8 \mathrm{E}-08$ & $5.5 \mathrm{E}-08$ & $4.9 \mathrm{E}-07$ & $4.0 \mathrm{E}-07$ \\
\hline Pipe Break & $3.4 \mathrm{E}-07$ & $3.6 \mathrm{E}-07$ & $3.0 \mathrm{E}-06$ & $2.7 \mathrm{E}-06$ \\
\hline Seismic (PGA $<0.6 \mathrm{~g})$ & $1.7 \mathrm{E}-07$ & $1.8 \mathrm{E}-07$ & $6.3 \mathrm{E}-07$ & $6.0 \mathrm{E}-07$ \\
\hline Seismic $(\mathrm{PGA} \geq 0.6 \mathrm{~g})$ & $4.3 \mathrm{E}-07$ & $4.2 \mathrm{E}-07$ & $4.2 \mathrm{E}-07$ & $4.2 \mathrm{E}-07$ \\
\hline LOCA w/LOOP & $2.2 \mathrm{E}-06$ & $1.1 \mathrm{E}-06$ & $6.3 \mathrm{E}-06$ & $6.3 \mathrm{E}-06$ \\
\hline \hline Total & $1.1 \mathrm{E}-05$ & $9.8 \mathrm{E}-06$ & $6.9 \mathrm{E}-05$ & $6.4 \mathrm{E}-05$ \\
\hline
\end{tabular}

Case $1=$ Both units operating

Case 2 = One unit operating, one unit shutdown, fuel not completely offloaded, RHR out of service part of the time Case $3=$ One unit operating, one unit refueling, $1 \mathrm{SFPC}$ pump required to maintain $\mathrm{T}<200^{\circ} \mathrm{F}$

Case $4=$ One unit operating, one unit refueling, 2 SFPC pumps required to maintain $\mathrm{T}<200^{\circ} \mathrm{F}$ 


\section{POST-HEATUP ACCIDENT PROGRESSION: DISCUSSION}

\subsection{Post-Heatup Hazards}

During a loss of spent fuel pool cooling scenario, hazards to the rest of the plant can arise due to: the cause of the scenario (e.g., flooding water from a loss of inventory event); the plant response to the event (e.g., pool makeup water flowing through an unisolated leak); and the direct consequences of the scenario (e.g., heat and steam released during pool boiling). These hazards can be grouped into two categories based on their transport mechanisms: heat/steam and flooding. (Radiation, while a hazard to plant personnel attempting to mitigate the scenario, is a lesser hazard with respect to equipment performance during the course of the accident. Fires and their associated consequences are also not treated in this study; zircaloy cladding fires following a complete loss of spent fuel pool inventory are addressed in Ref. 2. Note that, as discussed in Section 3.1, the likelihood of these scenarios in single unit plants may be higher than estimated in Ref. 2.)

The following sections provide general qualitative discussions of the heat/steam and flooding hazards from the standpoint of their ability to initiate a core damage scenario, followed by discussions specific to the base case plant analyzed in this study. Note that a given hazard will be a potential problem to the core only if:

a) isolation is failed, i.e., there exists a pathway that allows movement of the hazard from the spent fuel area to vital safety equipment;

b) vital safety equipment functionality is lost due to the effects of the hazard;

c) operator hazard mitigation efforts fail, i.e., operators do not isolate or divert the hazard from the areas housing the vital safety equipment; and

d) operator efforts to recover failed equipment are unsuccessful.

It is important to recall that, per Eq. 2.1, a release of steam, heat, or water does not guarantee ECCS equipment damage. Even if some ECCS equipment are damaged, core damage is not guaranteed. Alternative equipment/systems and operator recovery actions may need to fail before core damage occurs.

To provide a risk perspective, typical at-power core damage frequencies estimated without consideration of scenarios involving the spent fuel pool generally fall in the range of $10^{-6}$ to $10^{-4}$ per reactor year for internal events; external events contributions can be of similar magnitude. The results of two shutdown risk analyses (internal events) indicate that the annualized frequency of core damage during shutdown may be lower than the at-power value. (NUREG/CR-6143 estimates an annual core damage frequency of $2 \times 10^{-6} / \mathrm{yr}$ for Grand Gulf, Unit 1 during a refueling outage [15]; NUREG/CR-6144 estimates an annual core damage frequency of $5 \times 10^{-6} / \mathrm{yr}$ for Surry, Unit 1 during mid-loop operations [16]; the comparable at-power values are $4 \times 10^{-6} / \mathrm{yr}$ and $4 \times 10^{-5} / \mathrm{yr}$, respectively.) The instantaneous frequencies, obtained by dividing the shutdown 
values by the fraction of time the plant is in shutdown, may be comparable to or greater than the atpower values.

The total pool boiling annual probabilities reported in Section 3 are around $5 \times 10^{-5}$. Assuming a baseline (non-SFP) core damage frequency of around $5 \times 10^{-6} / \mathrm{yr}$, it can be seen that the combined failure probability of safety barriers (a)-(d) listed above and of the safety systems not damaged by the spent fuel pool scenario needs to be greater than around $10^{-3}$ in order for spent fuel pool-initiated scenarios to be visible ( $>1 \%$ ) contributors to core damage risk. Because the unavailability of a typical safety system is around $10^{-2}$, this implies that the boiling associated with a severe spent fuel pool accident must damage most of the plant's ECCS equipment with high probability in order for the accident to affect core damage frequency.

Table 4.1 shows the impacts of the initiating events on the post-boiling safety barriers. (These are impacts beyond those associated with the heat/steam release from a postulated boiling spent fuel pool, e.g., limited room access.) It can be seen that for the dominant contributors to pool boiling (LOOP, loss of inventory), two of the safety barriers are unaffected. The third and fourth barriers can be affected, but, in the case of LOOP, some of the effects may actually be positive.

The preceding discussion applies to the risk associated with spent fuel pool accidents affecting core cooling. Scenarios involving spent fuel pool dryout and subsequent cladding fires do not require the failure of multiple engineered barriers to cause problems; they only require that pool boiling continue long enough that dryout conditions are reached. Because pool boil-off times are greatly reduced in cases where the pool has lost a large amount of inventory, the scenarios of special concern involve endstate FPSF1. Table 3.4 shows that the annual probability of FPSF1 is around $6 \times 10^{-6}$; this is comparable to the best-estimate probability for BWR pool draining reported in Ref. 2 (although the dominant contributors to this probability differ greatly from those reported in Ref. 2). Based on the value-impact analysis of Ref. 2, it might be argued therefore that the risk is not high enough to implement any of the alternatives identified in Ref. 2. However, as discussed in Section 3.1, the results of this study are based on a two-unit plant with a connected spent fuel pool. If credit is not taken for the makeup systems associated with the second unit, the estimated annual probability of endstate FPSF1 could be a factor of 7 higher (based on the HRA method used in this study). Additional investigation is needed to determine if the risk from this scenario is indeed significant.

\subsection{Heat and Steam}

\subsubsection{Spatial Isolation}

Heat and/or steam from the spent fuel pool has the potential to damage ECCS equipment through direct and indirect pathways. Two direct pathways are:

- transport through open air passages to the equipment; and

- transport through the plant heating, ventilation, and air-conditioning (HVAC) systems. 
Given the compartmentalization typical of commercial nuclear power plant designs, the first mechanism is not likely to be a significant contributor to risk. ${ }^{1}$ However, as seen in numerous external events analyses, plant layouts and communication paths between compartments (intended or otherwise) tend to be highly plant-specific. A plant walkdown is needed to confirm that this mechanism is not important for a given plant.

The second mechanism can potentially lead to widespread effects throughout the affected plant. Depending on the alignment of the ventilation system at the time of the accident, operator actions may be needed to isolate the spent fuel pool area from key equipment areas. (Tripping the ventilation system should greatly reduce the rate of heat/steam transport, but may not entirely prevent it.) Given the length of time available to the operators ${ }^{2}$, the likelihood of failure is expected to be small. (For example, assuming that the need for action is obvious, the time available is expansive, stress is high, experience is low but the required actions are not especially difficult, procedures are available but not very specific, and the plant has a retrofit control system with good ergonomics, use of the worksheet shown in Figure 2.5 leads to a nominal estimate of $7 \times 10^{-3}$.) Again, due to plant-to-plant variations in design, a plant-specific analysis is needed to determine if this expectation is met for a given plant.

An indirect pathway for equipment loss due to heat/steam release from the spent fuel pool involves the plant's fire protection systems. As discussed in Ref. 18, steam can lead to the undesired actuation of a fire protection system through moisture intrusion into a fire protection system controller, activation of heat/smoke detectors, or melting of fusible links. Of 67 Licensee Event Reports on steam release events reviewed in Ref. 18, four involved actuations of the fire protection system. Three events involved smoke detector actuation in the same room as the steam release; the other event involved melting of a fusible link in the same room as the steam release, moisture ingress into a controller, and the actuation of the fire protection system in an adjacent room. (It is not clear if any of these four events involved steam of the quality that would be released from a spent fuel pool boiling at atmospheric pressure.) Ref. 18 estimates the generic probability of equipment damage, given actuation of a fire suppression system, for different suppression system types:

$\begin{array}{ll}\text { Water: } & 0.27 / \text { actuation } \\ \mathrm{CO}_{2}: & 0.015 / \text { actuation } \\ \text { Halon: } & 0.0054 / \text { actuation }\end{array}$

(The estimates for $\mathrm{CO}_{2}$ and Halon are based on zero observed events in the database.)

Of course, the probability of equipment damage is expected to vary as a function of equipment type and design. If the probability of fire protection system actuation given exposure to a steam release is on the order of $10^{-1}$ and the probability of equipment damage is also on the order of $10^{-1}$, then the combined probability of equipment damage due to a steam-initiated fire

\footnotetext{
${ }^{1}$ Intervening barriers, e.g., fire doors, can be failed of course, but the likelihood of such failures would have to be counted against the $10^{-3}$ margin discussed in the preceding section.

${ }^{2}$ Utility calculations for Susquehanna indicate that even if the HVAC system continues to run, environmental qualification temperatures - around $104^{\circ} \mathrm{F}$ - will not be exceeded for at least 6 hours after the start of boiling.
} 
suppression system actuation will be around $10^{-2}$. Because: a) this indirect pathway still requires the transport of heat/steam to a fire protection system controller, heat detector, or sprinkler head; b) multiple ECCS components must be damaged to seriously challenge core cooling; and c) these components are generally well separated and are not vulnerable to a single suppression system actuation, it is not expected that this pathway, by itself, will be a significant contributor to risk for most initiators. (The earthquake initiator may provide an exception, since severe earthquakes can trigger fire suppression systems [18]. However, this is not a spent fuel pool issue.)

\subsubsection{Equipment Vulnerability}

Most of the equipment in a nuclear power plant is relatively robust with respect to heated environments. For example, Ref. 19 reports the results of full-scale fire tests, in which electrical cables were exposed to a severe fire environment. The cable temperatures at which electrical failure occurred ranged from $420^{\circ} \mathrm{F}$ to $860^{\circ} \mathrm{F}$. Ref. 20 notes that the standard design temperature of electrical cabinets is $120^{\circ} \mathrm{C}$, i.e., about $250^{\circ} \mathrm{F}$. These temperatures are above the temperature expected of steam leaving a boiling spent fuel pool.

TWo groups of components that may be vulnerable to the temperatures associated with steam released from the spent fuel pool are:

- $\quad$ sensitive electronic equipment, e.g., solid-state components in advanced protection system cabinets

- $\quad$ equipment tripped or isolated by local high temperature signals (e.g., RCIC and HPCI turbines).

Long term exposures to elevated temperatures present possible problems for major components (e.g., large pumps). Extended losses of room cooling have been shown to be visible risk contributors in some risk studies. However, the likelihood of such extended exposures is not expected to be very high because of the time available for operators to mitigate the event. (Note also that in all of the scenarios contributing to the FPIS1 and FPSF1 endstates, either offsite or emergency diesel generator power is available.)

Aside from temperature issues, the vulnerability of equipment to a steam environment is less clear. Sensitive electronic equipment can be affected by elevated humidity levels, and it may be possible for steam condensation on electrical equipment (e.g., aging cables) to cause problems. Ref. 21 notes that the switchgear at Susquehanna are rated for $90 \%$ relative humidity, but argues that such a humidity level cannot be achieved within the switchgear cabinets, due to the elevated temperatures within the cabinets. Further investigation on the mechanism of failure is needed to validate this argument.

\subsubsection{Hazard Mitigation}

In the case of the heat/steam hazard, mitigation involves either the isolation of the spent fuel pool area from other key plant areas, or the active diversion of steam. Manual operator actions will be required; the likelihood of success depends on the same factors routinely considered in human 
reliability analyses, e.g., accessibility and availability of equipment, quality of procedures and training, and time available. Note that the mitigation efforts can be affected by the characteristics of the initiating event, as shown in Table 4.1.

\subsubsection{Equipment Recovery}

If irreparable damage has not occurred, equipment lost during the scenario may be recovered in many cases simply by allowing the affected equipment to cool/dry off. (Equipment recovery is not an issue, of course, if hazard mitigation efforts are not successful.) For example, in the case of HPCI/RCIC room temperature isolation signals, the signal can be reset once the temperature level drops. As in the case of hazard mitigation, manual actions will be required. These actions can be affected by the initiating event, as shown in Table 4.1.

\subsection{Flooding}

The treatment of SFP-initiated flooding scenarios is similar to the treatment of other internal flooding scenarios in conventional analyses [22]. Thus, the discussion on safety barriers (a)-(d) identified in Section 4.1 is straightforward. Note that in principle, SFP-initiated floods should be treated in standard internal flooding analyses. However, most of these analyses have been performed for operating units (i.e., for Case 1) only; the results of this study indicate that a significant flooding risk may arise during refueling, due to the higher (instantaneous) frequency of loss of inventory events. Note also that conventional flooding studies are not likely to address scenarios involving a combination of pool boiling and plant flooding (i.e., scenarios leading to endstate FPSF1).

\subsubsection{Spatial Isolation}

For a flooding event to seriously challenge the ECCS function, there must be a path from the source of the flooding to multiple ECCS equipment areas. This path can include non-watertight doors (e.g., fire doors) and drainage systems (water may back up through drains if anti-backflow devices are not installed or functioning).

\subsubsection{Equipment Vulnerability}

It can be assumed that most electrical equipment is vulnerable to flooding, as long as the water level rises high enough to immerse key component parts. In addition, some equipment (e.g., electrical panels) may be vulnerable to water spray or dripping.

\subsubsection{Hazard Mitigation}

Unlike the heat/steam hazard, flooding may occur relatively rapidly, especially in the case of large seal failures. Noting that the FPSF1 endstate is only arrived at in scenarios where the operators have failed to isolate the flood, the likelihood of success of further mitigation efforts may be relatively low. 


\subsubsection{Equipment Recovery}

In conventional flooding analyses, credit is not usually taken for recovery of equipment damaged by a flood.

\subsection{Application to Base Case Plant}

This section applies the preceding discussion points to the base case plant, which is largely based on the Susquehanna Steam Electric Station (SSES). ${ }^{3}$ The information underlying the application is drawn from a limited walkdown ${ }^{4}$ of the SSES and from discussions with Pennsylvania Power and Light Co. staff.

\subsubsection{Heat and Steam Hazard}

Noting that the conditional probability of core damage given spent fuel pool boiling must be on the order of $10^{-3}$ or higher for spent fuel pool boiling accidents to become important contributors to risk, it does not appear that spent fuel pool boiling accidents are important contributors at the base case plant. The reasons for this conclusion are as follows.

- While transport of heat and steam throughout key areas of the plant is possible (via the HVAC system in recirculation mode), the length of time required for significant room heatup (see Footnote 2 ) greatly reduces the likelihood of operator failure.

- Transport of significant amounts of heat and steam from the spent fuel pool area to areas housing ECCS equipment via open air passages (as opposed to transport through the HVAC system) appears to be very unlikely, due to the separation of the spent fuel pool area from other parts of the reactor building and the fact that the spent fuel pool area is significantly higher than the ECCS equipment areas.

- The only ECCS equipment with potential vulnerability to the elevated temperatures caused by the postulated pool boiling and steam transport appear to be the HPCI and RCIC turbines (which are isolated on high room temperature $-167^{\circ} \mathrm{F}$ - signals).

- The plant has provisions to divert steam through the standby gas treatment system, should pool boiling occur.

\subsubsection{Flooding Hazard}

In contrast with the heat/steam hazard, the flooding hazard associated with certain loss of spent fuel pool cooling accidents is more difficult to dismiss as a risk contributor.

\footnotetext{
${ }^{3}$ The base case analysis employs generic estimates for initiating event frequencies, and does not necessarily reflect SSES-specific design or operational details.

${ }^{4}$ The walkdown covered major ECCS equipment and areas, but did not cover cable routings, the fire protection system or penetrations.
} 
- The frequency of flooding is greater than the frequency of boiling. The annual flooding probability may be on the order of $10^{-3}$, as shown in Table 3.6. Focusing on large seal failures alone, the cutset results for endstates FPSF1, FPSF2, and FPSF3 can be used to show that the annual probability of flooding is around $3 \times 10^{-4}$. Using this latter value, scenarios with a $2 \times 10^{-4}$ conditional probability of core damage could be visible risk contributors.

- The boundaries between elevations in the reactor building are not necessarily watertight. As indicated by conversations with utility staff, it is probably fair to assume that, at least in the case of a failure of the inflatable seal between the reactor cavity and the reactor building during refueling, all flood water will eventually end up in the bottom floor of the reactor building (where the major ECCS equipment are housed). It is not clear that all flood water will end up in the reactor building sump (as assumed in Ref. 3). Note also that the room drains on the bottom floor employ normally closed manual valves instead of check valves. While the valve positions are checked every refueling outage, there is a possibility that the valves could be mispositioned, providing a flow path from the sump to each affected room.

- For large flooding events, the time available to take mitigative actions may be significantly less than for room heatup events.

The above reasons do not guarantee that the conditional core damage probability is greater than $2 \times 10^{-4}$, but they do indicate that further investigation of the flooding hazard may be needed. Note that the Individual Plant Examination for the SSES indicates that the core damage frequency due to flooding during normal operations is around $4 \%$ of the total core damage frequency [23]; it is not clear from available documentation that the analysis addresses floods involving the spent fuel pool. 
Table 4.1 - Post-Boiling Impacts for Initiating Event Classes

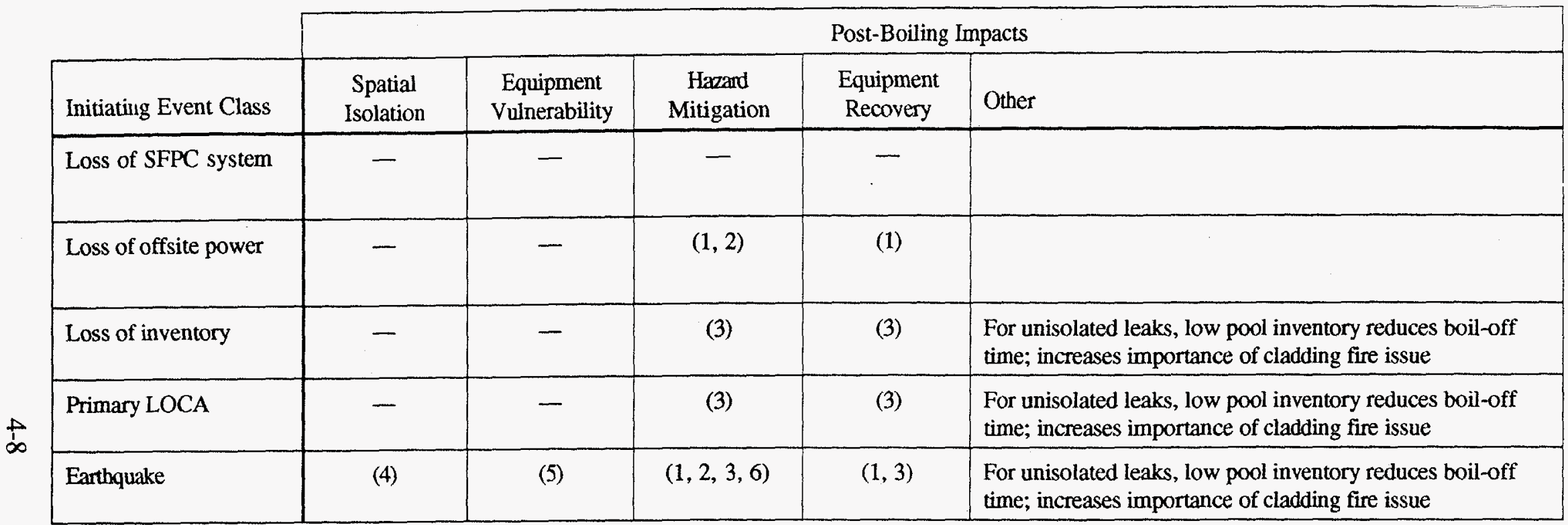

\section{NOTES:}

1) Power may be unavailable to various systems. (Endstates include contributions from scenarios where either diesel generators are available or offsite power has been recovered. In all cases, some power is available; station blackout scenarios provide a direct challenge to the core, independent of the spent fuel pool.)

2) Loss of power may actually be beneficial from the standpoint of circulation of heat/steam by the ventilation systems.

3) Flooding may inhibit access to different areas of the plant.

4) Severe seismic events might affect barriers that ordinarily prevent the passage of steam/hot air or water to other areas of the plant.

5) Seismic events might distort or damage electrical cabinet boundaries and increase the vulnerability of electrical equipment enclosed in those cabinets.

6) Seismic events might fail equipment used to mitigate hazards (e.g., dampers, forced ventilation systems). 


\section{RISK ASSESSMENT INSIGHTS FROM OPERATIONAL DATA}

In order to gain additional insights concerning the risk associated with spent fuel pools, operational data collected by the AEOD were reviewed. The primary objective of the review was to identify issues that should be addressed in the risk model (e.g., observed initiators, representative sequences of events). A secondary objective was to develop, where possible, quantitative insights relevant to the risk model. This section summarizes the results of the review.

\subsection{Event Data}

Table 5.1 provides a breakdown of reported spent fuel pool events included in the AEOD database by event type. (This breakdown is current as of June 13, 1996; it has been changed since then.) Both actual occurrences and potential events ${ }^{1}$ are shown.

The AEOD database covers events reported over the period 1976 through June, 1996. Table 5.2 shows a breakdown of the events by year. (The total number shown is less than that shown in Table 5.1, since a number of events in Table 5.1 are included in multiple event type categories.) It can be seen that the annual number of events increases about halfway through the time period.

Two key classes of events of interest to this study involve loss of spent fuel pool cooling and loss of spent fuel pool inventory. The loss of cooling events for which severity information are available are listed in Table 5.3. The loss of inventory events for which severity information are available are listed in Table 5.4. Table 5.4 distinguishes between the events that involved the failure of inflatable seals from other losses of inventory.

The loss of cooling events primarily resulted from loss of electrical power to the SFPC pumps, and/or from engineered safety features (ESF) actuations causing the load shed of the pumps. In most cases, plant staff quickly restored SFPC. In those cases where the cooling loss was extended, lack of operator awareness was often the cause. In none of the reported events did the cooling loss result in pool temperatures exceeding the plant Technical Specification limits (where applicable) or approaching boiling conditions.

From the standpoint of a risk assessment, the Wolf Creek event (September 30, 1994) is one of the more notable loss of SFPC events. In this event, the entire reactor core had been offloaded to the SFP and the plant staff calculated the time to boil to be about 5.8 hours. A significant portion of the ' $A$ ' train systems were out of service for maintenance, including the component cooling water (CCW) required for the ' $A$ ' train SFPC heat exchanger. The ' $A$ ' emergency diesel generator (EDG) was also out of service for testing. While in this condition, the operators discovered smoke emanating from the ' $\mathrm{B}$ ' train SFPC pump inboard bearing, and were forced to secure the pump. In 18 minutes, the operators were able to restore the ' $\mathrm{A}$ ' $\mathrm{CCW}$ train to

\footnotetext{
${ }^{1}$ Potential events involve either: a) conditions which degraded the ability of the plant to respond to an initiating event, or b) hypothesized scenarios which have become potentially important due to the acquisition of new knowledge (e.g., concerning accident phenomenology or plant conditions).
} 
service and start the 'A' SFPC pump. Later, during subsequent post-maintenance testing of the 'A' train EDG, the diesel's exciter transformer failed and caught fire. With no backup power available to the only operable SFPC pump (the ' $A$ ' pump), the licensee began seeking ways to temporarily supply emergency power to the pump in case offsite power failed. Fortunately, this did not occur in the two days it took to restore the EDG.

The loss of inventory events primarily resulted from loss of inflatable seals (usually from loss of air) or from system alignment problems. Not all of the reports specified the amount or duration of the inventory loss. Of those that reported the amount of inventory lost, the scenarios ranged from small leaks to large rapid losses.

The largest loss of inventory event in the database is the well-known Haddam Neck event (August 21, 1984). During that event, the refueling cavity seal failed while the cavity was filled. Within 20 minutes, 200,000 gallons of water spilled through to the lower containment levels. Preparations had been underway for opening the fuel transfer tube, but the tube was shut at the time of the event. Had the transfer tube been open, the SFP could have been drained leaving spent fuel partially uncovered.

Comparing the event categorization of Table 5.1 with the INEL SFP model documented in Appendix A, it can be shown that almost all of the categories and subcategories are explicitly treated in the model (through the identification and quantification of initiating events). The exception is the "Other" category, which involves events outside the bounds of the study (e.g., boron dilution events in PWRs).

\subsection{Mapping to Risk Model}

The risk model deals with the failure of mitigating systems (the safety barriers) as well as with initiating events. To determine if the risk model addresses observed combinations of initiating event/safety barrier failures, the events in the AEOD database were reviewed to determine how they would map to the risk model. (This mapping procedure is similar in spirit to that performed in the accident sequence precursor - ASP - program for reactor incidents. The only difference is that the analysis performed in this study is qualitative; no effort is made to determine "how close" an event came to spent fuel pool boiling. Of course, the quantitative models developed in this study could be applied for this purpose.)

The results of the mapping analysis are shown in Tables 5.5 and 5.6. Table 5.5 shows the mapping of actual and potential events to the initiating events defined in Section 2.2. (The number in parentheses corresponds to events which occurred in the time period 1987 - June 1996.) It can be seen that the loss of spent fuel pool cooling and loss of inventory initiating events appear to be the most likely. However, it should be cautioned that the database is focused on spent fuel pool issues. Thus, for example, loss of offsite power events for which spent fuel pool impacts have not been reported are not included in the database.

Table 5.6 shows, for events which had impacts or potential impacts beyond the initiating event, the event tree top events potentially affected (but not usually failed). Comparing Tables 5.5 and 5.6, it can be seen that most of the event sequences did not progress beyond the initiating 
event. Most events were quickly identified and corrected by plant staff prior to significant consequences to the spent fuel pool. Of those that progressed beyond the initiating event, most involved indication or operator awareness issues. Except for the previously mentioned Wolf Creek loss of spent fuel pool cooling event, all of the actual events (and most of the potential events) listed in Table 5.6 are explicitly treated in the risk model. The Wolf Creek event is not completely treated because the SFPC and RHR fault tree models developed in this report do not explicitly treat loss of $\mathrm{AC}$ power. While this is a weakness in the fault trees, it should be pointed out that the likelihood of a concurrent LOOP is generally lower by an order of magnitude or more than the human error and common cause failure probabilities included in the fault trees.

\subsection{On Reductions in Seal Failure Frequency}

In Ref. 13, it is estimated that "advances in seal design, increased awareness and surveillance" will lead to a factor of 10 reduction in the frequency of seal failure. However, Table 5.4 shows that 6 seal failure events have occurred in the time period $(1976$ - 1986) and 5 have occurred in the period (1987 - June, 1996). Counting the events for which severity data were not found, the respective numbers are 7 and 8 . Since the number of operating reactors has not changed dramatically since 1976 , there appears to be little support for the proposed reduction.

Ref. 13 also estimates the fraction of serious seal failures (i.e., failures with the potential to quickly drain the pool) to be about 0.01 . The evidence provided by the AEOD database is less conclusive here. While one out of the 11 seal failure events in Table 5.4 was a rapid, large draining event (the Haddam Neck event), it has been argued that this was an event associated with a unique design. Without this event, the statistical evidence does not support large estimates for the frequency of severe seal failures. (Of course, it also does not provide strong evidence that the failure frequency is as small as 0.01.) A more thorough investigation of seal designs, operational practices (including inspection, testing, and maintenance), failure mechanisms, and failure recovery resources and practices is needed to provide a technically based estimate of severe seal failure frequencies.

\subsection{Concluding Remarks}

As a result of this review of the AEOD database, the following conclusions relevant to the construction and evaluation of the risk model can be drawn.

- While a number of events relevant to the loss of spent fuel pool cooling are included in the AEOD database, none of these events resulted in substantial heating of the pool or uncovering of the fuel. (There has been at least one "near miss" - the Haddam Neck seal failure event.) This implies that the frequency of significant loss of cooling should be less than $10^{-3} / \mathrm{ry}$.

- The INEL risk model documented in the report appendices explicitly treats most of the events included in the database.

- $\quad$ Almost all of the categories and subcategories of events included in the AEOD database are explicitly treated in the model. The categories and subcategories not 
treated are either not directly relevant to the loss of spent fuel pool cooling issue or appear to be probabilistically dominated by categories/subcategories with the same impact.

- $\quad$ All of the relevant events can be mapped to the initiating events treated in the risk model.

- Of the events which apparently affected safety barriers treated in the event trees, most can be directly treated by the model.

- $\quad$ The Wolf Creek event provides one exception, because LOOP events subsequent to a loss of spent fuel pool cooling have not been explicitly treated.

- For those events which correlate to one of the initiating events modeled in this report, very few of the safety barriers modeled by the event tree top events have been seriously degraded (or even challenged).

- $\quad$ The database appears to indicate that the frequency of reported seal failures has remained relatively constant over time. Also, while it does not preclude small-valued estimates $(0.01$ or less) for the frequency of serious seal failures, it does not support these estimates either. 
Table 5.1 - Breakdown of AEOD Database Events

\begin{tabular}{|c|c|c|c|c|}
\hline \multirow[b]{3}{*}{ Type of Event } & \multirow{2}{*}{\multicolumn{3}{|c|}{ Counts $^{a}$}} & \multirow[b]{3}{*}{ Type \# } \\
\hline & & & & \\
\hline & Actual & Potential & Total & \\
\hline Loss of Water & 46 & 47 & 93 & \\
\hline Gates Leak & 10 & 2 & 12 & 1 \\
\hline Transfer Tube Leaks & 0 & 0 & 0 & 2 \\
\hline Pool Leaks & 9 & 1 & 10 & 3 \\
\hline Pool Seismically Damaged & 0 & 8 & 8 & 4 \\
\hline Anti-Siphon Device Fails & 1 & 1 & 2 & 5 \\
\hline Refuel Cavity Seal Leaks & 2 & 0 & 2 & 6 \\
\hline Loss of Coolable Geometry & 0 & 0 & 0 & 7 \\
\hline Drop of "Penetrating" Load & 5 & 30 & 35 & 8 \\
\hline Pipe Problems & 0 & 3 & 3 & 9 \\
\hline Alignment Problems & 19 & 1 & 20 & 23 \\
\hline System Interaction & 0 & 1 & 1 & 31 \\
\hline Loss of Makeup Capability & 0 & $\overline{6}$ & $\overline{6}$ & \\
\hline Valve Problems & 0 & 1 & 1 & 12 \\
\hline Pipe Problems & 0 & 4 & 4 & 13 \\
\hline LOOP w/Failure to Restore & 0 & 1 & 1 & 14 \\
\hline Loss of Cooling & 58 & 36 & 94 & \\
\hline Pumps Stop (Loss Electric Power) & 38 & 9 & 47 & 15 \\
\hline Pump Problems & 5 & 15 & 20 & 33 \\
\hline Heat Exchangers Fail & 0 & 1 & 1 & 16 \\
\hline Loss of HX Cooling & 8 & 4 & 12 & 17 \\
\hline Pipe Problems & 1 & 1 & 2 & 18 \\
\hline Alignment Problems & 2 & 0 & 2 & 25 \\
\hline Inadequate Cooling & 0 & 6 & 6 & 28 \\
\hline ESF Isolation Loss of Cooling & 4 & 0 & 4 & 29 \\
\hline Loss of Non-SFP Equipment & 4 & 2 & $\overline{6}$ & \\
\hline Boiling & 0 & 0 & 0 & 20 \\
\hline Flooding & 4 & 0 & 4 & 21 \\
\hline Susquehanna Effect & 0 & 2 & 2 & 24 \\
\hline Other & 16 & 45 & 61 & \\
\hline Ventilation & 5 & 24 & 29 & 26 \\
\hline Criticality & 0 & 18 & 18 & 27 \\
\hline Loss of Monitoring Capability & 0 & 3 & 3 & 32 \\
\hline Other & 11 & 0 & 11 & 30 \\
\hline
\end{tabular}

${ }^{a}$ Count as of 6/13/96; revisions have been made since then.

b"Type" field coded in AEOD database.

'Total count $=260$; total number of events $=245$ (some events are in multiple categories). 
Table 5.2 - Breakdown of AEOD Database Events By Year

\begin{tabular}{|c|c|}
\hline Year & Number \\
\hline \hline not known & 2 \\
\hline 1976 & 1 \\
\hline 1980 & 3 \\
\hline 1981 & 7 \\
\hline 1982 & 6 \\
\hline 1983 & 5 \\
\hline 1984 & 8 \\
\hline 1985 & 11 \\
\hline 1986 & 7 \\
\hline 1987 & 15 \\
\hline 1988 & 17 \\
\hline 1989 & 20 \\
\hline 1990 & 14 \\
\hline 1991 & 15 \\
\hline 1992 & 20 \\
\hline 1993 & 20 \\
\hline 1994 & 21 \\
\hline 1995 & 36 \\
\hline $1996^{\mathrm{a}}$ & 17 \\
\hline Total & 245 \\
\hline
\end{tabular}

${ }^{\mathrm{a}}$ As of June, 1996 
Table 5.3 - Loss of SFP Cooling Events ${ }^{\mathrm{a}}$

\begin{tabular}{|l|c|c|c|l|}
\hline Plant & $\begin{array}{c}\text { Date } \\
\text { (y/m/d) }\end{array}$ & $\begin{array}{c}\text { Duration } \\
\text { (hr) }\end{array}$ & $\begin{array}{c}\text { Heatup } \\
\left({ }^{\circ} \mathbf{F}\right)\end{array}$ & Notes \\
\hline \hline Point Beach 1 & $81 / 01 / 02$ & 0.03 & & \\
\hline Haddam Neck & $87 / 08 / 14$ & 1.3 & 6 & \\
\hline Browns Ferry 1 & $87 / 12 / 04$ & 0.10 & & \\
\hline Peach Bottom 2 & $87 / 12 / 30$ & $1+$ & & \\
\hline Haddam Neck & $90 / 06 / 08$ & 0.42 & & \\
\hline Duane Arnold & $90 / 07 / 09$ & minutes & & \\
\hline Turkey Point 4 & $91 / 03 / 13$ & 1.5 & 3 & \\
\hline Indian Point 2 & $91 / 06 / 22$ & 0.60 & & \\
\hline Turkey Point 4 & $91 / 06 / 26$ & 1 & 0 & \\
\hline Haddam Neck & $91 / 07 / 17$ & 8 & 3 & \\
\hline Turkey Point 3 & $91 / 07 / 24$ & 0.32 & 1 & \\
\hline Haddam Neck & $91 / 08 / 14$ & 10.5 & 3 & \\
\hline Haddam Neck & $91 / 09 / 20$ & 6 & & \\
\hline Haddam Neck & $92 / 01 / 31$ & 1.5 & & \\
\hline Nine Mile 1 & $92 / 02 / 21$ & 0.25 & & \\
\hline Haddam Neck & $92 / 02 / 22$ & 1.67 & & \\
\hline Comanche Peak 1 & $92 / 05 / 11$ & 17 & 5 & \\
\hline Indian Point 2 & $92 / 06 / 19$ & 0.17 & & \\
\hline FitzPatrick & $92 / 06 / 23$ & 7.5 & 7 & \\
\hline Millstone 2 & $92 / 07 / 06$ & 1.5 & 4 & \\
\hline Cooper & $93 / 03 / 28$ & 0.17 & & \\
\hline Cooper & $93 / 05 / 14$ & 0.25 & 0 & \\
\hline South Texas 2 & $93 / 06 / 14$ & 13 & 19 & \\
\hline Haddam Neck & $93 / 06 / 22$ & 0.05 & & \\
\hline Haddam Neck & $93 / 06 / 26$ & 0.67 & 4 & \\
\hline Duane Amold & $93 / 08 / 13$ & 6 & 7 & Partial loss \\
\hline LaSalle 2 & $93 / 09 / 14$ & 5 & 5 & \\
\hline Farley 2 & $93 / 10 / 05$ & 3 & 40 & \\
\hline Salem 1 & $93 / 10 / 21$ & 0.08 & & \\
\hline Haddam Neck & $94 / 04 / 23$ & $13+$ & 7 & \\
\hline Seabrook 1 & $94 / 08 / 11$ & 24 & 30 & \\
\hline Wolf Creek & $94 / 09 / 30$ & 0.30 & & Time to boil = 5.8 hr \\
\hline Indian Point 3 & $95 / 02 / 27$ & 2.25 & & \\
\hline Diablo Canyon 1 & $95 / 10 / 21$ & 8 & 20 & \\
\hline San Onofre 1 & $95 / 10 / 25$ & 0.33 & 1 & Estimated time \\
\hline Limerick 1 & $96 / 02 / 20$ & 0.87 & 2 & \\
\hline Haddam Neck & $96 / 03 / 01$ & 32 & 16 & \\
\hline II & & & \\
\hline
\end{tabular}

${ }^{2}$ Includes only the 37 events for which severity information is available; database includes 56 loss of SFPC events. 
Table 5.4 - Loss of SFP Inventory Events ${ }^{a}$

\begin{tabular}{|c|c|c|c|c|c|c|c|}
\hline Plant & $\begin{array}{c}\text { Date } \\
(\mathrm{y} / \mathrm{m} / \mathrm{d})\end{array}$ & $\begin{array}{c}\text { Duration } \\
\text { (hr) }\end{array}$ & $\begin{array}{l}\text { Amount } \\
\text { (gal / ft) }\end{array}$ & $\begin{array}{r}\text { Seal } \\
\text { Fail? }\end{array}$ & $\begin{array}{l}\text { Rflg } \\
\text { Otg? }^{\mathrm{b}}\end{array}$ & $\begin{array}{c}\text { Est } \\
\text { Size }^{c} \\
\end{array}$ & Notes \\
\hline Davis Besse & $82 / 02 / 01$ & & & & - & $\mathbf{M}$ & Below TSL ${ }^{d}$ \\
\hline Salem 1 & $82 / 02 / 01$ & 0.33 & $23,000 /-$ & & - & $S$ & $\begin{array}{l}\text { Est. } 20 \text { hrs drainage time } e^{e} \\
\text { connected to Rx cavity }\end{array}$ \\
\hline Trojan & $82 / 06 / 10$ & & & & $Y$ & $\mathrm{~L}$ & 15" below TSL; fast \\
\hline Wolf Creek & $87 / 12 / 22$ & & & & $\mathrm{Y}$ & $S$ & $22 \mathrm{ft}$ above $\mathrm{TAF}^{t}$ \\
\hline Harris & $89 / 01 / 17$ & & -15 & & $\mathbf{N}$ & $\mathrm{L}$ & Sounds fast, easily fixed \\
\hline Clinton & $89 / 02 / 03$ & & -10.42 & & $\mathrm{Y}$ & M & \\
\hline Millstone 2 & $92 / 07 / 06$ & & $-/ 1.2$ & & $\mathrm{~N}$ & $\mathrm{~L}$ & Sounds fast, easily fixed \\
\hline La Salle 2 & $93 / 01 / 01$ & & & & $Y$ & $S$ & Small leak \\
\hline Indian Point 1 & $94 / 05 / 18$ & & & & $\mathrm{~N}$ & $\mathrm{~S}$ & Small leak \\
\hline Hatch 1 & $94 / 12 / 28$ & & & & $\mathbf{N}$ & $S$ & Small leak \\
\hline San Onofre 1 & $95 / 05 / 16$ & & & & $\mathrm{~N}$ & $\mathrm{~S}$ & Small leak \\
\hline Braidwood 1,2 & $95 / 05 / 30$ & & $3,000 / 0.25$ & & $\mathbf{N}$ & - & \\
\hline Duane Arnold & $95 / 06 / 14$ & & & & $\mathbf{N}$ & $S$ & 5" below TSL \\
\hline Cooper & $95 / 10 / 31$ & & $10,000 / 0.1$ & & $\mathrm{Y}$ & $S$ & $\begin{array}{l}\text { Est. } 26 \text { hrs drainage time, } \\
\text { connected to Rx cavity }\end{array}$ \\
\hline Arkansas 2 & $96 / 03 / 20$ & & $900 / 0.13$ & & $\mathbf{N}$ & $S$ & \\
\hline Trojan & $80 / 05 / 22$ & & & $\mathrm{Y}$ & $Y$ & - & 10" below TSL \\
\hline Arkansas 2 & $81 / 05 / 15$ & & -12 & $Y$ & - & - & \\
\hline Haddam Neck & $84 / 08 / 21$ & 0.33 & $200,000 /-$ & $\mathrm{Y}$ & Y & $\mathrm{L}$ & Refueling cavity loss only \\
\hline San Onofre 2 & $84 / 10 / 02$ & 0.70 & $-/ 1.7$ & $\mathrm{Y}$ & - & $S$ & $\begin{array}{l}\text { Est. } 8 \mathrm{hrs} \text { drainage time; } \\
\text { no fuel in SFP }\end{array}$ \\
\hline Sequoyah 1,2 & $85 / 12 / 18$ & 1 & -12 & $Y$ & $Y$ & - & \\
\hline Hatch 1 & $86 / 12 / 02$ & 24 & $-15.5^{\circ}$ & $\mathrm{Y}$ & $\mathrm{N}$ & $S$ & \\
\hline Surry 1 & $88 / 05 / 17$ & & $25,800 /-$ & $\mathrm{Y}$ & $\mathrm{Y}$ & - & \\
\hline Wolf Creek & $91 / 09 / 23$ & 4 & & $\mathrm{Y}$ & $Y$ & $S$ & Below TSL \\
\hline $\begin{array}{l}\text { Comanche } \\
\text { Peak } 1\end{array}$ & $93 / 10 / 26$ & & $20,000 /-$ & Y & Y & $\mathrm{L}$ & \\
\hline Hope Creek & $94 / 04 / 13$ & & $20,000 /-$ & $\mathrm{Y}$ & $\mathrm{Y}$ & _- & $22 \mathrm{ft}$ above TAF \\
\hline Indian Point 2 & $95 / 01 / 20$ & & $-13+$ & $\mathrm{Y}$ & $\mathrm{N}$ & - & $20 \mathrm{ft}$ above TAF \\
\hline
\end{tabular}

${ }^{a}$ Includes only the 26 events for which severity information is available; database has 29 loss of inventory events. The database contains 4 additional seal failures for which severity information was not found: San Onofre (November 5, 1984), Surry (October 2, 1988), Point Beach (September 30, 1992), and San Onofre (April 12, 1995).

${ }^{\mathrm{b}}$ Did event occur during a refueling outage?

${ }^{c}$ Estimates are based on interpretation of event narratives. Estimated size is large if operators have a small amount of time to isolate the leak and small if they have an expansive amount of time. Note that the rate of level drop during a small leak may still be great enough to dominate boiling as a mechanism for inventory loss, at least until the maximum level drop occurs.

${ }^{d}$ Technical Specification Limit

'Top of Active Fuel 
Table 5.5 - Mapping of AEOD Database Events to Initiating Events

\begin{tabular}{|l|r|r|r|}
\cline { 2 - 4 } \multicolumn{1}{c|}{} & \multicolumn{3}{c|}{ Event Counts $^{\mathrm{a}}$} \\
\hline Initiating Event & \multicolumn{1}{c|}{ Actual } & \multicolumn{1}{c|}{ Potential } & \multicolumn{1}{c|}{ Total } \\
\hline \hline Loss of spent fuel pool cooling (LOSFP) & $56(53)$ & $23(21)$ & $79(74)$ \\
\hline Loss of offsite power (LP1, LP2, LP3) & $4(4)$ & $14(4)$ & $18(8)$ \\
\hline Loss of inventory (LINVC, LINVR) & $30(20)$ & $13(6)$ & $43(26)$ \\
\hline Primary LOCA (PLOCA, PLOCR) & $0(0)$ & $1(1)$ & $1(1)$ \\
\hline Seismic (EQE) & $0(0)$ & $10(7)$ & $10(7)$ \\
\hline & & & \\
\hline
\end{tabular}

${ }^{a}$ Numbers in parentheses represent events occurring in the time period 1987 - June, 1996 
Table 5.6 - Mapping of AEOD Database Events to Initiating Events and Top Events

\begin{tabular}{|c|c|c|c|c|c|}
\hline Plant & $\begin{array}{c}\text { Date } \\
(\mathrm{y} / \mathrm{m} / \mathrm{d})\end{array}$ & $\begin{array}{c}\text { Actual/ } \\
\text { Potential } \\
\end{array}$ & $\mathrm{IE}^{\mathrm{a}}$ & Top Events ${ }^{b, \varepsilon}$ & Notes \\
\hline La Salle & 93/01/01 & A & LOINV & OER & Indication \\
\hline Trojan & $80 / 05 / 22$ & A & LONNV & OER & Indication \\
\hline Trojan & $82 / 06 / 10$ & A & LONNV & OER & Indication \\
\hline Wolf Creek & $87 / 12 / 22$ & A & LOINV & OER & Indication \\
\hline Wolf Creek & $91 / 09 / 23$ & A & LOINV & OER & Indication \\
\hline Nine Mile & $92 / 02 / 21$ & A & LOSFP & S1, R1, LS1 & Ultimate heat sink, RHR OOS \\
\hline Seabrook & $94 / 08 / 11$ & A & LOSFP & OER & Awareness \\
\hline South Texas & $93 / 06 / 14$ & A & LOSFP & OER & Awareness \\
\hline Wolf Creek & $94 / 09 / 30$ & A & LOSFP & S1, R1, LS1 & SFPC system (1 train), RHR OOS \\
\hline WNP & $93 / 04 / 28$ & $\mathrm{P}$ & LOCA & ALT-C, SSNV & \\
\hline Oconee & $96 / 01 / 08$ & $\mathrm{P}$ & LOINV & ERMUP, LTMUP & Makeup \\
\hline Catawba & $88 / 01 / 09$ & $\mathrm{P}$ & $\begin{array}{l}\text { LOINV, } \\
\text { LOSFP }\end{array}$ & $\begin{array}{l}\text { ALT-C, ERMUP, } \\
\text { LTMUP }\end{array}$ & Alternate cooling, makeup \\
\hline Cook & $96 / 04 / 14$ & $\mathrm{P}$ & LOOP & DG1N2, DG1O2 & Diesel generators \\
\hline Davis Besse & $96 / 04 / 03$ & $\mathrm{P}$ & LOOP & DG1N2, DG1O2 & Diesel generators \\
\hline Diablo Canyon & $91 / 02 / 13$ & $\mathrm{P}$ & LOOP & DG1N2, DG1O2 & Diesel generators \\
\hline Susquehanna & $92 / 10 / 20$ & $\mathbf{P}$ & & & Susquehanna issues \\
\hline Arkansas & $96 / 05 / 22$ & $\mathrm{P}$ & LOSFP & S1, LS1 & Heat load \\
\hline Millstone & $93 / 09 / 17$ & $\mathrm{P}$ & LOSFP & $S 1, L S 1$ & Heat load \\
\hline Nine Mile & $96 / 03 / 28$ & $\mathbf{P}$ & LOSFP & S1, LS1 & Heat load \\
\hline Oyster Creek & $83 / 12 / 23$ & $\mathbf{P}$ & LOSFP & S1, LS1 & Spent fuel pool cooling \\
\hline River Bend & $91 / 04 / 15$ & $\mathrm{P}$ & LOSFP & OER & Appendix $\mathrm{R}$, indication \\
\hline San Onofre & $90 / 04 / 24$ & $\mathrm{P}$ & LOSFP & $\mathrm{S} 1, \mathrm{LS} 1$ & Heat load \\
\hline WNP & $90 / 20 / 24$ & $\mathrm{P}$ & LOSFP & & Appendix R \\
\hline Diablo Canyon & $91 / 04 / 10$ & $\mathrm{P}$ & Seismic & LTMUP & Alternate cooling, makeup \\
\hline Millstone & $95 / 05 / 17$ & $P$ & Seismic & LTMUP & Makeup \\
\hline WNP & $89 / 08 / 11$ & $\mathbf{P}$ & Seismic & & Appendix R \\
\hline
\end{tabular}

${ }^{\text {aIE }}=$ initiating event, LOINV $=$ loss of inventory, LOSFP = loss of spent fuel pool cooling system, LOCA = loss of coolant accident, LOOP = loss of offsite power

'See Appendix A for definition of top events

'Top events affected (but not necessarily failed) 


\section{REFERENCES}

1. U.S. Nuclear Regulatory Commission, Reactor Safety Study (WASH-1400), NUREG 75/014, 1975.

2. U.S. Nuclear Regulatory Commission, Regulatory Analysis for the Resolution of Generic Issue 82, "Beyond Design Basis Accidents in Spent Fuel Pools", NUREG-1353, 1989.

3. T.V. Vo, T.R. Blackburn, T.M. Mitts, H.K. Phan, Risk Analysis for Spent Fuel Pool Cooling at Susquehanna Electric Power Station (Draft Report), Pacific Northwest Laboratory, prepared for the U.S. Nuclear Regulatory Commission Office of Nuclear Reactor Regulation under Contract DE-AC06-76RLO 1830, October 1994.

4. U.S. Nuclear Regulatory Commission, Final Safety Evaluation by the Office of Nuclear Reactor Regulation Regarding Loss of Spent Fuel Pool Cooling Events, Susquehanna Steam Electric Station, Units 1 and 2, Pennsylvania Power and Light Company, Docket Nos. 50-387 and 50-388, 1995.

5. S. Kaplan and B.J. Garrick, "On the Quantitative Definition of Risk, Risk Analysis, 1, 1127 (1981).

6. N. Siu, S. Khericha, S. Conroy, S. Beck, Loss of Spent Fuel Pool Cooling PRA: Interim Letter Report, Idaho National Engineering Laboratory, prepared for the U.S. Nuclear Regulatory Commission Office of Analysis and Evaluation of Operational Data under JCN E8238, July 1996.

7. K.D. Russell, et al., Systems Analysis Programs for Hands-on Integrated Reliability Evaluations (SAPHIRE), Version 5.0: Technical Reference Manual, NUREG/CR-6116, July 1994.

8. J.A. Schroeder, Simplified Plant Risk Model for Susquehanna 1 \& 2 (ASP BWR C), Rev. 2, prepared for the U.S. Nuclear Regulatory Commission under JCN W6467-5, 1995.

9. H.S. Blackman and J.C. Byers, ASP Human Reliability Methodology Development, draft report prepared for the U.S. Department of Energy under DOE Idaho Operations Office Contract DE-AC07-94ID13223, Idaho National Engineering Laboratory, 1995.

10. A.D. Swain, Handbook of Human Reliability Analysis with Emphasis on Nuclear Power Plant Applications, NUREG/CR-1278, 1983.

11. M.T. Drouin, F.T. Harper, and A.L. Camp, Analysis of Core Damage Frequency from Internal Events: Methodology Guidelines, NUREG/CR-4550, Vol. 1, 1987. 
12. A. Mosleh, Procedure for Analysis of Common-Cause Failures in Probabilistic Safety Analysis, NUREG/CR-5801, 1993.

13. V.L. Sailor, et al, Severe Accidents in Spent Fuel Pools in Support of Generic Safety Issue 82, NUREG/CR-4982, 1987.

14. J.W. Minarick, "Revised LOOP Recovery and PWR Seal LOCA Models," ORNL/NRC/LTR-89/11, technical letter report prepared for the U.S. Nuclear Regulatory Commission, August 1989.

15. J. Darby, et al, Evaluation of Potential Severe Accidents During Low Power and Shutdown Operations at Grand Gulf, Unit 1, NUREG/CR-6143, 1994.

16. T.L. Chu, et al, Evaluation of Potential Severe Accidents During Low Power and Shutdown Operations at Grand Gulf, Unit 1, NUREG/CR-6144, 1994.

17. P. Sobel, Revised Livermore Seismic Hazard Estimates for 69 Nuclear Power Plant Sites East of the Rocky Mountains, Draft Report for Comment, NUREG-1488, 1993.

18. J. Lambright, et al, Evaluation of Generic Issue 57: Effects of Fire Protection System Actuation on Safety-Related Equipment, NUREG/CR-5580, 1992.

19. D.D. Cline, W.A. vonRiesemann, and J.M. Chavez, Investigation of Twenty-Foot Separation Distance as a Fire Protection Method as Specified in 10CFR50, Appendix R, NUREG/CR-3192, 1983.

20. Pickard, Lowe and Garrick, Inc., Indian Point Probabilistic Safety Study, performed for Consolidated Edison Co. and the Power Authority of the State of New York, 1982.

21. C. Kukielka and J.J. Winders, Jr., "Impact of High Temperature and Humidity on $4160 \mathrm{~V}$ Switch Gear Operation," Pennsylvania Power \& Light Co. Study EC-RISK-1047, Rev. 0, 1994.

22. American Nuclear Society and Institute of Electrical and Electronics Engineers, $P R A$ Procedures Guide, NUREG/CR-2300, 1982.

23. C.A. Boschetti, et al, Susquehanna Steam Electric Station Individual Plant Examination, Pennsylvania Power \& Light Co., NPE-91-001, 1991. 
Appendix A

Spent Fuel Pool Model 


\section{APPENDIX A - SPENT FUEL POOL MODEL}

This appendix summarizes the event tree/fault tree developed in this study to analyze spent fuel pool risk for a variety of plant configurations and operating practices. The following sections discuss the modeling approach, the key model features, the initiating events treated, the event trees for sequences leading to pool heatup and event trees for post heatup sequences, and system fault trees. Appendix B discusses the quantification of basic events, Appendix $\mathrm{C}$ discusses the human reliability analysis, and Appendix D provides the key modeling assumptions.

\section{A.1 Modeling Approach}

This study is aimed at the quantitative evaluation of loss of spent fuel pool cooling (SFPC) scenarios up to the point of pool boiling and the qualitative evaluation of the risk associated with these scenarios. The risk stems from three groups of scenarios: those that involve the active fuel in the core, those that involve the spent fuel in the spent fuel pool, and those that involve both. The models developed in this study address all three groups.

It is useful to note that, with respect to scenarios that can affect the core, the modeling approach employed is analogous to that used in the analysis of the so-called external events (e.g., internal fires). This approach divides the accident scenario analysis into three portions: a) the quantitative hazard analysis (e.g., the frequency of fires of a given size in a given location), b) the equipment fragility analysis (e.g., the conditional probability of damage to a given set of equipment, given the fire), and c) the plant response analysis (e.g., the conditional probability of core damage, given the loss of the given set of equipment). In simplified mathematical form,

$$
\mathrm{CDF}=\sum_{\mathrm{j}} \lambda_{\mathrm{j}} \phi_{\mathrm{edlj}} \phi_{\mathrm{cdlj}, \mathrm{ed}}
$$

where $\lambda_{j}$ is the frequency of hazard scenario $j, \phi_{\text {edj }}$ is the conditional probability of equipment damage, given hazard scenario $j$, and $\phi_{c d l j, e d}$ is the conditional probability of core damage, given equipment damage and hazard scenario $\mathrm{j}$.

In this study, it can be seen that $\lambda_{\mathrm{j}}$ corresponds to the near boiling frequency (NBF) associated with a given scenario; this is assessed quantitatively. The term $\phi_{\text {edlj, }}$ on the other hand, is not quantified in this work. (This term is highly dependent on the particular geometry, equipment layout, and ventilation conditions for the plant being analyzed. Furthermore, the analysis of heat and mass transport needed to support quantification is beyond the scope of this limited study.) Qualitative issues affecting the likelihood of equipment damage are discussed in the main body of this report. The term $\phi_{c d j, e d}$ is not treated in this work, but can be quantified using the internal events model for the plant in question, as long as the likelihood of operator errors is not drastically affected by the spent fuel pool boiling event. 


\section{A.2 Key Features}

The SAPHIRE Version 5.0 [A.1] software package is used to implement the event/tree fault tree model documented in this appendix. The fault tree linking approach employed by SAPHIRE ensures that shared equipment dependencies between top events (e.g., due to common support systems) are properly treated. Other dependencies (e.g., sequence-dependent human error probabilities) are treated using the SAPHIRE capability to employ user-defined rules for assigning different fault trees to different event sequences.

Note that the models described in the following sections are based largely on the Susquehanna plant, a two-unit boiling water reactor with two spent fuel pools, a SFPC system powered off of a non-safety bus and cooled by non-safety service water, residual heat removal (RHR) assist cooling as backup to the SFPC system, and a safety-related emergency service water system to provide makeup when normal pool makeup is unavailable or inadequate. The event tree models are expected to be generic enough to allow analysis of a variety of other plant configurations. (For example, they can treat plants where the fuel pools are not cross-tied, as they are at Susquehanna.) However, the success criteria and the fault trees developed are appropriate to Susquehanna.

\section{A.3 Initiating Events and Cases}

The initiating events modeled are derived from the master logic diagram shown in Figure A.1, comparison with the list of initiating events treated in Ref. A.2, and comparison with the list of initiating events treated in Refs. A.2 and A.3. The classes of initiating events treated in this study are as follows:

- $\quad$ Loss of Spent Fuel Pool Cooling System (LOSFP)

This event includes loss of the SFPC system due to hardware failures and human errors. It also includes system loss due to loss of cooling to the SFPC heat exchangers and due to internal flooding and fires.

Note that in principle, the loss of heat exchanger cooling, internal flooding, and internal fires should be treated as separate initiating events, since these causes for loss of SFPC might also affect other parts of the plant. (At Susquehanna, heat exchanger cooling is normally provided by a non-safety service water system.) These events are intentionally grouped with direct losses of SFPC because of the limited scope of this study, and because the results of Ref. A. 2 indicate that, at least in the case of Susquehanna, the contributions to risk from the loss of service water and internal flooding initiators are relatively small.

- Loss of Offsite Power (LOOP)

In this analysis, the LOOP event includes the extended LOOP and station blackout (SBO) events. 


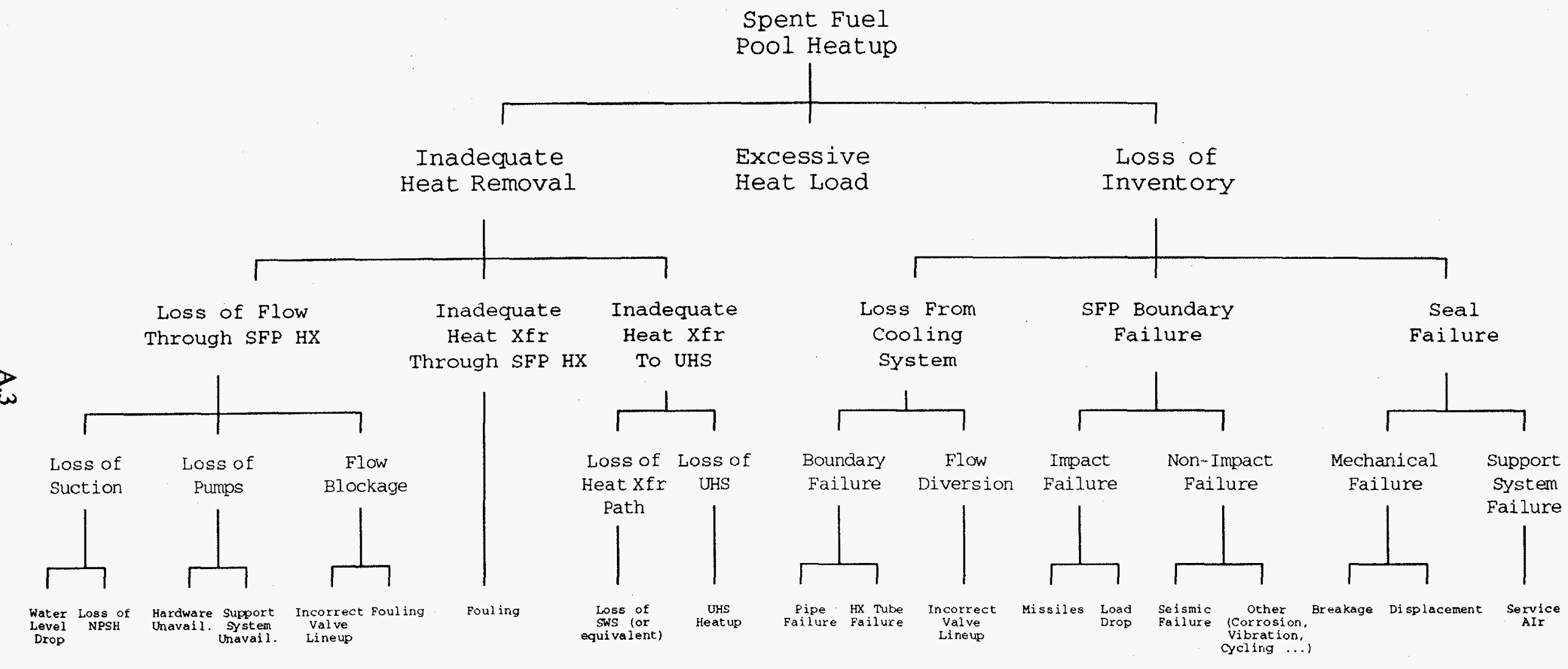

Figure A.1 - Master Logic Diagram for Spent Fuel Pools 
This event includes losses of inventory from leaks/breaks from the failure of piping or gates/seals. Only leaks/breaks for which the outgoing flow rate exceeds the normal makeup flow rate are considered. Losses of inventory due to structural failure of the spent fuel pool boundary (e.g., due to missiles, heavy load drops, thermal stresses) are not treated. This category of events may need to be re-examined, depending on the quantitative results of the models documented in this study.

- Loss of Primary Coolant (PLOCA)

This event covers pipe break LOCAs in an operating unit and special outage-associated LOCAs (both "J" LOCAs, i.e., connected system LOCAs, and "K" LOCAs, i.e., maintenance-induced LOCAs) in a unit undergoing refueling. LOCAs during operation are of potential concern because they can, for some plant designs, lead to an automatic trip of the SFPC system, and because they create a demand for the RHR system, which serves as an alternate cooling system for the spent fuel pool. In the case of the J and K LOCAs, the event provides a potential means for quickly draining the spent fuel pool down to the bottom of the transfer gate.

- $\quad$ Seismic Events (EQE)

This event covers seismically-induced losses of offsite power, SFPC piping integrity, and spent fuel pool boundary integrity. Two classes of earthquakes are treated: those with peak ground acceleration (PGA) between $0.2 \mathrm{~g}$ and $0.6 \mathrm{~g}$, and those with PGA above $0.6 \mathrm{~g}$.

The specific initiating events addressed in this analysis are listed in Table A.1. Events occurring during refueling are treated differently than those that occur during operation. In the case of LOSFP and LOOP, distinctions are also drawn for events occurring during a $1 / 3$ core offload refueling and those occurring during a full core offload refueling.

The following different plant configurations ("cases") are analyzed. Table A.2 presents a comparison of the cases considered in this study and those considered in Ref. A.2.

- Case 1 - Both units operating.

- Case 2 - Unit 2 operating, Unit 1 refueling ( $1 / 3$ core offload).

- Case 3 - Unit 2 operating, Unit 1 refueling (full core offload). 
Table A.1 - Initiating Event Frequencies (Instantaneous)

\begin{tabular}{|l|l|c|c|}
\hline Initiating Event & Description & Frequency (/yr) & Source \\
\hline LSFP1 & Loss of SFPC system, Case 1 & $2.4 \mathrm{E}-2$ & Data (see App. B) \\
\hline LSFP2 & Loss of SFPC system, Case 2 & $2.8 \mathrm{E}-1$ & Data (see App. B) \\
\hline LSFP3 & Loss of SFPC system, Case 3 & $2.8 \mathrm{E}-1$ & Data (see App. B) \\
\hline LP1 & Loss of offsite power, Case 1 & $8.0 \mathrm{E}-2$ & Ref. A.4 \\
\hline LP2 & Loss of offsite power, Case 2 & $8.0 \mathrm{E}-2$ & Ref. A.4 \\
\hline LP3 & Loss of offsite power, Case 3 & $8.0 \mathrm{E}-2$ & Ref. A.4 \\
\hline LINVC & Large loss of inventory, Case 1 & $2.0 \mathrm{E}-3$ & Data (see App. B) \\
\hline LINCS & Small loss of inventory, Case 1 & $5.0 \mathrm{E}-3$ & Data (see App. B) \\
\hline LINVR & Large loss of inventory, Cases 2 and 3 & $2.0 \mathrm{E}-2$ & Data (see App. B) \\
\hline LINRS & Small loss of inventory, Cases 2 and 3 & $3.0 \mathrm{E}-2$ & Data (see App. B) \\
\hline PLOCA & Primary LOCA, Case 1 & $1.5 \mathrm{E}-2$ & Ref. A.5 \\
\hline PLOCR & Primary LOCA, Cases 2 and 3 & $1.2 \mathrm{E}-1$ & Ref. A.6, A.7 (see App. B) \\
\hline EQE & Seismic event (0.2g $<$ PGA $\leq 0.6 \mathrm{~g})^{\mathrm{a}}$ & $1.2 \mathrm{E}-4$ & Ref. A.8 \\
\hline
\end{tabular}

"Earthquakes with PGA $>0.6 \mathrm{~g}$ are for the purposes of this analysis, assumed to lead directly to core damage (with frequency $3.2 \mathrm{E}-6 / \mathrm{yr}$ ).

Table A.2 - Mapping of INEL and Ref. A.2 Cases

\begin{tabular}{|l|c|c|c|}
\cline { 2 - 4 } \multicolumn{1}{c|}{} & Both units operating & $\begin{array}{c}\text { Unit } 2 \text { operating, } \\
\text { Unit } 1 \text { refueling } \\
\text { (1/3 core discharge) }\end{array}$ & $\begin{array}{c}\text { Unit } 2 \text { operating, } \\
\text { Unit } 1 \text { refueling } \\
\text { (full core discharge) }\end{array}$ \\
\hline INEL Case \# & 1 & 2 & 3 \\
\hline Ref. 3 Case \# & 1,2 & $3,4,5^{\mathrm{a}}$ & $3,4,5$ \\
\hline
\end{tabular}

${ }^{a}$ Not clear if Ref. A. 2 treats $1 / 3$ core discharges 


\section{A.4 NBF Event Trees and Success Criteria}

In general, the structure and level of detail of the NBF event trees are similar to those of the event trees presented in Ref. A.2. The three key differences are as follows.

1) Those trees that model initiators with potential direct impacts on the core (LOOP, seismic, PLOCA) include a top event (UNREC) indicating if recovery is uncomplicated. Assuming that operators are generally more concerned with the core than the spent fuel pool, a complicated recovery can inhibit the operators from devoting sufficient resources to deal with the spent fuel pool in a timely fashion. Appendix B provides the operational definition for complicated scenarios used in this analysis.

2) The trees explicitly allow for the possibility that operators will not respond to the initiating event until pool boiling occurs. This delay can be due to lack of awareness (e.g., failed instrumentation) or distraction (e.g., due to a complicated recovery). Note that the AEOD database includes a number of events in which operator response was delayed for many hours, although none were delayed to such an extent that pool boiling occurred.

3) The LOOP, seismic, and primary LOCA trees represent the possibility of "direct core damage" (i.e., core damage not due to the consequences of a spent fuel pool scenario) for complicated scenarios. The purpose of this treatment is to ensure that any final core damage frequency estimates developed from the results of this study do not double count risk contributing scenarios. (Thus, for example, station blackout scenarios which lead directly to core damage are not included in the NBF estimation, even though they could lead to pool boiling.)

This section contains the event trees for near boiling frequency (NBF), the top event definitions, and the success criteria associated with each top event. The event trees appear on the following pages:

Initiating Event Class. Case (Initiating Event)

Loss of spent fuel pool cooling, Case 1 (LSFP1)

Pages

Loss of spent fuel pool cooling, Case 2 (LSFP2)

A.9-A.10

Loss of spent fuel pool cooling, Case 3 (LSFP3)

A.11-A. 12

Loss of offsite power, Case 1 (LP1)

A.13-A.14

Loss of offsite power, Case 2 (LP2)

A.18-A. 21

Loss of offsite power, Case 3 (LP3)

A. $22-$ A. 25

Large loss of inventory, Case 1 (LINVC)

A. $26-$ A. 29

Small loss of inventory, Case 1 (LINCS)

A. 35

Large loss of inventory, Cases 2 and 3 (LINVR)

A.36

Small loss of inventory, Cases 2 and 3 (LINRS)

A. 37

Primary LOCA, Case 1 (PLOCA)

A. 38

Primary LOCA, Cases 2 and 3 (PLOCR)

A. $42-\mathrm{A} .43$

Seismic event (EQE)

A. 44

A. 48 
The endstates for these trees are defined as follows:

OK Scenario recovery is successful

CD Core damage

FPIS1 Boiling; scenario involves loss of SFPC, spent fuel pool (SFP) level is not maintained

FPIS2 Near boiling of SFP; scenario involves late restoration of SFPC

FPIS3 Steaming; scenario involves use of alternate cooling system; SFP level is maintained

FPSF1 Combination of end states FPIS1 (boiling) and FPISF (flooding)

FPSF2 Combination of end states FPIS2 (near boiling) and FPISF (flooding)

FPSF3 Combination of end states FPIS3 (steaming) and FPISF (flooding)

Note that the direct core damage (CD) endstate is treated only to ensure that scenarios which lead to core damage before pool boiling are excluded from the analysis; the CD endstate is not modeled for some sequences where SFP cooling is assured. The resulting CD endstate frequencies are provided for accounting purposes only, and should not be interpreted as representing the total core damage frequency. 


\section{A.4.1 Loss of Spent Fuel Pool Cooling}

Three event trees are used to model this class of initiating events. Event tree LSFP1 deals with Case 1, LSFP2 deals with Case 2, and LSFP3 deals with Case 3. The event trees, top event definitions, and success criteria are listed in the following pages. Note that each event tree has one transfer tree. 


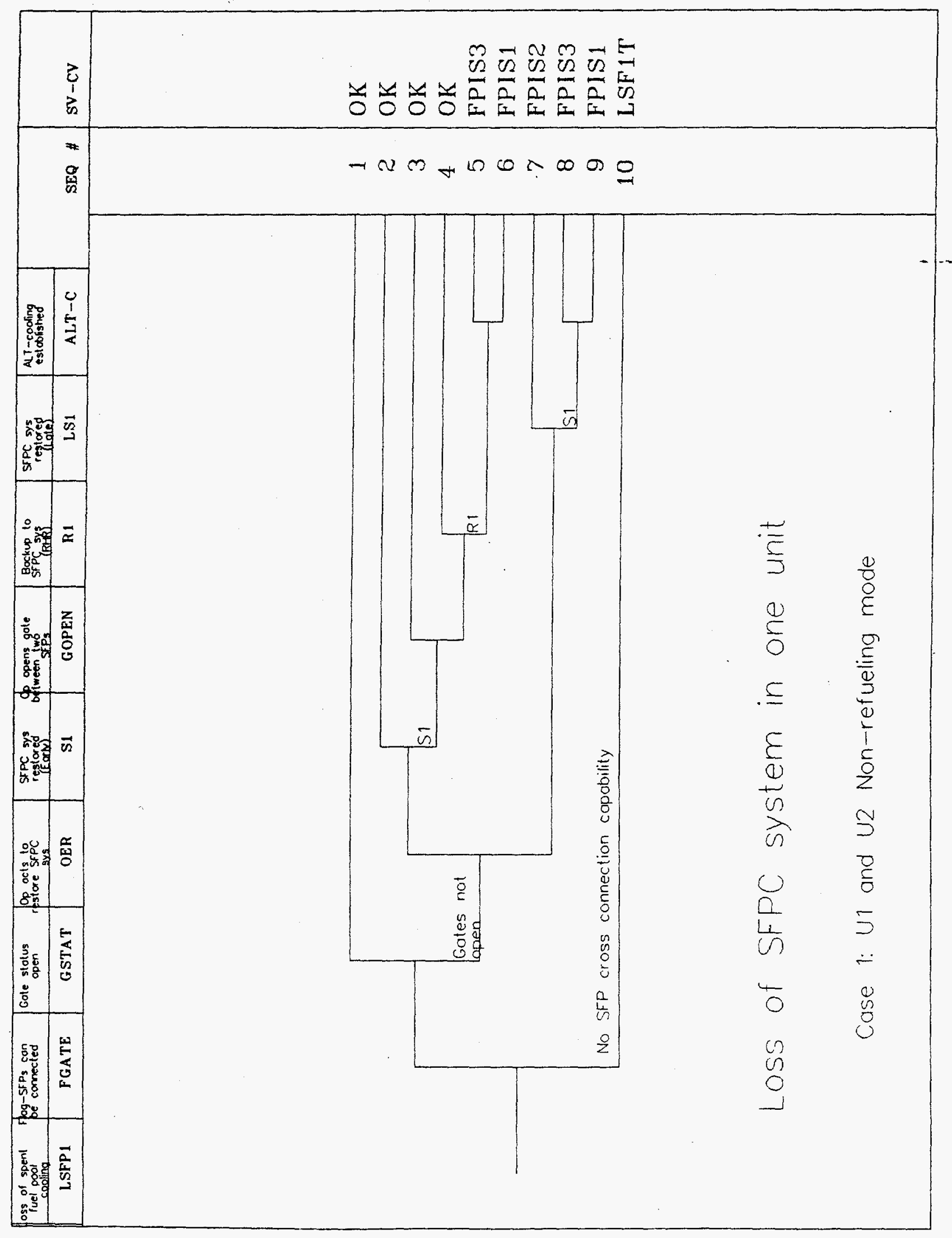

A.9 


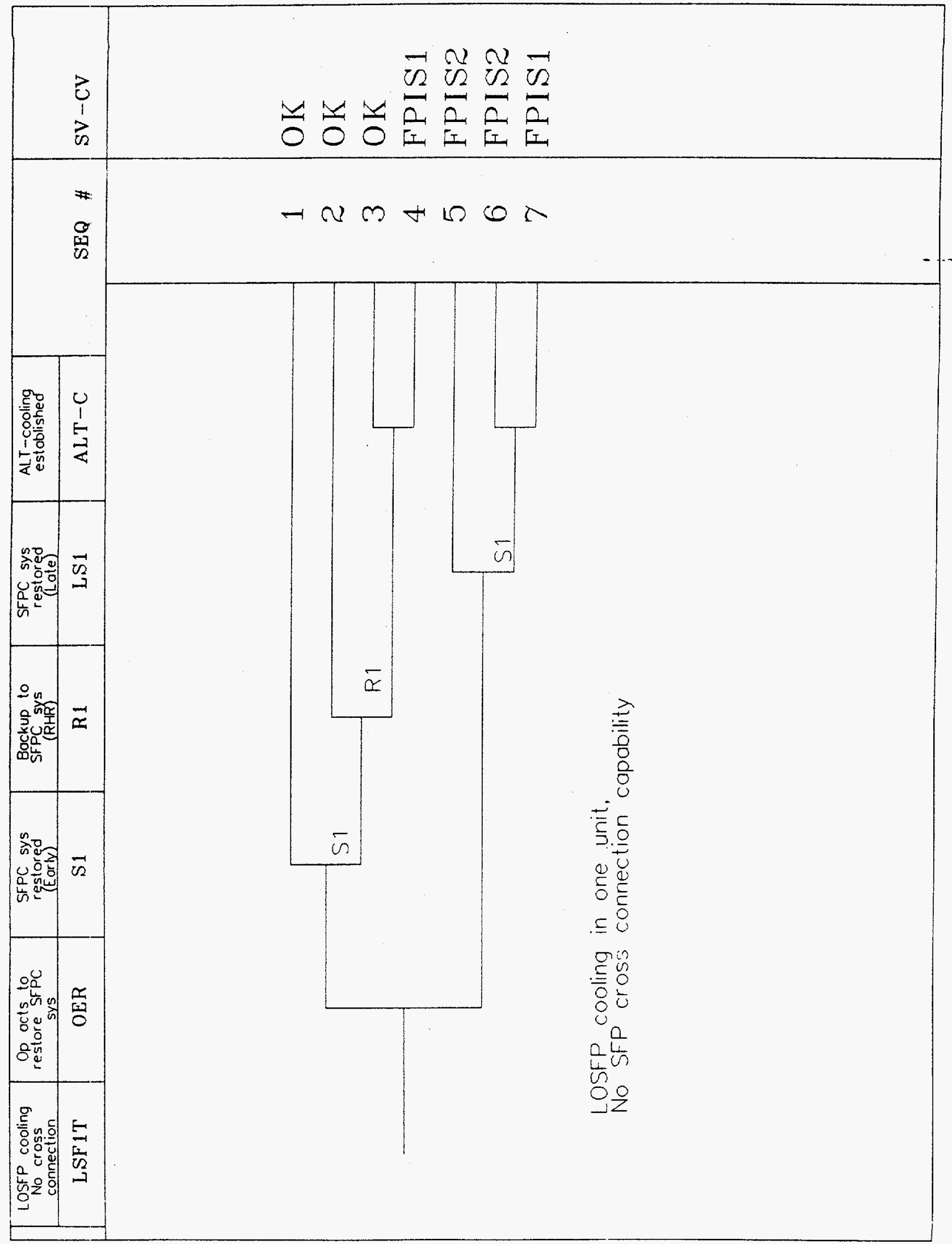

A. 10 


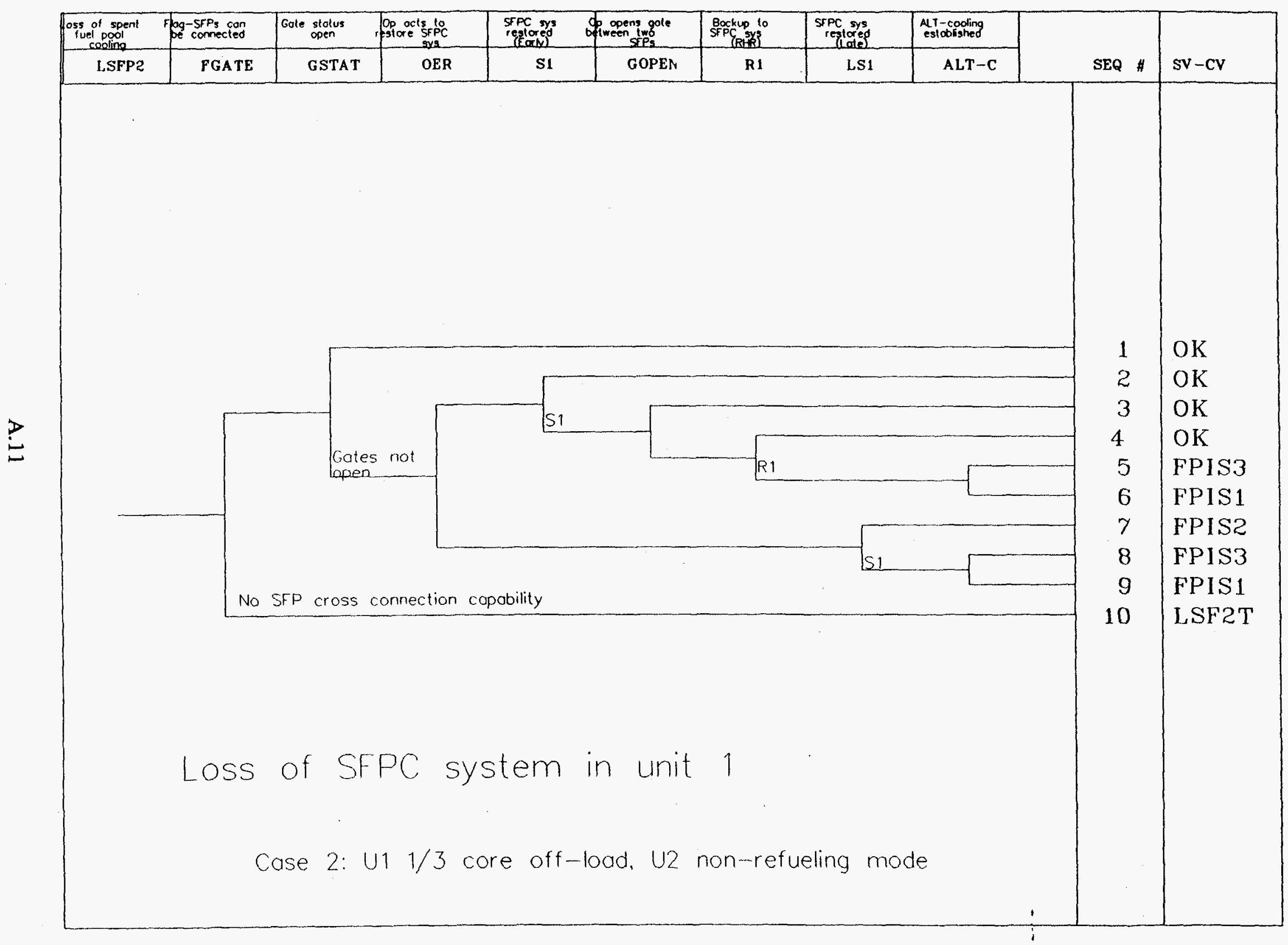




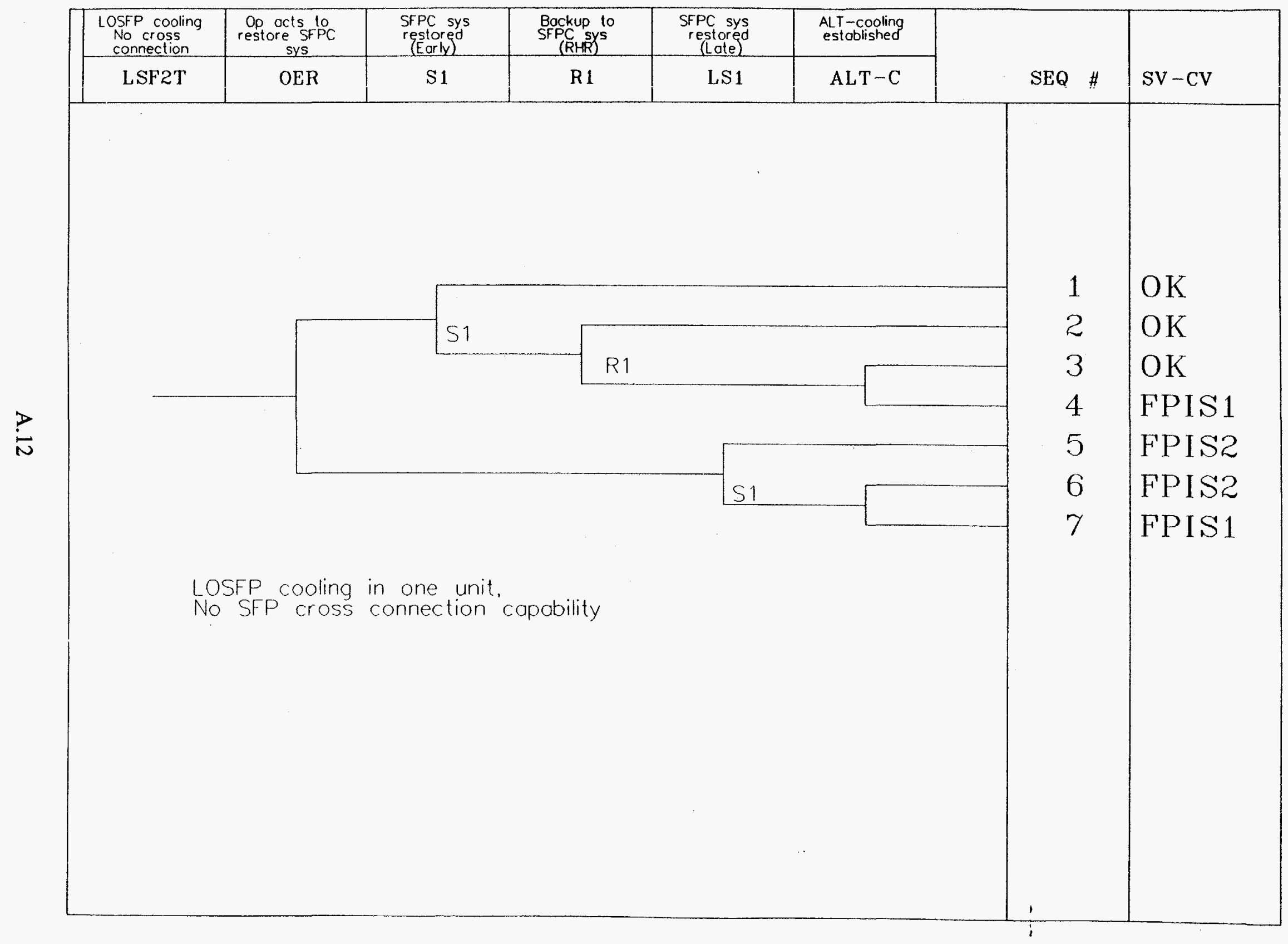




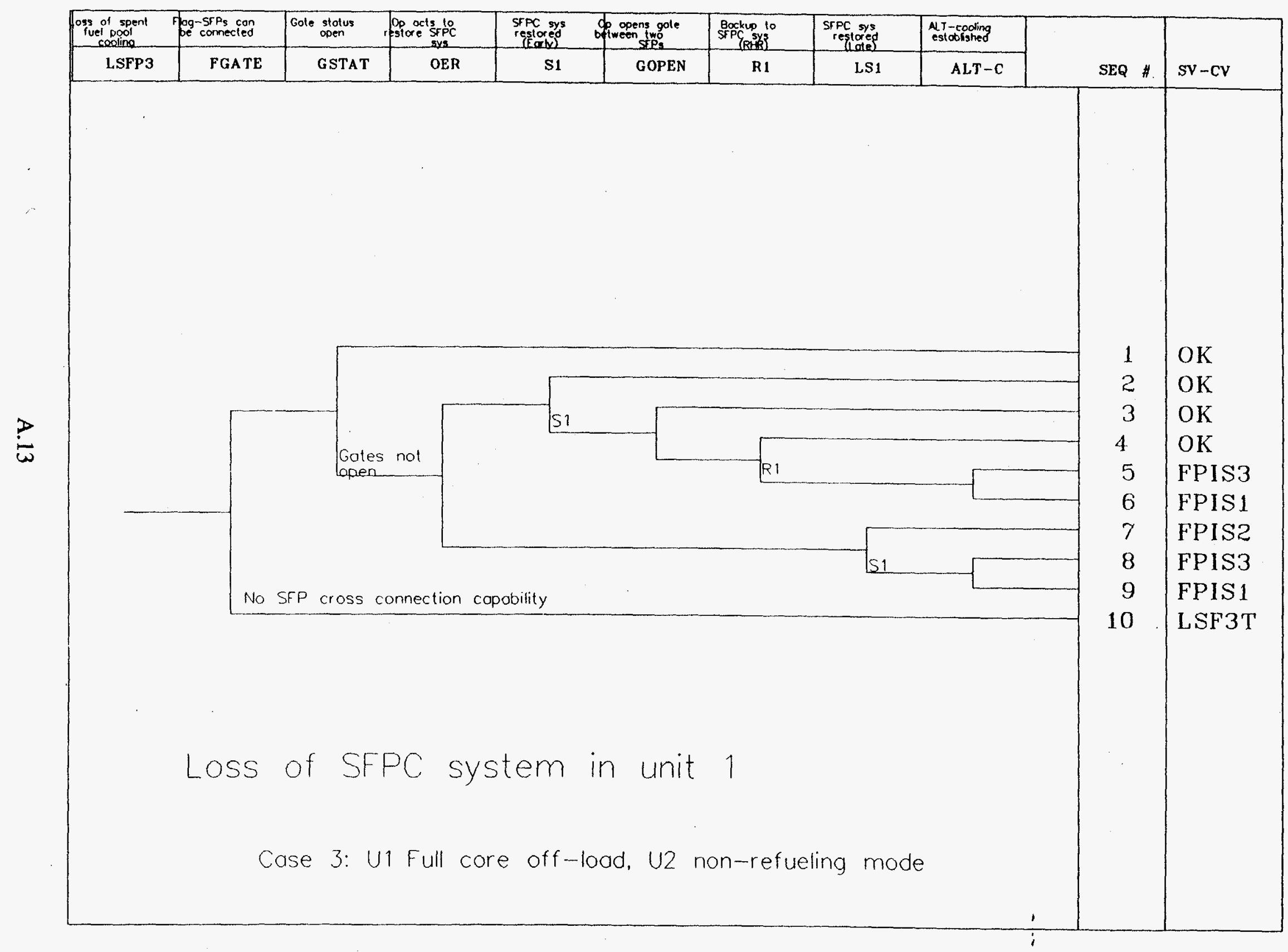




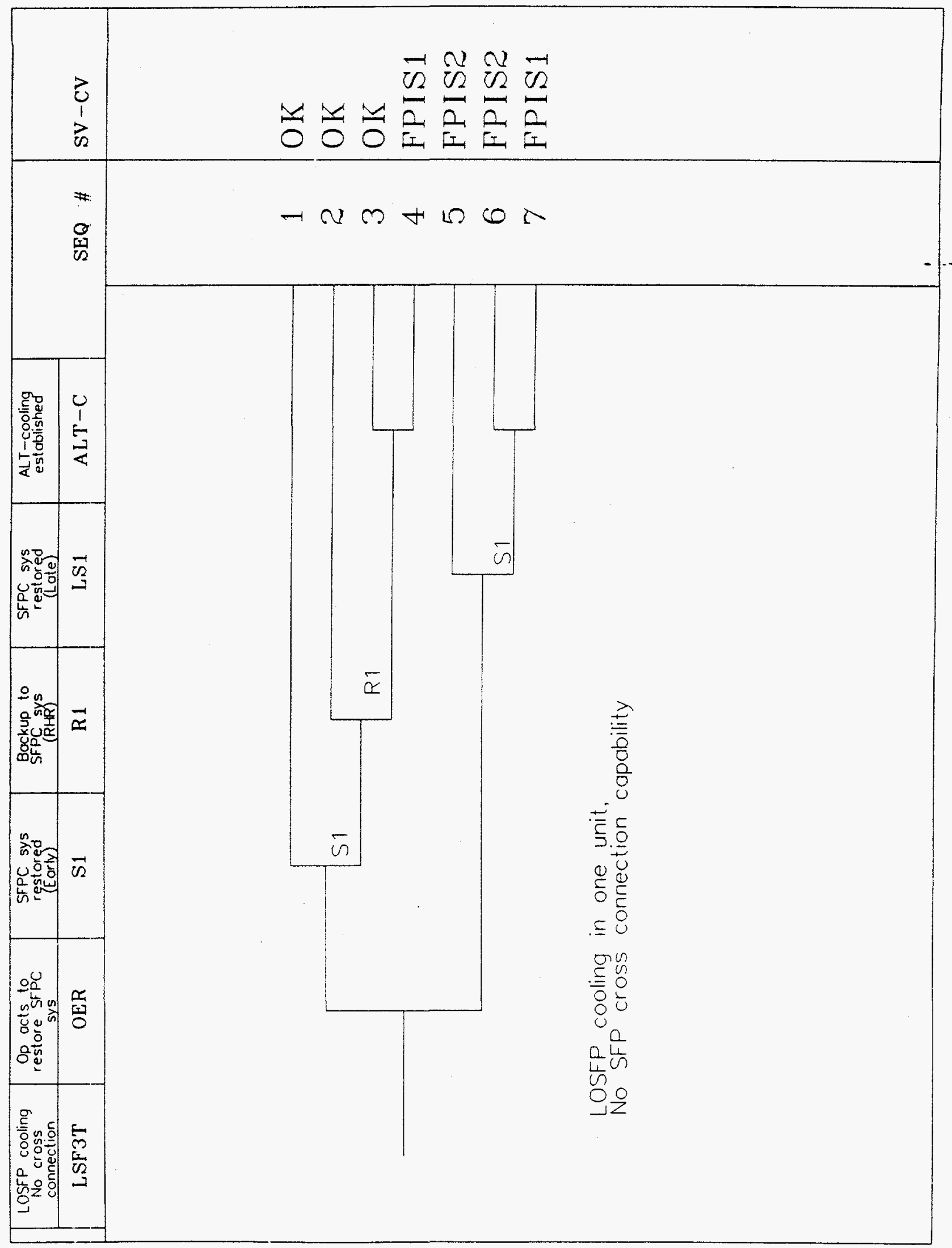

A. 14 
Top Event Definitions - Loss of Spent Fuel Pool Cooling System Event Trees

LSFP1 Loss of SFPC system at Unit 1 while both units are operating (Case 1). (Initiating events LSFP2 and LSFP3 treat Cases 2 and 3.) This initiating event is analyzed only for cases where the spent fuel pools are not initially cross-connected.

FGATE A flag event: the plant being modeled has the capability to cross-connect the spent fuel pool by opening a gate (or gates). (Note that the upward branches in the event tree, per the usual convention, represent a "yes or success" answer to the top event question.)

GSTAT Status of cross-connect gate(s): the spent fuel pools are cross connected or not at the time of initiating event.

OER Operator response to the loss of SFPC system: operator attempts to restore SFP cooling soon after the initiating event.

S 1 Restoration of the SFPC system: operators successfully reestablish cooling.

GOPEN Opening of the gate: operators successfully open the gate(s) and cross-connect the spent fuel pools.

R1 RHR cooling: operators successfully reestablish cooling using the Unit 1 RHR.

LS1 Late restoration of the SFPC system: similar to the top event S1 except all the actions must be taken remotely. (This top event is challenged when the pool has reached near boiling conditions. It is assumed that by this stage, there are a multitude of indications and alarms that will notify the operators of the SFP problems.)

ALT-C Alternate cooling: operators successfully establish evaporative/boiloff cooling by providing water using alternate cooling (e.g., fire water system). 
Success Criteria - Loss of Spent Fuel Pool Cooling System Event Trees

Case 1 (LSFP1)

\begin{tabular}{|c|c|c|c|}
\hline S1 & R1 & LS1 & ALTC \\
\hline 1 of 3 SFPC pumps & 1 train RHR & 1 of 3 SFPC pumps & $\begin{array}{l}\text { Any available alternate } \\
\text { cooling system }\end{array}$ \\
\hline
\end{tabular}

Case 2 (LSFP2)

\begin{tabular}{|c|c|c|c|}
\hline S1 & R1 & LS1 & ALT-C \\
\hline 2 of 3 SFPC pumps & 1 train of RHR & 2 of 3 SFPC pumps & $\begin{array}{l}\text { Any available alternate } \\
\text { cooling system }\end{array}$ \\
\hline
\end{tabular}

Case 3 (LSFP3)

\begin{tabular}{|c|c|c|c|}
\hline S1 & R1 & LS1 & ALT-C \\
\hline 3 of 3 SFPC pumps & 1 train of RHR & 3 of 3 SFPC pumps & $\begin{array}{l}\text { Any available alternate } \\
\text { cooling system }\end{array}$ \\
\hline
\end{tabular}




\section{A.4.2 Loss of Offsite Power}

Three event trees are used to model this class of initiating events. Event tree LP1 deals with Case 1, LP2 deals with Case 2, and LP3 deals with Case 3. The event trees, top event definitions, and success criteria are listed in the following pages. Note that each event tree has three transfer trees. 


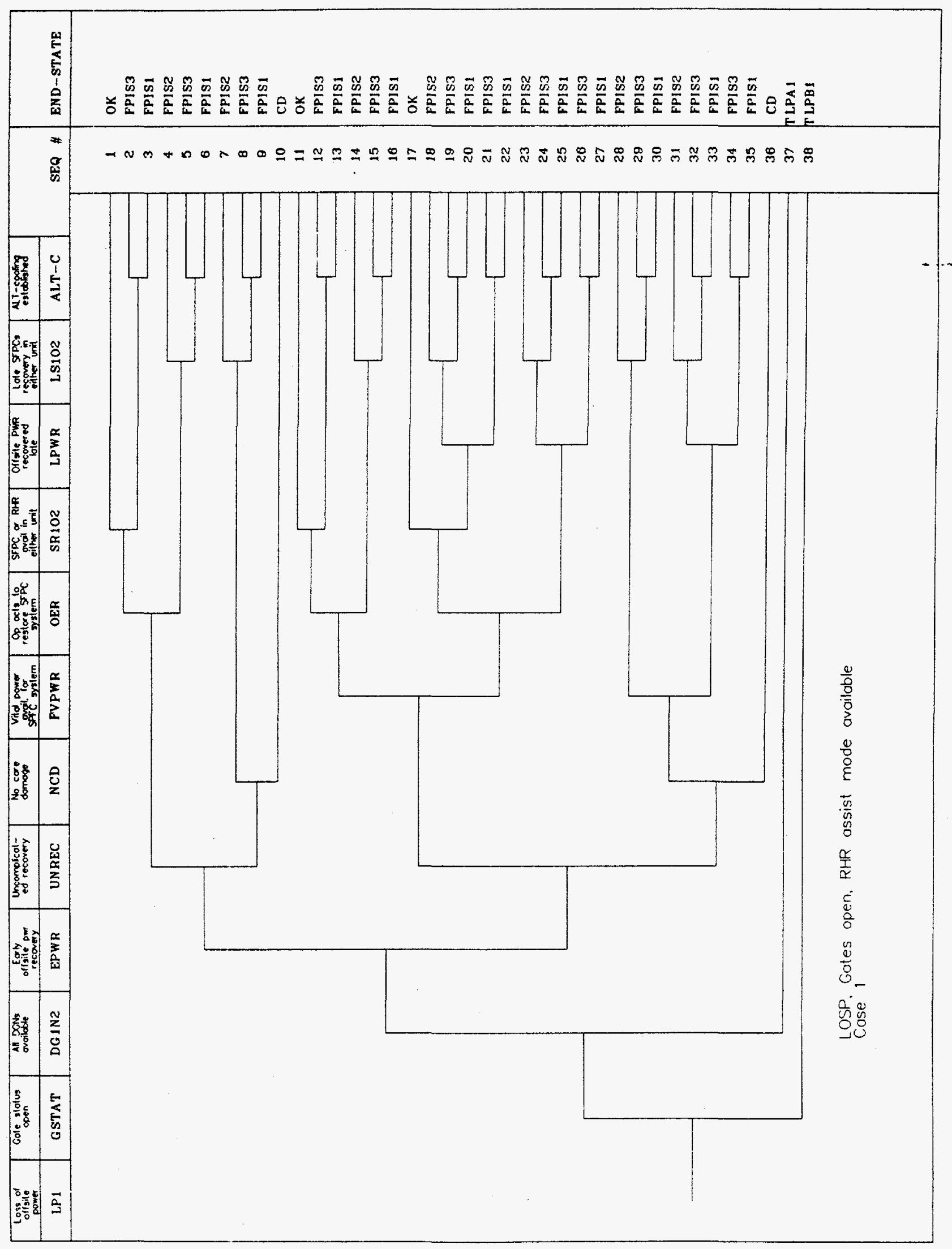

A. 18 


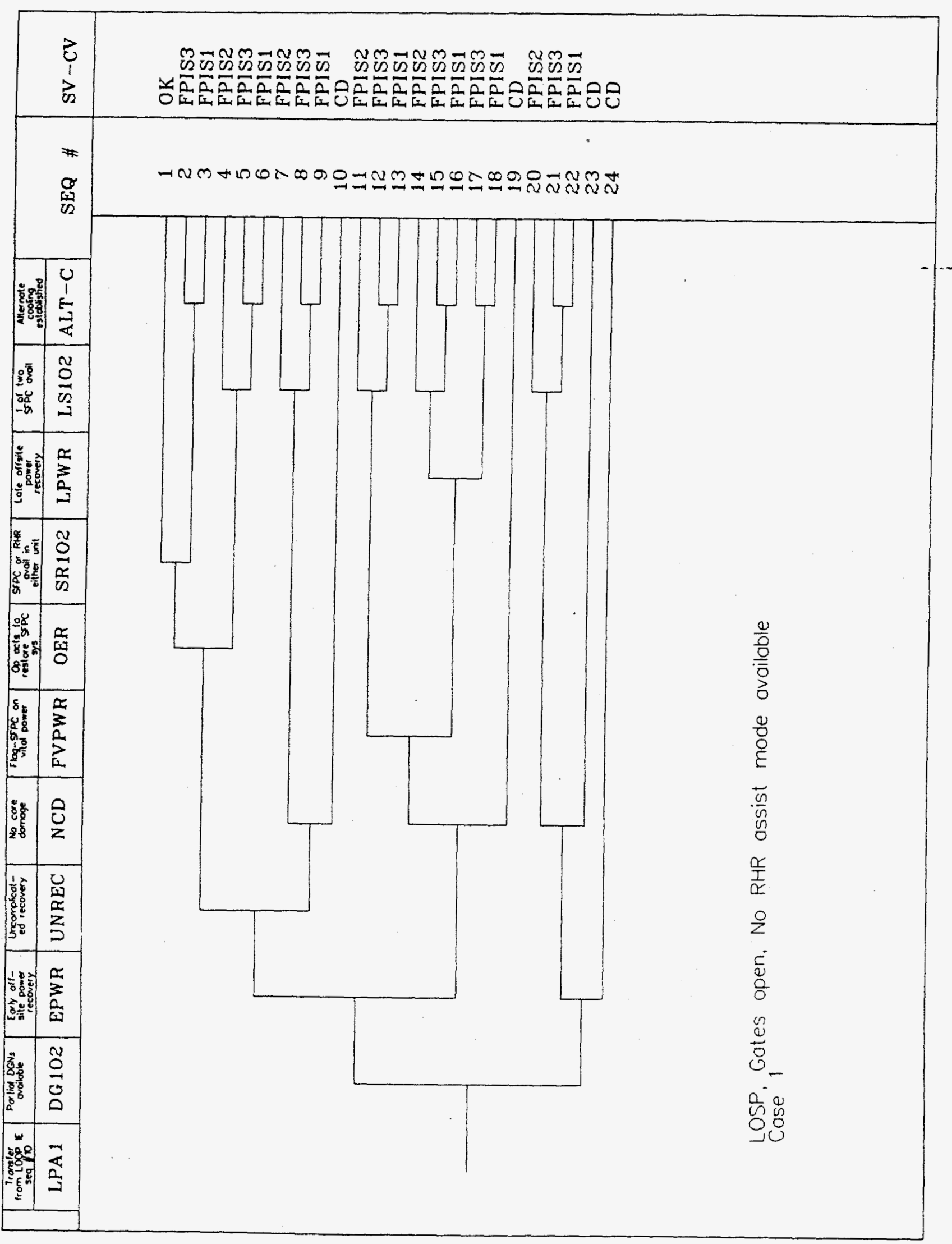

A. 19 


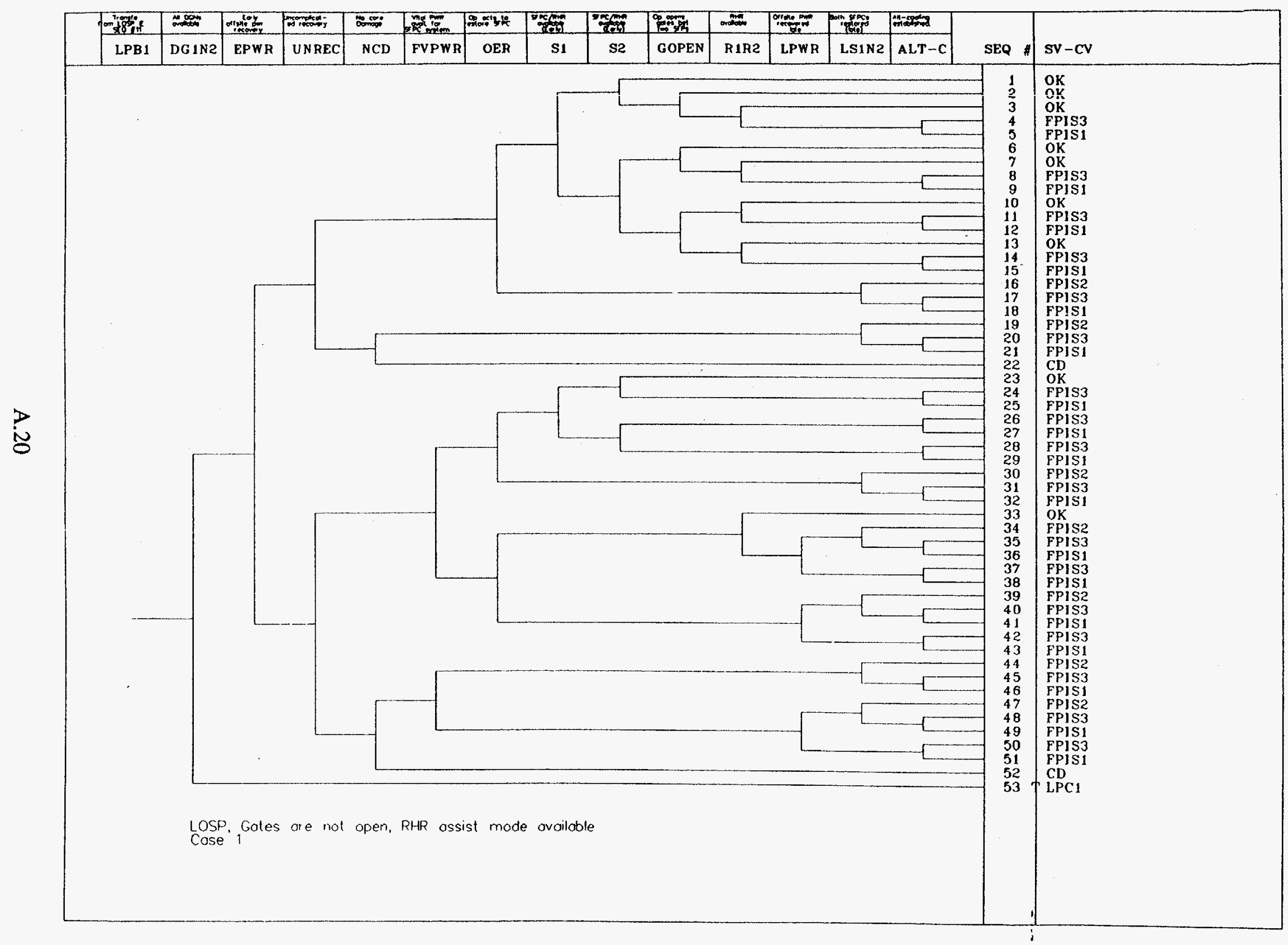




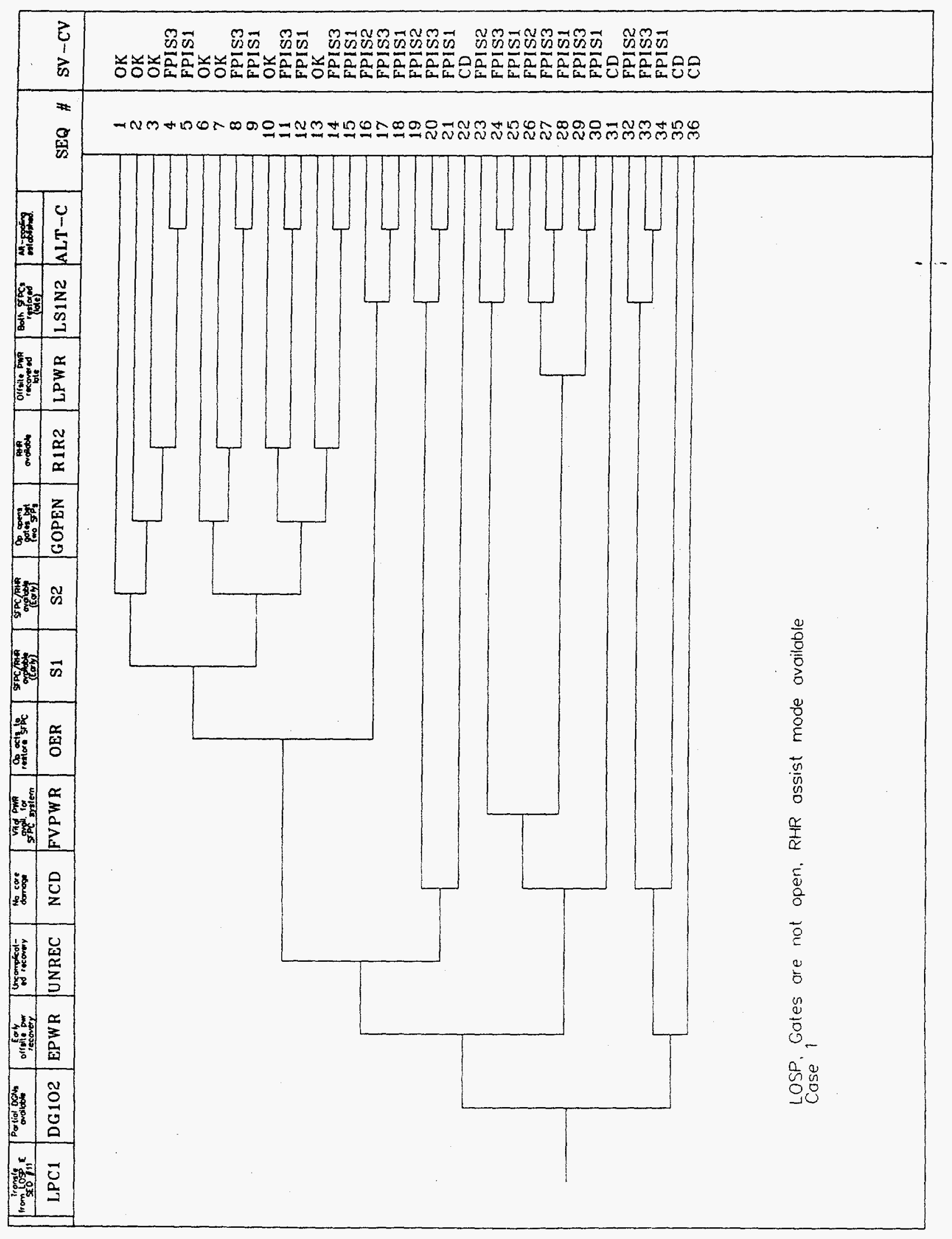

A. 21 


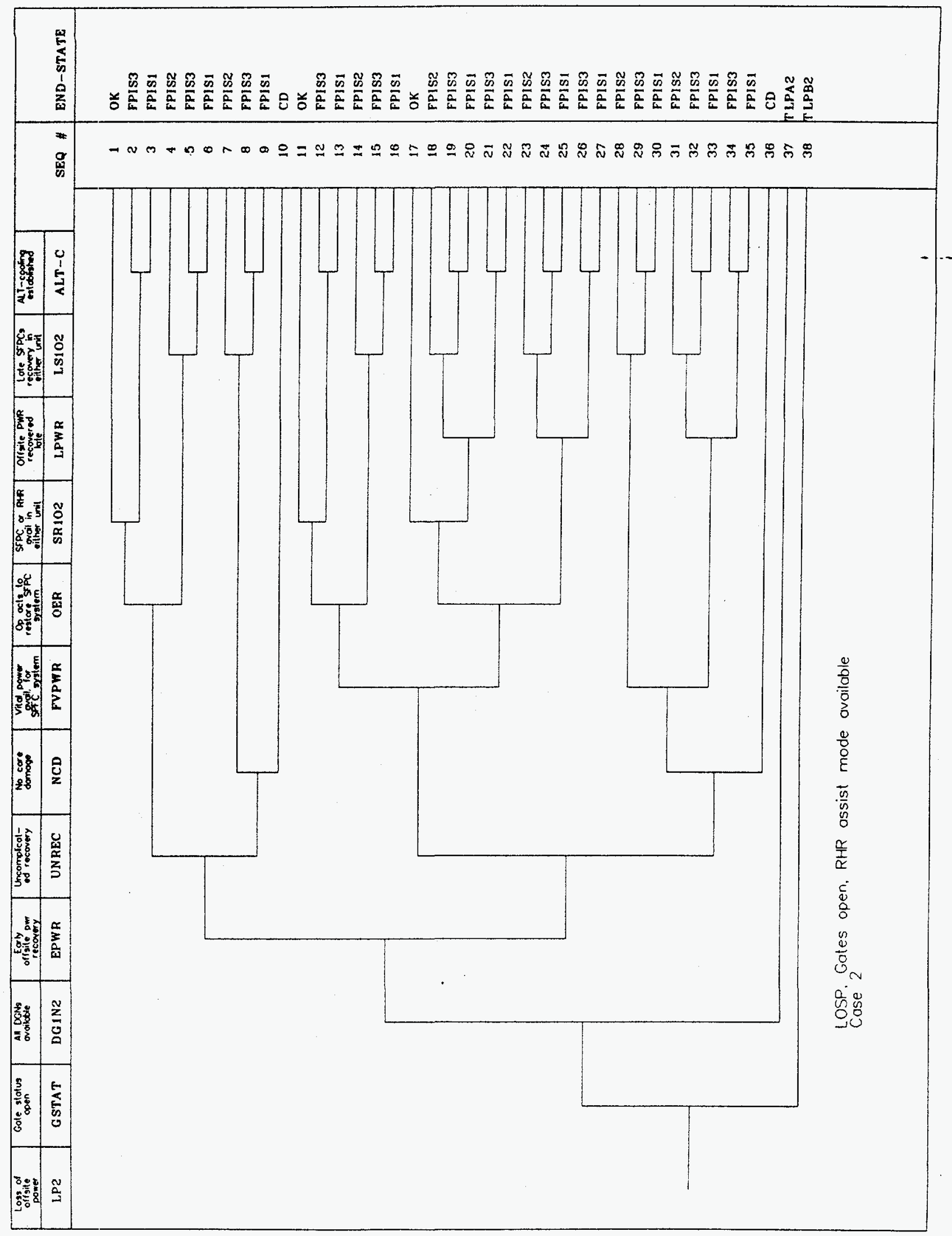




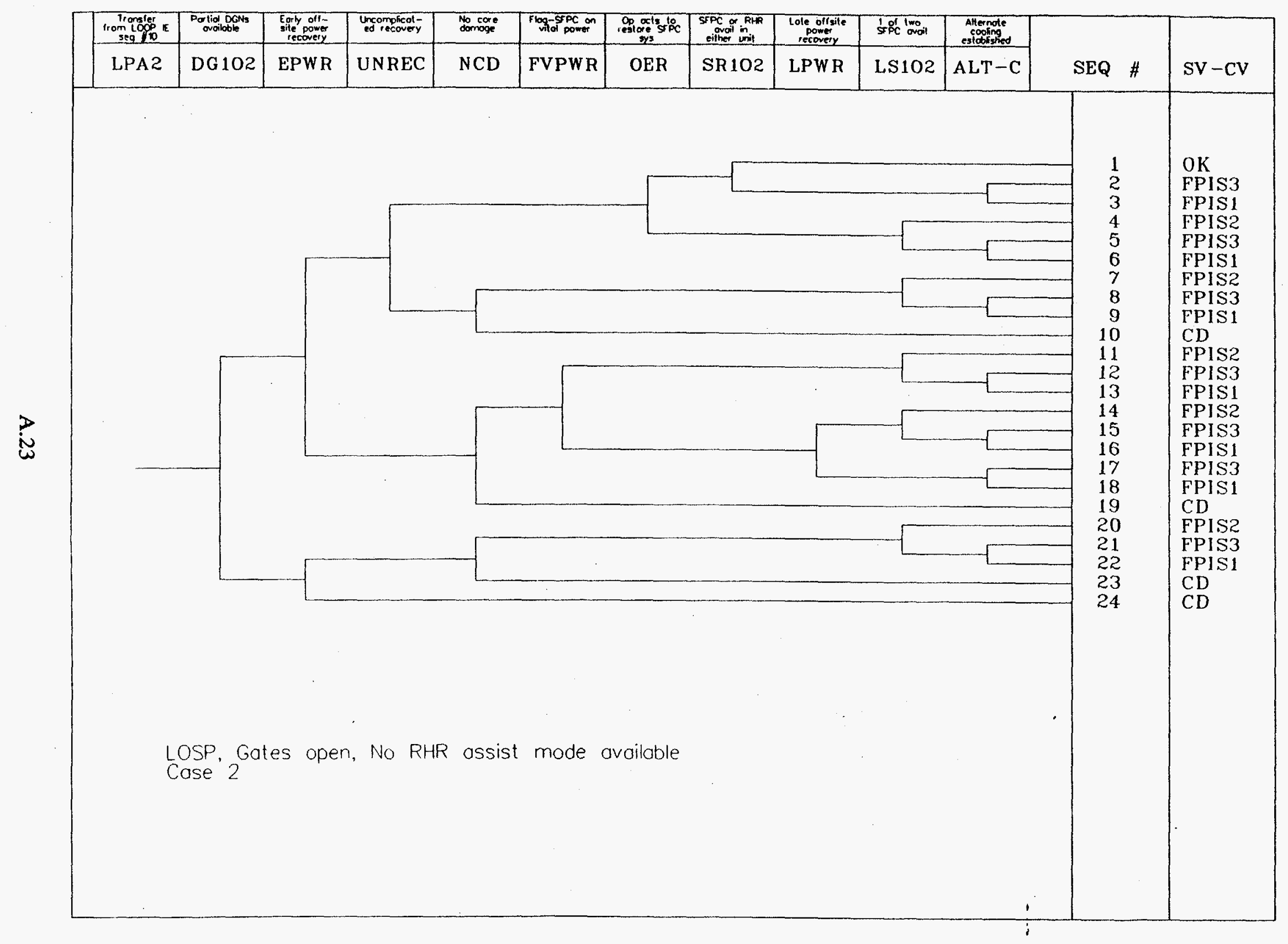




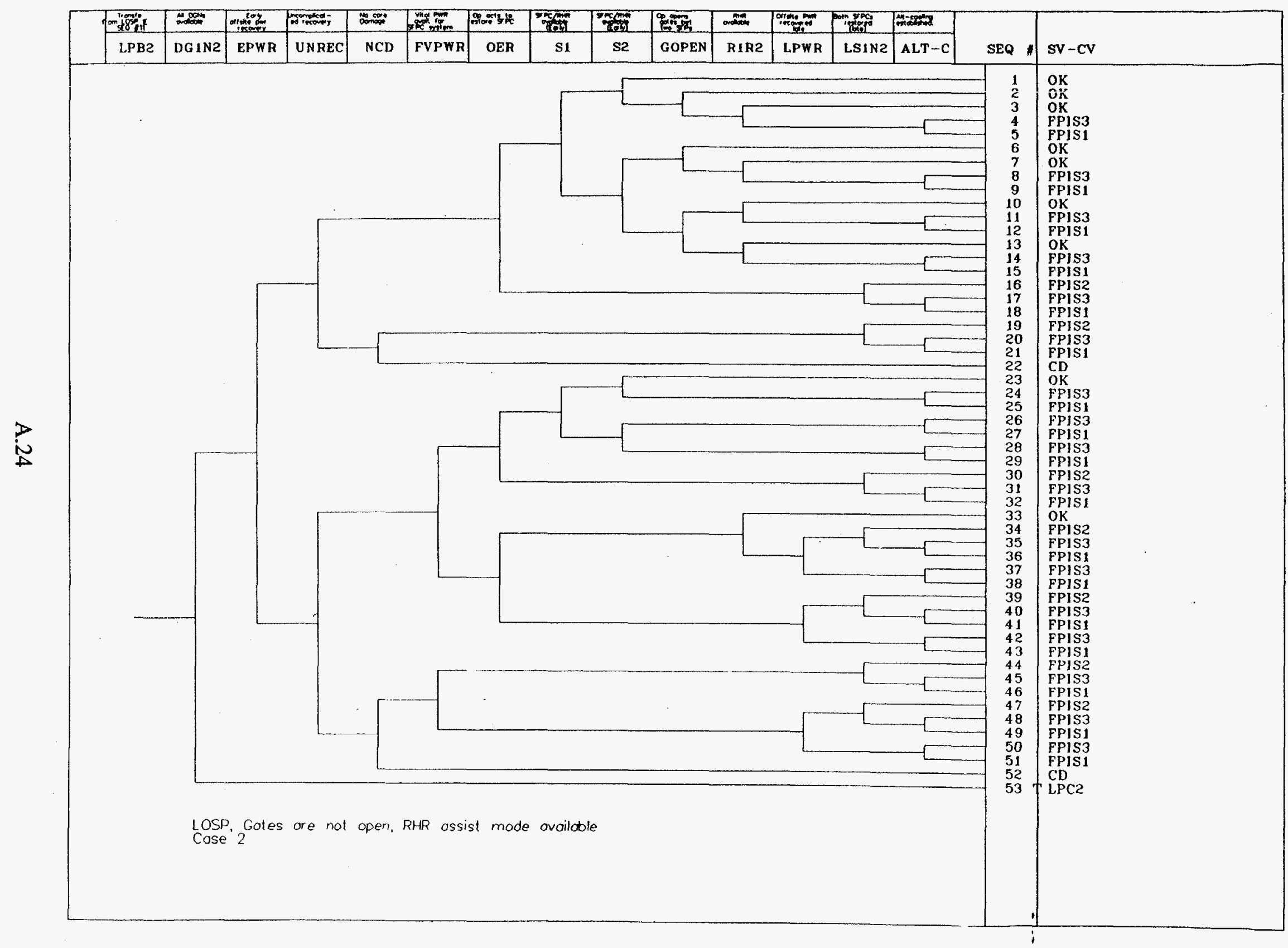




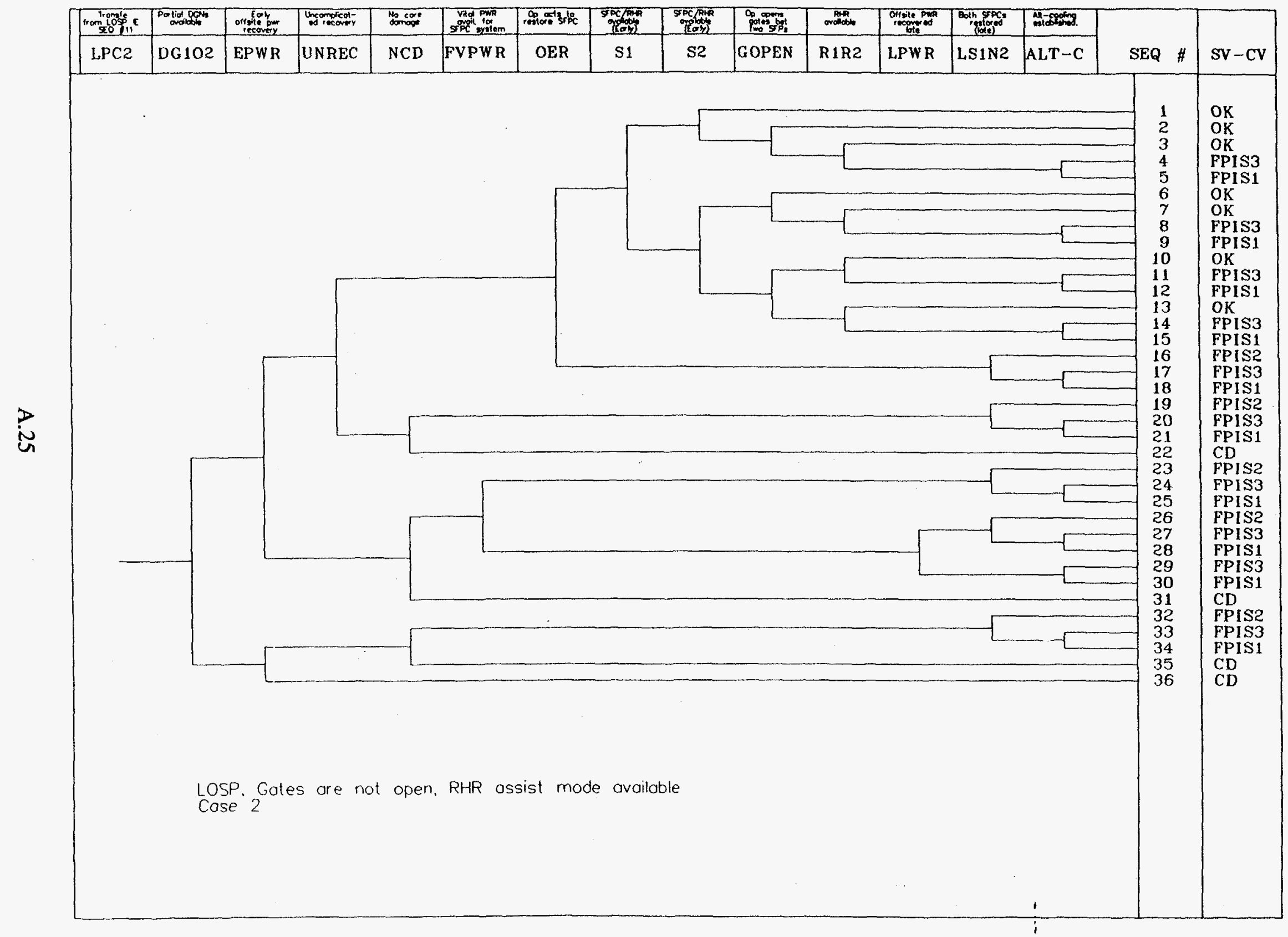




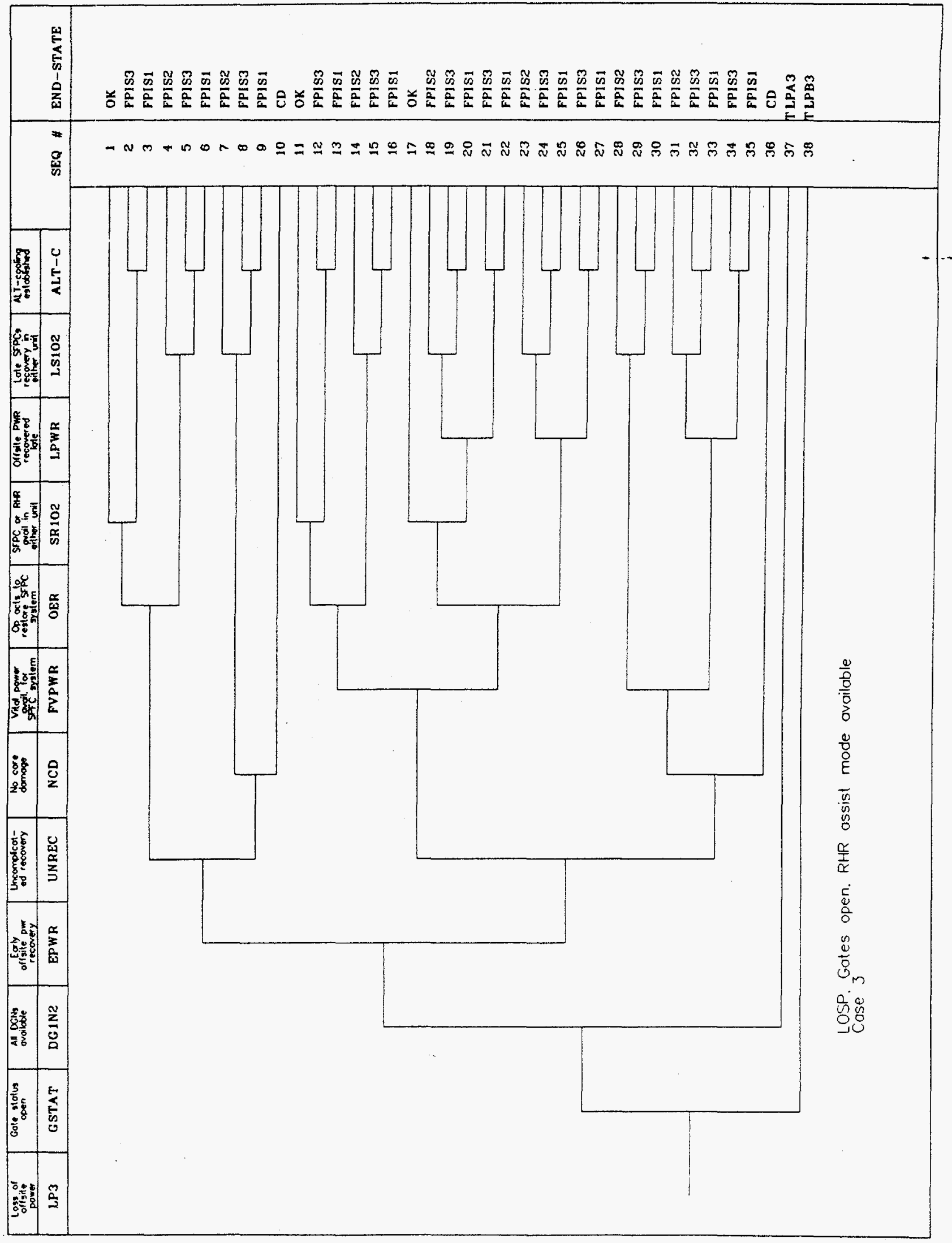




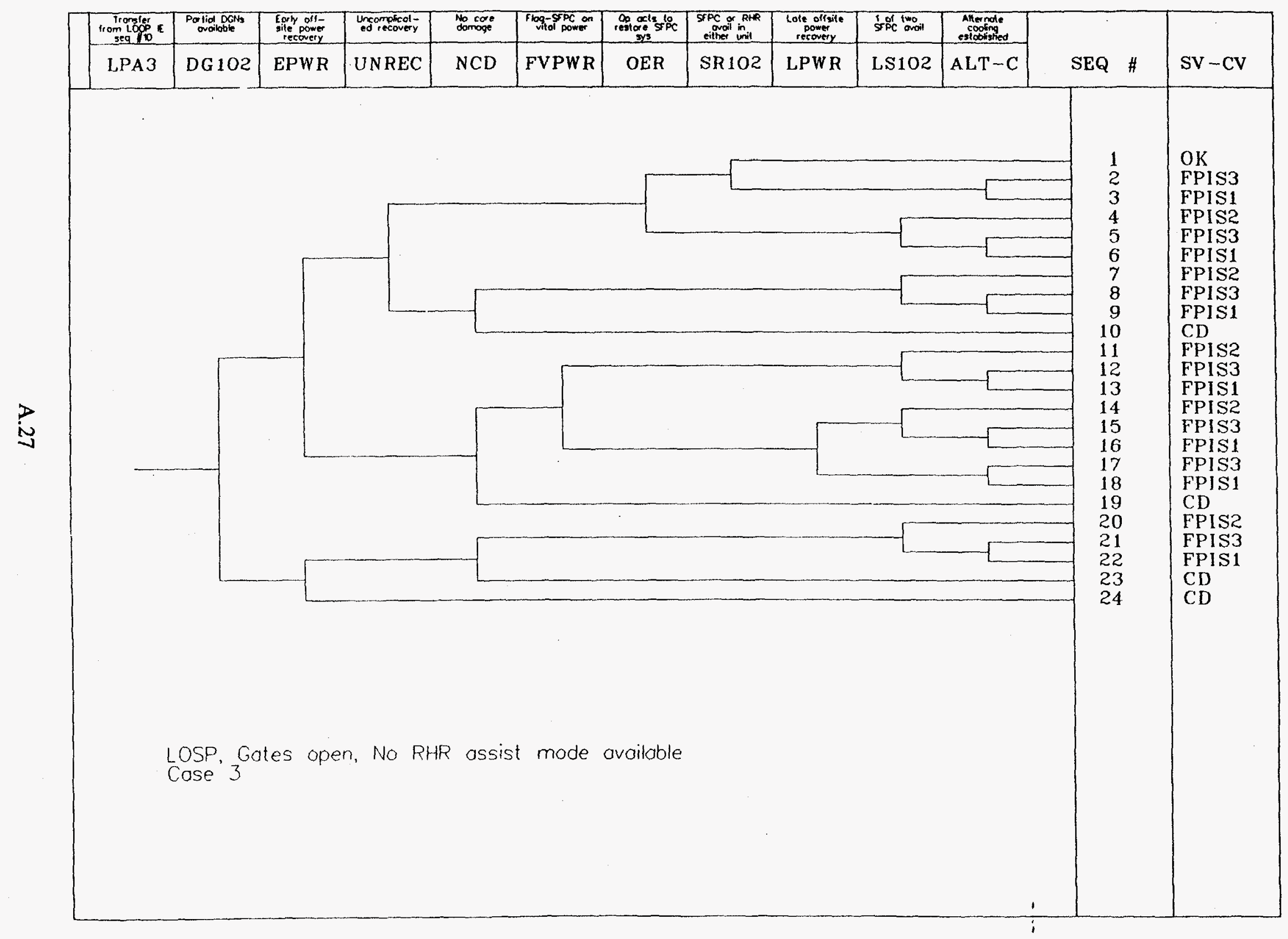




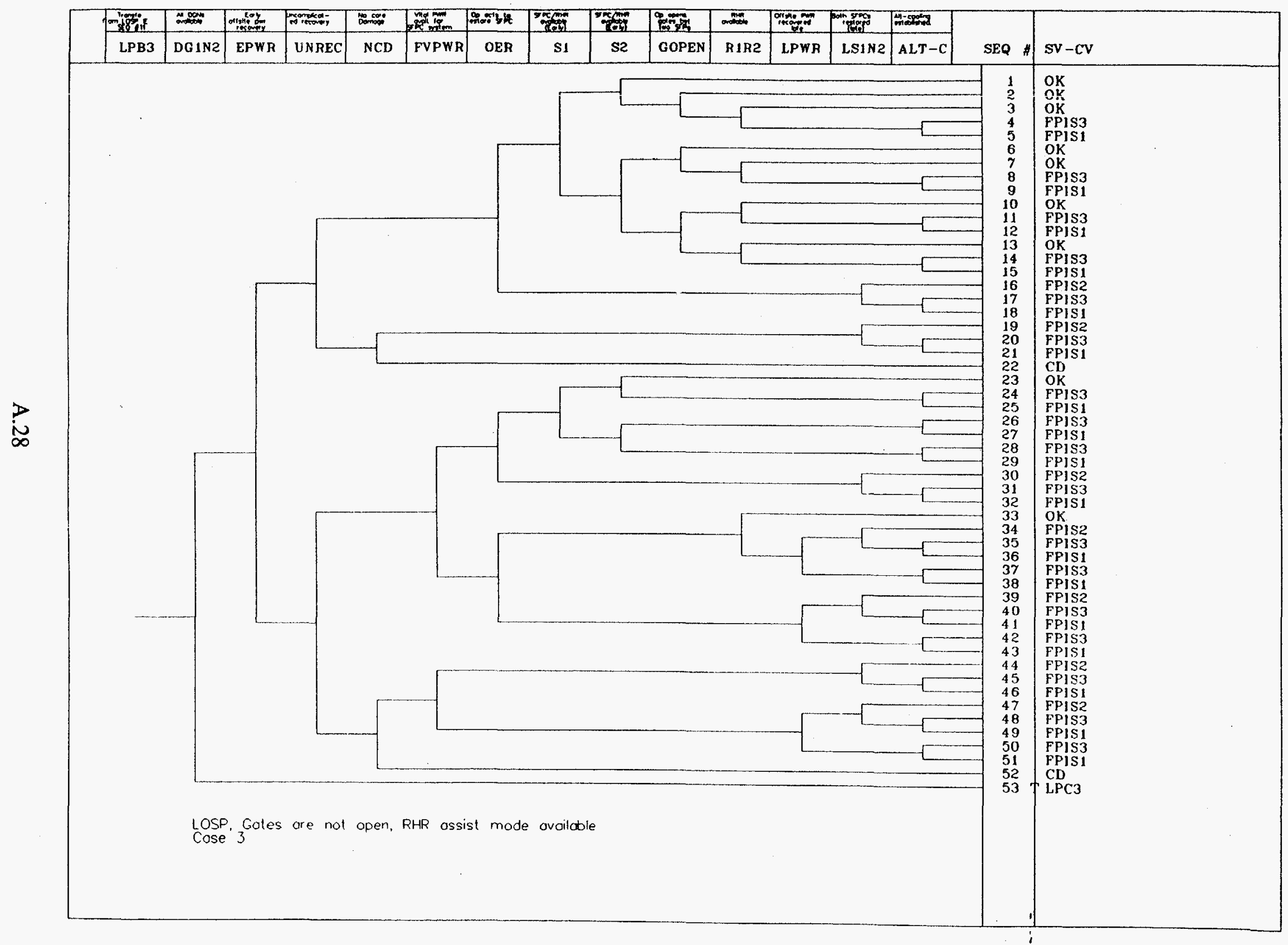




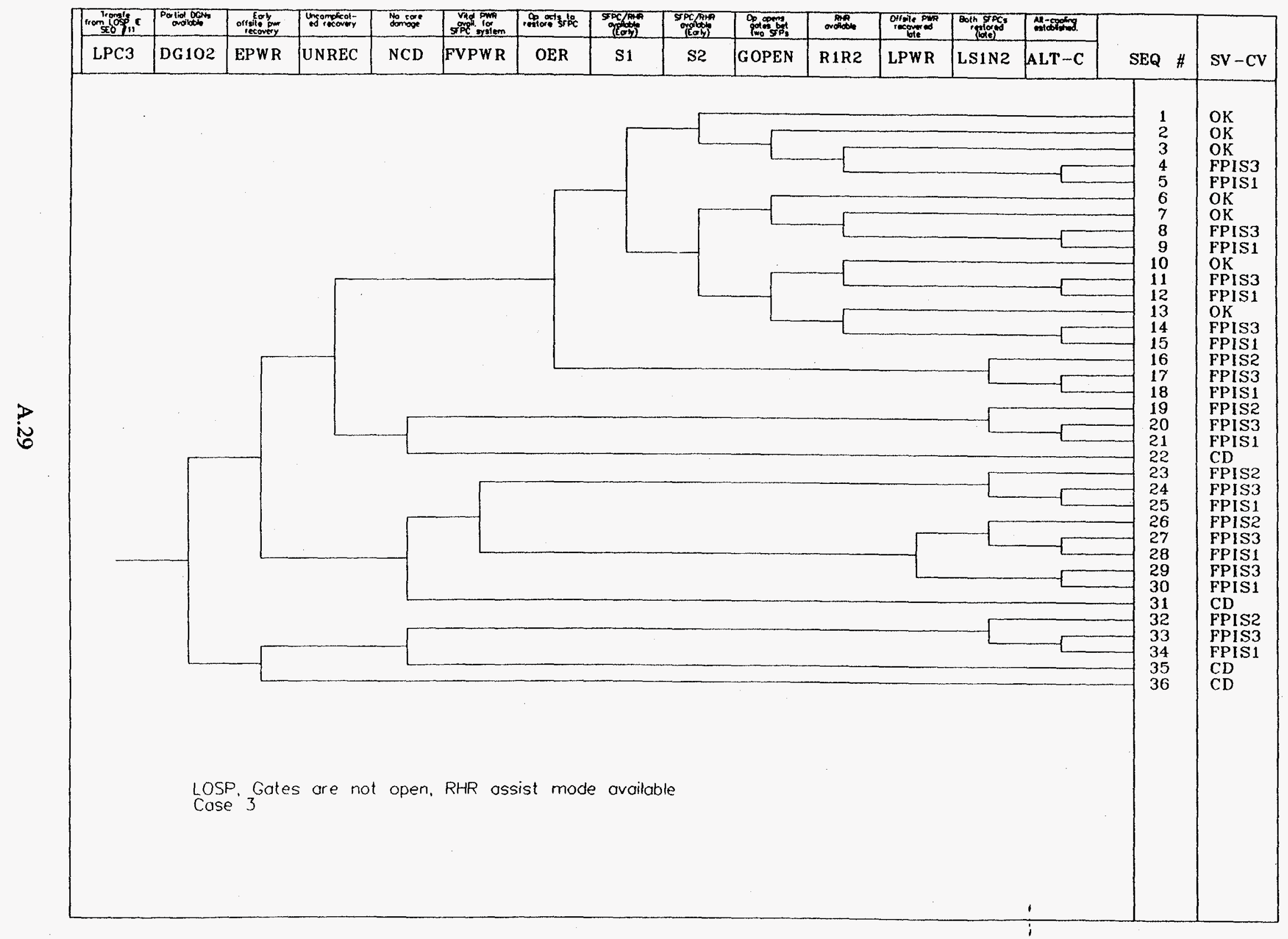




\section{Top Event Definitions - Loss of Offsite Power Event Trees}

LP1 Site-wide loss of offsite power while both units are in operating mode (Case 1). (Initiating events LP2 and LP3 treat Cases 2 and 3 refueling unit; i.e., unit 1, for 1/3 offload and full offload, respectively.)

GSTA T Status of cross-connect gate(s): the spent fuel pools are cross connected or not at the time of initiating event.

DG1N2 Availability of all (four) emergency diesel generators (EDGs).

EPWR Early offsite power recovery: offsite power is recovered in 4 hours. (If all EDGs fail, it is assumed that the core cannot be cooled past 4 hours since DC power will last only for 4 hours.)

UNREC Uncomplicated recovery on primary side: operators are not distracted from restoring spent fuel pool cooling prior to boiling.

NCD No core damage. This top event is questioned only during scenarios involving complicated recovery.

FVPWR A flag event: the plant being modeled has the capability to load SFPC pumps on EDGs.

OER Operator response to the loss of SFPC system: operator attempts to restore SFPC soon after the initiating event.

SR102 Restoration of the spent fuel pool cooling: operators successfully reestablish cooling using SFPC or RHR from either unit.

LPWR Late offsite power recovery: offsite power is recovered after 16 hours. (After 16 hours it is assumed that RHR cannot be used.)

LS102 Late restoration of the SFPC system: operators successfully reestablish cooling using SFPC from either unit.

ALT-C Alternate cooling: operators successfully establish evaporative/boiloff cooling by providing water using the alternate cooling system (e.g., fire water system).

DG102: No station blackout : between 1 and 3 EDGs are available.

S 1 Restoration of the SFPC system: operators successfully reestablish cooling to Unit 1 SFP.

S 2 Restoration of the SFPC system: operators successfully reestablish cooling to Unit 2 SFP.

GOPEN Opening of the gate: operators successfully open the gate(s) and cross connect the spent fuel pools if the SFPC in one of the unit fails.

R1R2 RHR cooling: operators successfully reestablish cooling in both SFPs using RHR for the respective units.

LS1N2 Late restoration of the SFPC system: operators successfully reestablish cooling in both SFPs using SFPC for the respective units. 


\section{Success Criteria - Loss of Offsite Power Event Tree}

Case 1, Gates Open

\begin{tabular}{|l|l||l|l|l|}
\hline DGs Available & Offsite Power & \multicolumn{1}{|c|}{ SR1O2 } & \multicolumn{1}{c|}{ LS1O2 } & \multicolumn{1}{c|}{ AlT-C } \\
\hline All & Early recovery & $\begin{array}{l}2 \text { of } 6 \text { SFPC pumps or } \\
1 \text { train RHR in any unit }\end{array}$ & 2 of 6 SFPC pumps & $\begin{array}{l}\text { Any available alternate } \\
\text { cooling system }\end{array}$ \\
\hline All & Late recovery & 1 train RHR in any unit & 2 of 6 SFPC pumps & $\begin{array}{l}\text { Any available alternate } \\
\text { cooling system }\end{array}$ \\
\hline All & None & 1 train RHR in any unit & Not modeled & $\begin{array}{l}\text { Any available alternate } \\
\text { cooling system }\end{array}$ \\
\hline Some & Early recovery & $\begin{array}{l}2 \text { of } 6 \text { SFPC pumps or 1 } \\
\text { train RHR in any unit }\end{array}$ & 2 of 6 SFPC pumps & $\begin{array}{l}\text { Any available alternate } \\
\text { cooling system }\end{array}$ \\
\hline Some & Late recovery & Not modeled & 2 of 6 SFPC pumps & $\begin{array}{l}\text { Any available alternate } \\
\text { cooling system }\end{array}$ \\
\hline Some & None & Not modeled & Not modeled & $\begin{array}{l}\text { Any available alternate } \\
\text { cooling system }\end{array}$ \\
\hline None & Early recovery & Not modeled & 2 of 6 SFPC pumps & $\begin{array}{l}\text { Any available alternate } \\
\text { cooling system }\end{array}$ \\
\hline
\end{tabular}

Case 1, Gates Not Open

\begin{tabular}{|l|l|}
\hline \multicolumn{1}{|c|}{ DG power } & Offsite Power \\
\hline All & Early recovery \\
\hline All & Late recovery \\
\hline All & None \\
\hline Some & Early recovery \\
\hline Some & Late recovery \\
\hline Some & None \\
\hline None & Early recovery \\
\hline
\end{tabular}

\begin{tabular}{|c|c|c|c|c|}
\hline $\mathrm{SI}$ & S2* & R1R2 & LS1N2 & ALT-C \\
\hline $\begin{array}{l}1 \text { of } 3 \text { SFPC pumps in } \\
\text { Unit } 1\end{array}$ & $\begin{array}{l}2 \text { of } 3 \text { SFPC pumps in } \\
\text { Unit } 2\end{array}$ & $\begin{array}{l}1 \text { train of RHR in the } \\
\text { unit where no SFPC } \\
\text { pump is a vailable }\end{array}$ & $\begin{array}{l}1 \text { of } 3 \text { SFPC pumps in } \\
\text { each unit }\end{array}$ & $\begin{array}{l}\text { Any available alternate } \\
\text { cooling system }\end{array}$ \\
\hline & & $\begin{array}{l}1 \text { train of RHR in each } \\
\text { unit }\end{array}$ & $\begin{array}{l}1 \text { of } 3 \text { SFPC pumps in } \\
\text { each unit }\end{array}$ & $\begin{array}{l}\text { Any available alternate } \\
\text { cooling system }\end{array}$ \\
\hline & & $\begin{array}{l}1 \text { train RHR in each } \\
\text { unit }\end{array}$ & Not modeled & $\begin{array}{l}\text { Any available alternate } \\
\text { cooling system }\end{array}$ \\
\hline $\begin{array}{l}1 \text { of } 3 \text { SFPC pumps in } \\
\text { Unit } 1\end{array}$ & $\begin{array}{l}2 \text { of } 3 \text { SFPC pumps in } \\
\text { Unit } 2\end{array}$ & $\begin{array}{l}1 \text { train } R H R \text { in the unit } \\
\text { where no SFPC pump is } \\
\text { available }\end{array}$ & $\begin{array}{l}1 \text { of } 3 \text { SFPC pumps in } \\
\text { each unit }\end{array}$ & $\begin{array}{l}\text { Any available alternate } \\
\text { cooling system }\end{array}$ \\
\hline Not modeled & Not modeled & Not modeled & $\begin{array}{l}1 \text { of } 3 \text { SFPC pumps in } \\
\text { each unit }\end{array}$ & $\begin{array}{l}\text { Any available alternate } \\
\text { cooling system }\end{array}$ \\
\hline Not modeled & Not modeled & Not modeled & Not modeled & $\begin{array}{l}\text { Any available alternate } \\
\text { cooling system }\end{array}$ \\
\hline Not modeled & Not modeled & Not modeled & $\begin{array}{l}1 \text { of } 3 \text { SFPC pumps in } \\
\text { each unit }\end{array}$ & $\begin{array}{l}\text { Any available alternate } \\
\text { cooling system }\end{array}$ \\
\hline
\end{tabular}

* Given SFPC system in Unit 1 fails 
Case 2, Gates Open

\begin{tabular}{|l|l||l|l|l|}
\hline \multicolumn{1}{|c|}{ DG power } & Offsite Power & \multicolumn{1}{|c|}{ SR1O2 } & \multicolumn{1}{c|}{ LS1O2 } & \multicolumn{1}{c|}{ ALT-C } \\
\hline Al! & Early recovery & $\begin{array}{l}3 \text { of } 6 \text { SFPC pumps or } \\
1 \text { train RHR in any unit }\end{array}$ & 3 of 6 SFPC pumps & cooling system \\
\hline All & Late recovery & 1 train RHR in any unit & 3 of 6 SFPC pumps & $\begin{array}{l}\text { Any available alternate } \\
\text { cooling system }\end{array}$ \\
\hline All & None & 1 train RHR in any unit & Not modeled & $\begin{array}{l}\text { Any available alternate } \\
\text { cooling system }\end{array}$ \\
\hline Some & Early recovery & $\begin{array}{l}3 \text { of } 6 \text { SFPC pumps or } \\
1 \text { train RHR in any unit }\end{array}$ & 3 of 6 SFPC pumps & $\begin{array}{l}\text { Any available alternate } \\
\text { cooling system }\end{array}$ \\
\hline Some & Late recovery & Not modeled & 3 of 6 SFPC pumps & $\begin{array}{l}\text { Any available alternate } \\
\text { cooling system }\end{array}$ \\
\hline Some & None & Not modeled & Not modeled & $\begin{array}{l}\text { Any available alternate } \\
\text { cooling system }\end{array}$ \\
\hline None & Early recovery & Not modeled & 3 of 6 SFPC pumps & $\begin{array}{l}\text { Any available alternate } \\
\text { cooling system }\end{array}$ \\
\hline
\end{tabular}

$7 \quad$ Case 2, Gates Not Open

\begin{tabular}{|l|l|}
\hline \multicolumn{1}{|c|}{ DG power } & Offsite Power \\
\hline All & Early recovery \\
\hline All & Late recovery \\
\hline All & None \\
\hline Some & Early recovery \\
\hline Some & \\
\hline Some & Late recovery \\
\hline None & None \\
\hline
\end{tabular}

\begin{tabular}{|c|c|c|c|c|}
\hline S1 & $S 2^{*}$ & R1R2 & LS1N2 & ALT-C \\
\hline \multirow[t]{3}{*}{$\begin{array}{l}2 \text { of } 3 \text { SFPC pumps in } \\
\text { Unit } 1\end{array}$} & $\begin{array}{l}2 \text { of } 3 \text { SFPC pumps in } \\
\text { Unit } 2\end{array}$ & $\begin{array}{l}1 \text { train of RHR in the } \\
\text { unit where no SFPC } \\
\text { pump is available }\end{array}$ & $\begin{array}{l}2 \text { of } 3 \text { SFPC pumps in } \\
\text { each unit }\end{array}$ & $\begin{array}{l}\text { Any available alternate } \\
\text { cooling system }\end{array}$ \\
\hline & & $\begin{array}{l}1 \text { train of RHR in each } \\
\text { unit }\end{array}$ & $\begin{array}{l}2 \text { of } 3 \text { SFPC pumps in } \\
\text { each unit }\end{array}$ & $\begin{array}{l}\text { Any available alternate } \\
\text { cooling system }\end{array}$ \\
\hline & & $\begin{array}{l}1 \text { train of RHR in each } \\
\text { unit }\end{array}$ & Not modeled & $\begin{array}{l}\text { Any available alternate } \\
\text { cooling system }\end{array}$ \\
\hline $\begin{array}{l}2 \text { of } 3 \text { SFPC pumps } \\
\text { Unit } 1\end{array}$ & $\begin{array}{l}2 \text { of } 3 \text { SFPC pumps in } \\
\text { Unit } 2\end{array}$ & $\begin{array}{l}1 \text { train of RHR in the } \\
\text { unit where no SFPC } \\
\text { pump is available }\end{array}$ & $\begin{array}{l}2 \text { of } 3 \text { SFPC pumps in } \\
\text { each unit }\end{array}$ & $\begin{array}{l}\text { Any available alternate } \\
\text { cooling system }\end{array}$ \\
\hline Not modeled & Not modeled & Not modeled & $\begin{array}{l}2 \text { of } 3 \text { SFPC pumps in } \\
\text { each unit }\end{array}$ & $\begin{array}{l}\text { Any available alternate } \\
\text { cooling system }\end{array}$ \\
\hline Not modeled & Not modeled & Not modeled & Not modeled & $\begin{array}{l}\text { Any available alternate } \\
\text { cooling system }\end{array}$ \\
\hline Not modeled & Not modeled & Not modeled & $\begin{array}{l}2 \text { of } 3 \text { SFPC pumps in } \\
\text { each unit }\end{array}$ & $\begin{array}{l}\text { Any available alternate } \\
\text { cooling system }\end{array}$ \\
\hline
\end{tabular}

* Given SFPC system in Unit 1 fails 
Case 3, Gates Open

\begin{tabular}{|l|l||l|l|l|}
\hline \multicolumn{1}{|c|}{ DG power } & Offsite Power & \multicolumn{1}{|c|}{ SR1O2 } & \multicolumn{1}{c|}{ LS1O2 } & \multicolumn{1}{c|}{ ALT-C } \\
\hline All & Early recovery & $\begin{array}{l}\text { 4 of 6 SFPC pumps or } \\
\text { 1 train RHR in any unit }\end{array}$ & 4 of 6 SFPC pumps & $\begin{array}{l}\text { Any available alternate } \\
\text { cooling system }\end{array}$ \\
\hline All & Late recovery & 1 train RHR in any unit & 4 of 6 SFPC pumps & $\begin{array}{l}\text { Any available alternate } \\
\text { cooling system }\end{array}$ \\
\hline All & None & 1 train RHR in any unit & Not modeled & $\begin{array}{l}\text { Any available alternate } \\
\text { cooling system }\end{array}$ \\
\hline Some & Early recovery & $\begin{array}{l}\text { 4 of 6 SFPC pumps or 1 } \\
\text { train RHR in any unit }\end{array}$ & 4 of 6 SFPC pumps & $\begin{array}{l}\text { Any available alternate } \\
\text { cooling system }\end{array}$ \\
\hline Some & Late recovery & Not modeled & 4 of 6 SFPC pumps & $\begin{array}{l}\text { Any available alternate } \\
\text { cooling system }\end{array}$ \\
\hline Some & None & Not modeled & Not modeled & $\begin{array}{l}\text { Any available alternate } \\
\text { cooling system }\end{array}$ \\
\hline None & Early recovery & Not modeled & 4 of 6 SFPC pumps & $\begin{array}{l}\text { Any available alternate } \\
\text { cooling system }\end{array}$ \\
\hline
\end{tabular}

$>\quad$ Case 3, Gates Not Open

\begin{tabular}{|c|c|c|c|c|c|c|}
\hline DG power & Offsite Power & S1 & $S 2^{*}$ & R1R2 & LS1N2 & ALT-C \\
\hline All & Early recovery & $\begin{array}{l}3 \text { of } 3 \text { SFPC pumps in } \\
\text { Unit } 1\end{array}$ & $\begin{array}{l}3 \text { of } 3 \text { SFPC pumps in } \\
\text { Unit } 2\end{array}$ & $\begin{array}{l}1 \text { train of RHR in the } \\
\text { unit where no SFPC } \\
\text { pump is available }\end{array}$ & $\begin{array}{l}3 \text { of } 3 \text { SFPC pumps in } \\
\text { Unit } 1,1 \text { of } 3 \text { in Unit } 2\end{array}$ & $\begin{array}{l}\text { Any available alternate } \\
\text { cooling system }\end{array}$ \\
\hline All & Late recovery & & & $\begin{array}{l}1 \text { train of RHR in each } \\
\text { unit }\end{array}$ & $\begin{array}{l}3 \text { of } 3 \text { SFPC pumps in } \\
\text { Unit } 1,1 \text { of } 3 \text { in Unit } 2\end{array}$ & $\begin{array}{l}\text { Any available alternate } \\
\text { cooling system }\end{array}$ \\
\hline All & None & & & $\begin{array}{l}1 \text { train of RHR in each } \\
\text { unit }\end{array}$ & Not modeled & $\begin{array}{l}\text { Any available alternate } \\
\text { cooling system }\end{array}$ \\
\hline Some & Early recovery & $\begin{array}{l}3 \text { of } 3 \text { SFPC pumps } \\
\text { Unit } 1\end{array}$ & $\begin{array}{l}3 \text { of } 3 \text { SFPC pumps in } \\
\text { Unit } 2\end{array}$ & $\begin{array}{l}1 \text { train of RHR in the } \\
\text { unit where no SFPC } \\
\text { pump is available }\end{array}$ & $\begin{array}{l}3 \text { of } 3 \text { SFPC pumps in } \\
\text { Unit } 1,1 \text { of } 3 \text { in Unit } 2\end{array}$ & $\begin{array}{l}\text { Any available alternate } \\
\text { cooling system }\end{array}$ \\
\hline Some & Late recovery & Not modeled & Not modeled & Not modeled & $\begin{array}{l}3 \text { of } 3 \text { SFPC pumps in } \\
\text { Unit } 1,1 \text { of } 3 \text { in Unit } 2\end{array}$ & $\begin{array}{l}\text { Any available alternate } \\
\text { cooling system }\end{array}$ \\
\hline Some & None & Not modeled & Not modeled & Not modeled & Not modeled & $\begin{array}{l}\text { Any available aiternate } \\
\text { cooling system }\end{array}$ \\
\hline None & Early recovery & Not modeled & Not modeled & Not modeled & $\begin{array}{l}3 \text { of } 3 \text { SFPC pumps in } \\
\text { Unit } 1,1 \text { of } 3 \text { in Unit } 2\end{array}$ & $\begin{array}{l}\text { Any available alternate } \\
\text { cooling system }\end{array}$ \\
\hline
\end{tabular}

* Given SFPC system in Unit 1 fails 


\section{A.4.3 Loss of Inventory}

Four event trees are used to model this class of initiating events. Event tree LINVC deals with large losses of inventory during operation (Case 1), tree LINCS deals with small losses during operation, tree LINVR deals with large losses during refueling (Cases 2 and 3), and tree LINRS deals with small losses during refueling. The event trees, top event definitions, and success criteria are listed in the following pages. 


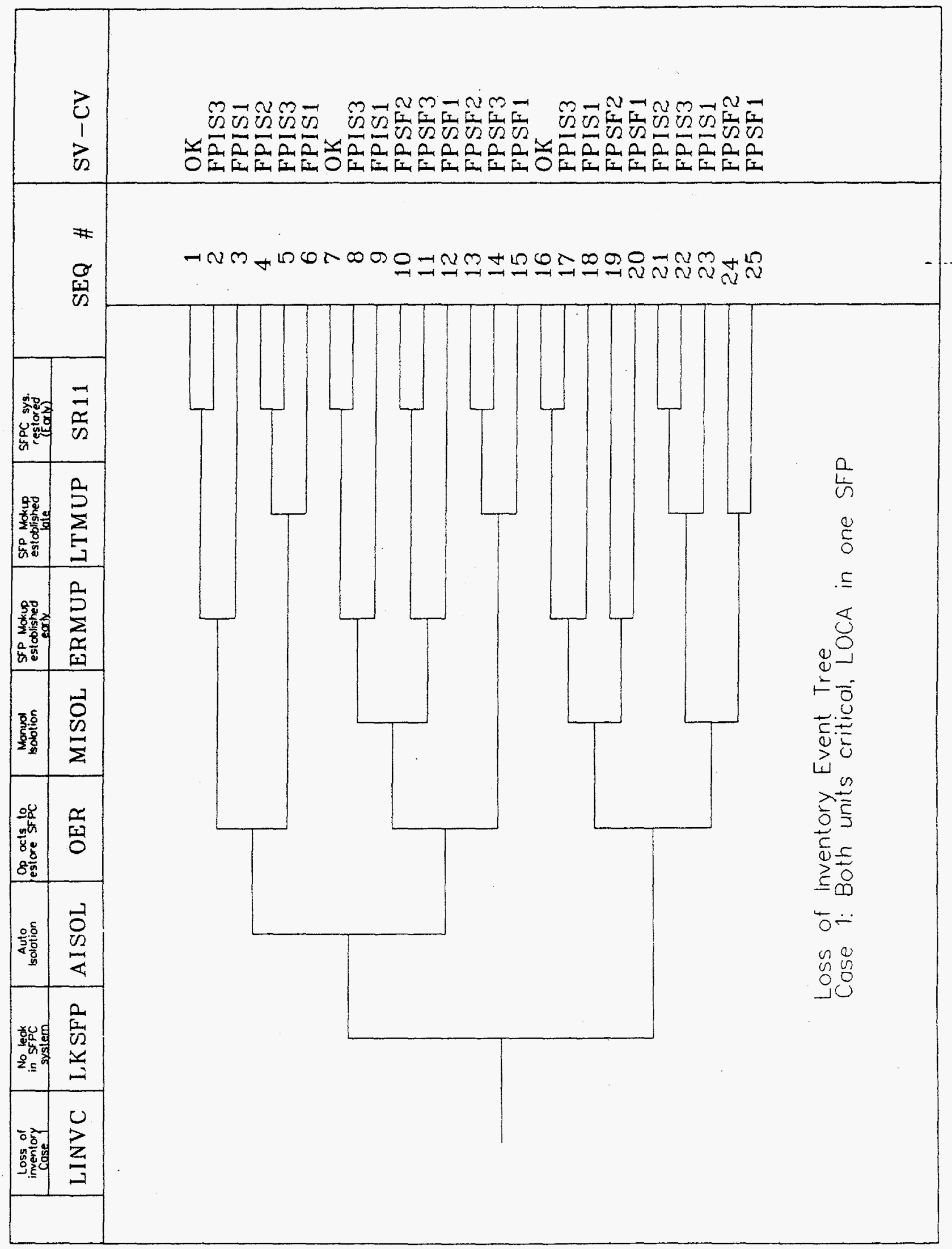




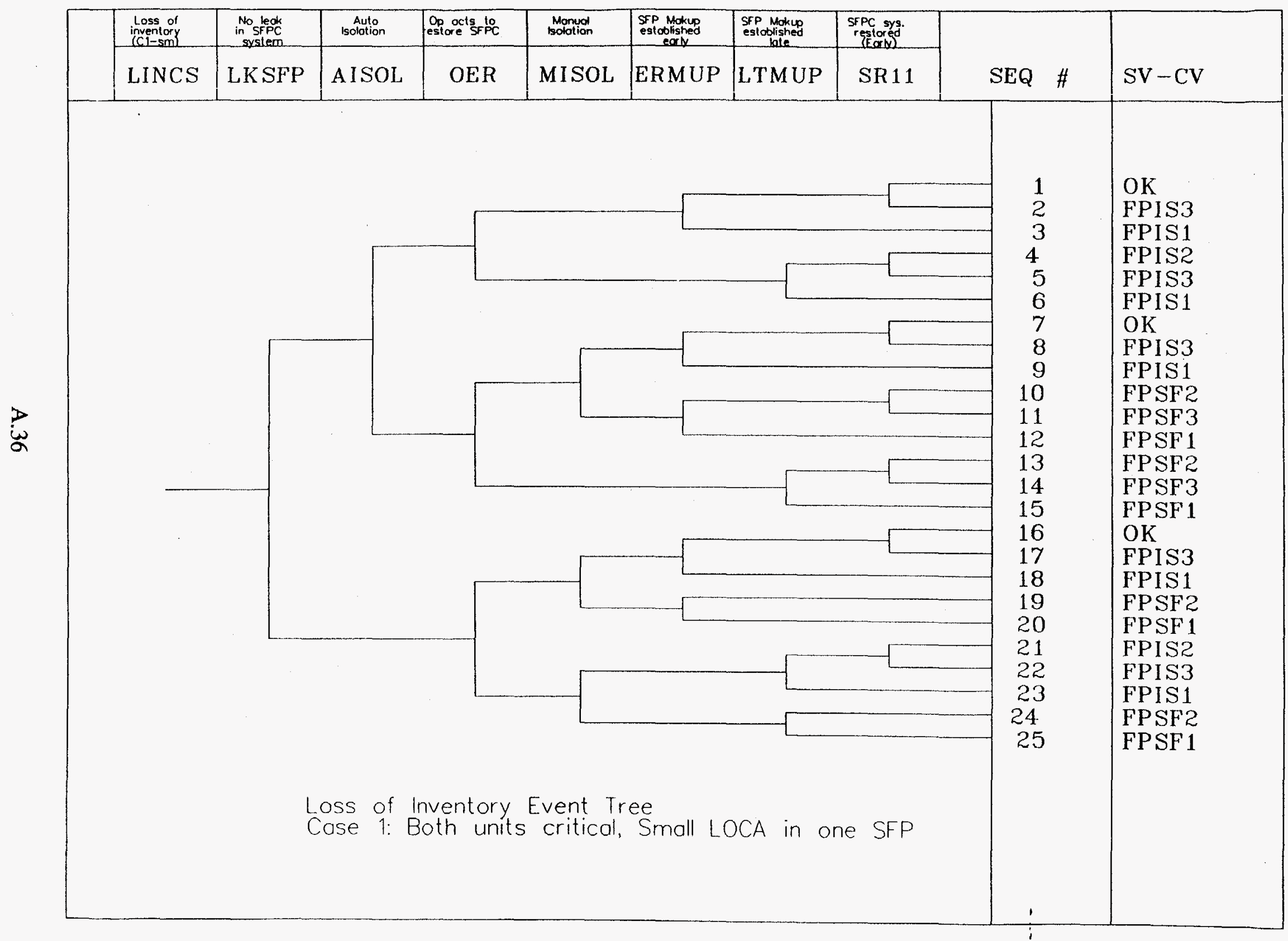




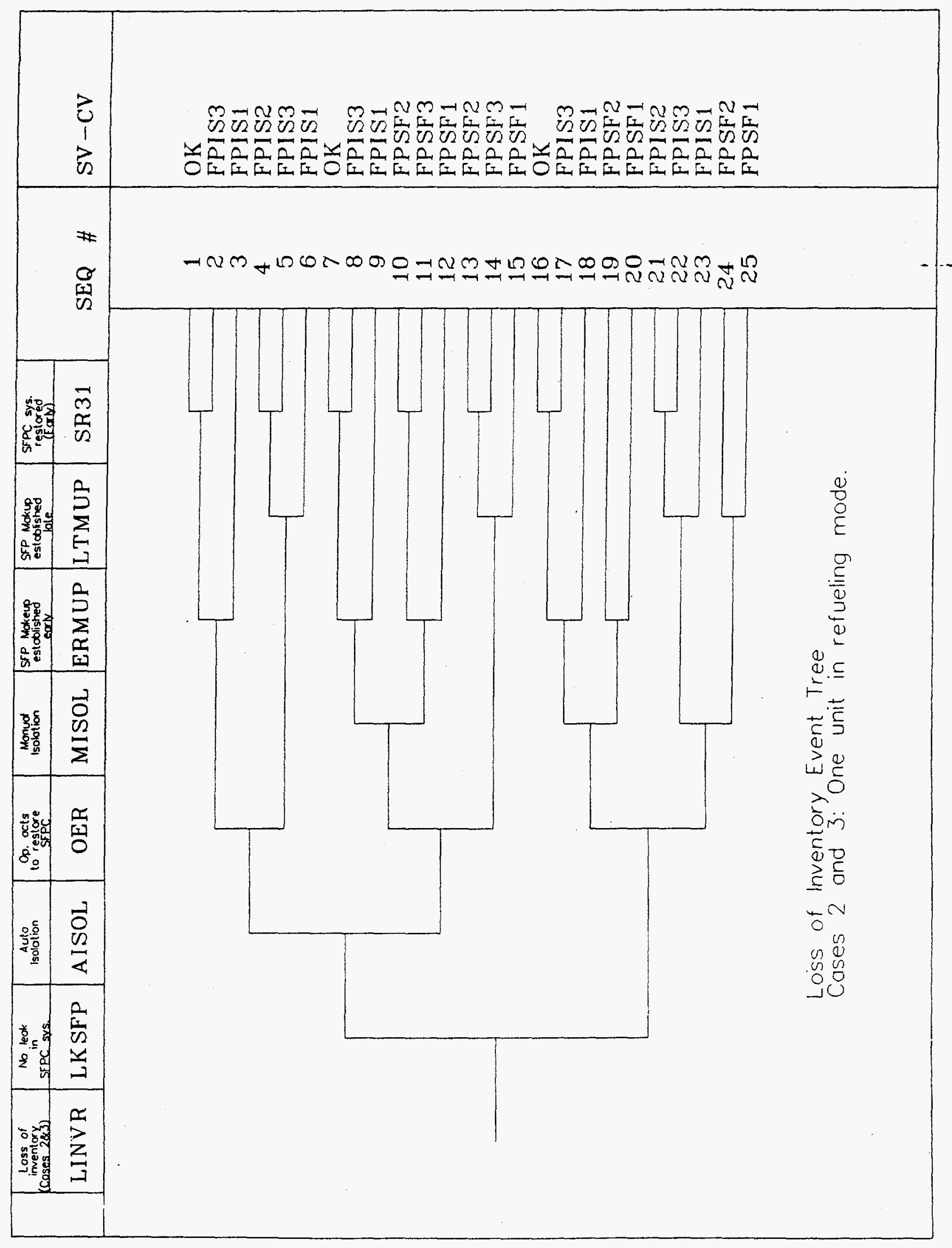




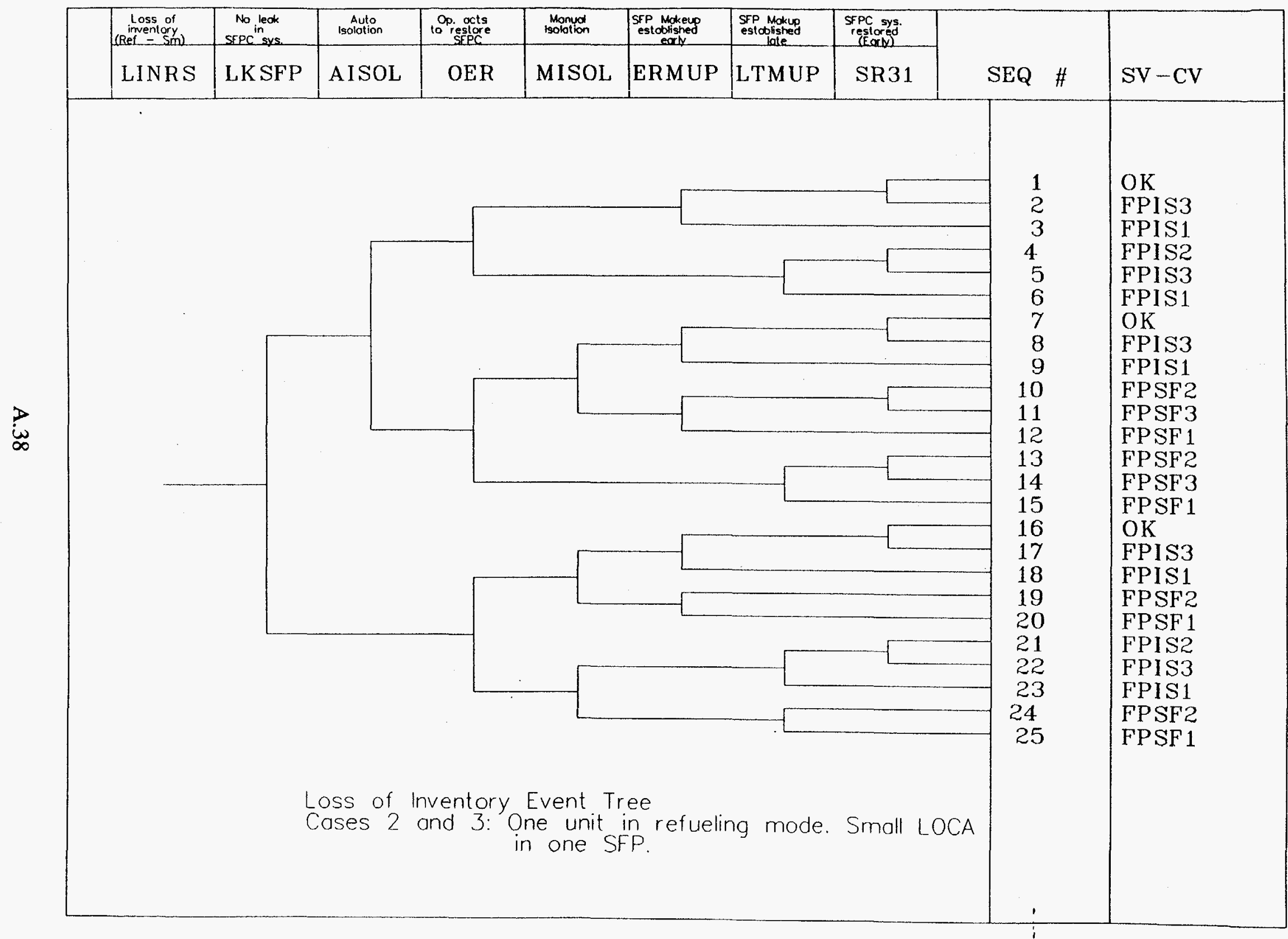




\section{Top Event Definitions - Loss of Inventory Event Trees}

LINVC Large loss of inventory from Unit 1 spent fuel pool while both units are operating (Case 1). (Initiating event LINCS represents a small loss of inventory while both units are operating, LINVR represents a large loss of inventory while Unit 1 is refueling and Unit 2 is operating, and LINRS represents a small loss of inventory while Unit 1 is refueling and Unit 2 is operating.)

LKSFP Leak is in SFPC system. (Lower branch indicates a leak resulting from failure of the spent fuel pool boundary.)

AISOL Auto isolation of leak due to siphon breaker. (Applicable only if the leak is in the SFPC system.)

OER Operator response to the loss of spent fuel pool cooling system: operator attempts to restore SFP cooling soon after the initiating event.

MISOL Manual isolation of leak: operator isolates the leak.

ERMUP Early spent fuel pool makeup: operator uses normal or alternate makeup systems. (In refueling mode, the ECCS can be used to provide makeup.)

LTMUP Late spent fuel pool makeup: operator uses normal or alternate makeup systems. (Due to radiation hazards, the operator actions required, e.g., to provide makeup using an alternate cooling system, may be difficult. All the actions must be taken remotely. In refueling mode, the ECCS can be used to provide makeup.)

SR11 Restoration of the SFPC system: operators successfully reestablish cooling using either SFPC. 
Success Criteria - Loss of Inventory Event Trees

Case 1

\begin{tabular}{|l|l|l|}
\hline \multicolumn{1}{|c|}{ ERMUP } & \multicolumn{1}{|c|}{ LTMUP } & \multicolumn{1}{|c|}{ SR11 } \\
\hline $\begin{array}{l}\text { Normal makeup or any } \\
\text { alternate cooling } \\
\text { system }\end{array}$ & $\begin{array}{l}\text { Normal makeup or any } \\
\text { alternate cooling } \\
\text { system which can be } \\
\text { operated remotely }\end{array}$ & $\begin{array}{l}1 \text { of 3 SFPC pumps or } 1 \\
\text { RHR train }\end{array}$ \\
\hline
\end{tabular}

Cases 2 and 3

\begin{tabular}{|c|c|c|}
\hline ERMUP & LTMUP & SR11 \\
\hline $\begin{array}{l}\text { ECCS injection, } \\
\text { Normal makeup or any } \\
\text { alternate cooling } \\
\text { system }\end{array}$ & $\begin{array}{l}\text { ECCS injection, } \\
\text { Normal makeup or Any } \\
\text { available alternate } \\
\text { cooling system }\end{array}$ & 3 of 3 SFPC pumps \\
\hline
\end{tabular}




\section{A.4.4 Loss of Primary Coolant}

Two event trees are used to model this class of initiating events. Event tree PLOCA deals with a LOCA when both units are operating (Case 1) and PLOCR deals with a LOCA in Unit 1 when Unit 1 is refueling and Unit 2 is operating (Cases 2 and 3). The event trees, top event definitions, and success criteria are listed in the following pages. Note that the PLOCA event tree has one transfer tree. 


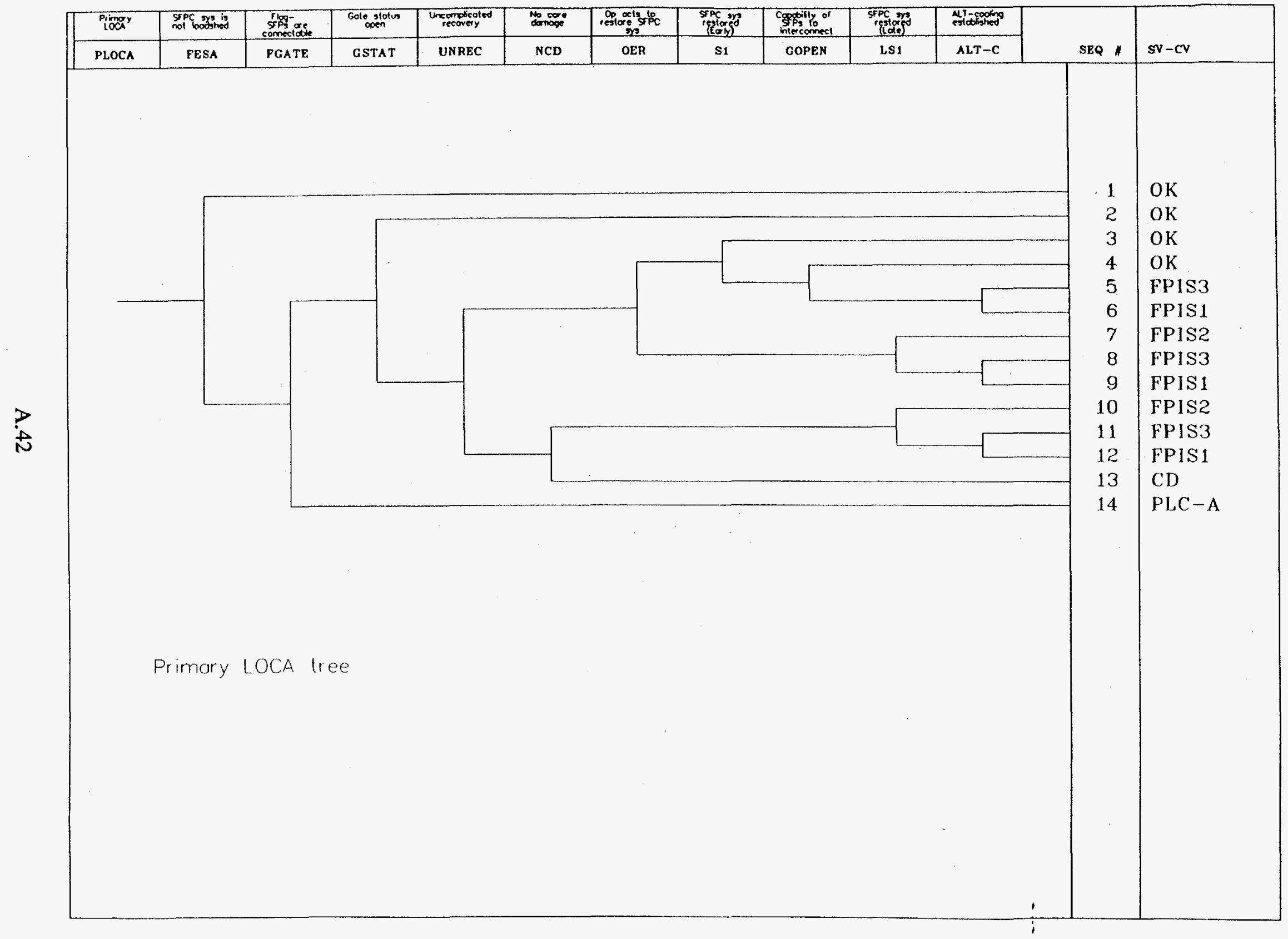




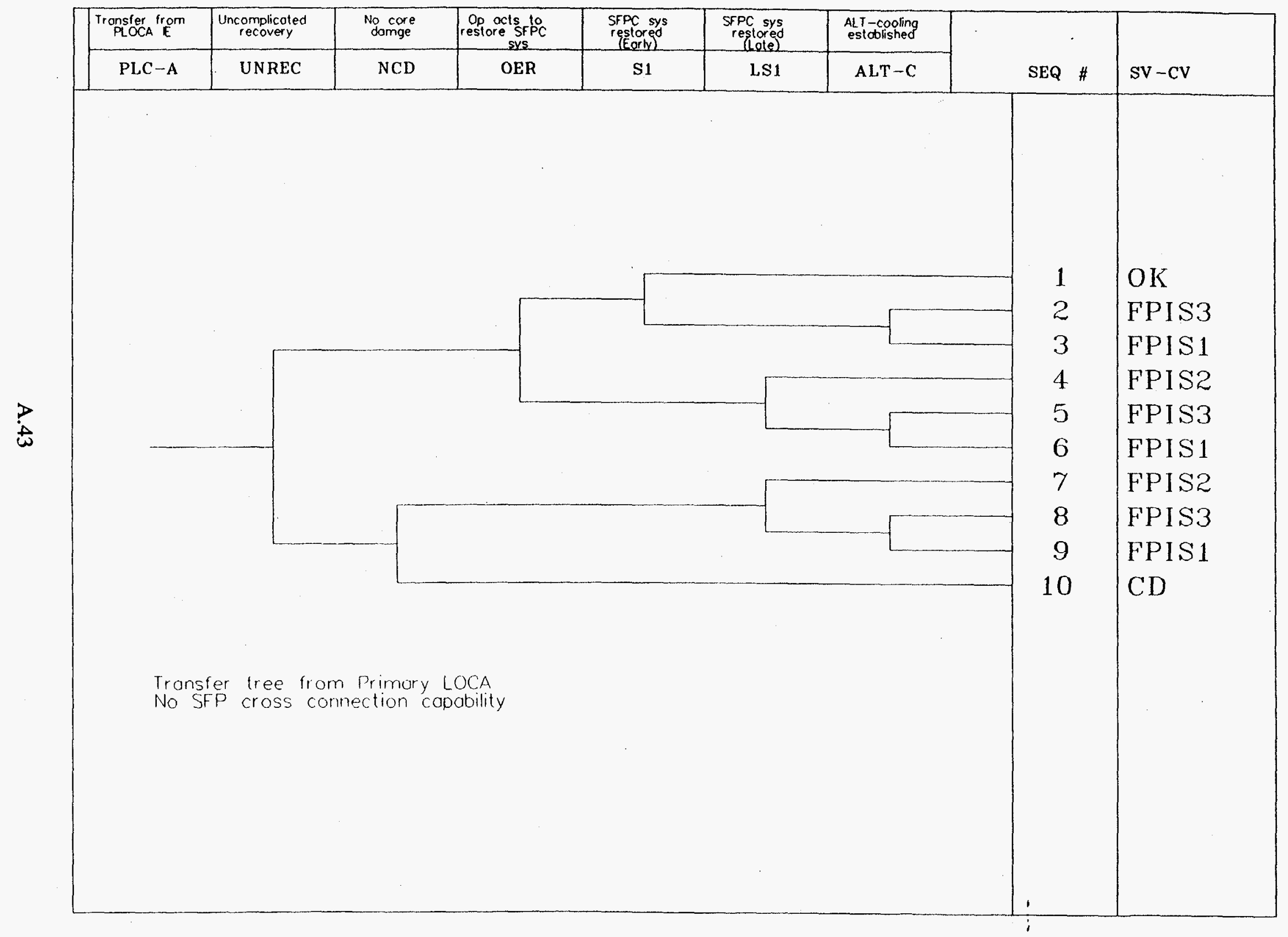




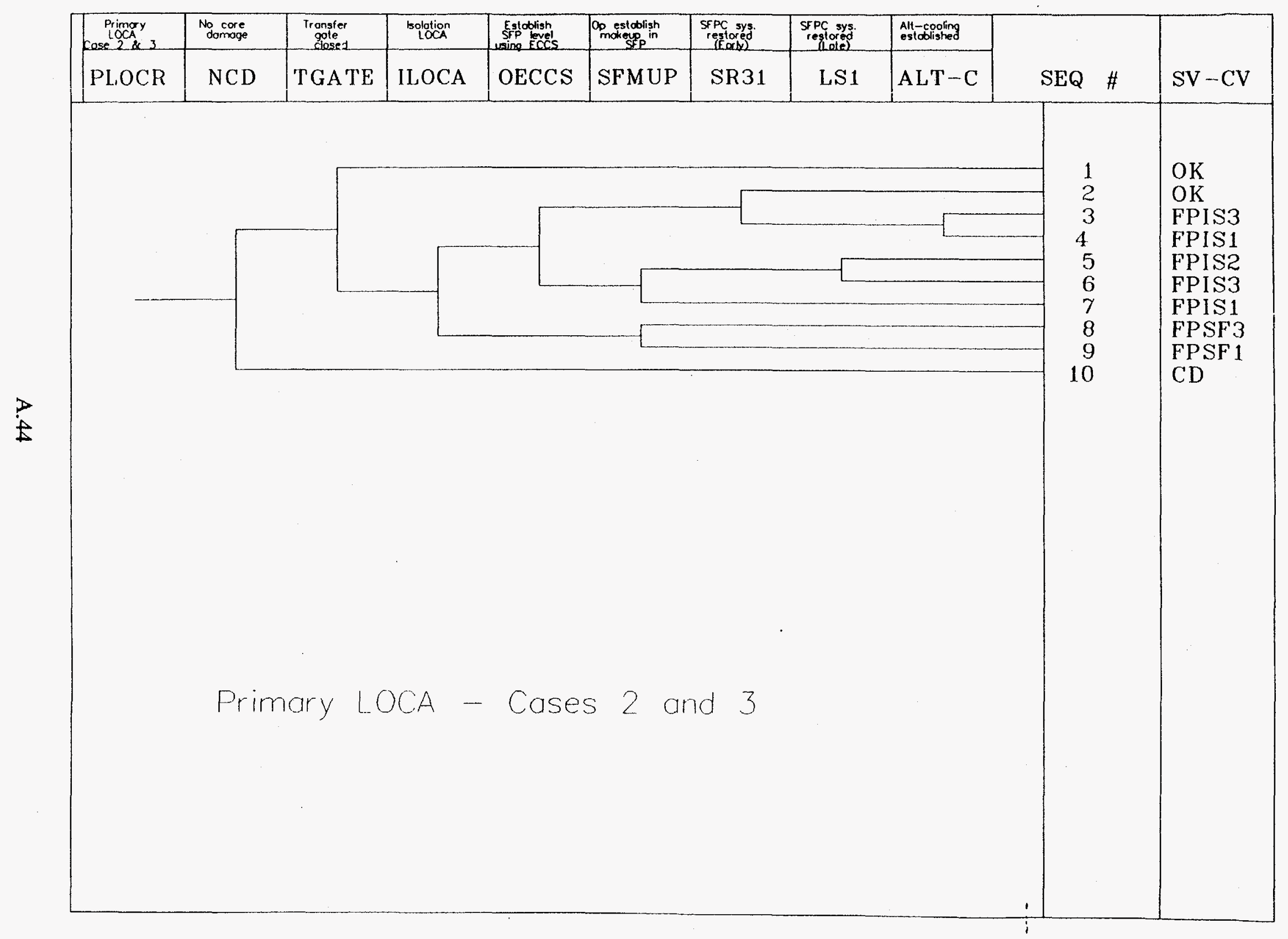




\section{Top Event Definitions - Primary LOCA Event Trees}

PLOCA Loss of coolant accident in primary system of Unit 1 while both units are operating (Case 1). (Initiating event PLOCR represents a LOCA in the primary system of Unit 1 during refueling, i.e., Cases 2 and 3.)

FESA A flag event: the SFPC system does not trip on ESF actuation in the plant being modeled (relevant for Case 1).

FGATE A flag event: the plant being modeled has the capability to cross-connect the spent fuel pool by opening a gate (or gates) (relevant for Case 1).

GSTA T Status of cross-connect gate(s): the spent fuel pools are cross connected or not at the time of initiating event (only for Case 1).

UNREC Uncomplicated recovery on primary side: operators are not distracted from restoring spent fuel pool cooling prior to boiling. (Relevant for Case 1.)

NCD No core damage. This top event is questioned only during scenarios involving complicated recovery. (Relevant for Case 1.)

OER Operator response to the loss of SFPC system: operator attempts to restore SFP cooling soon after the initiating event.

S 1 Restoration of the SFPC system: operators successfully reestablish cooling using either SFPC.

GOPEN Opening of the gate: operators successfully open the gate(s) and cross connect the spent fuel pools.

SR31 SFPC and RHR cooling: operators successfully reestablish cooling using Unit 1 SFPC or RHR.

LS1 Late restoration of the SFPC system: similar to the top event S1 except all the actions must be taken remotely.

ALT-C Alternate cooling: operators successfully establish evaporative/boiloff cooling by providing water using the alternate cooling system (e.g., fire water system).

TGATE Status of a transfer gate: the refueling cavity and the spent fuel pool are cross-connected at the time of initiating event (relevant for Case 2 and 3 ).

ILOCA Isolation of leak (relevant for Cases 2 and 3 ).

OECCS Operators restore the level in the spent fuel pool using ECCS (relevant for Cases 2 and 3 ).

SFMUP Operators restore the level in the spent fuel pool using SFP makeup or alternate cooling (relevant for Cases 2 and 3). 
Success Criteria - Primary LOCA Event Trees

Case 1

\begin{tabular}{|c|c|c|}
\hline SL & \multicolumn{1}{|c|}{ LS1 } & \multicolumn{1}{c|}{ ALTC } \\
\hline 1 of 3 SFPC pumps & 1 of 3 SFPC pumps & $\begin{array}{l}\text { Any available } \\
\text { alternate cooling } \\
\text { system }\end{array}$ \\
\hline
\end{tabular}

Cases 2 and 3

\begin{tabular}{|c|c|c|c|c|}
\hline OECCS & \multicolumn{1}{|c|}{ SFMUP } & SR31 & LS1 & \multicolumn{1}{c|}{ ALT-C } \\
\hline ECCS Injection & $\begin{array}{l}\text { Main SFP makeup or } \\
\text { alternate cooling }\end{array}$ & $\begin{array}{l}\text { 3 of 3 SFPC pumps } \\
\text { or 1 RHR train }\end{array}$ & 3 of 3 SFPC pumps & $\begin{array}{l}\text { Any available } \\
\text { alternate cooling } \\
\text { system }\end{array}$ \\
\hline
\end{tabular}




\section{A.4.5 Earthquake}

One event tree is used to model this class of initiating events. Note that earthquakes with peak ground acceleration (PGA) below $0.2 \mathrm{~g}$ are assumed to have negligible risk impact, and that earthquakes with PGA greater than $0.6 \mathrm{~g}$ are assumed to lead directly to core melt (for the purposes of this analysis.) The event tree, top event definitions, and success criteria are listed in the following pages. 


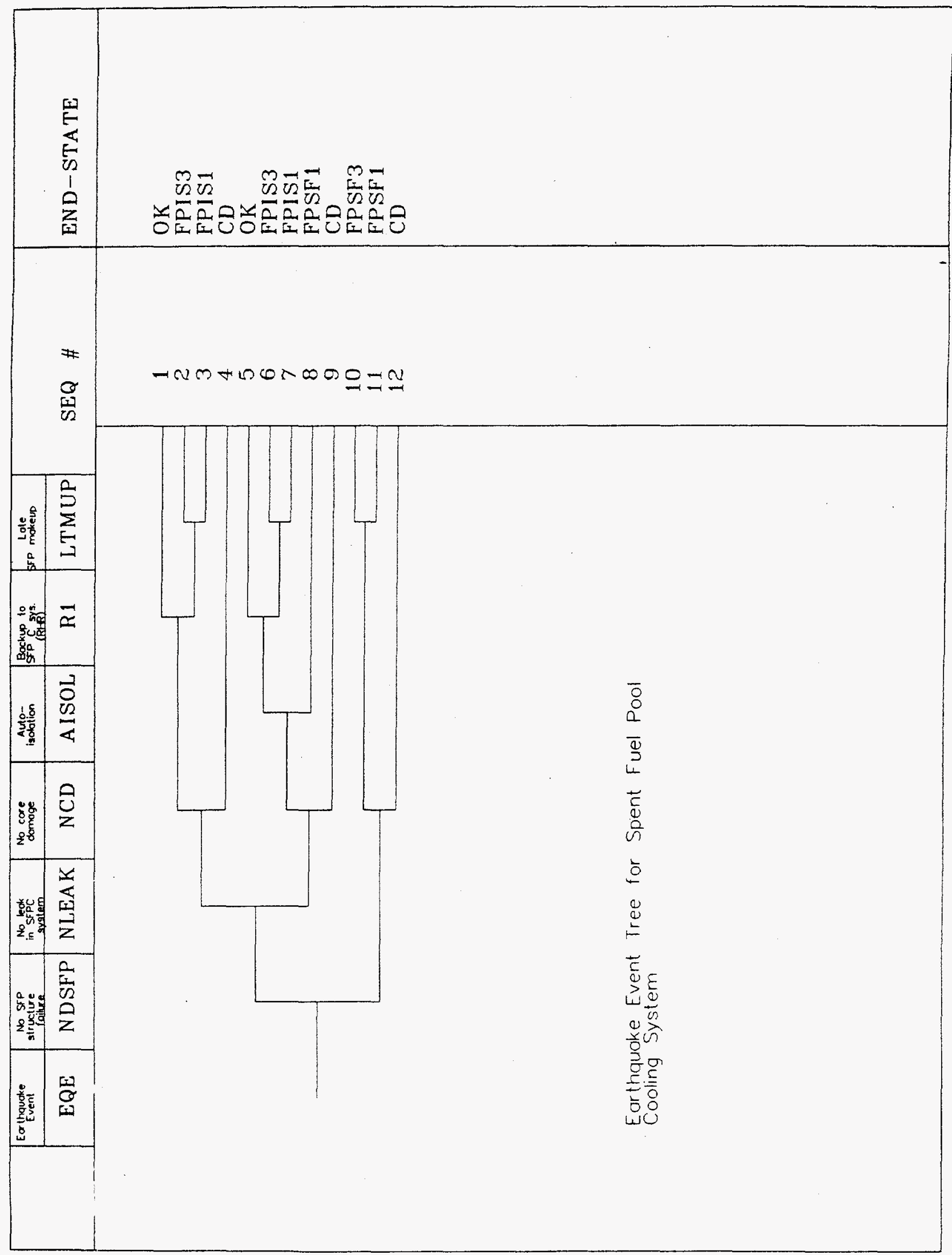




\section{Top Event Definitions - Seismic Event Tree}

EQE Seismic initiating event.

NDSFP No damage to the spent fuel pool structure from the seismic event.

NLEAK No leak through the SFPC system (caused by the seismic event).

NCD No direct core damage from the seismic event.

AISOL Auto isolation of leak due to siphon breaker. (Applicable only if the leak is in the SFPC system.)

R1 Restoration of spent fuel pool cooling using RHR.

LTMUP Late spent fuel pool makeup using alternate makeup systems. (Operator actions required would be difficult; all actions must be taken remotely.) 
Success Criteria - Seismic Event Tree

\section{All Cases}

\begin{tabular}{|l|c|}
\hline R1 & \multicolumn{1}{c|}{ LTMUP } \\
\hline $\begin{array}{l}\text { No SFPC system or } \\
\text { RHR makeup }\end{array}$ & $\begin{array}{l}\text { Any available alternate } \\
\text { cooling system }\end{array}$ \\
\hline
\end{tabular}




\section{A.5 Post-Heatup Event Trees}

The post-heatup event trees (PHETs) treat the progression of selected accident scenarios past pool heatup; one or more separate trees are developed for each non-successful endstate of the NBF trees. (Multiple trees are required for endstates where steaming and flooding effects are of potential concern.) They address the following issues: the spatial isolation of the spent fuel pool from other safety equipment, the vulnerability of exposed safety equipment to the hazards associated with the scenario (i.e., heat and humidity from pool boiling, water from losses of pool inventory), the ability of operators to divert steam/water away from the safety equipment, and the recoverability of safety equipment affected by the steam/water.

Four PHETs are used in this study. The first three treat the effects of pool heatup on the rest of the plant; the last treats the effect of flooding. (Note that since flooding and pool heatup are not mutually exclusive, a quantitative analysis will need to employ multiple PHETs for a number of NBF event tree endstates.) The PHETs and their entry conditions are as follows:

FPIS1 SFP boiling; SFPC has been lost, spent fuel pool (SFP) level is not maintained.

FPIS2 SFP heatup; SFPC has been restored late.

FPIS3 SFP steaming; alternate cooling is being used and SFP level is maintained.

FPISF Flooding has occurred.

These trees are presented in the following pages. 


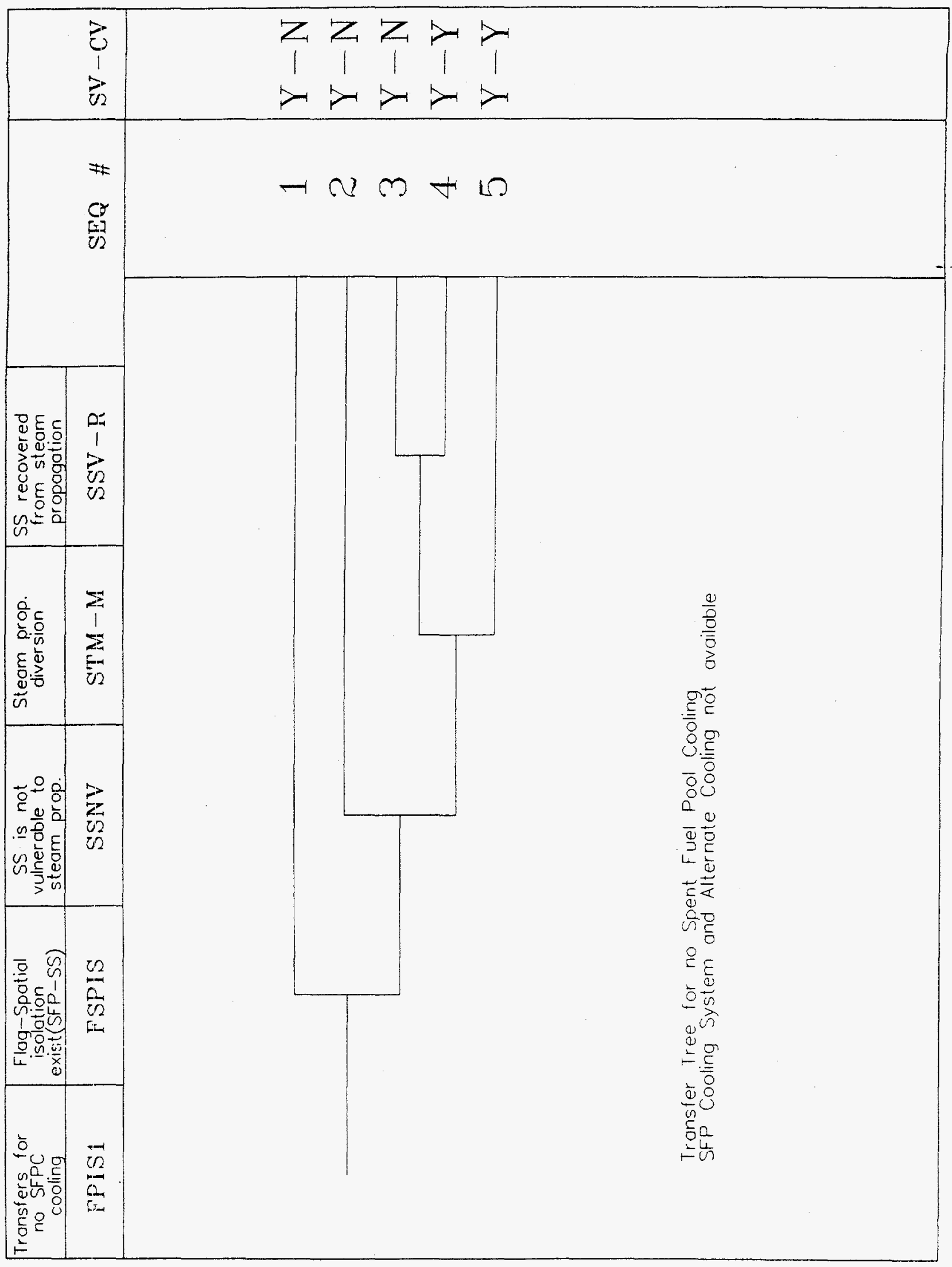

A. 52 


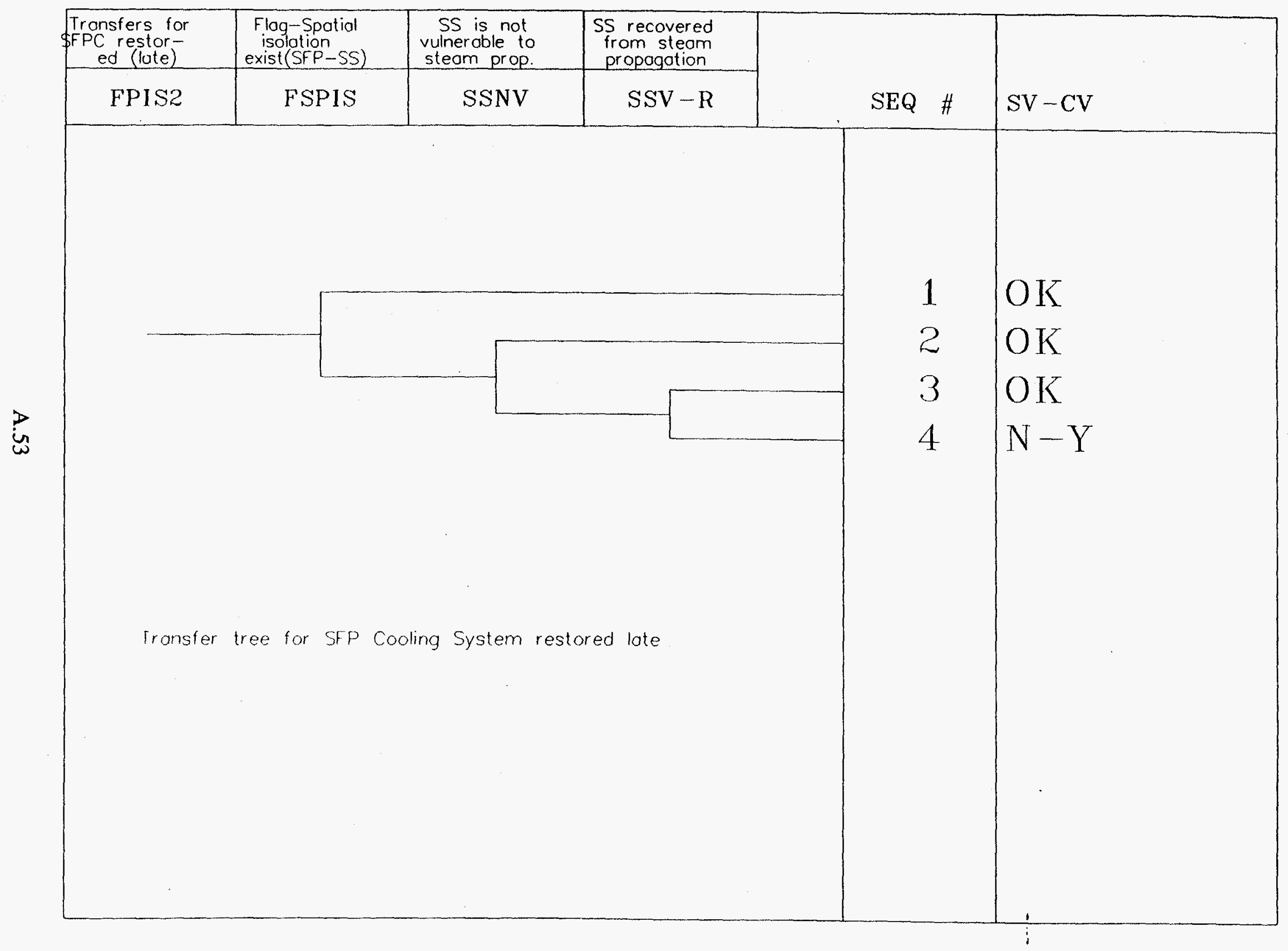




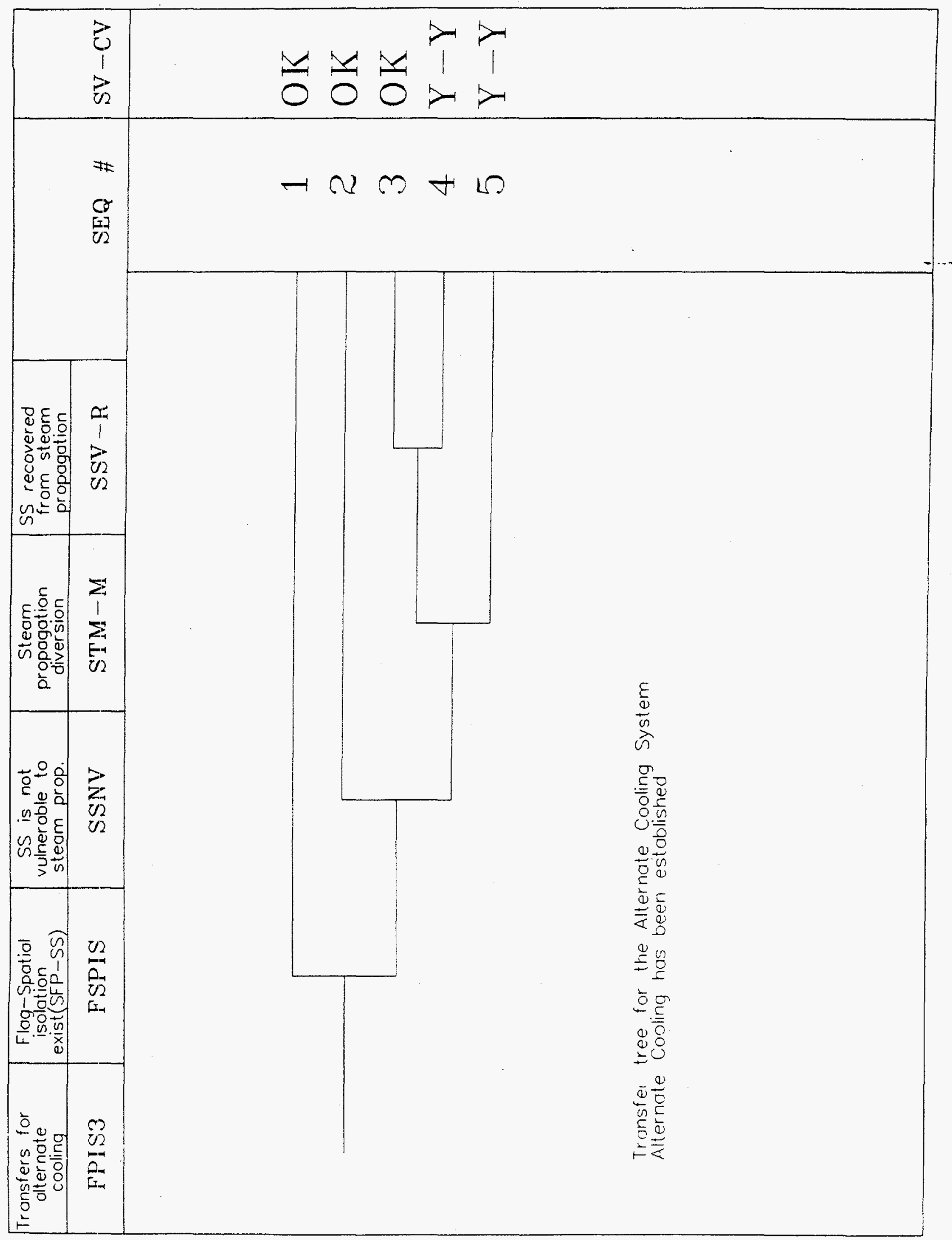




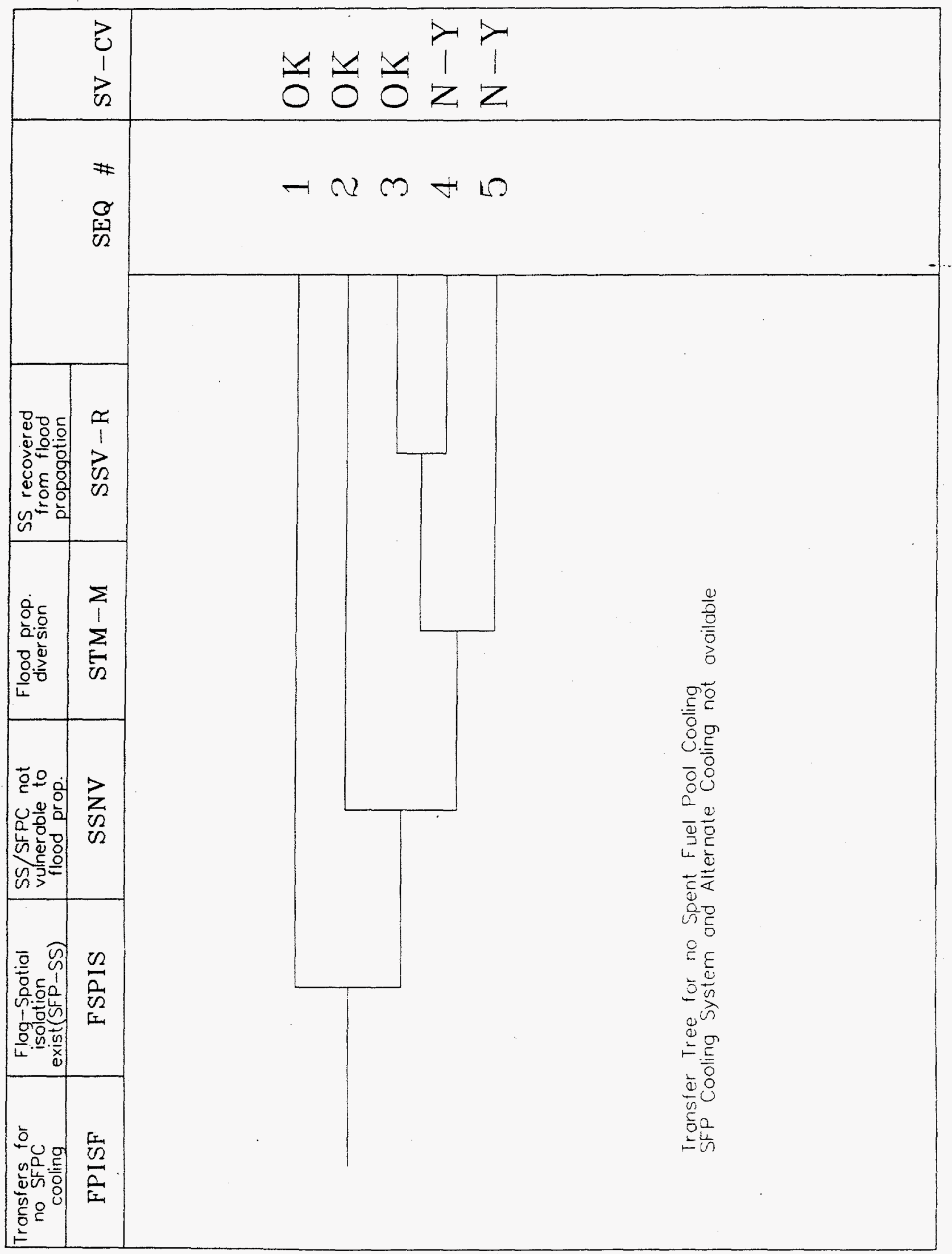




\section{A.6 Fault Trees}

This section presents the non-trivial (i.e., more than one basic event) fault trees. For many of these trees, e.g., for treating the unavailability of the SFPC system and the RHR system(s), the models supporting Ref. A. 2 have been used as a starting point. These trees have been modified using a modeling approach similar in spirit to that used in developing Accident Sequence Precursor (ASP) models (see for example Ref. A.5). Using this approach, components on a single pipe segment are generally grouped into super-components. In the case of makeup and alternate cooling top events, entire trains or systems of equipment are treated with a single super-component. Also, a number of low probability failure modes (e.g., normally closed manual valves transferring open during the scenario) are omitted. This simplified approach is judged to be adequate for treating spent fuel pool scenarios whose risk, as shown in Ref. A.2, tends to be dominated by human error contributions. 


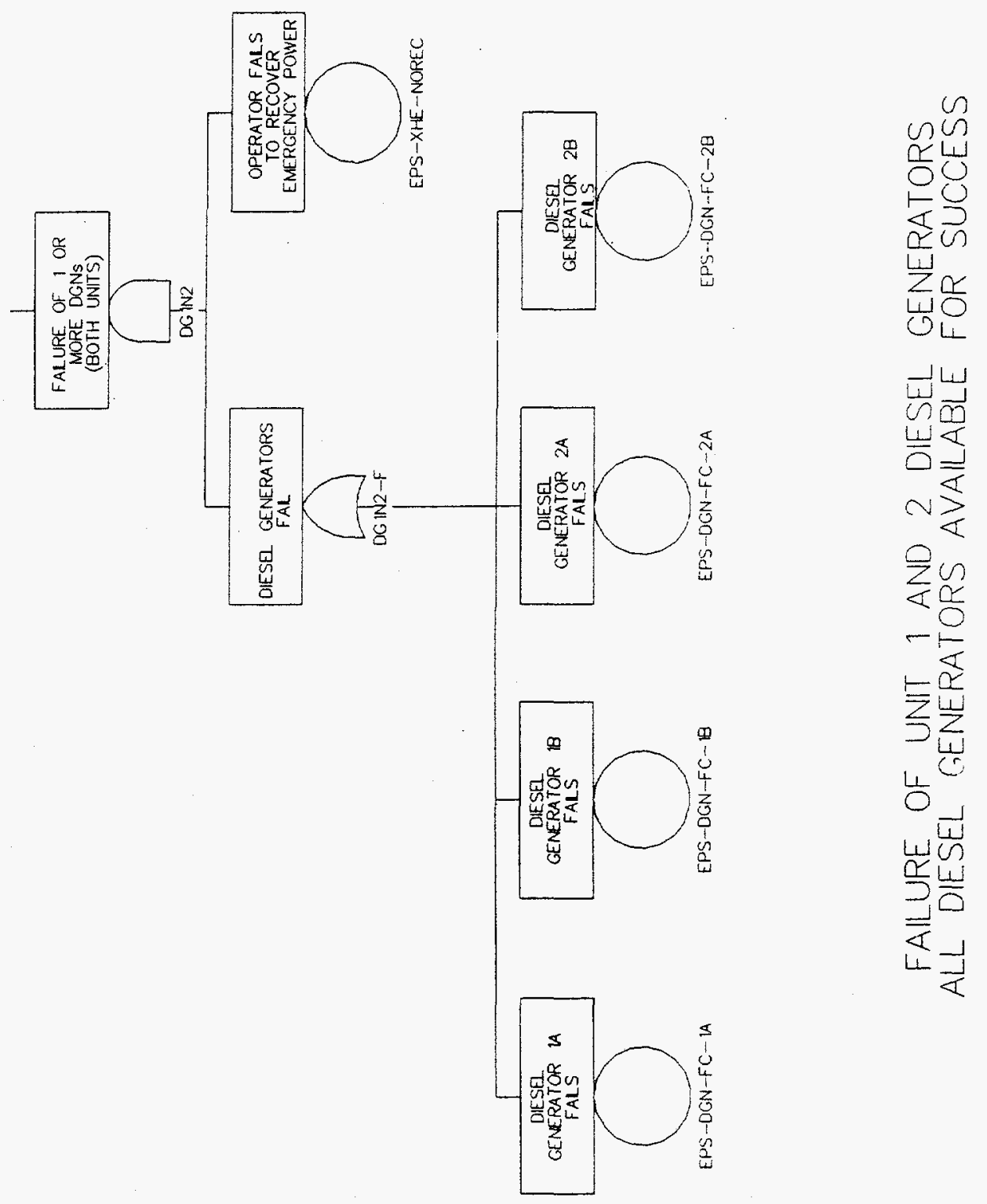




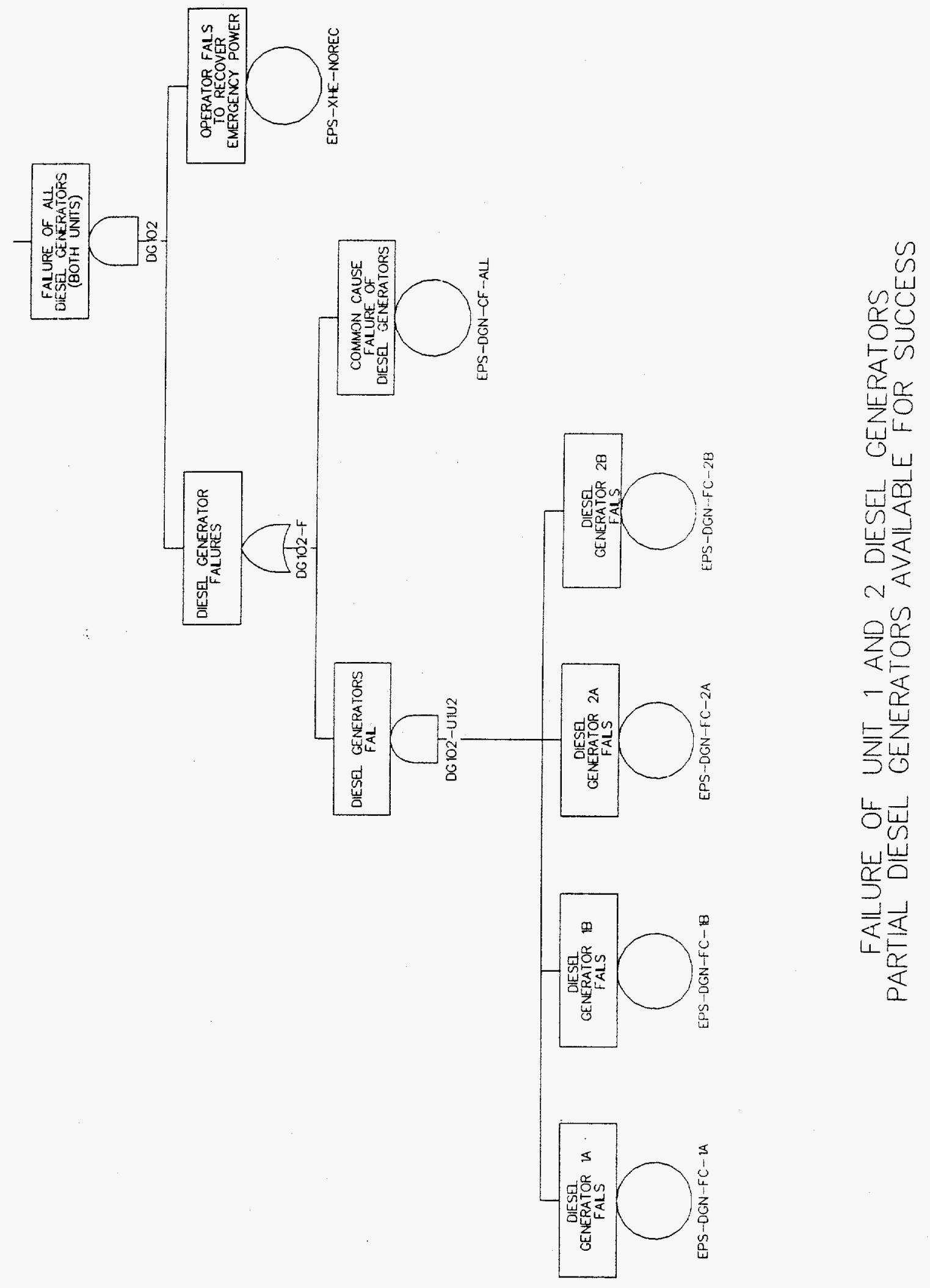




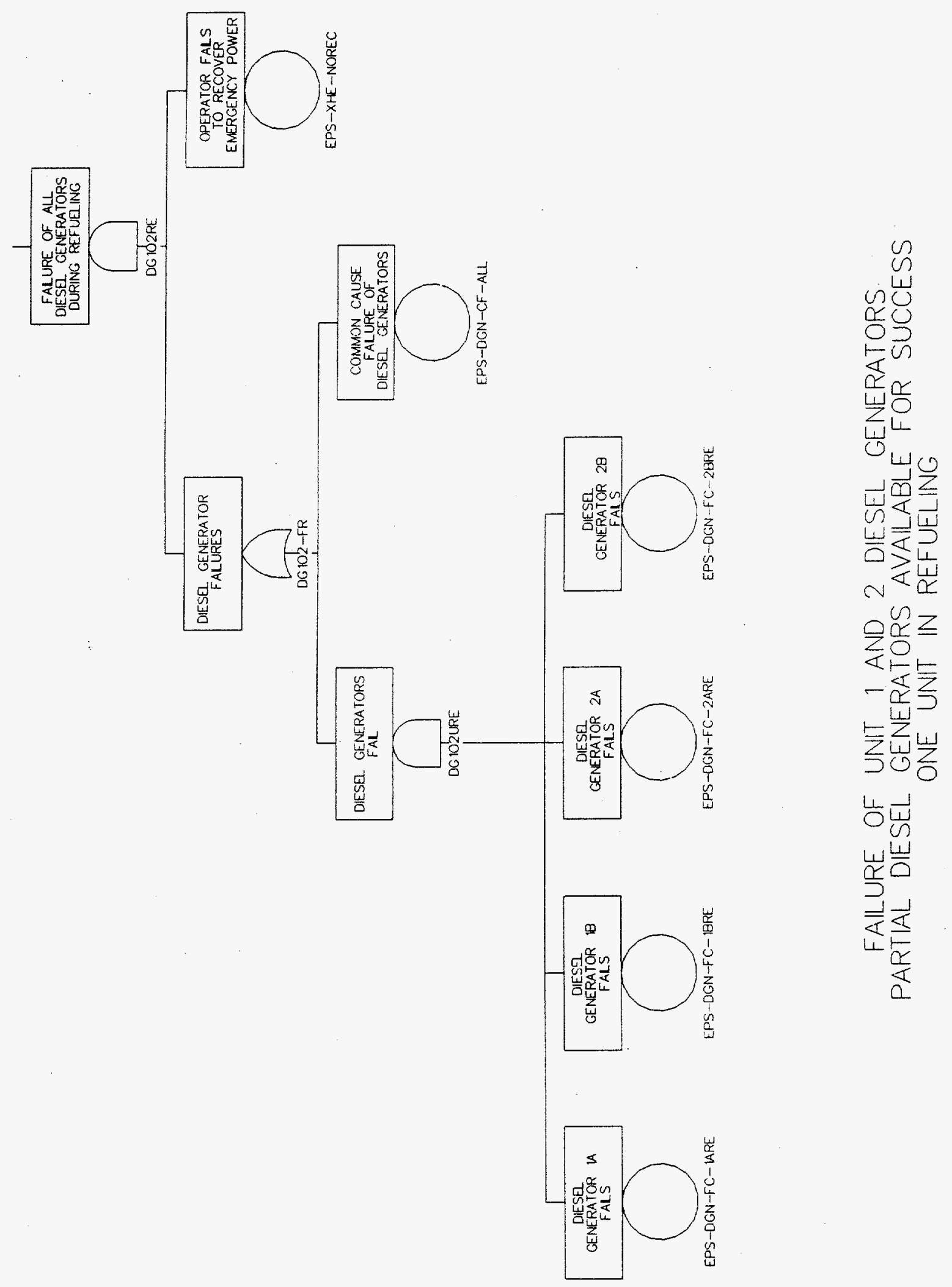




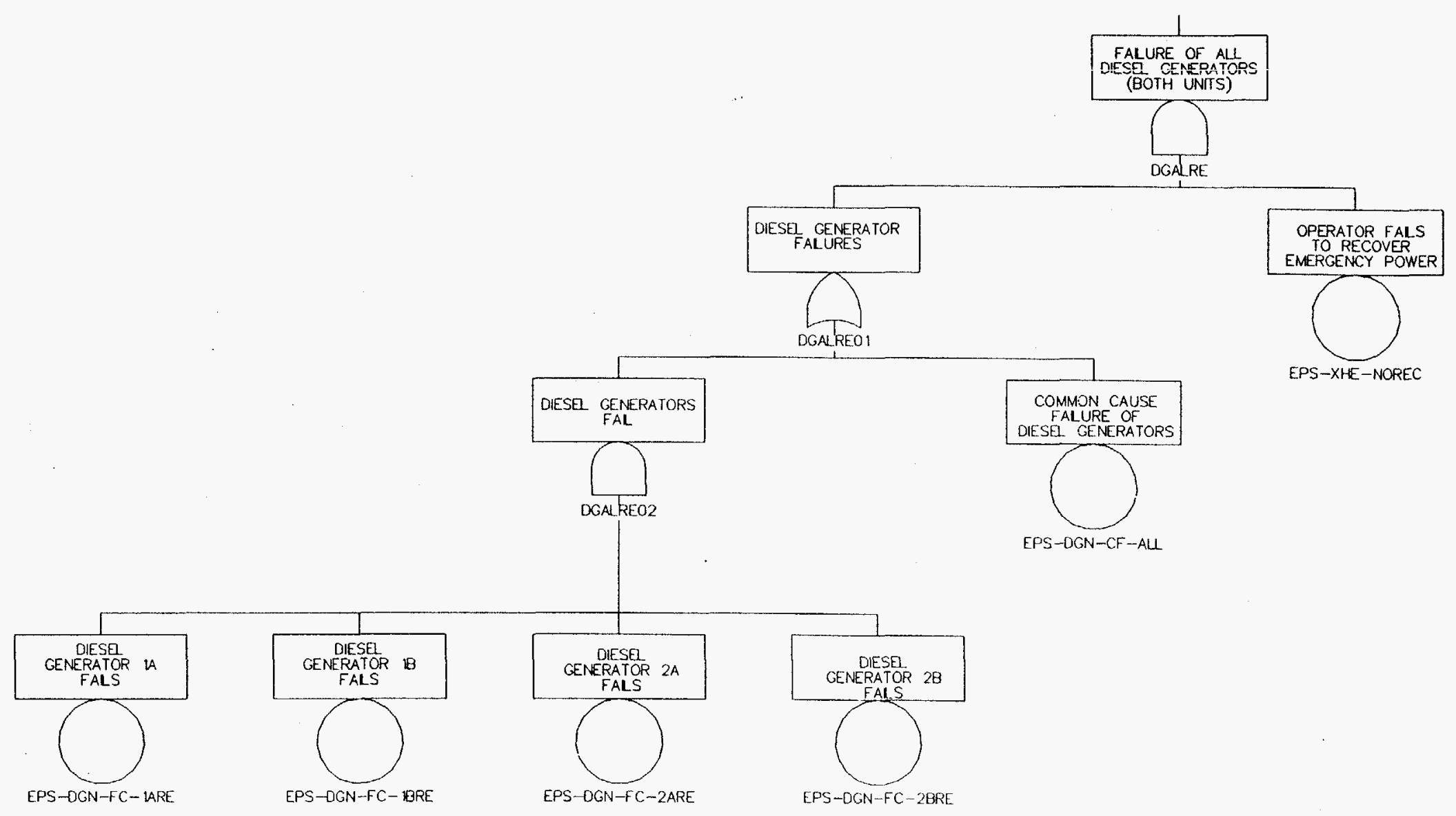

FAILURE OF UNIT 1 AND 2 DIESEL GENERATORS

PARTIAL DIESEL GENERATORS AVALABLE FOR SUCCESS

ONE UNIT IN REFUELING 


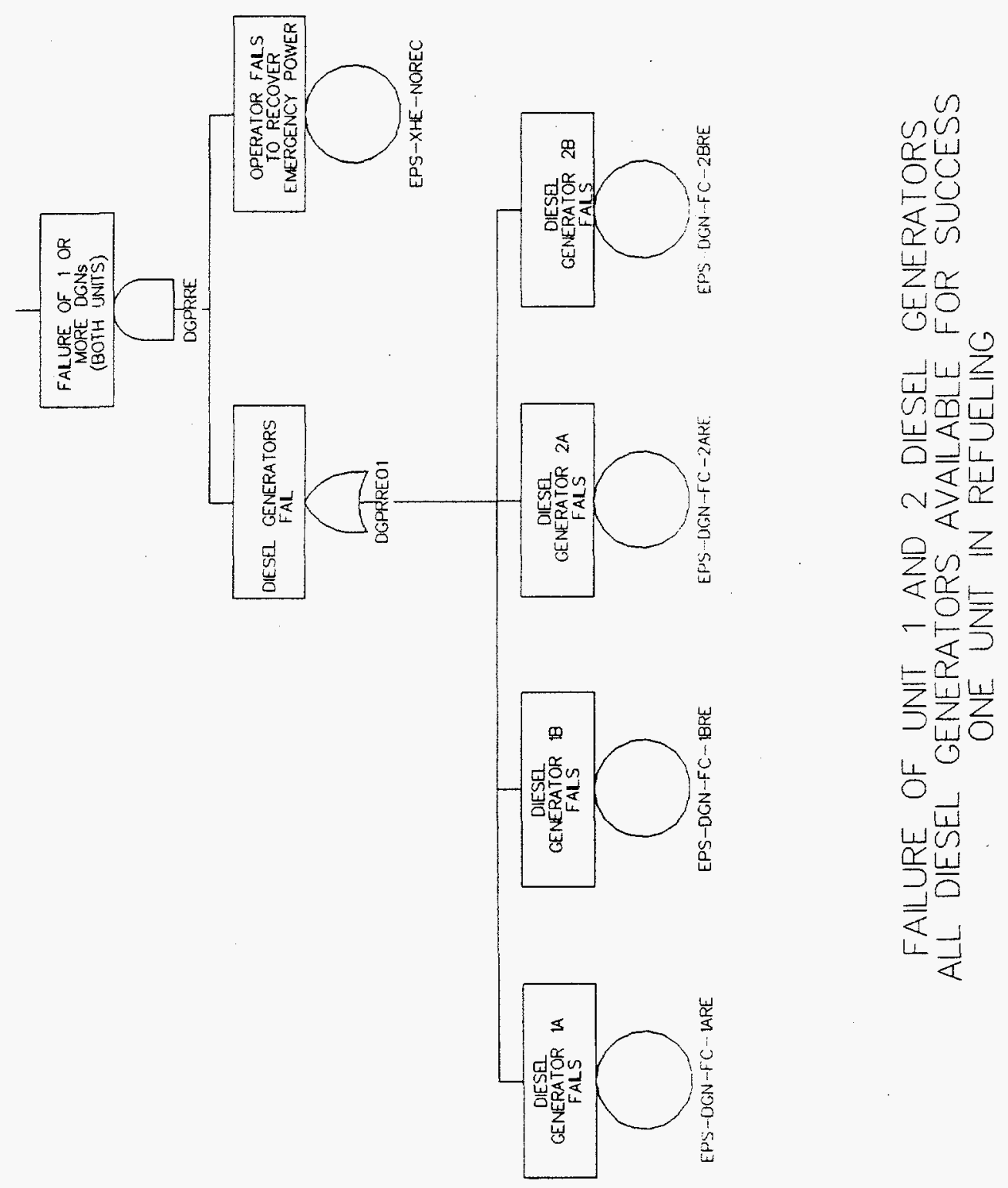




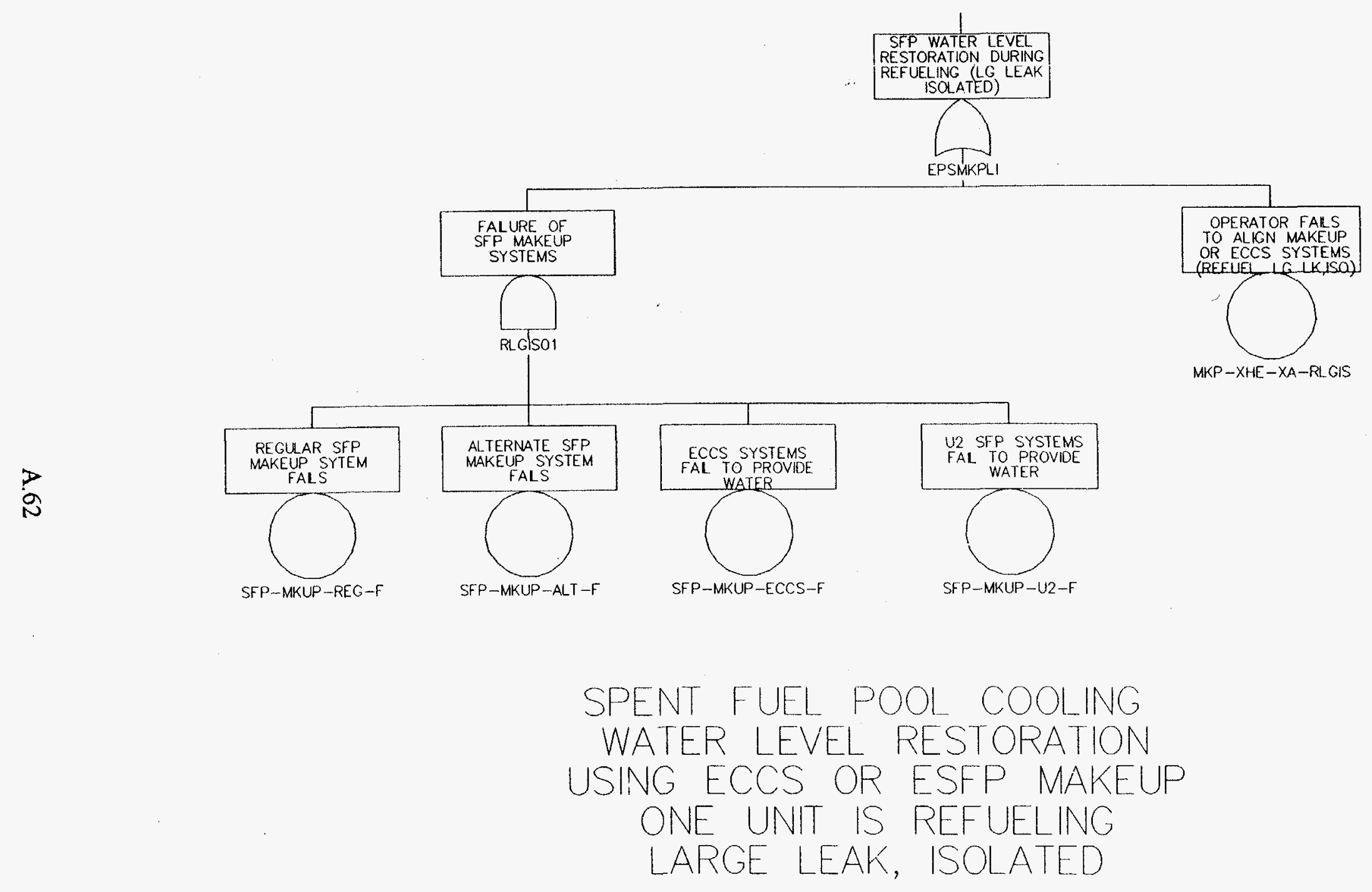




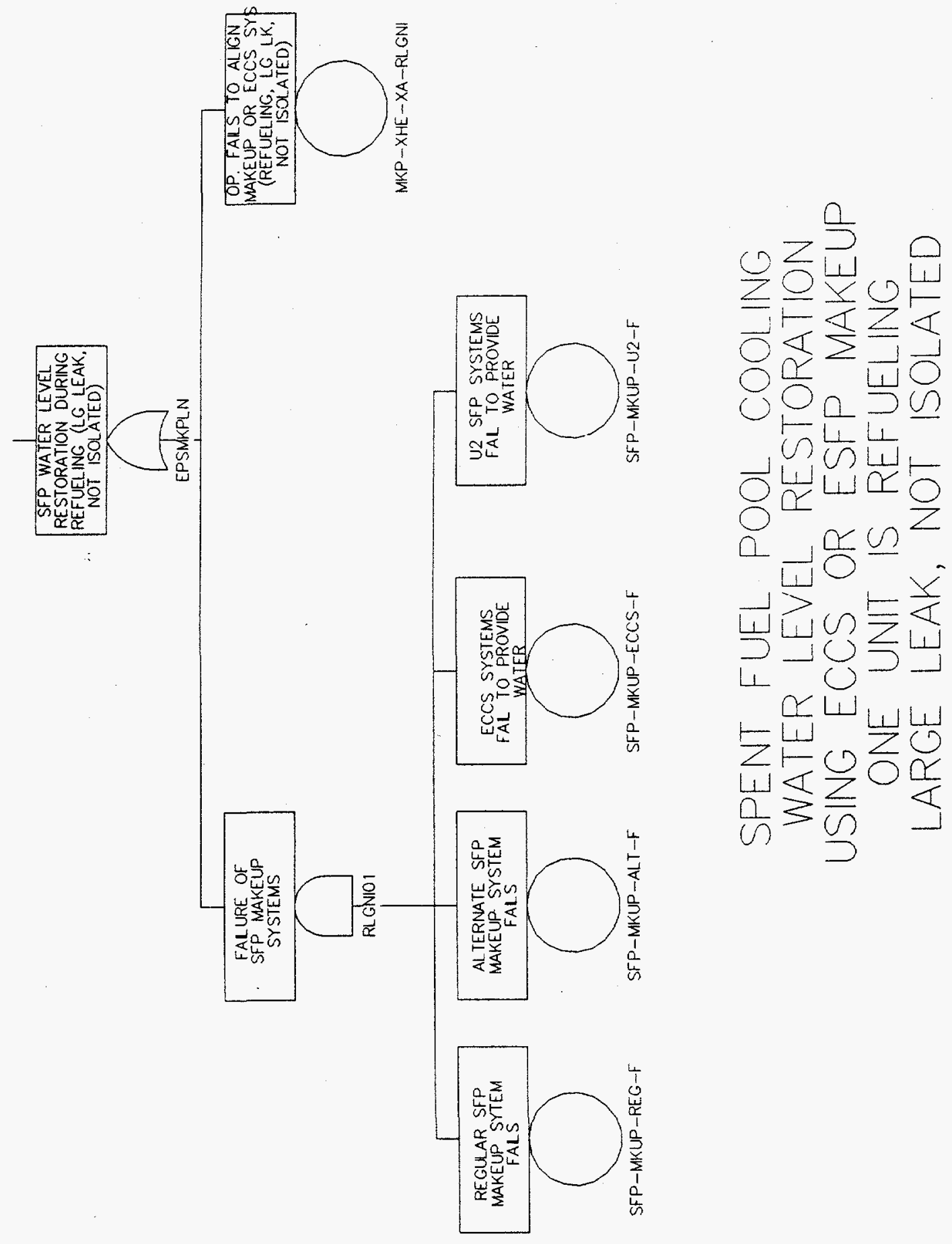




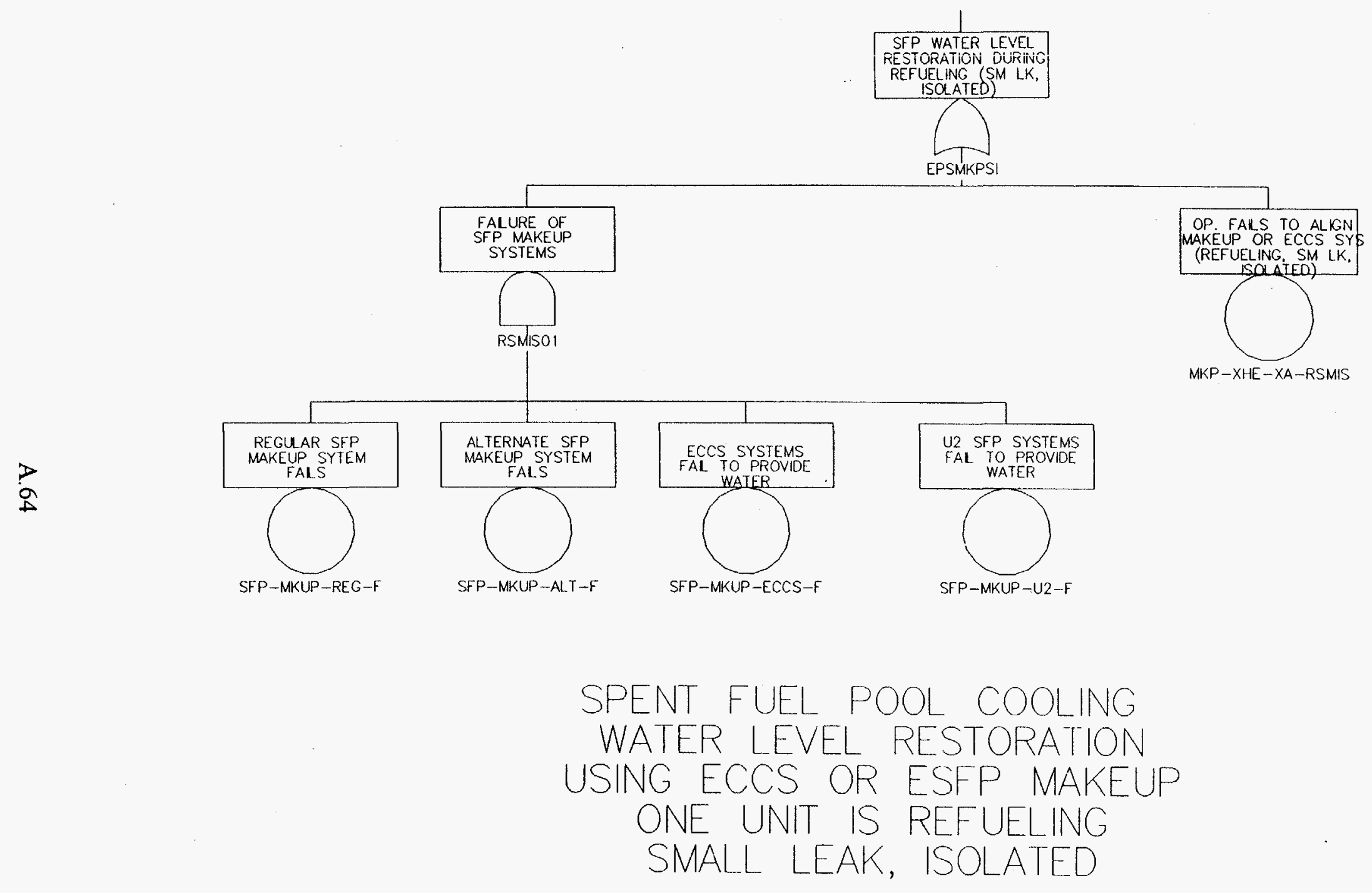




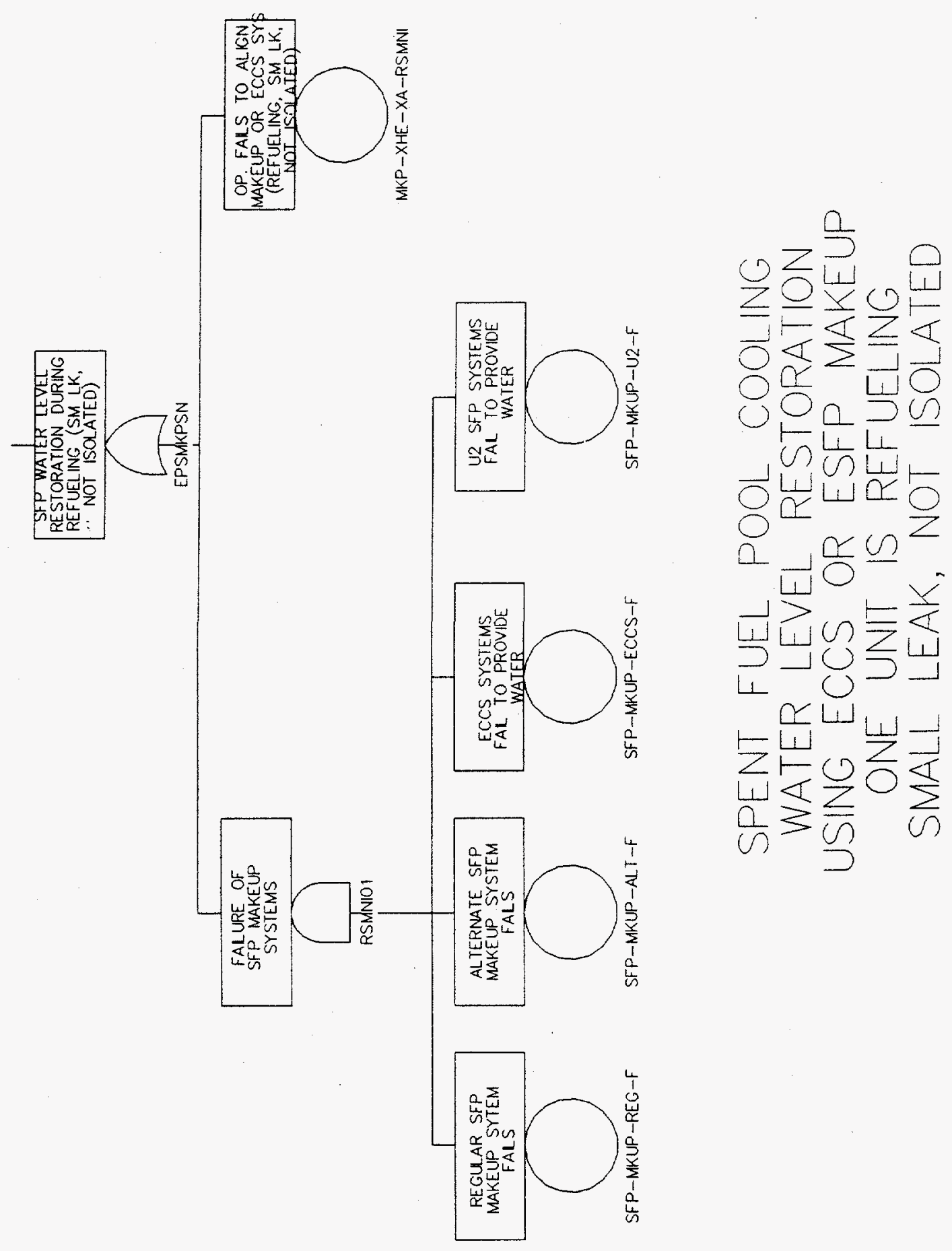

A. 65 


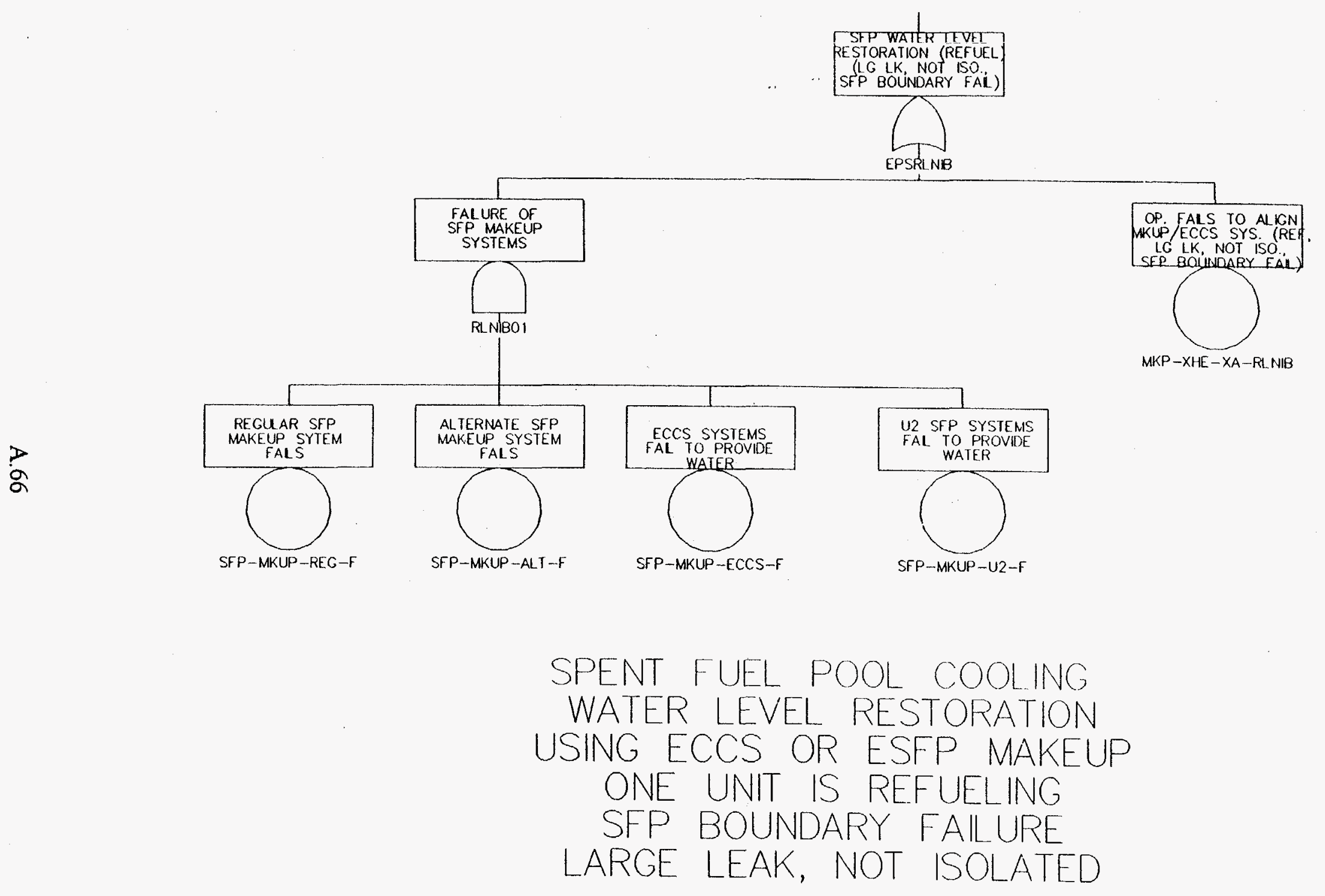




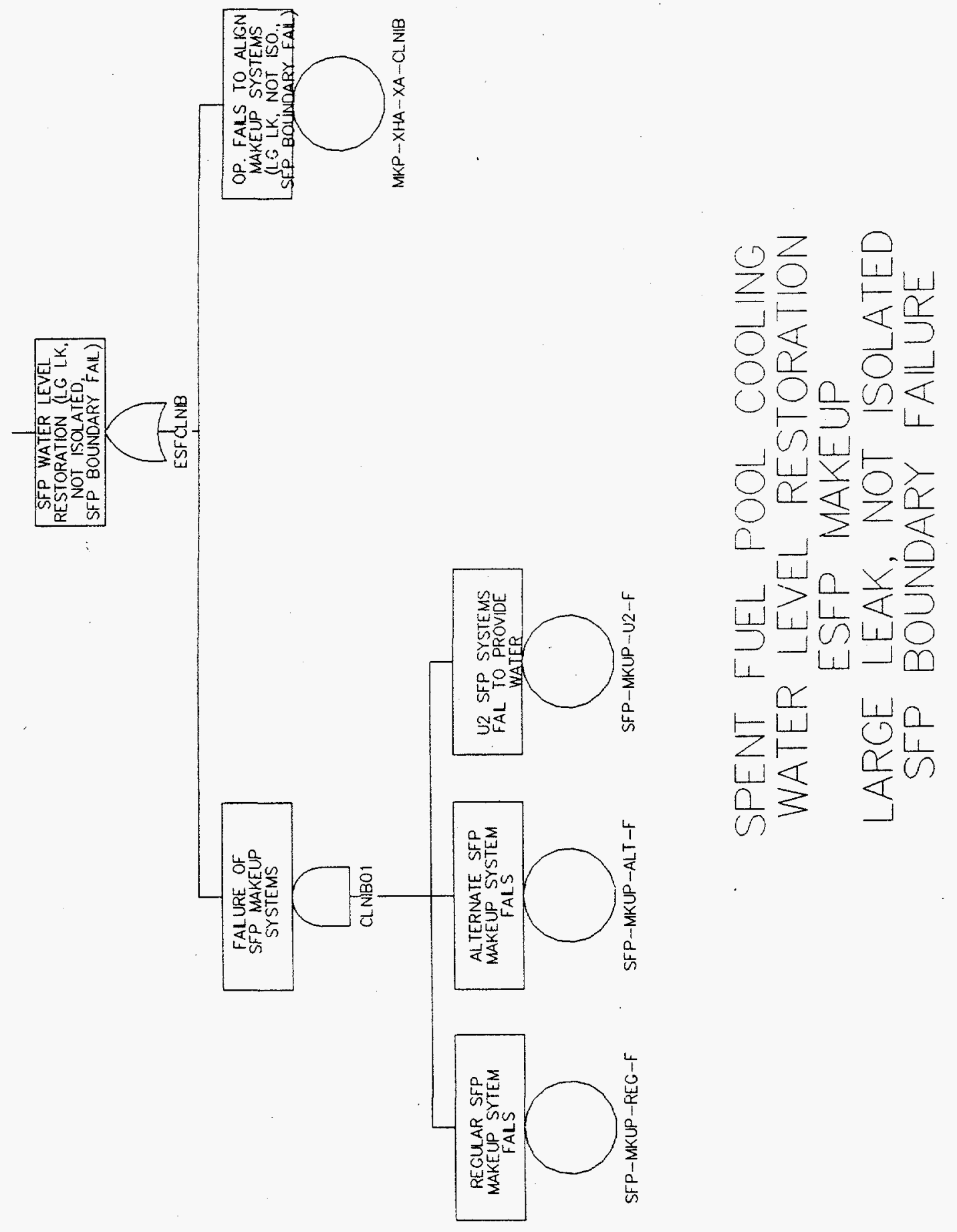



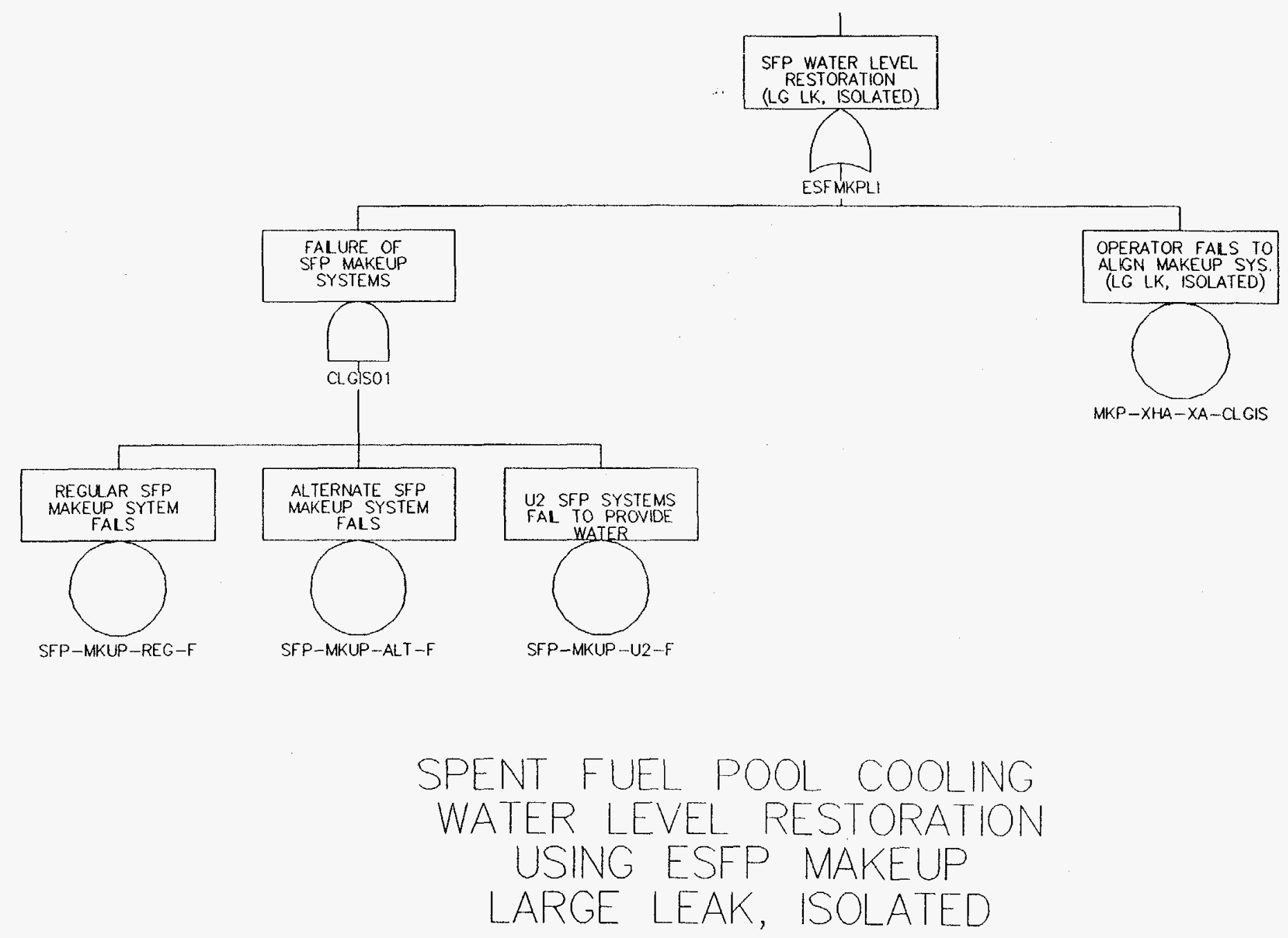


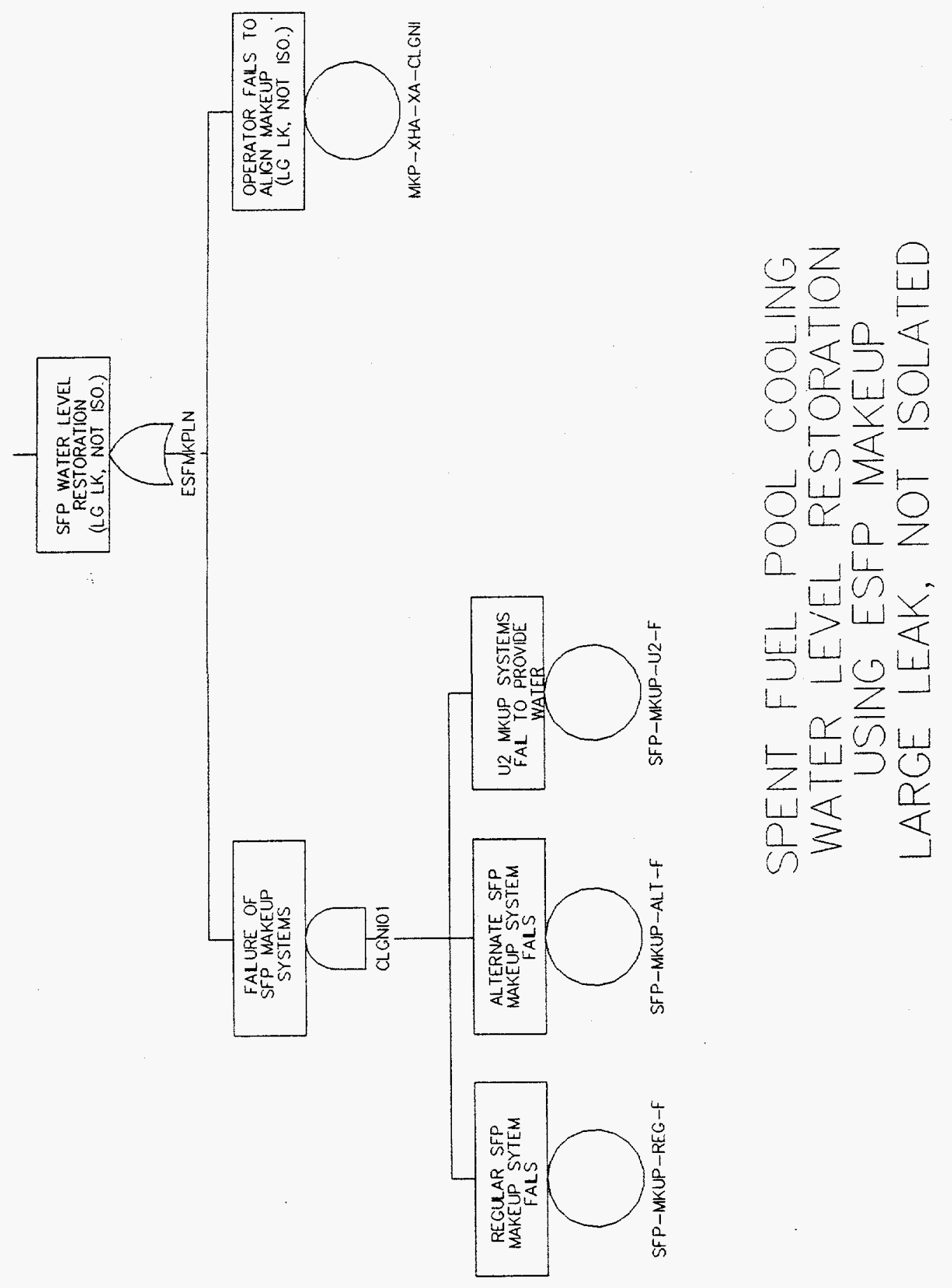




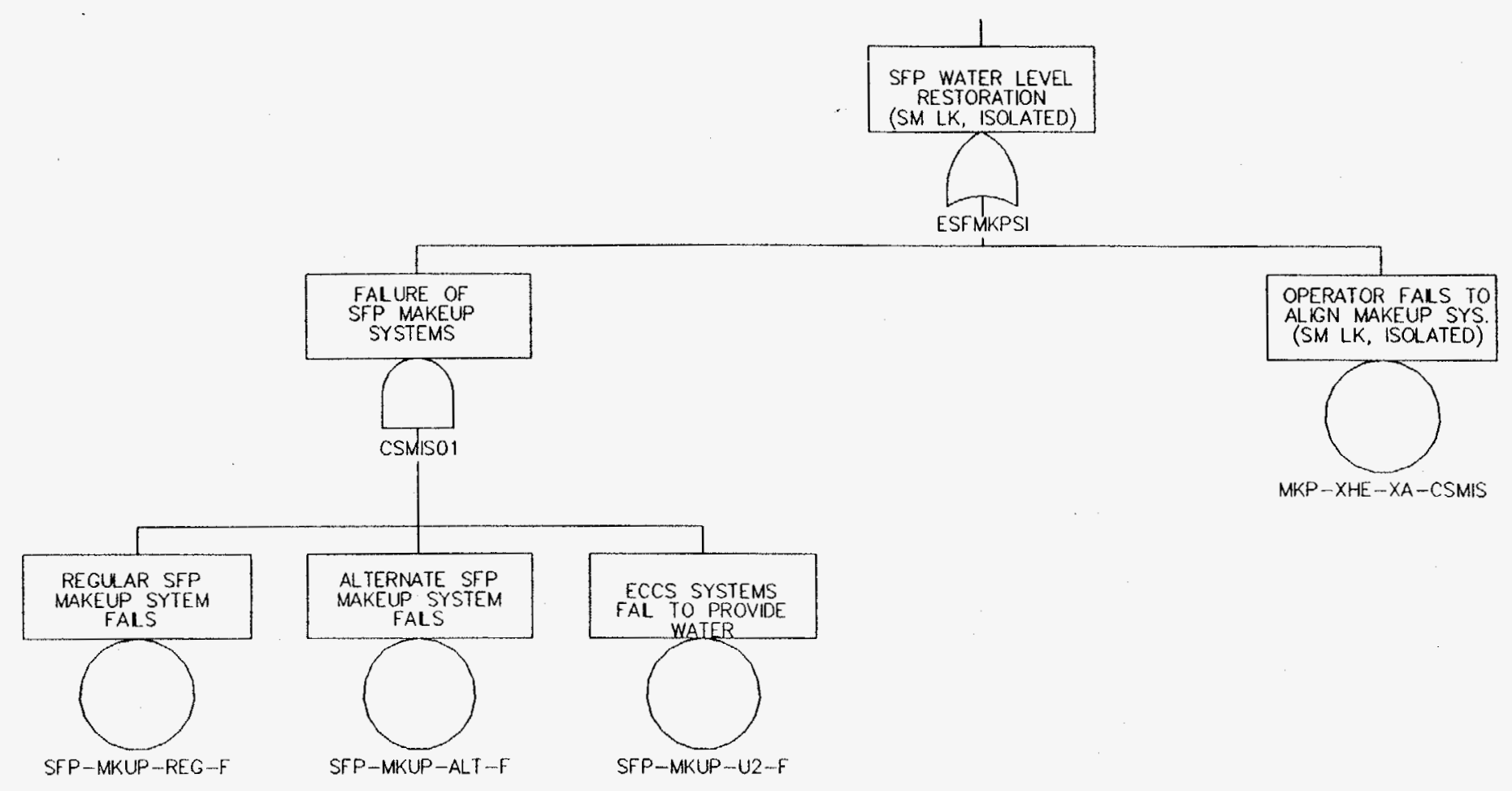

SPENT FUEL POOL COOLING WATER LEVEL RESTORATION USING ESFP MAKEUP SMALL LEAK, ISOLATED 


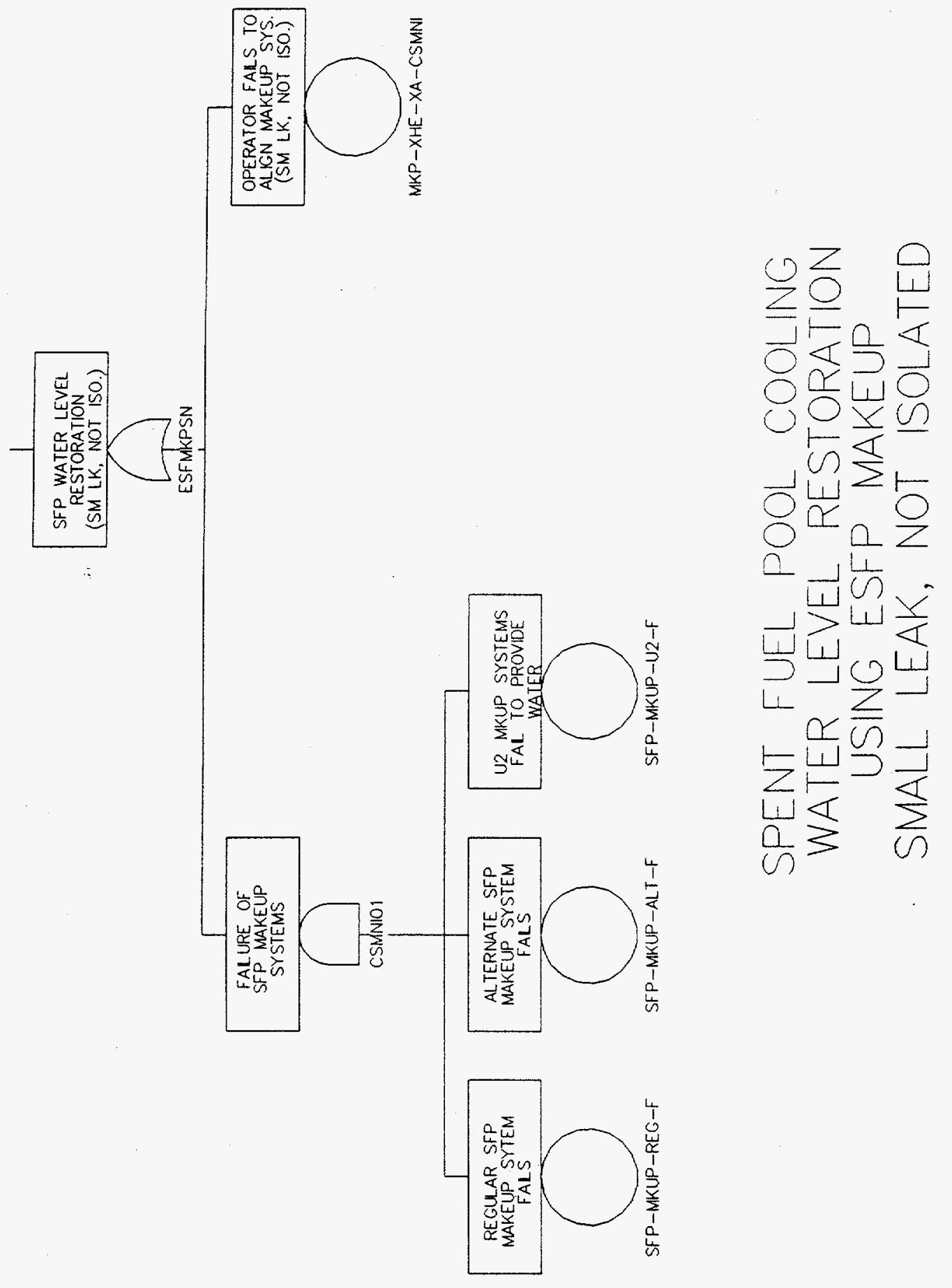




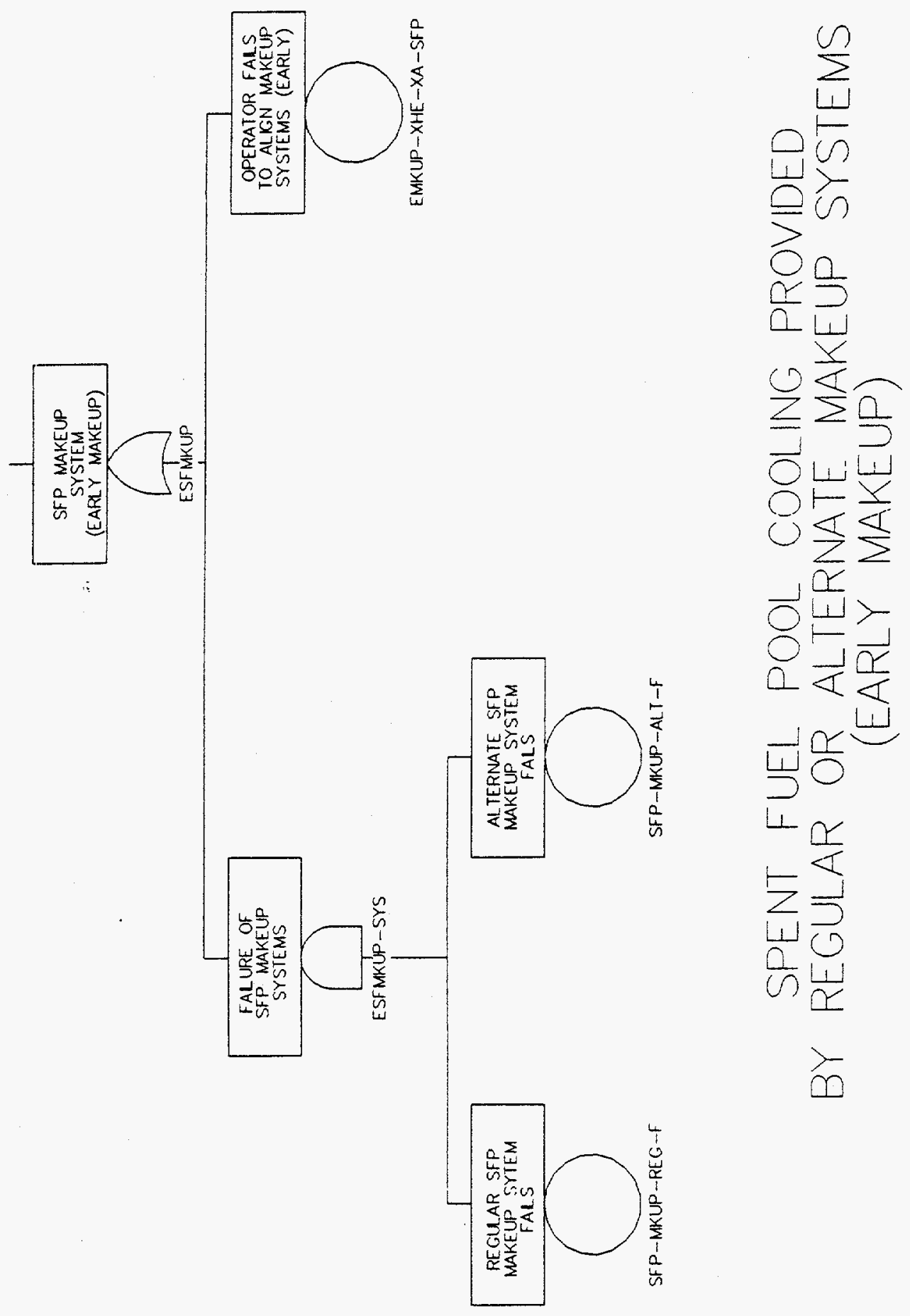

A. 72 

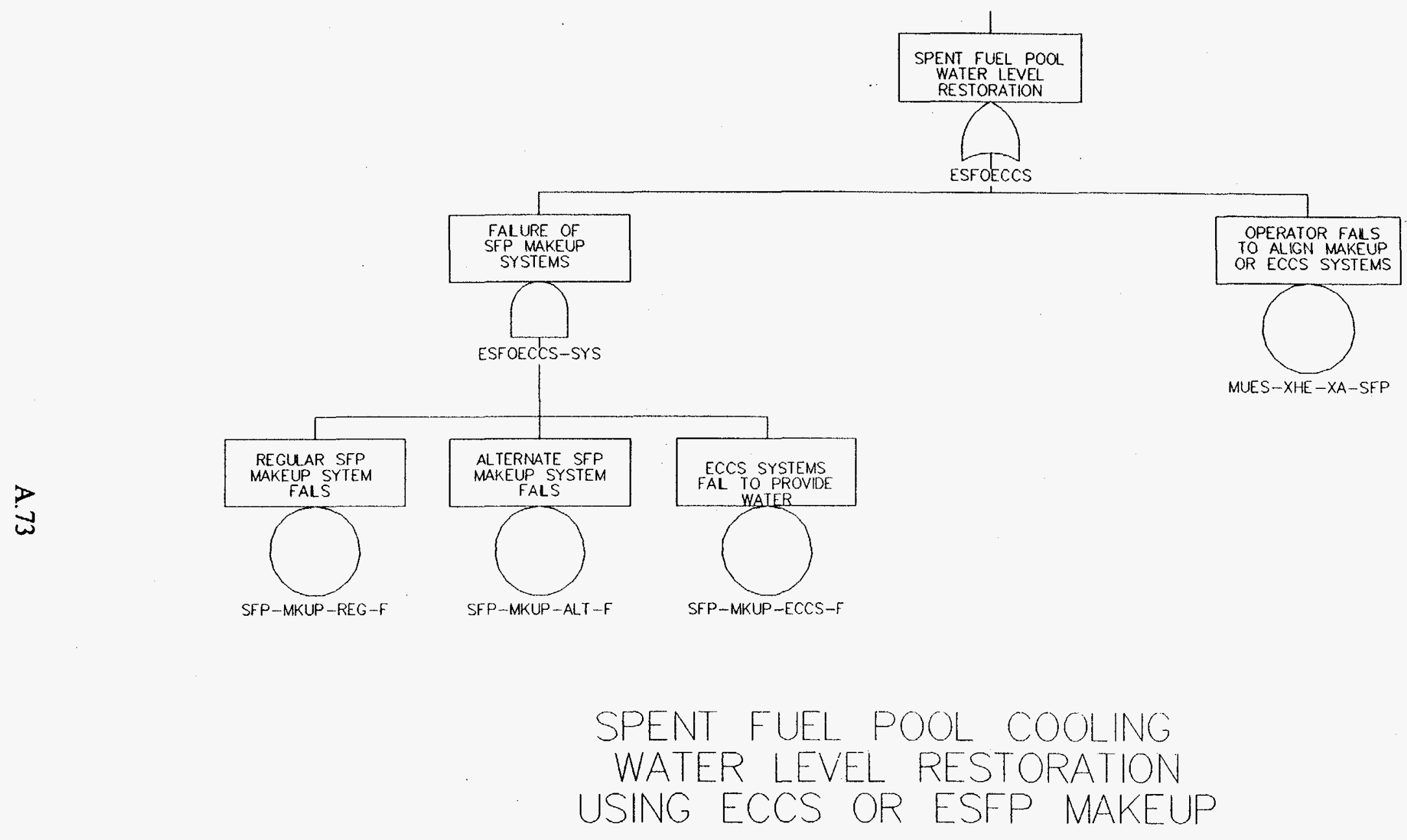


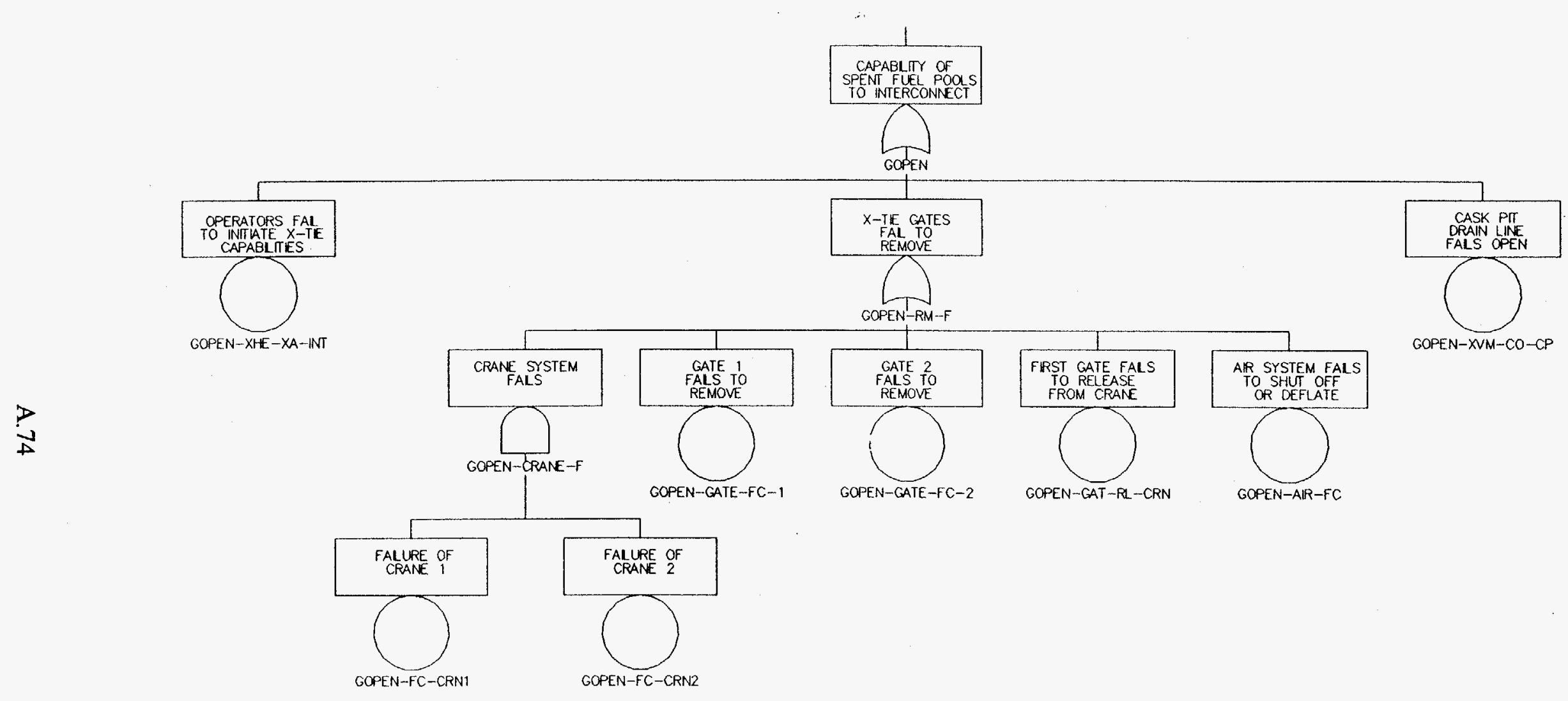

CAPABILITY OF SPENT FUEL POOLS TO INTERCONNECT 


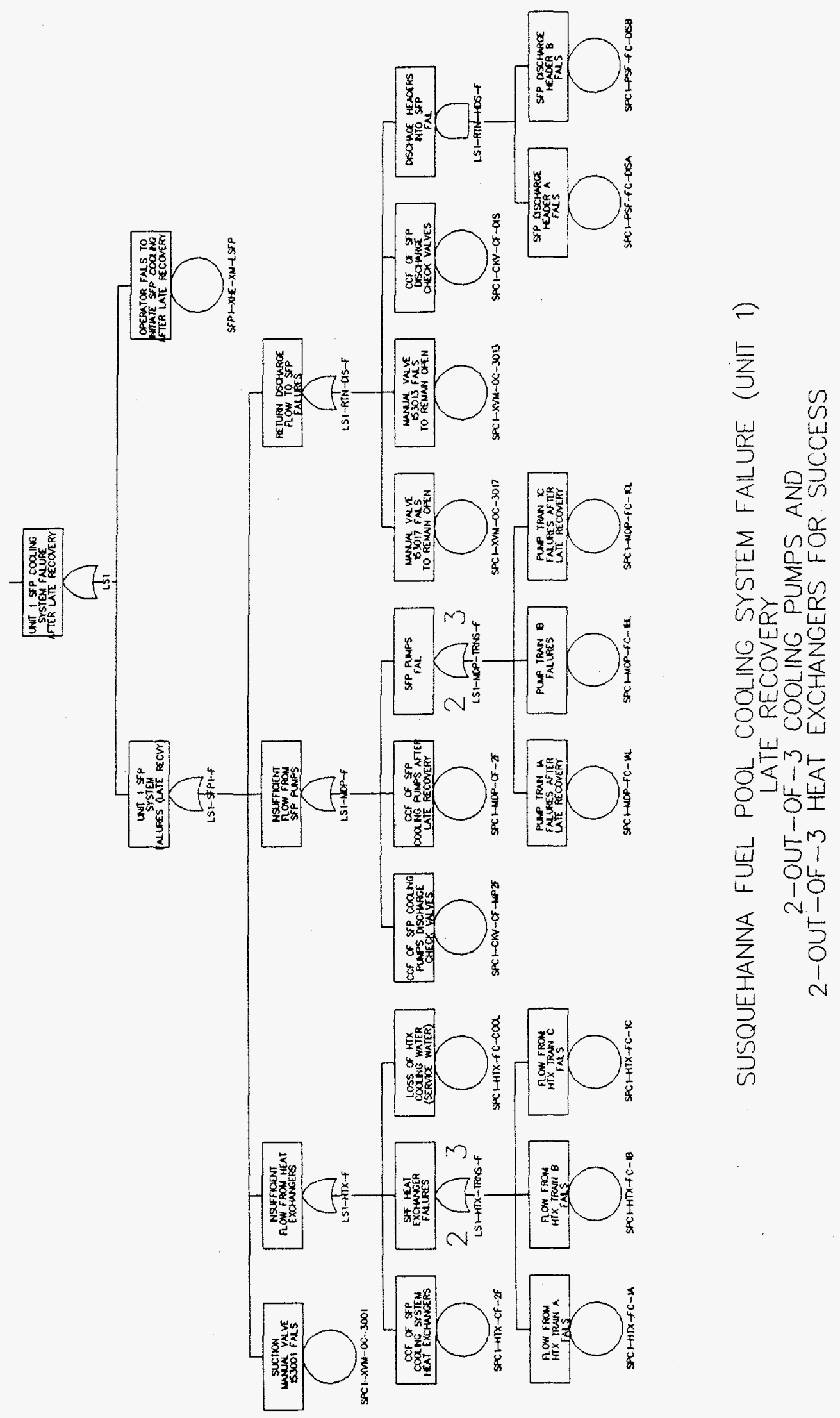




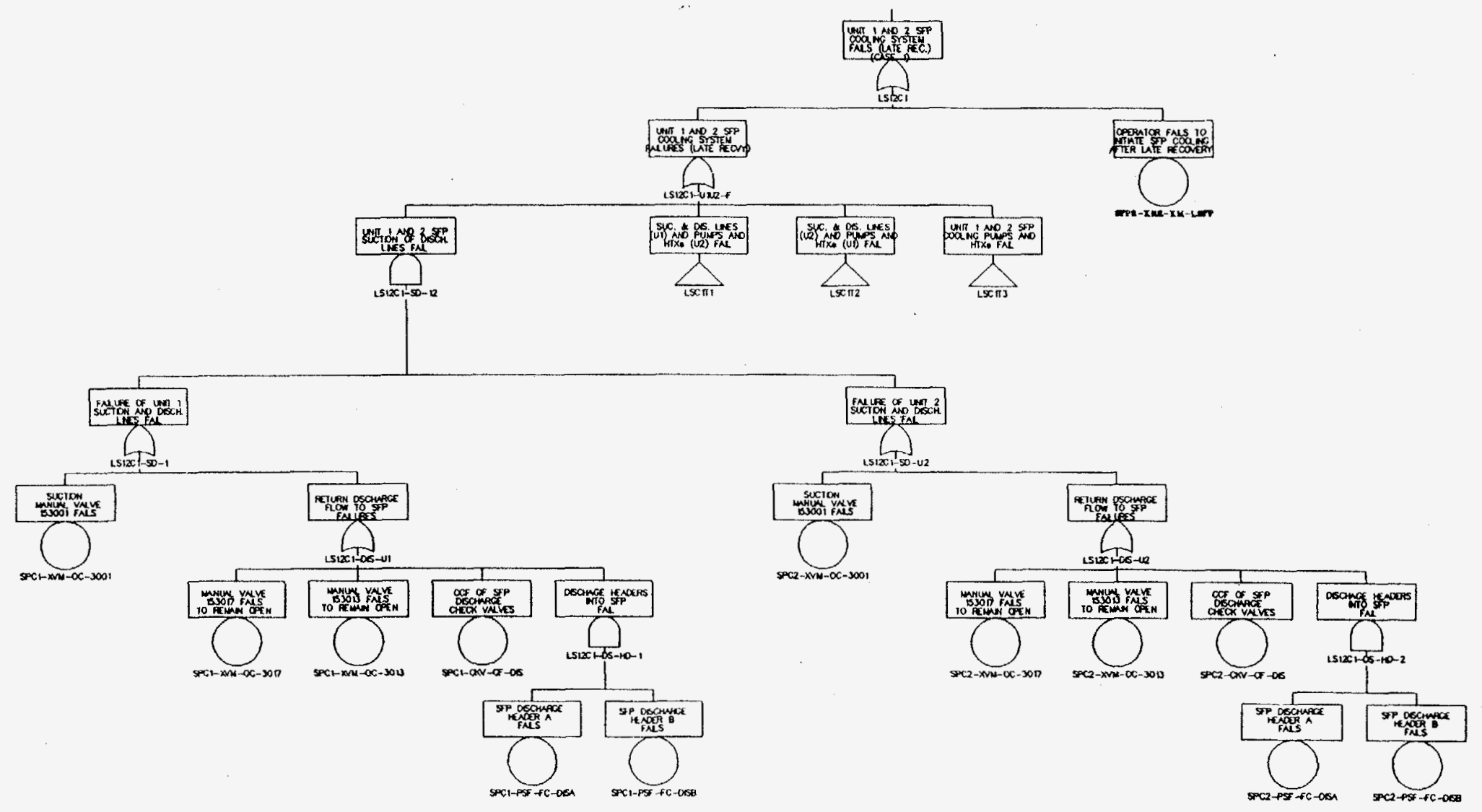

SUSQUEHANNA FUEL POOL COOLING SYSTEM FAILURE (UNITS 1 \& 2 )

2-OUT-OF -6 COOLING PUMPS FOR SUCCESS
COVER - CASE 1
SORE 


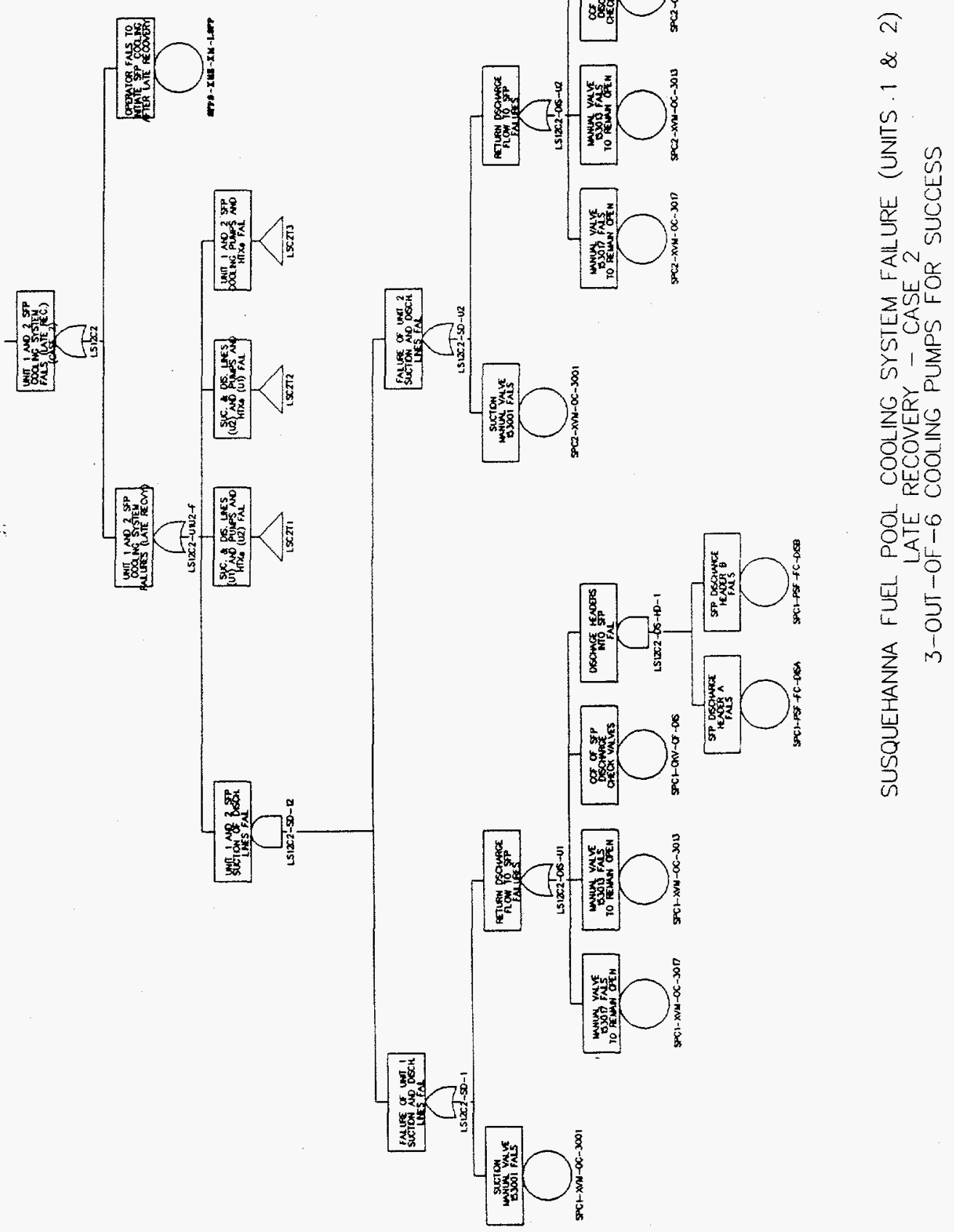




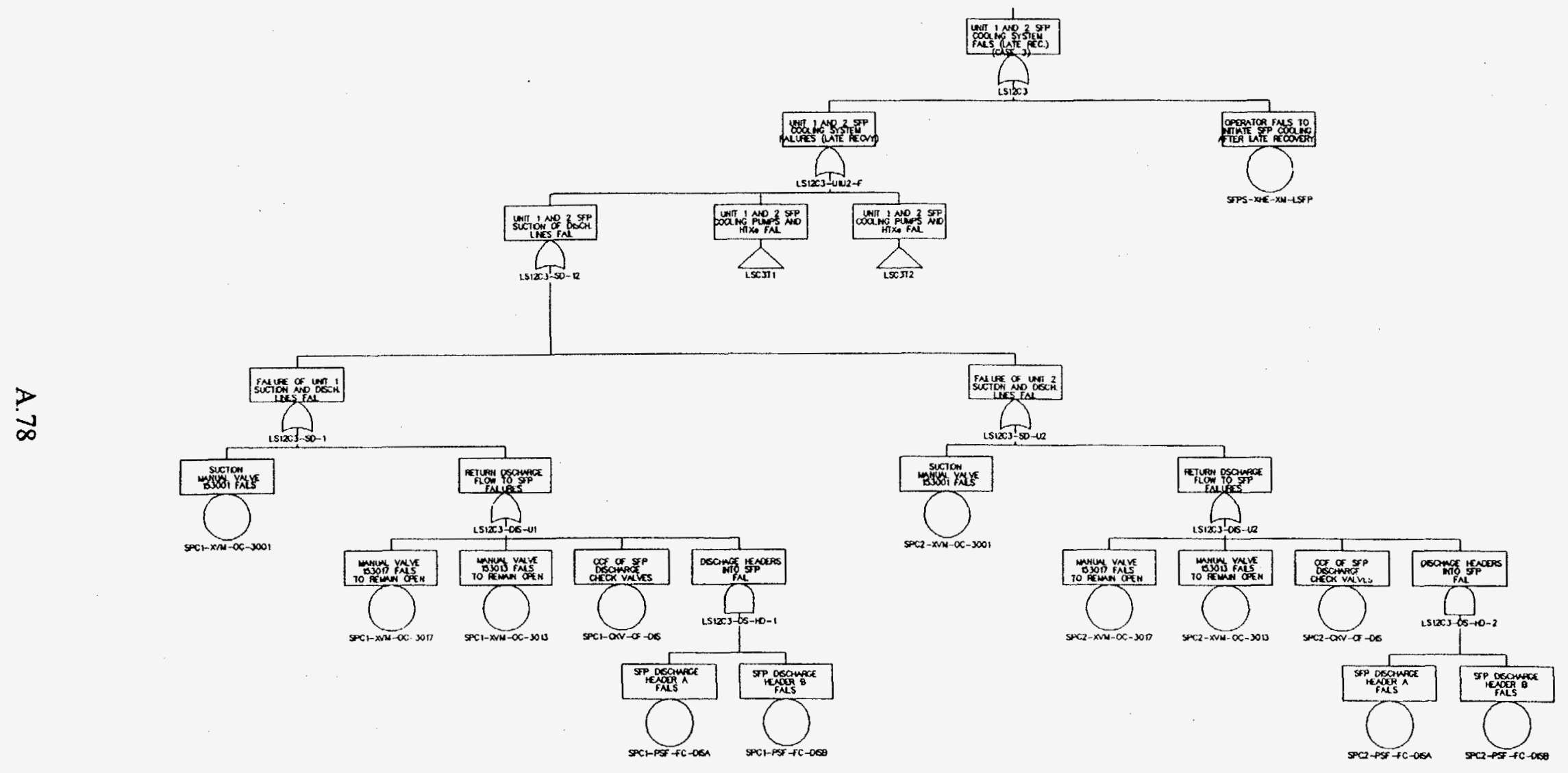

SUSQUEHANNA FUEL POOL COOLING SYSTEM FALURE (UNITS 1 \& 2 )

4-OUT-OF -6 COOLING PUMPS FOR SUCCESS 


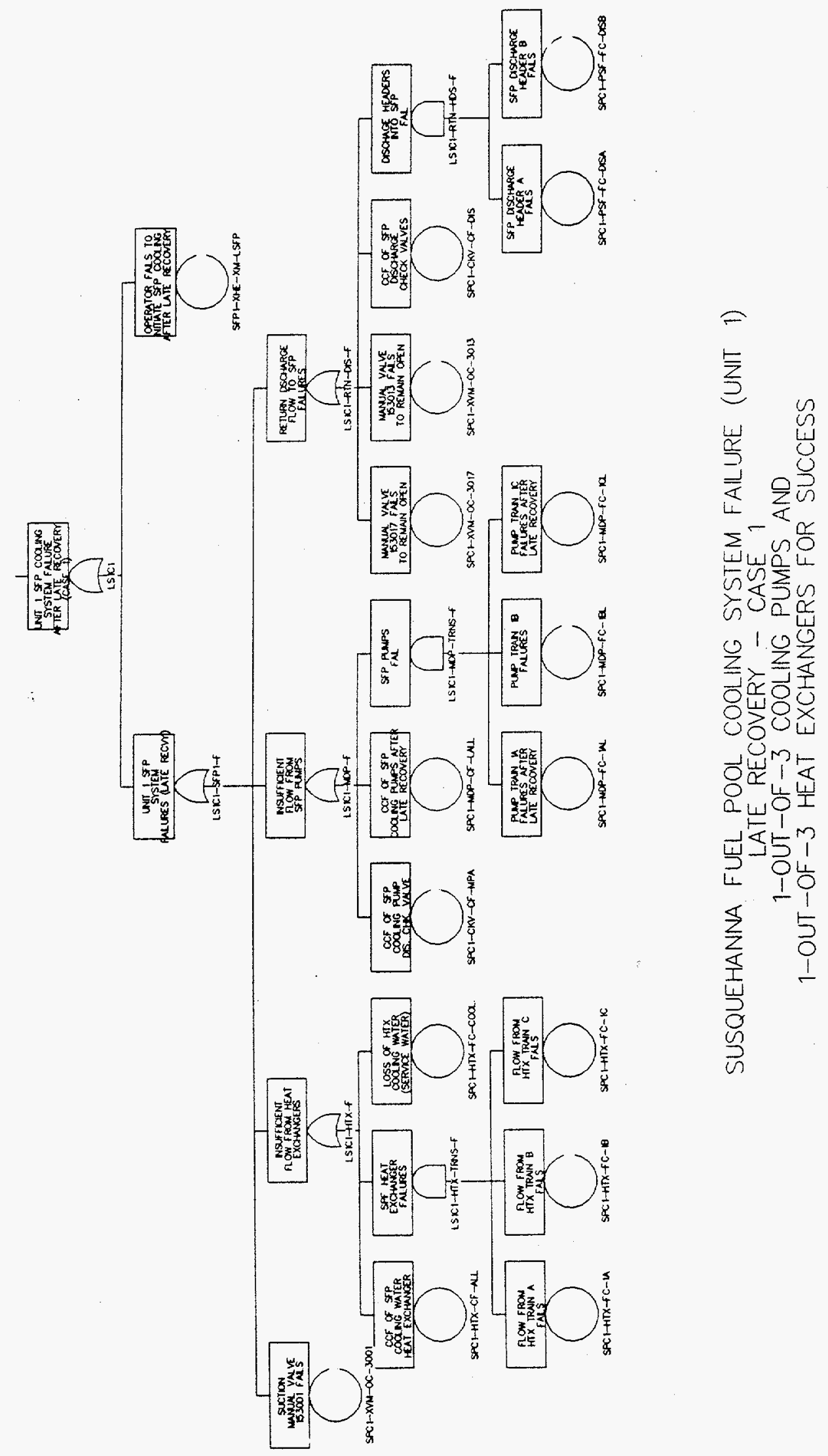




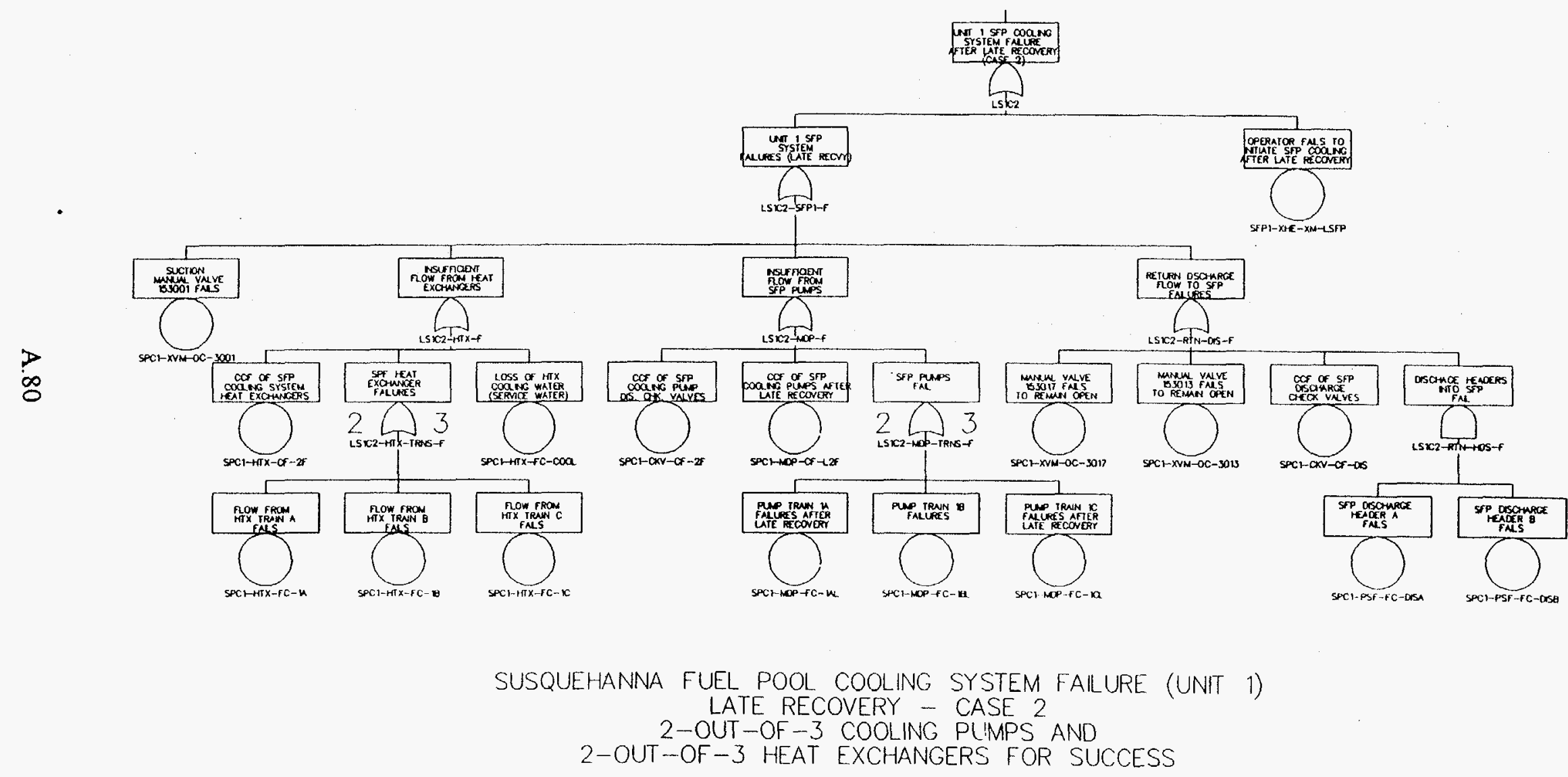




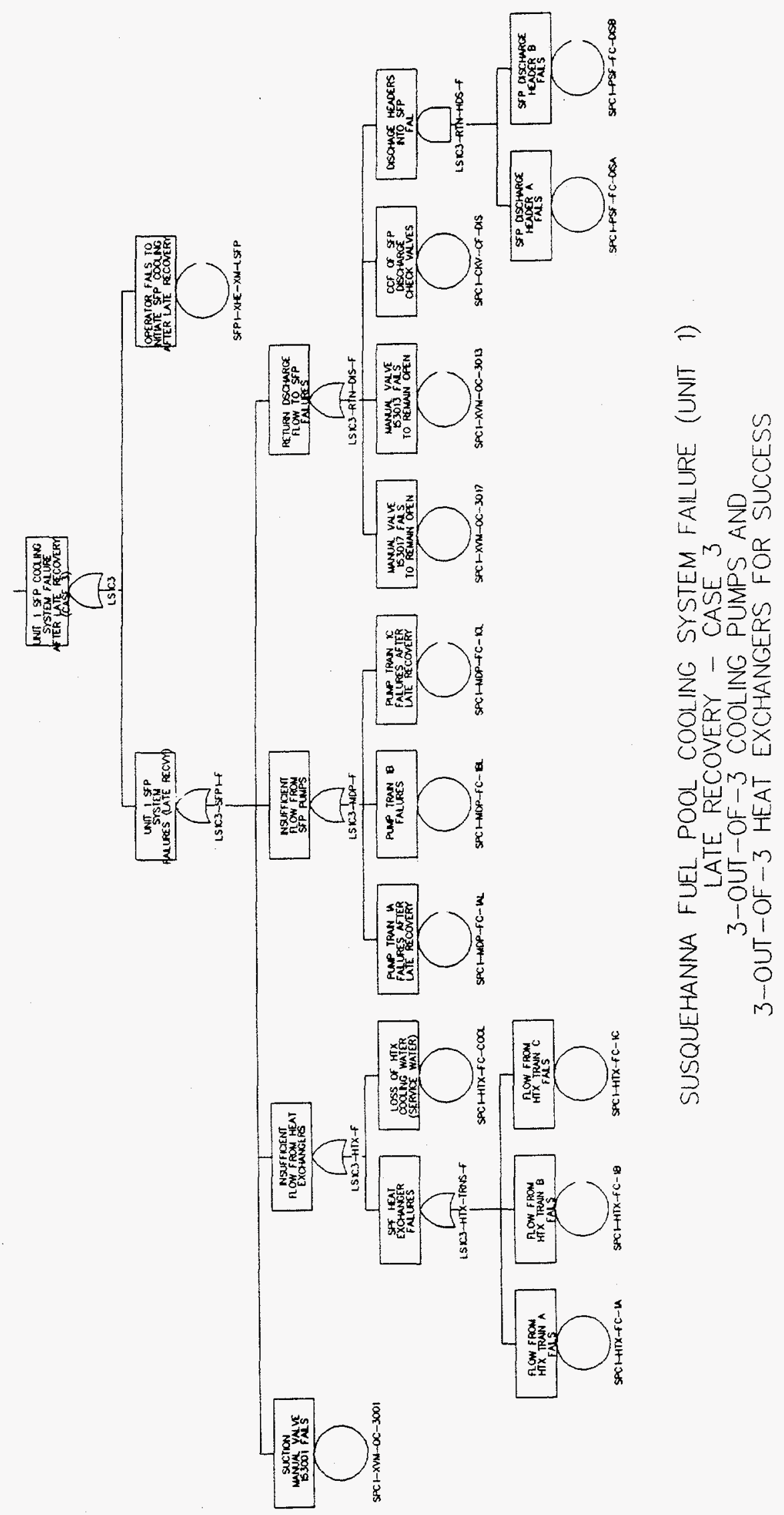



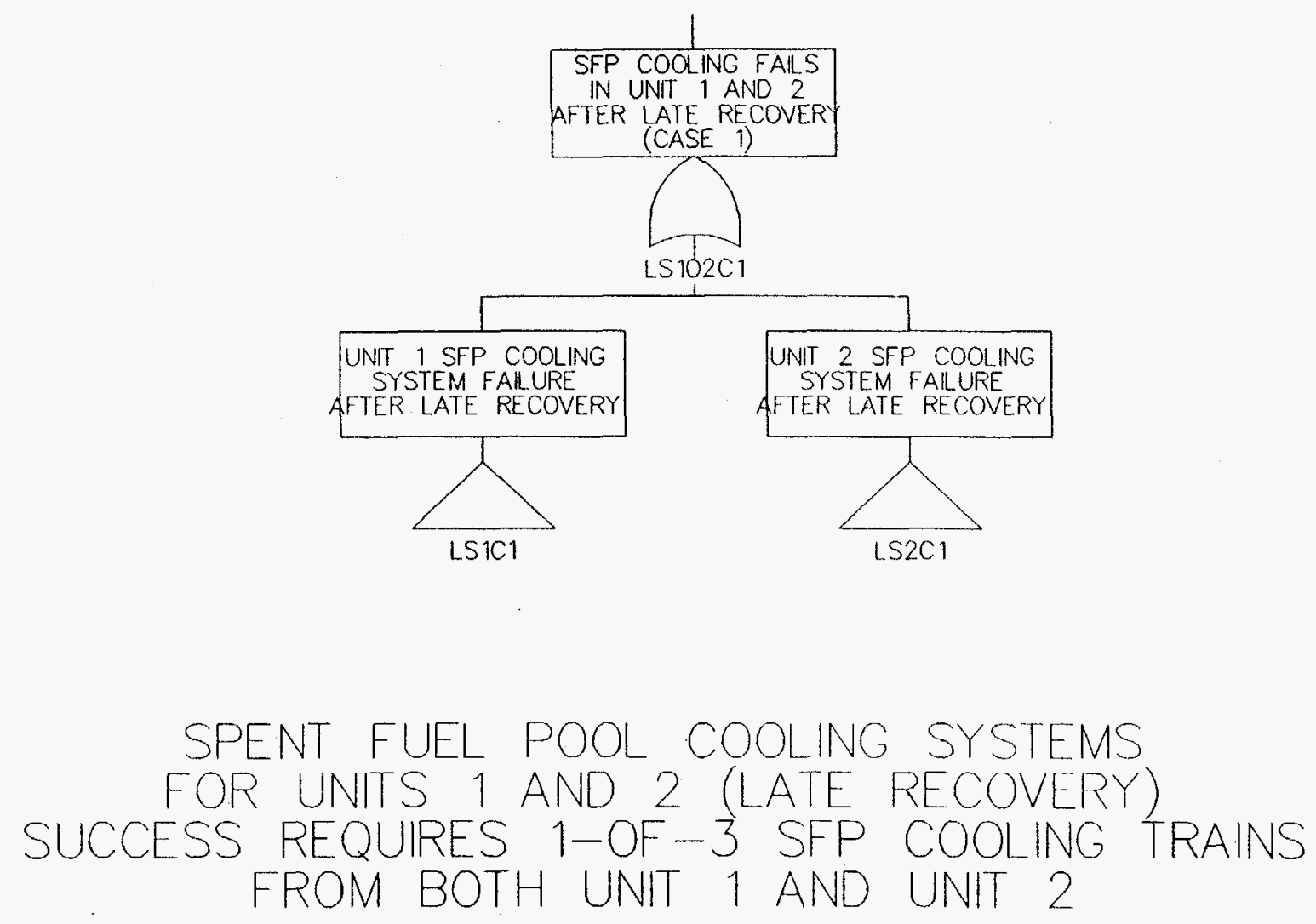

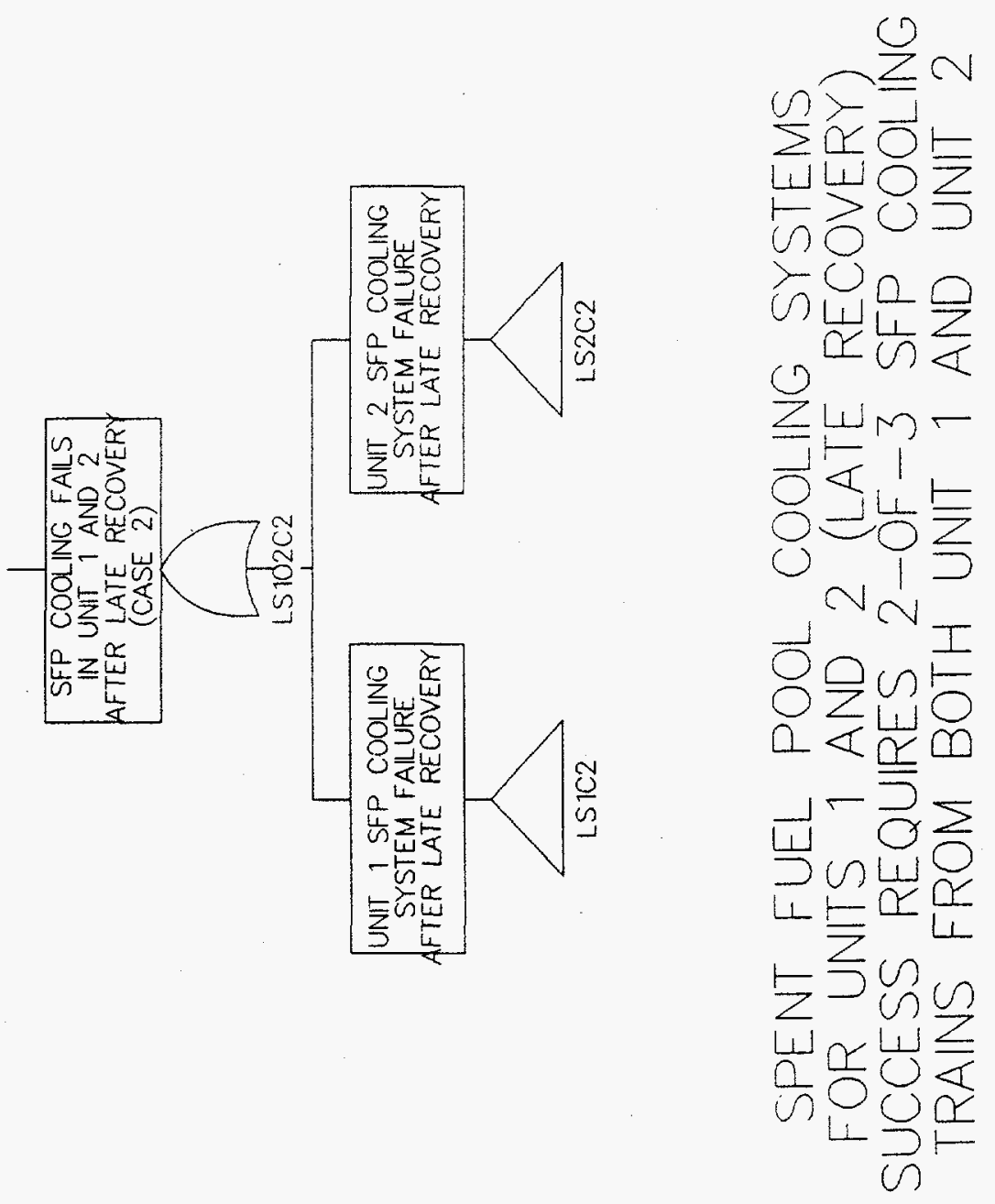


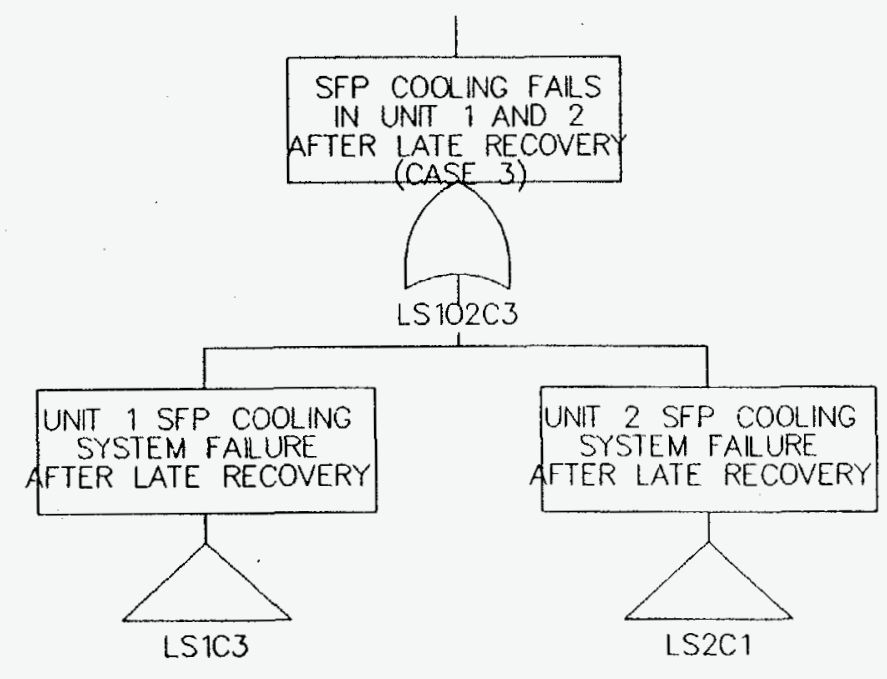

SPENT FUEL. POOL COOLING SYSTEMS FOR UNITS 1 AND 2 (LATE RECOVERY)

SUCCESS REQUIRES 3 -OF-3 SFP COOLING TRAINS FROM UNIT 1 AND $1-O F-3$ SFP COOLING TRAINS FROM UNIT 2 


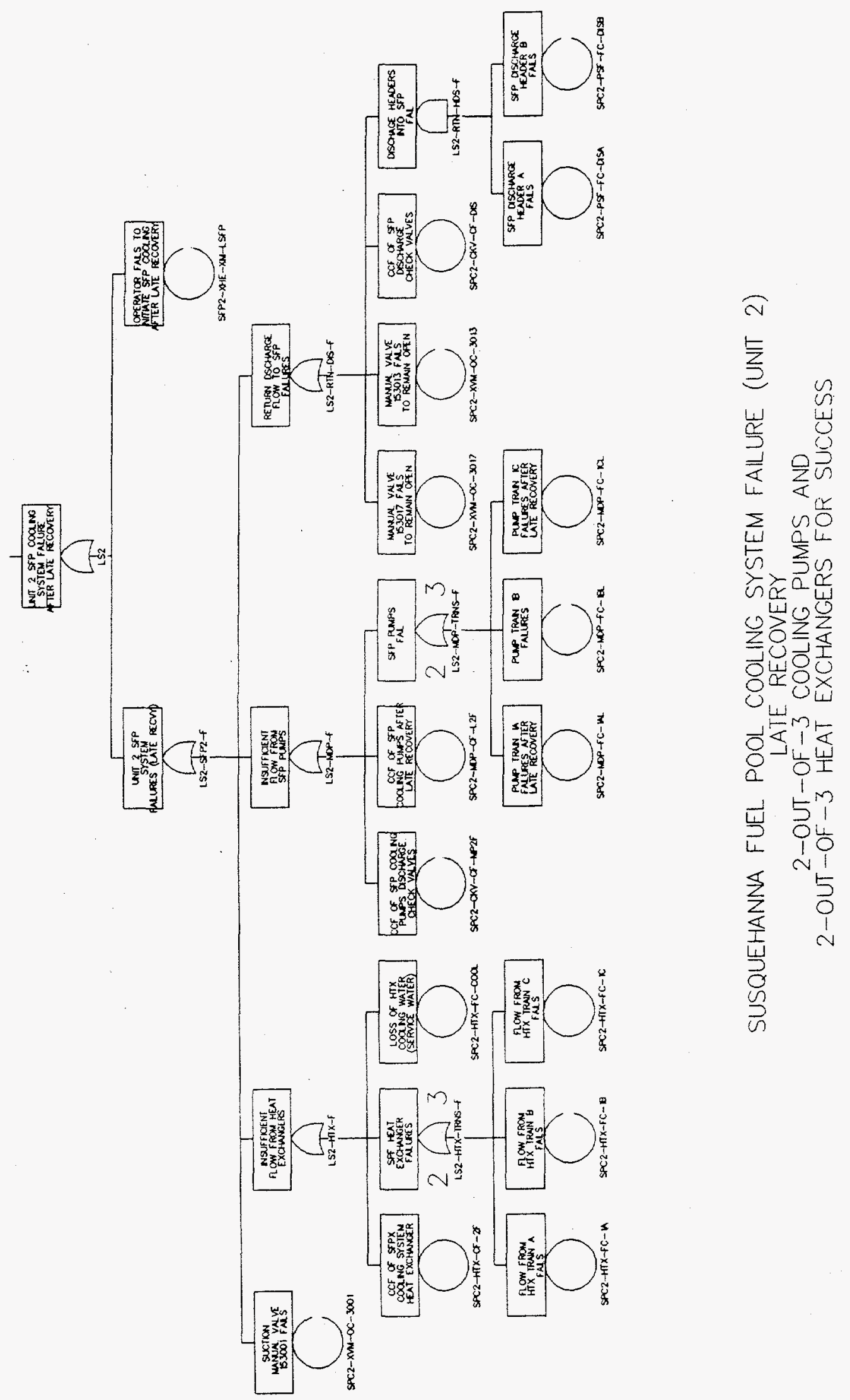




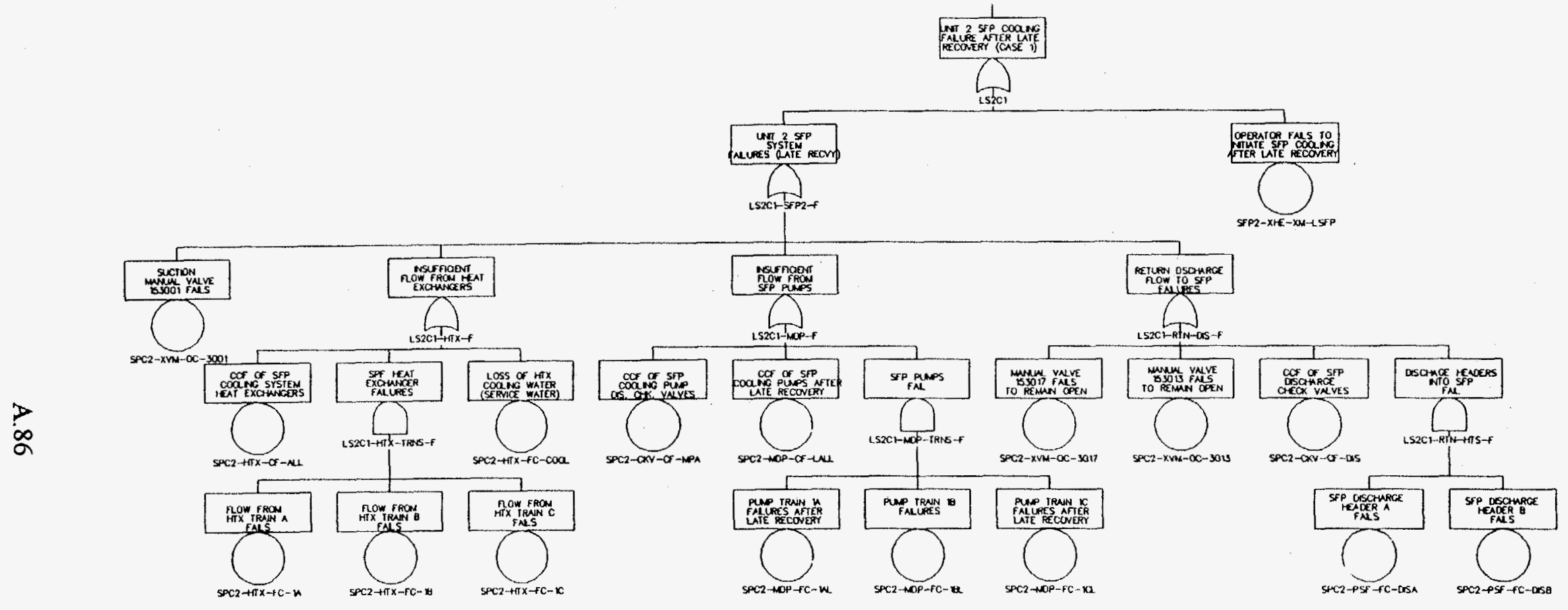

SUSQUEHANNA FUEL POOL COOLING SYSTEM FAILURE (UNIT 2) LATE RECOVERY - CASE 1

1-OUT-OF - 3 COOLING PUMPS AND
1-OUT-OF - 3 HEAT EXCHANGERS FOR SUCCESS 


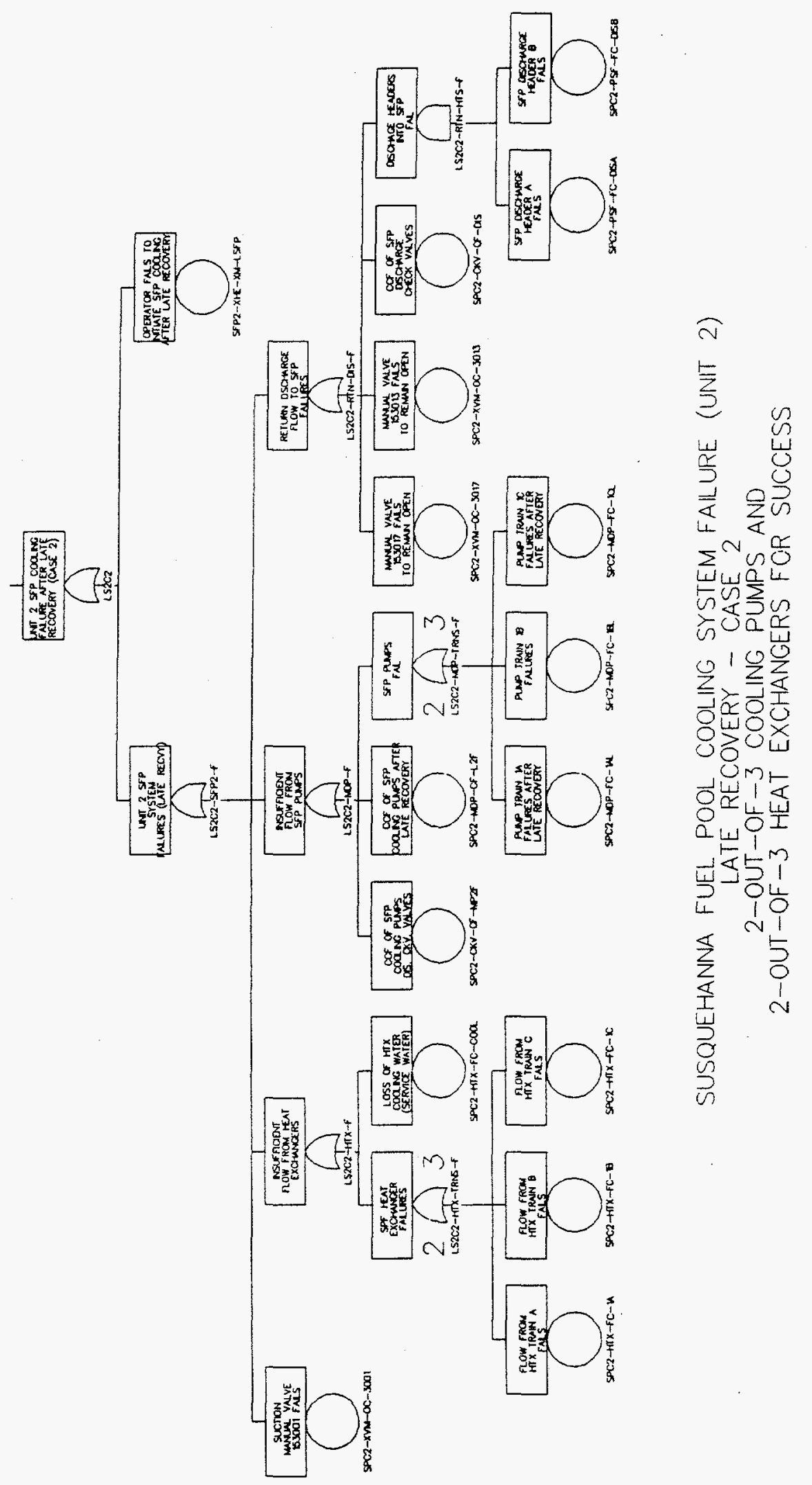




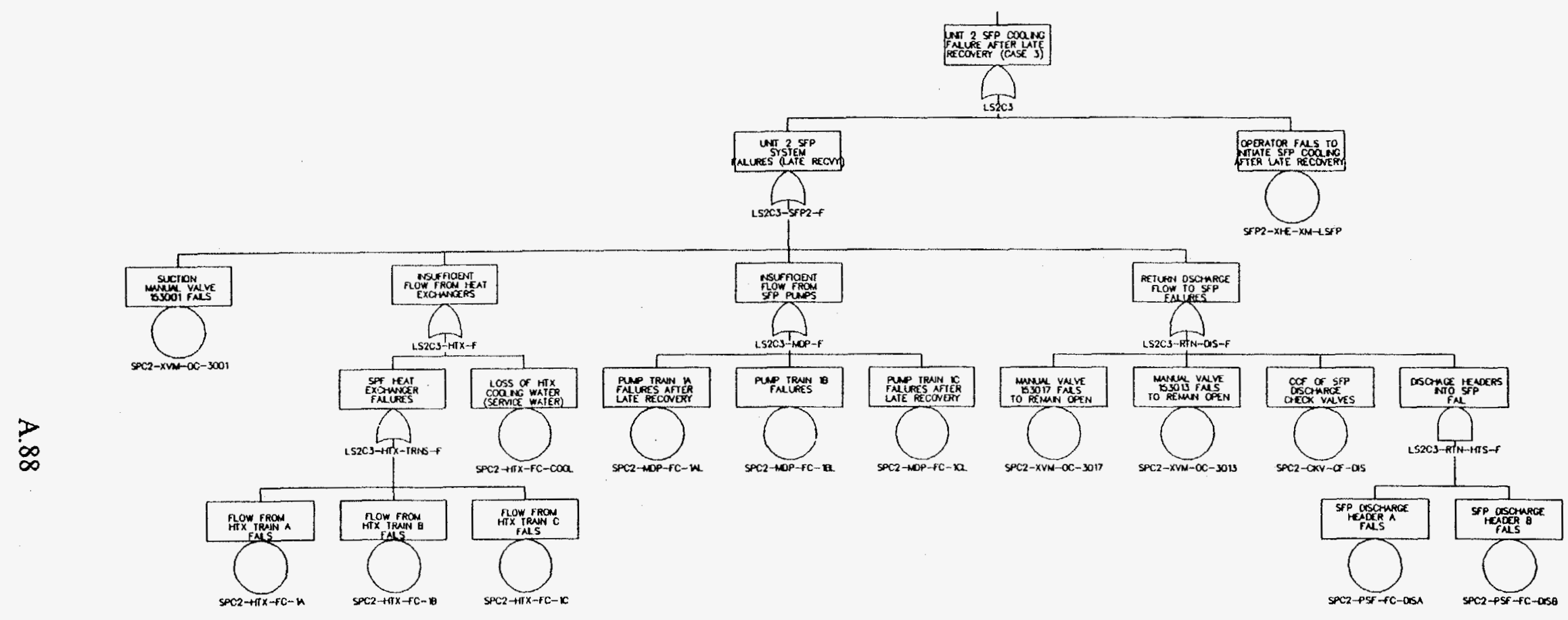

SUSQUEHANNA FUEL POOL COOLING SYSTEM FAILURE (UNIT 2) LATE RECOVERY - CASE 3 3-OUT-OF-3 COOLING PUMPS AND

3-OUT-OF - 3 HEAT EXCHANGERS FOR SUCCESS 


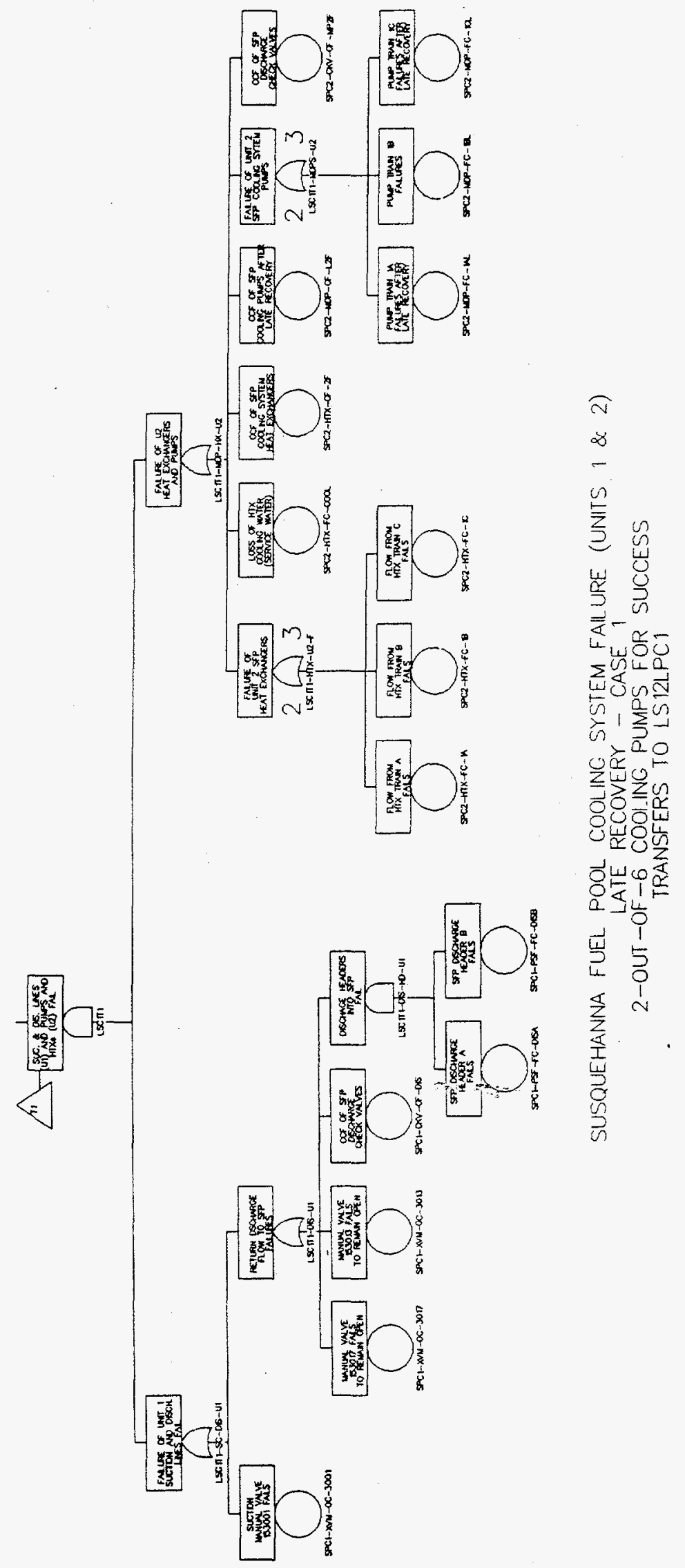

A. 89 



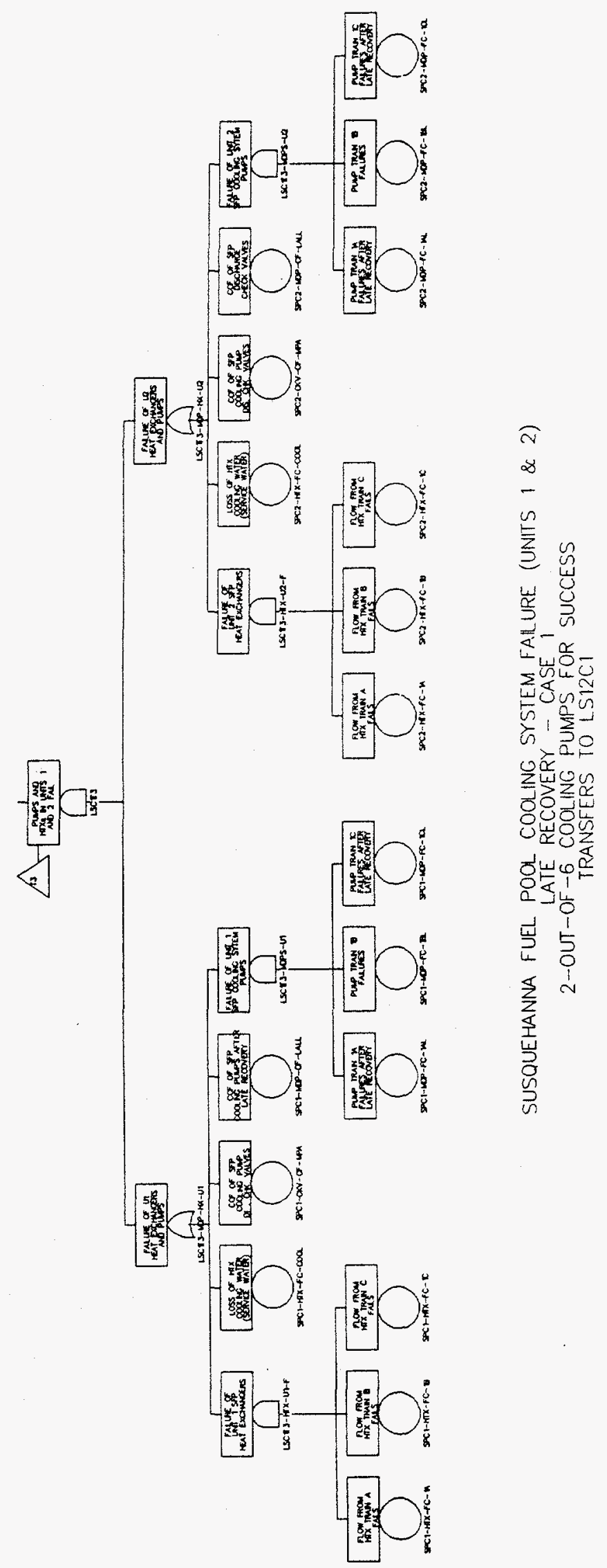

A. 91 


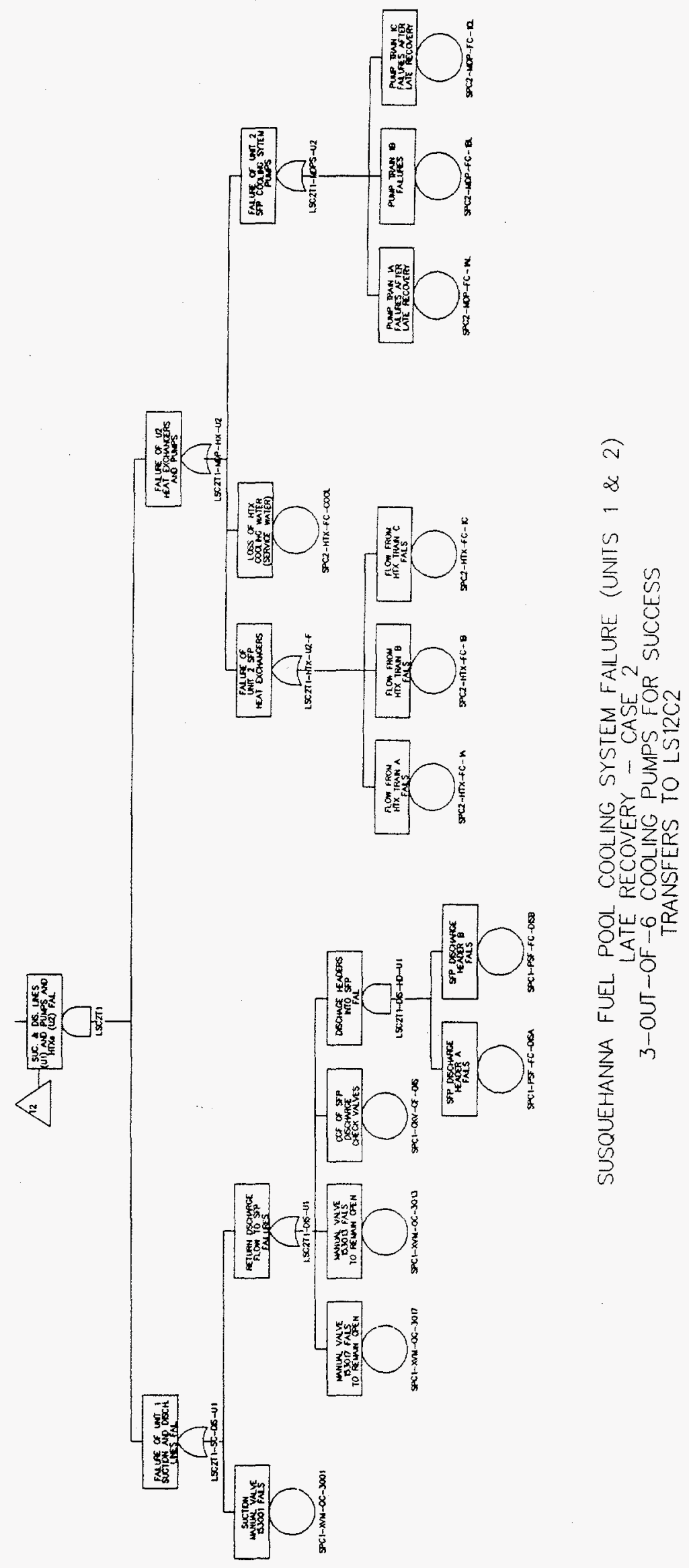

A. 92 


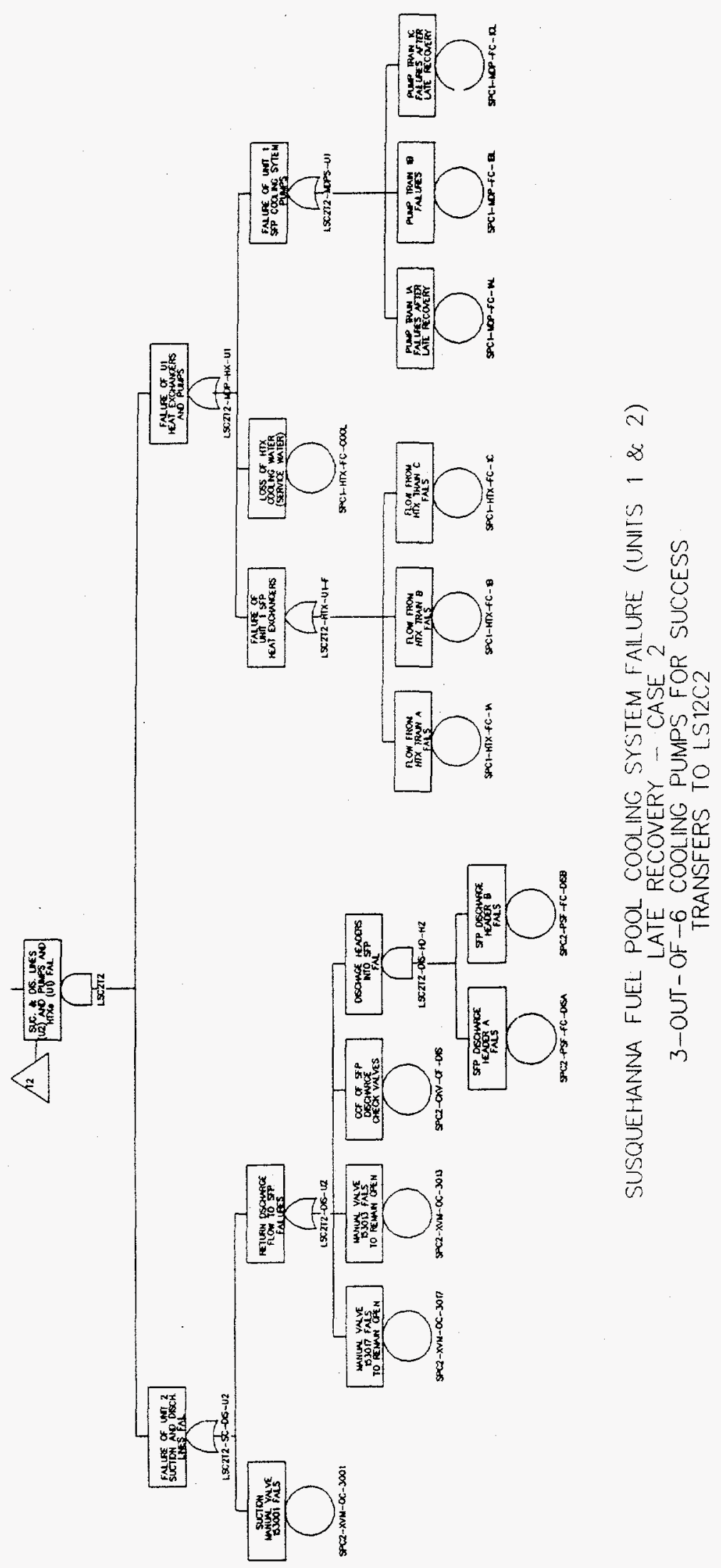

A. 93 


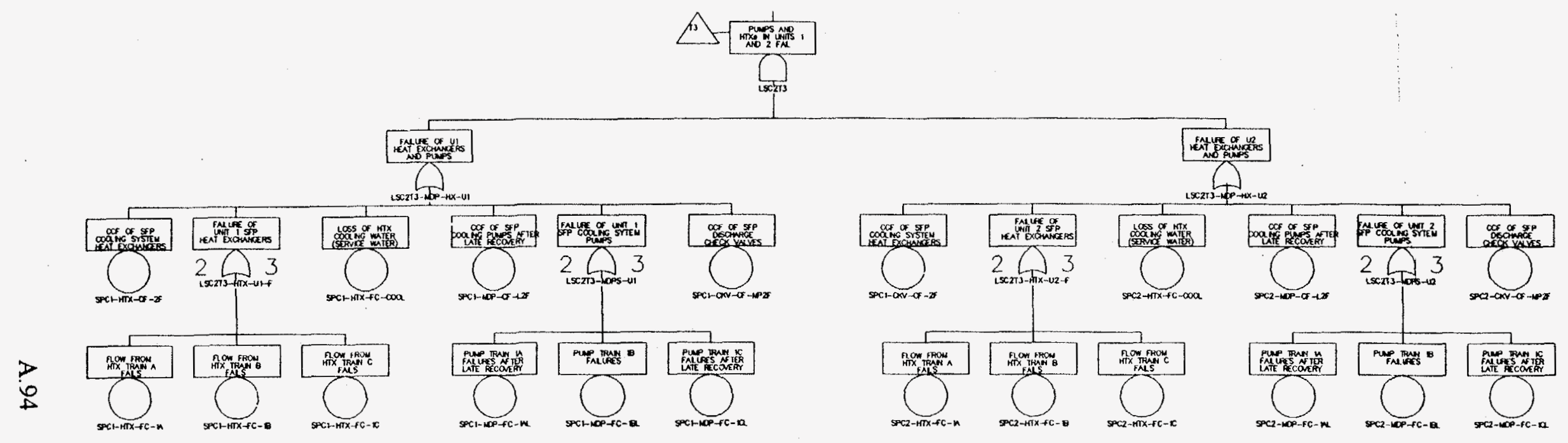

SUSQUEHANNA FUEL POOL COOLING SYSTEM FAILURE (UNITS 1 \& 2 )

LATE RECOVERY - CASE
3-OUT-OF-6 COOLING PUMPS FOR

TRANSFERS TO LS12C2 


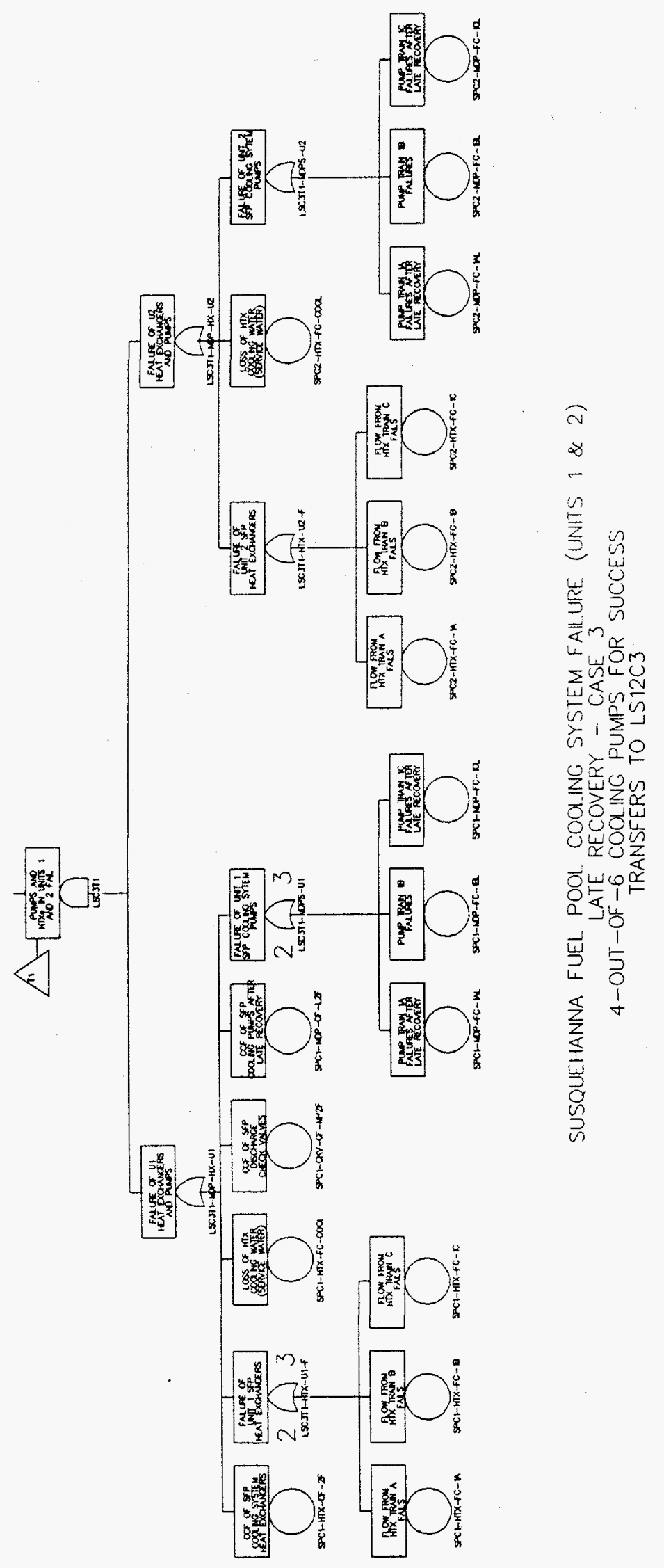

A. 95 


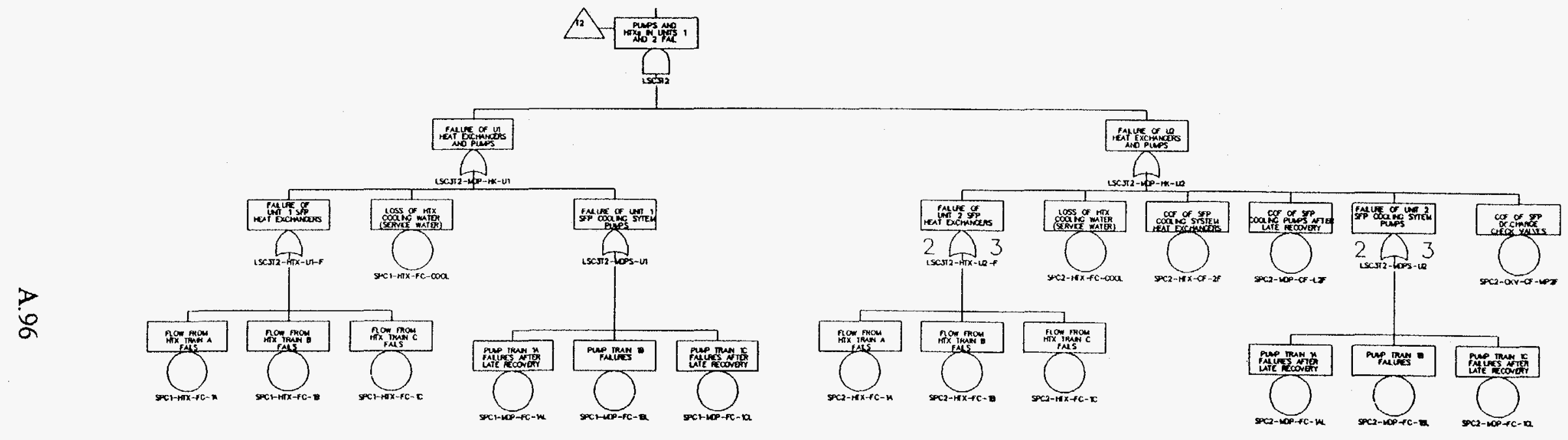

SUSQUEHANNA FIJEL POOL COOLING SYSTEM FALURE (UNITS 1 \& 2 )

LATE RECOVERY - CASE 3
4-OUT-OF -6 COOLING PUMPS FOR SUCCESS
TRANSFERS TO LS12C 3 


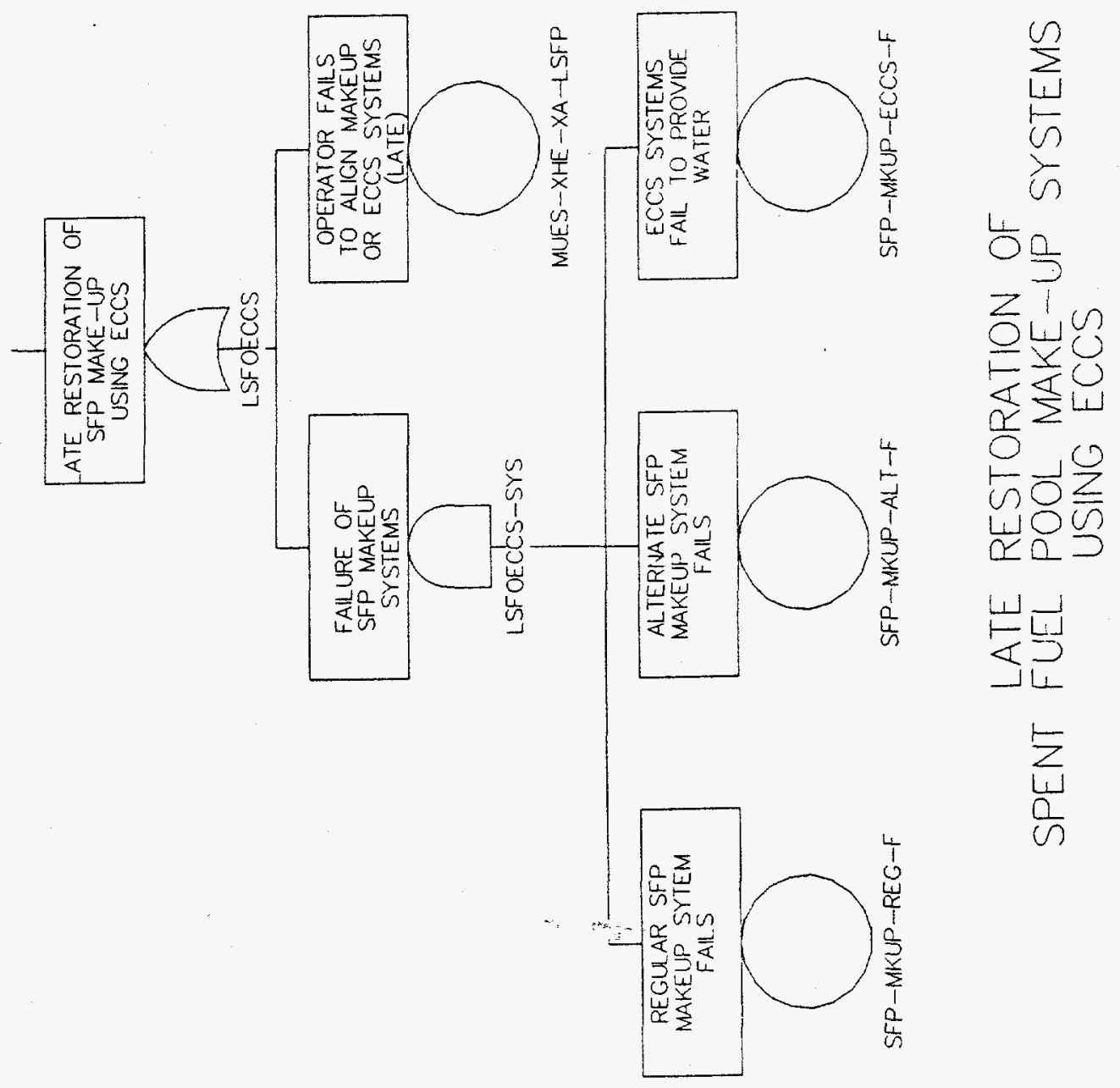




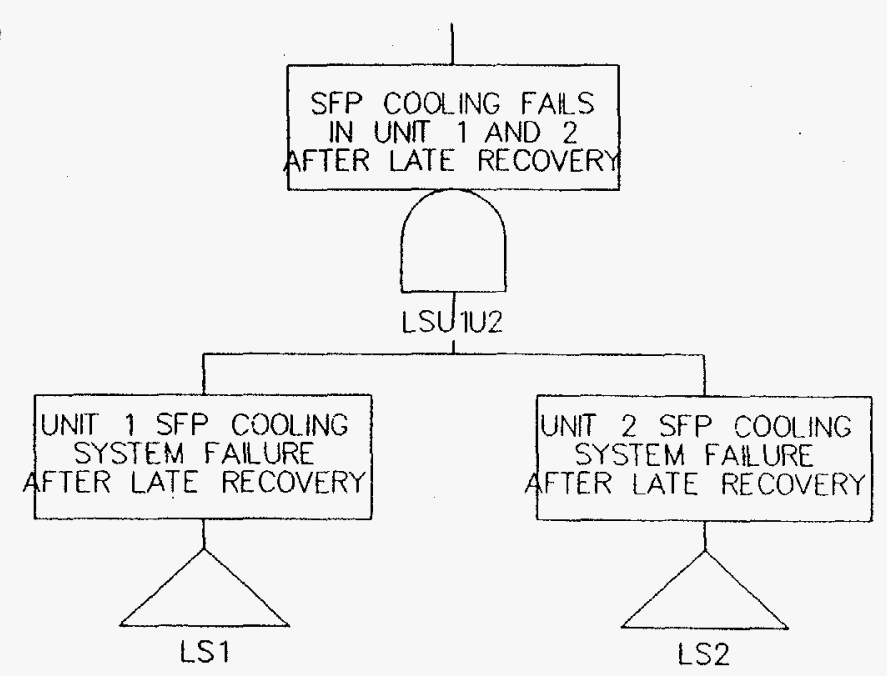

\footnotetext{
SPENT FUEL POOL COOLING SYSTEMS FOR UNITS 1 AND 2 (LATE RECOVERY) SUCCESS REQUIRES ONE OF TWO SPENT FUEL POOL COOLING SYSTEMS FROM EITHER UNIT
} 

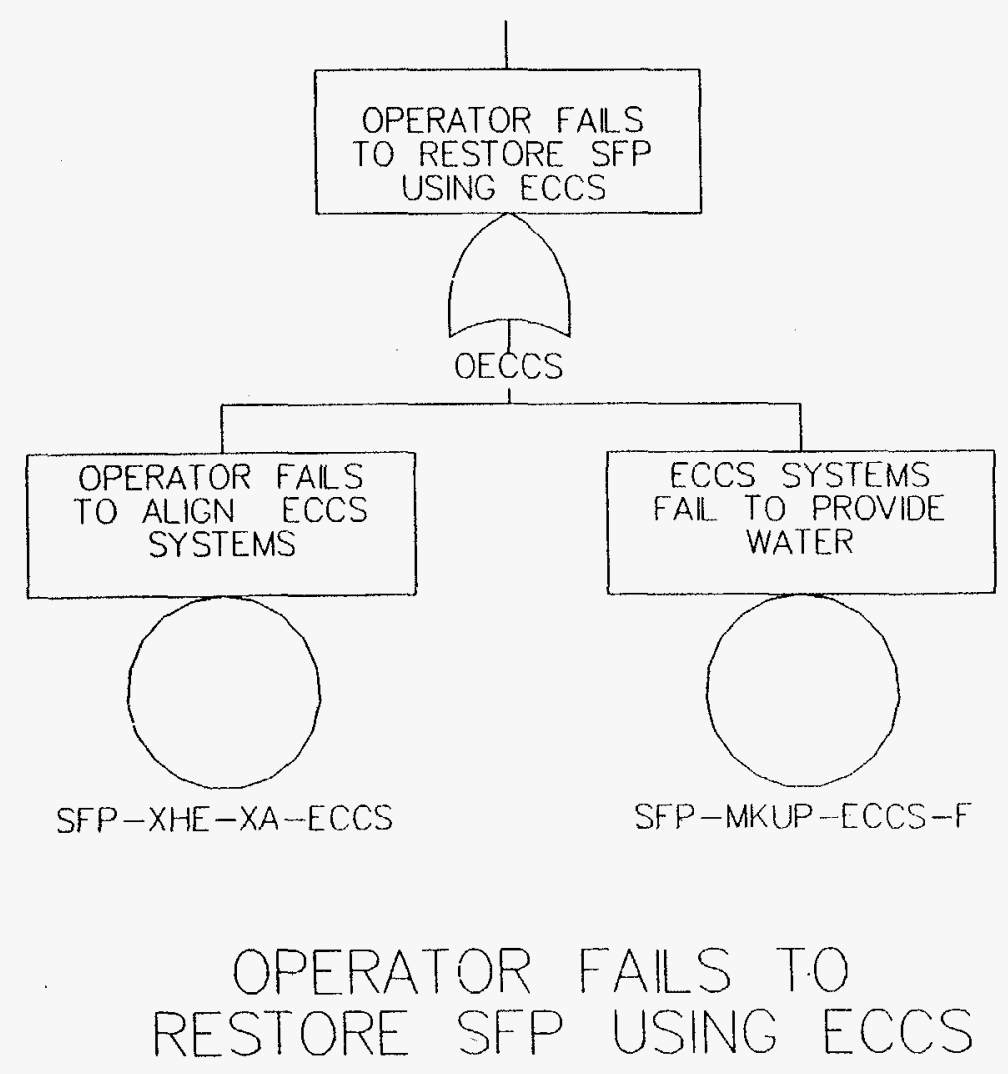


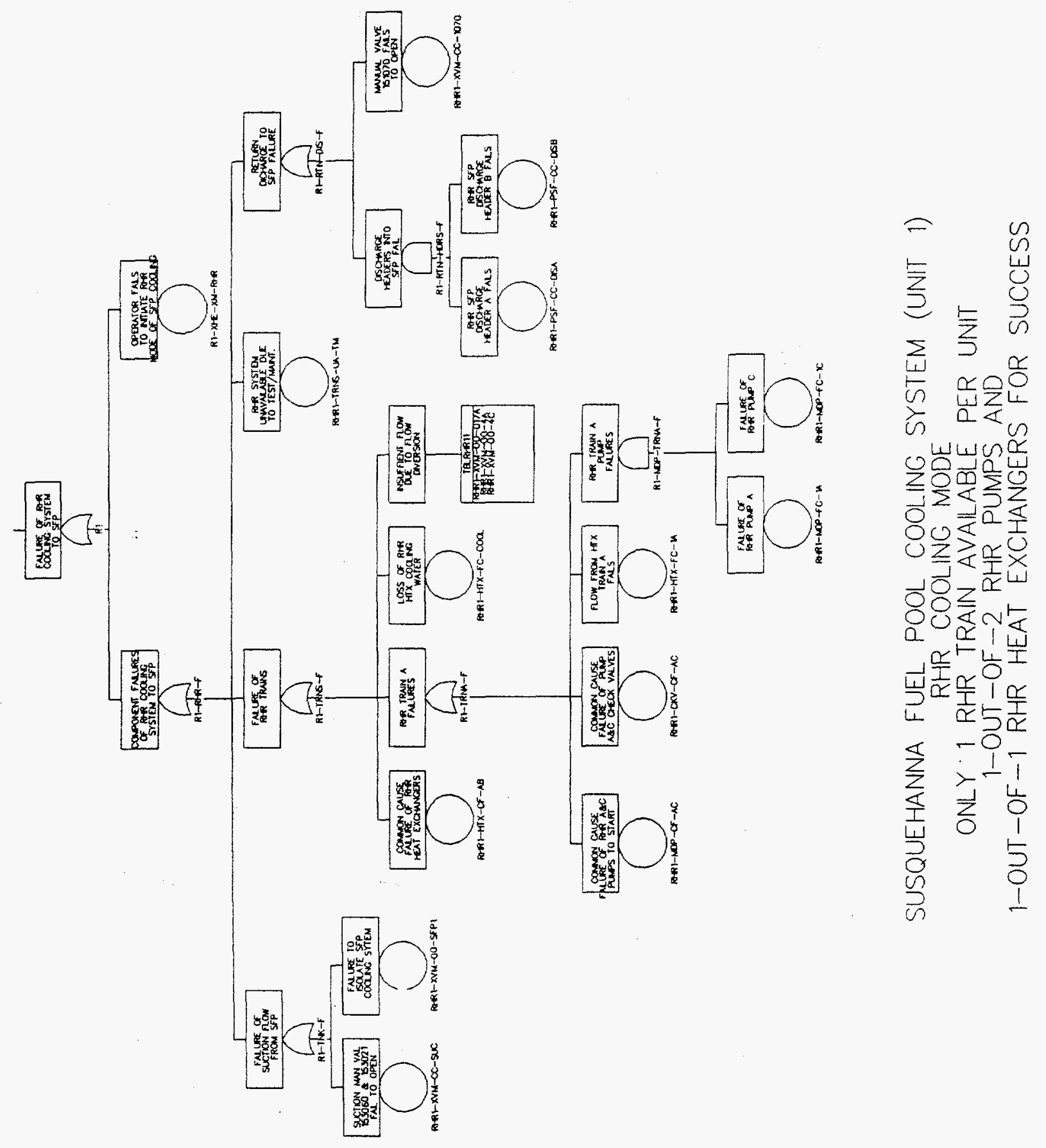




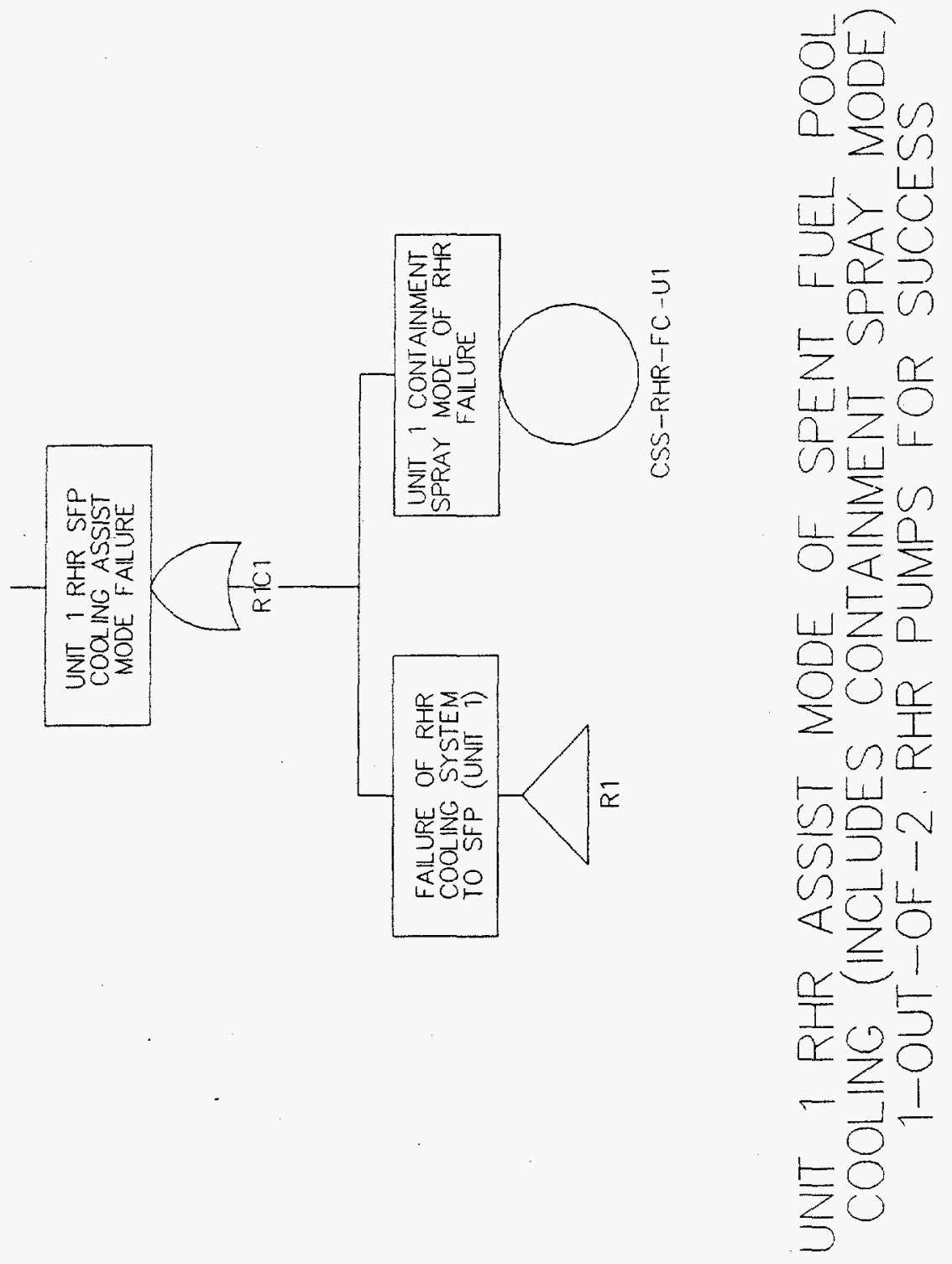

A. 101 


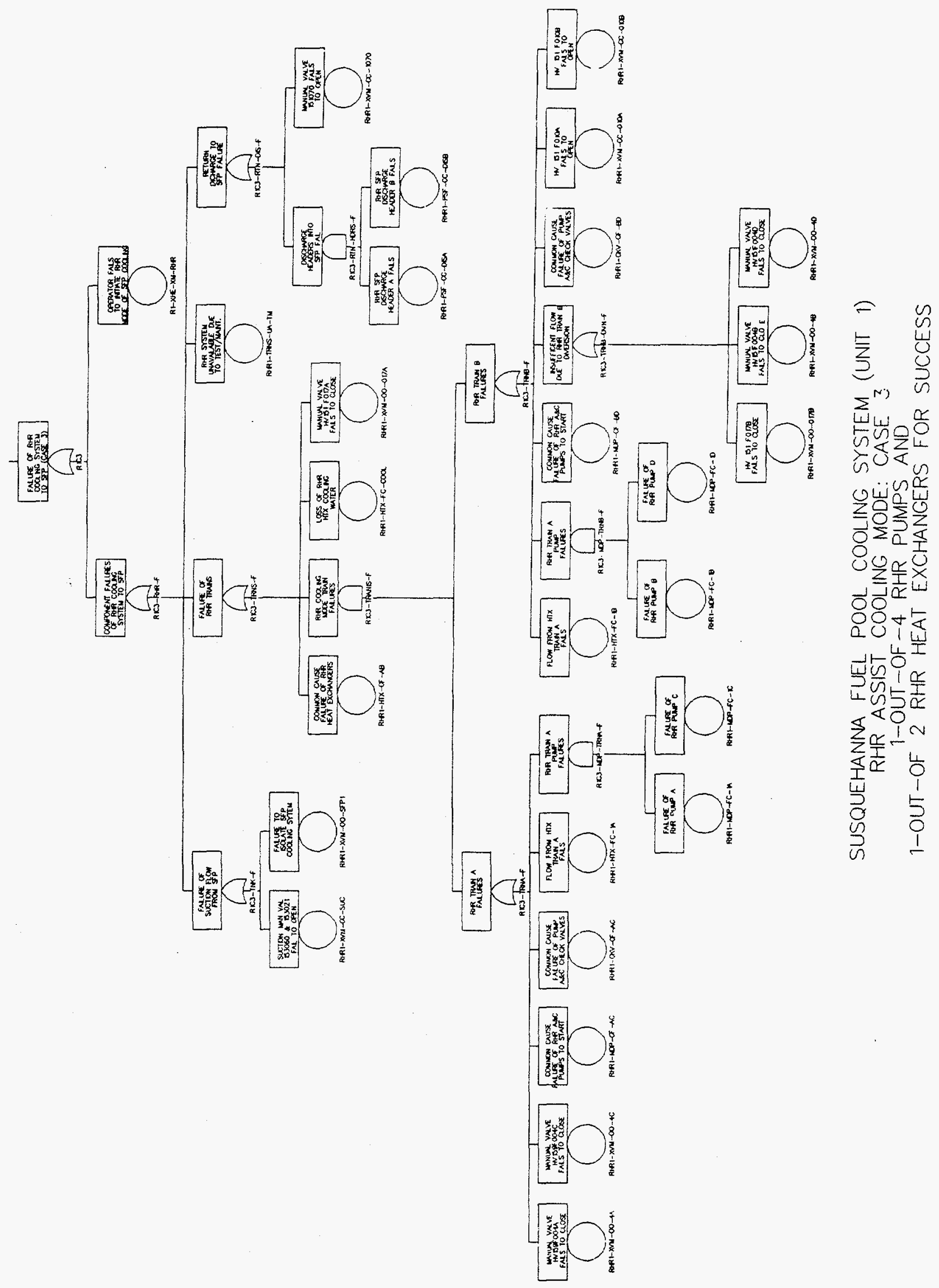

A. 102 


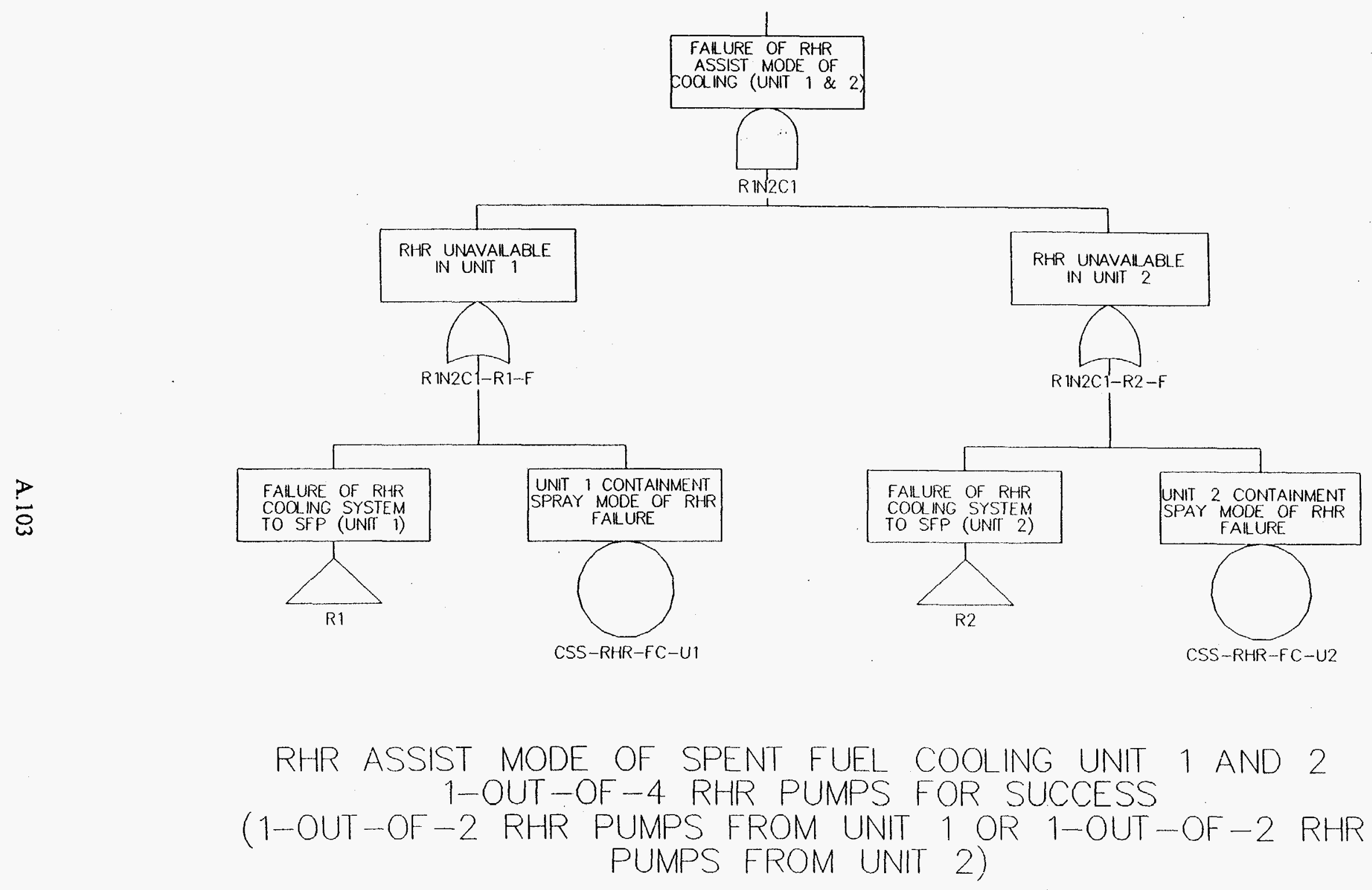




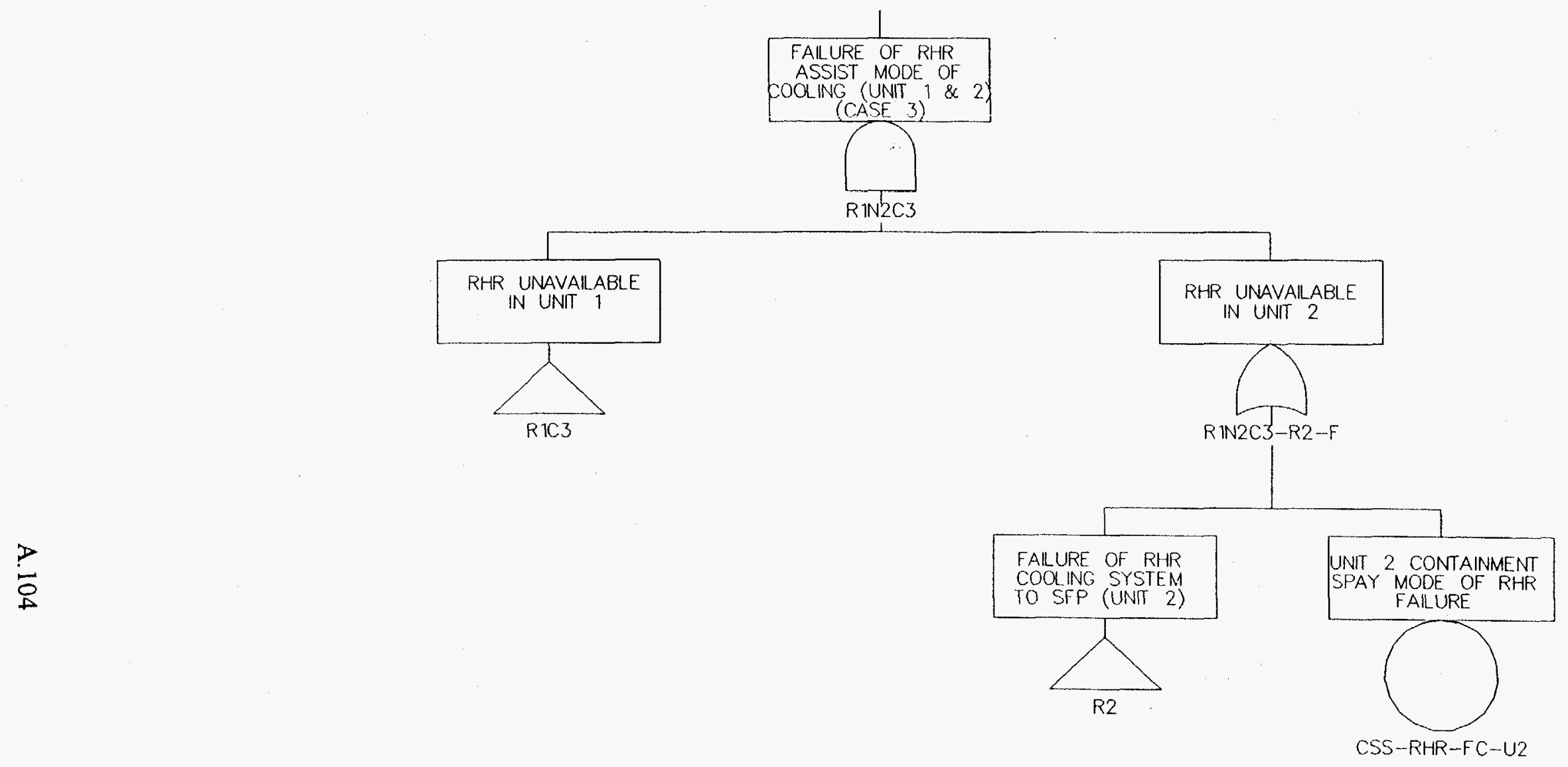

RHR ASSIST MODE OF SPENT FUEL COOLING UNIT 1 AND 2 CASE 3

1-OUT-OF-4. RHR PUMPS FROM UNIT 1 OR 1-OUT-OF-2 RHR PUMPS FROM UNIT 2 FOR SUCCESS 


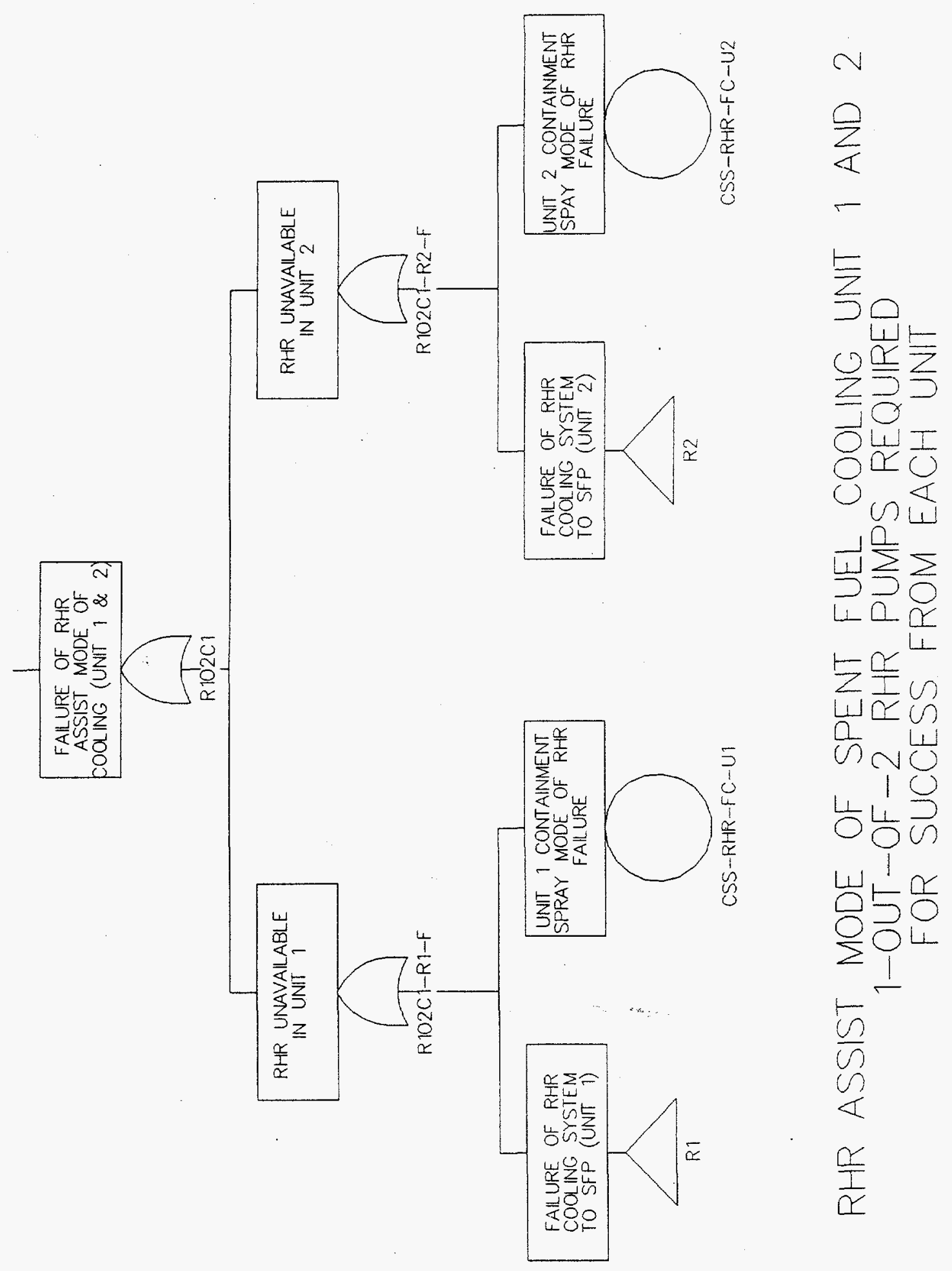

A. 105 


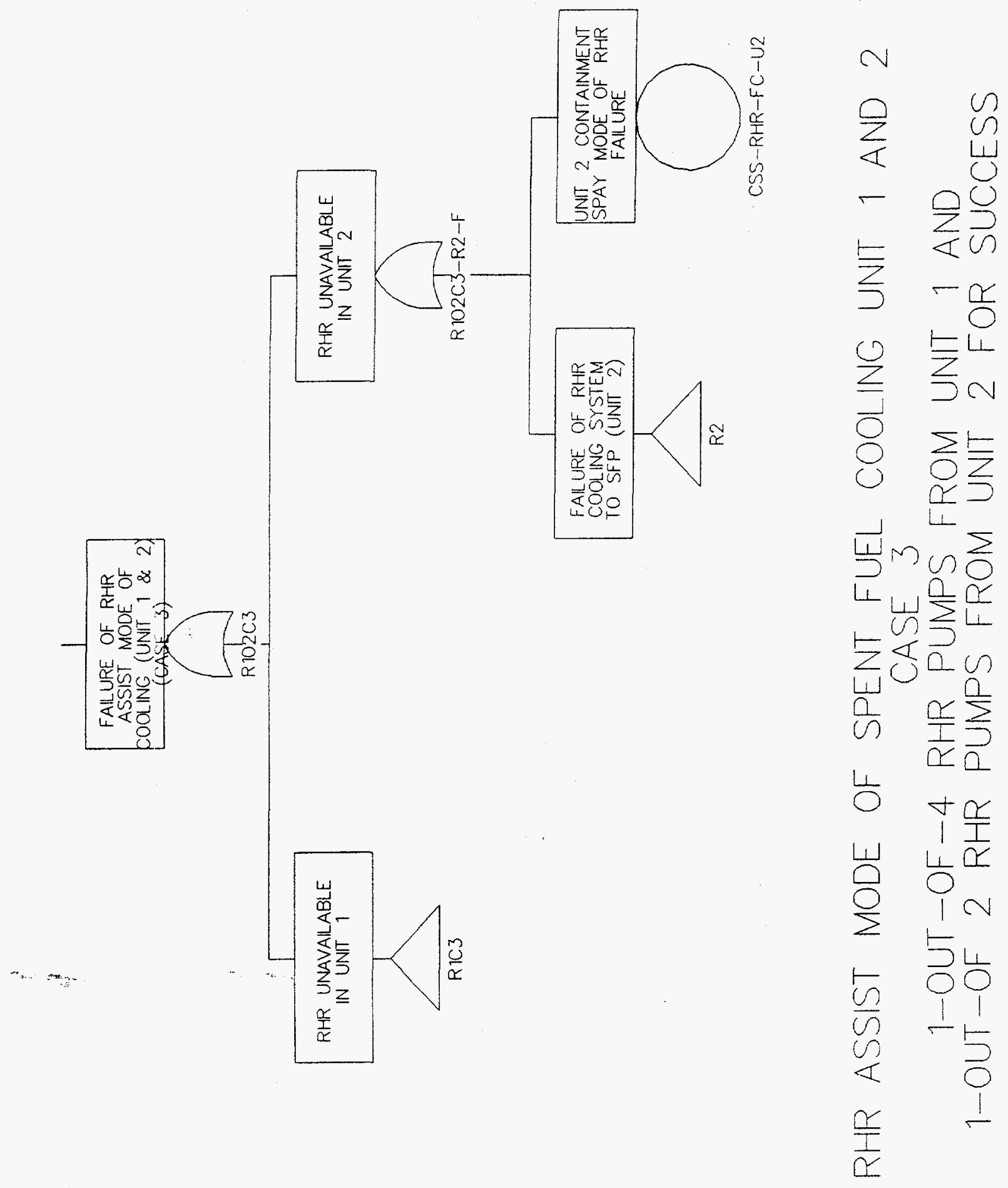




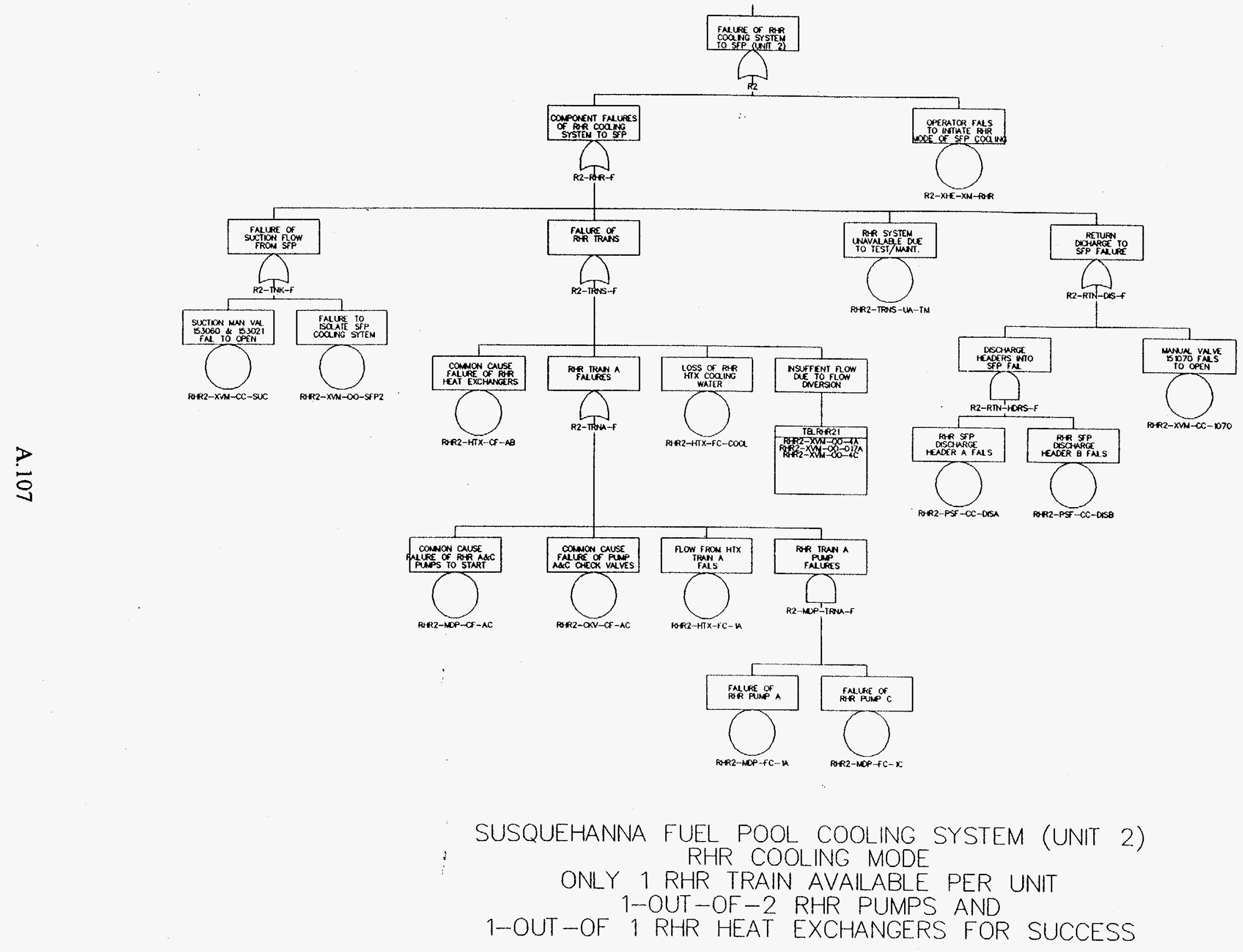




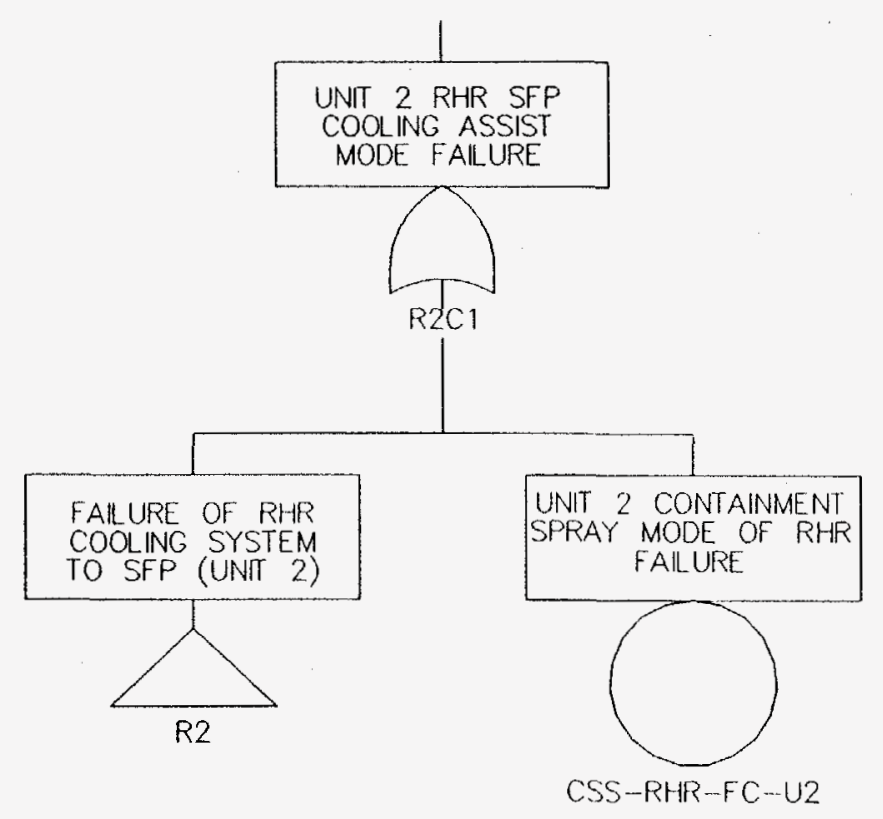

UNIT 2 RHR ASSIST MODE OF SPENT FUEL POOL COOLING (INCLUDES CONTAINMENT SPRAY MODE) 1-OUT-OF-2 RHR PUMPS FOR SUCCESS 

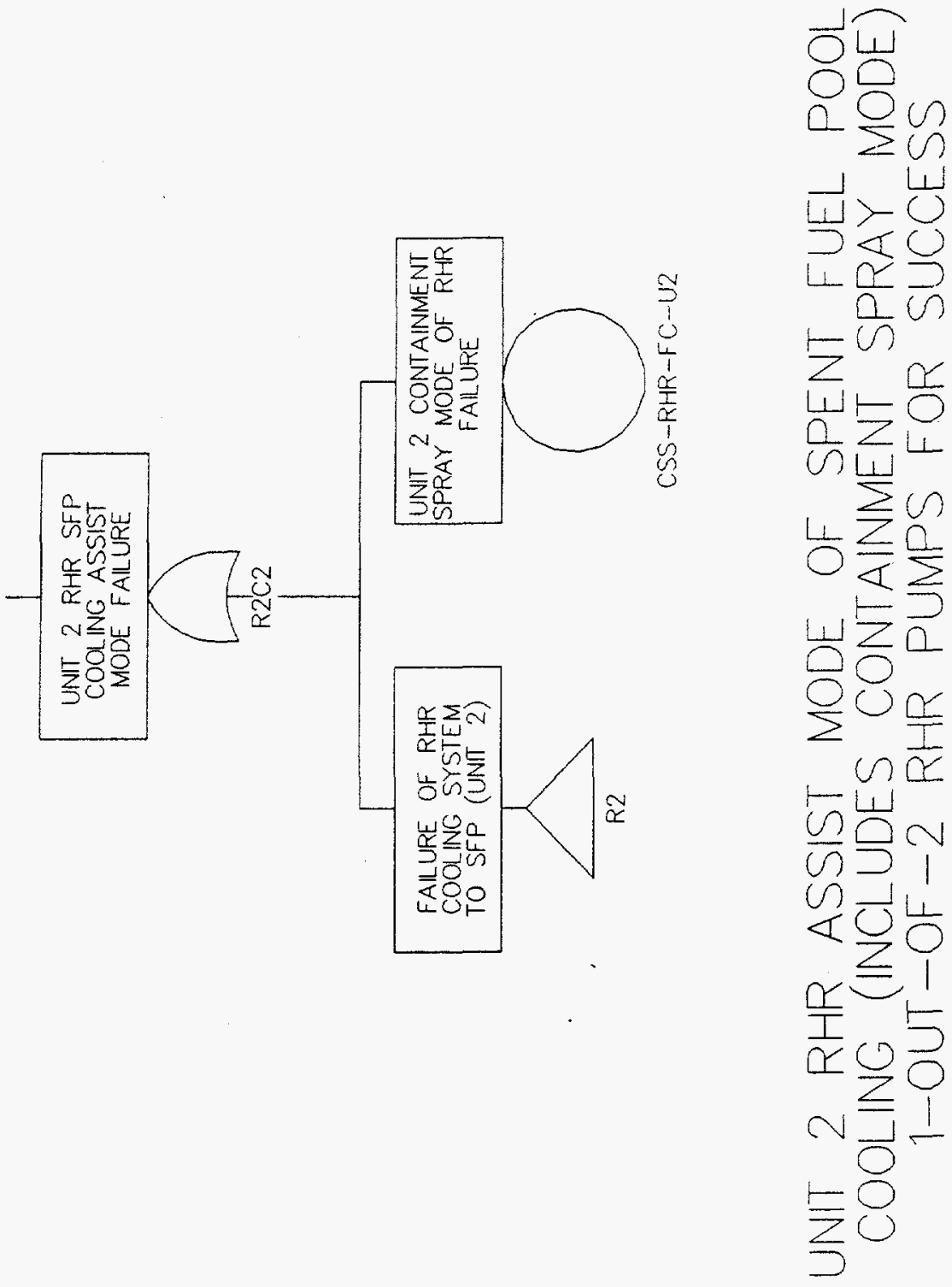


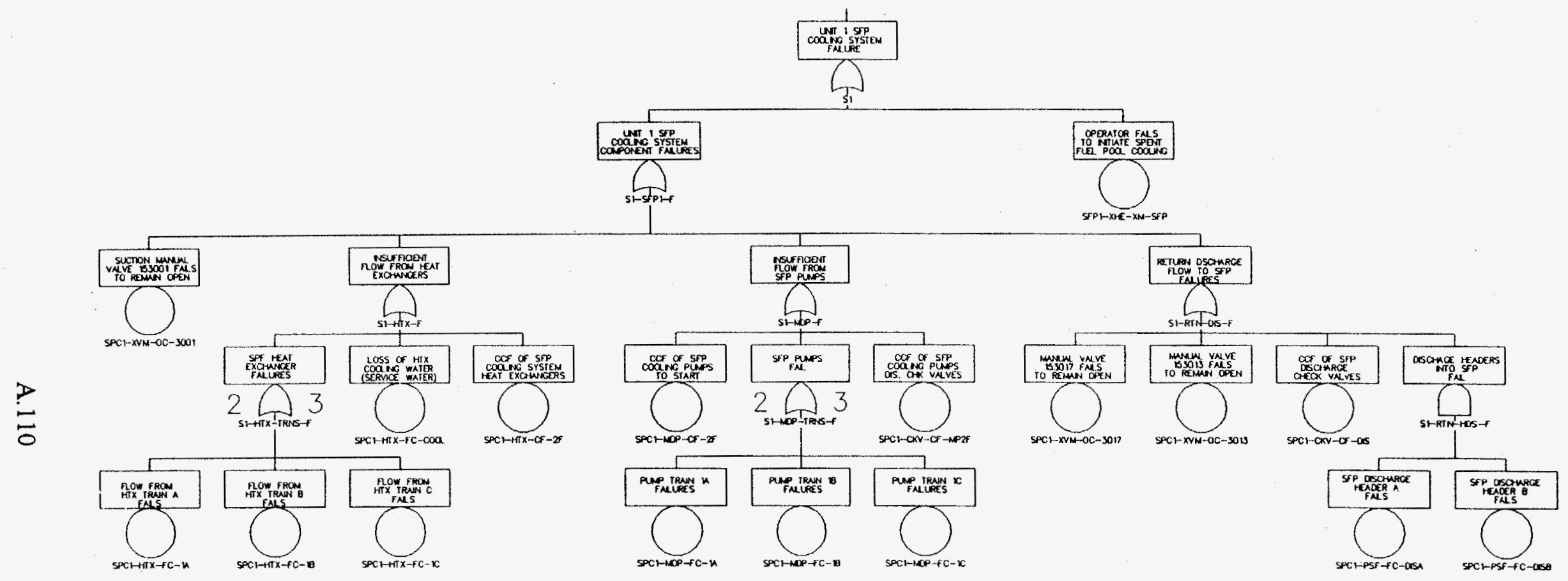

SUSQUEHANNA FUEL POOL COOLING SYSTEM FAILURE (UNIT 1) ONE REFUELING - ONE OPERATING

2-OUT-OF -3 COOLING PUMPS FOR SUCCESS

2-OUT-OF-3 HEAT EXCHANGERS FOR SUCCESS 


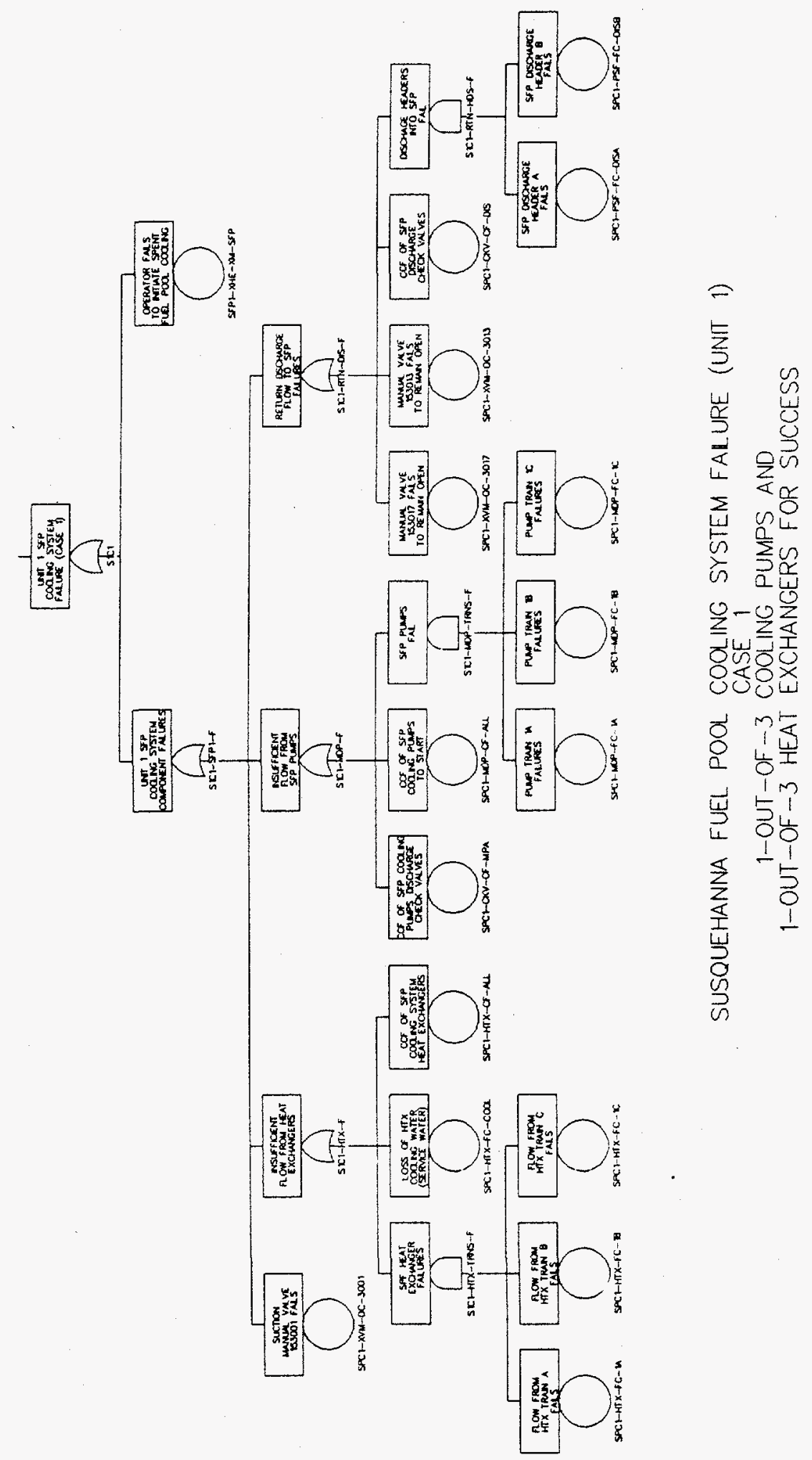




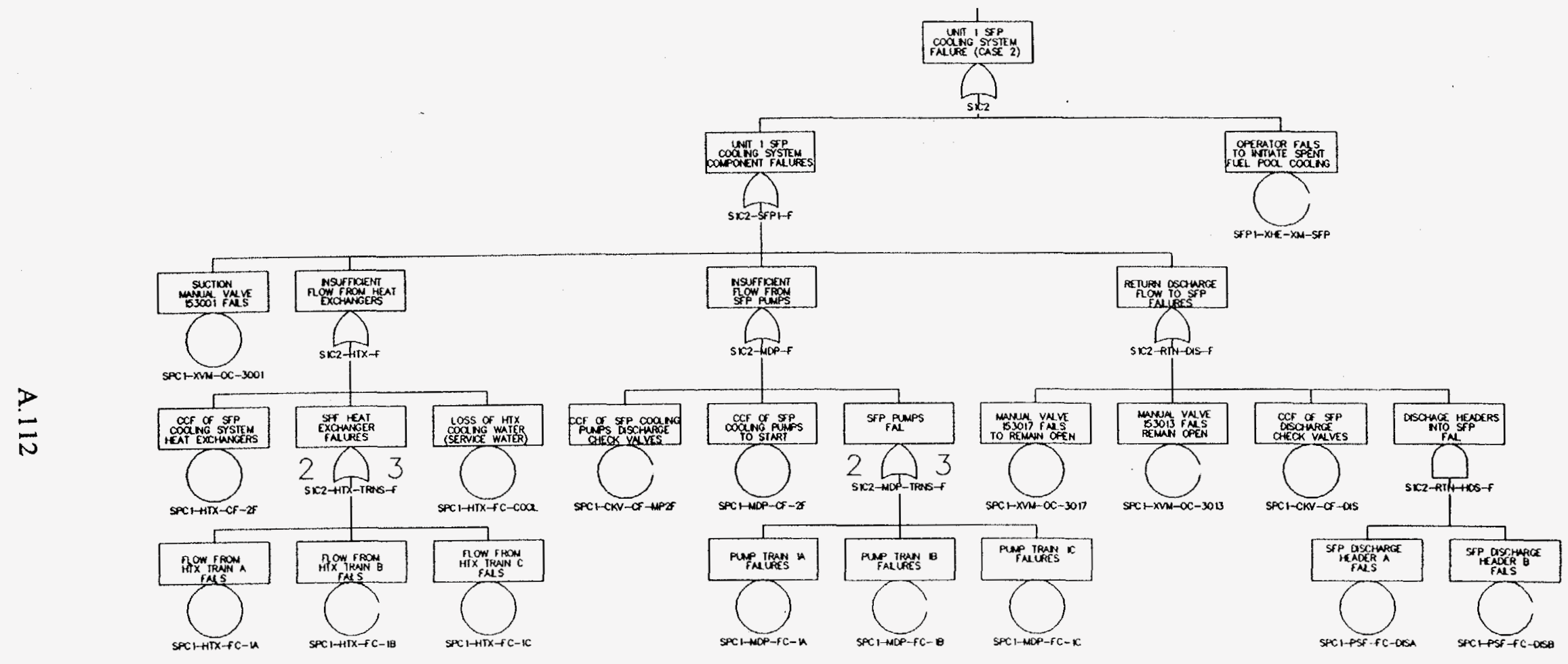

SUSQUEHANNA FUEL POOL COOLING SYSTEM FAILURE (UNIT 1) CASE 2

2-OUT-OF-3 COOLING PUMPS AND

2-OUT-OF-3 HEAT EXCHANGERS FOR SUCCESS 


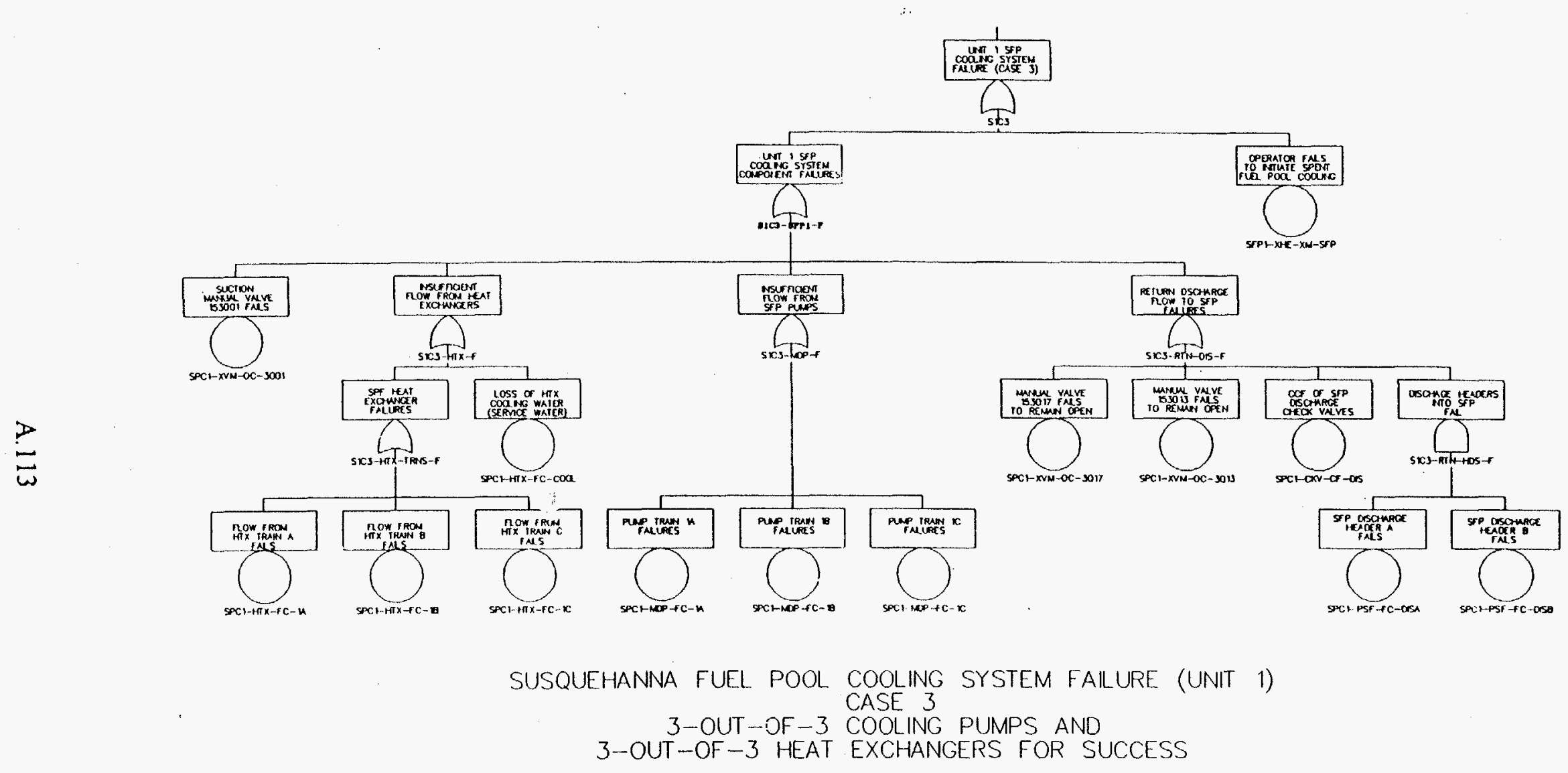




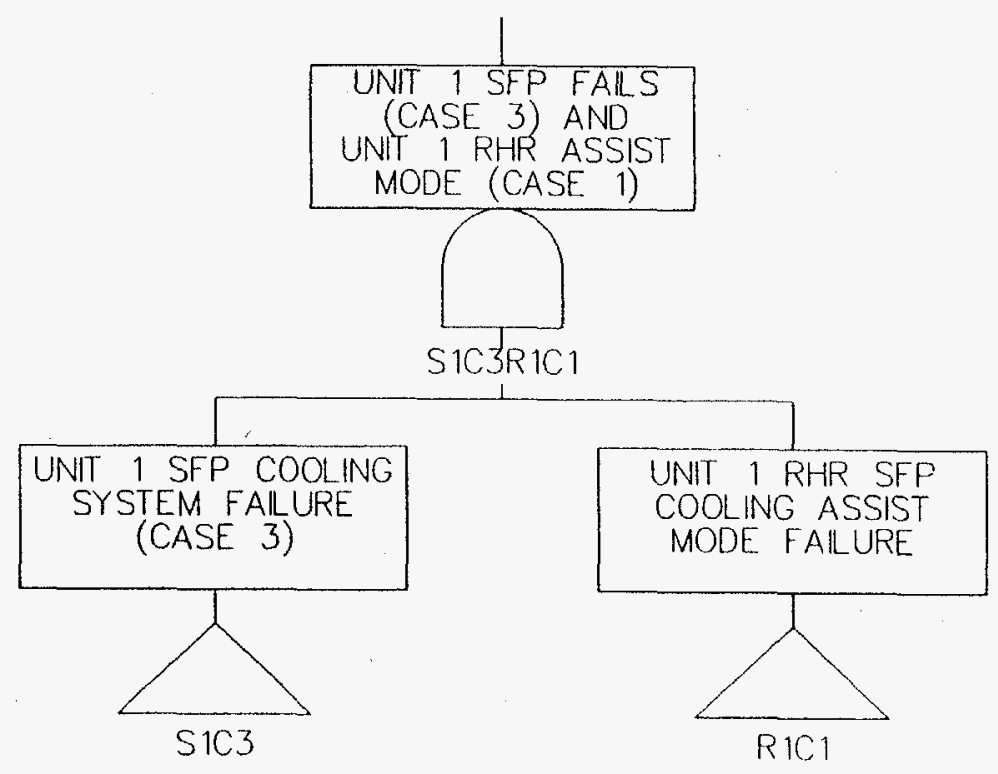

SPENT FUEL POOL COOLING SYSTEMS FOR UNIT 1. SUCCESS REQUIRES UNIT 1 SFP COOLING SYSTEM (CASE 1) OR UNIT 1 RHR ASSIST MODE (CASE 1) 


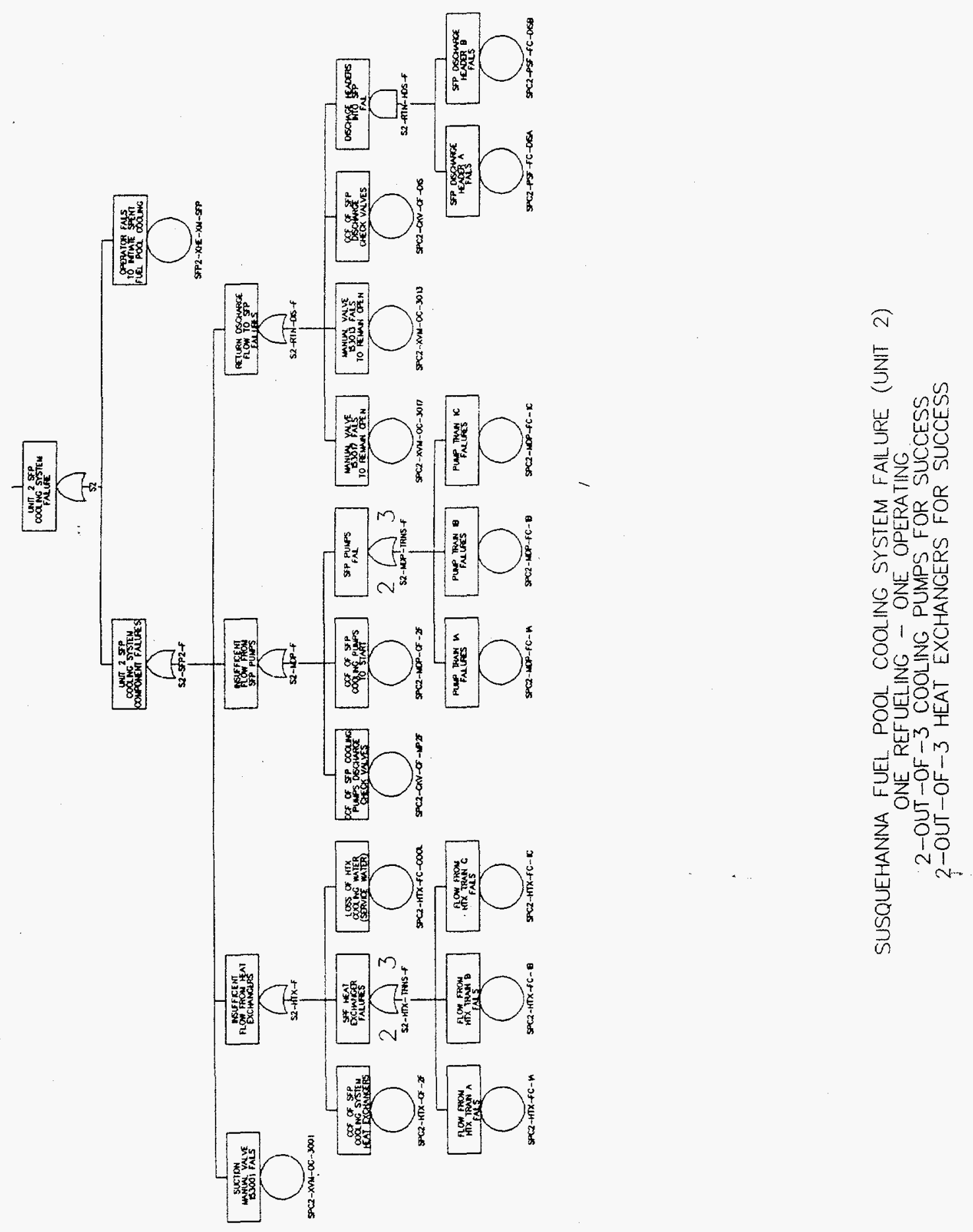




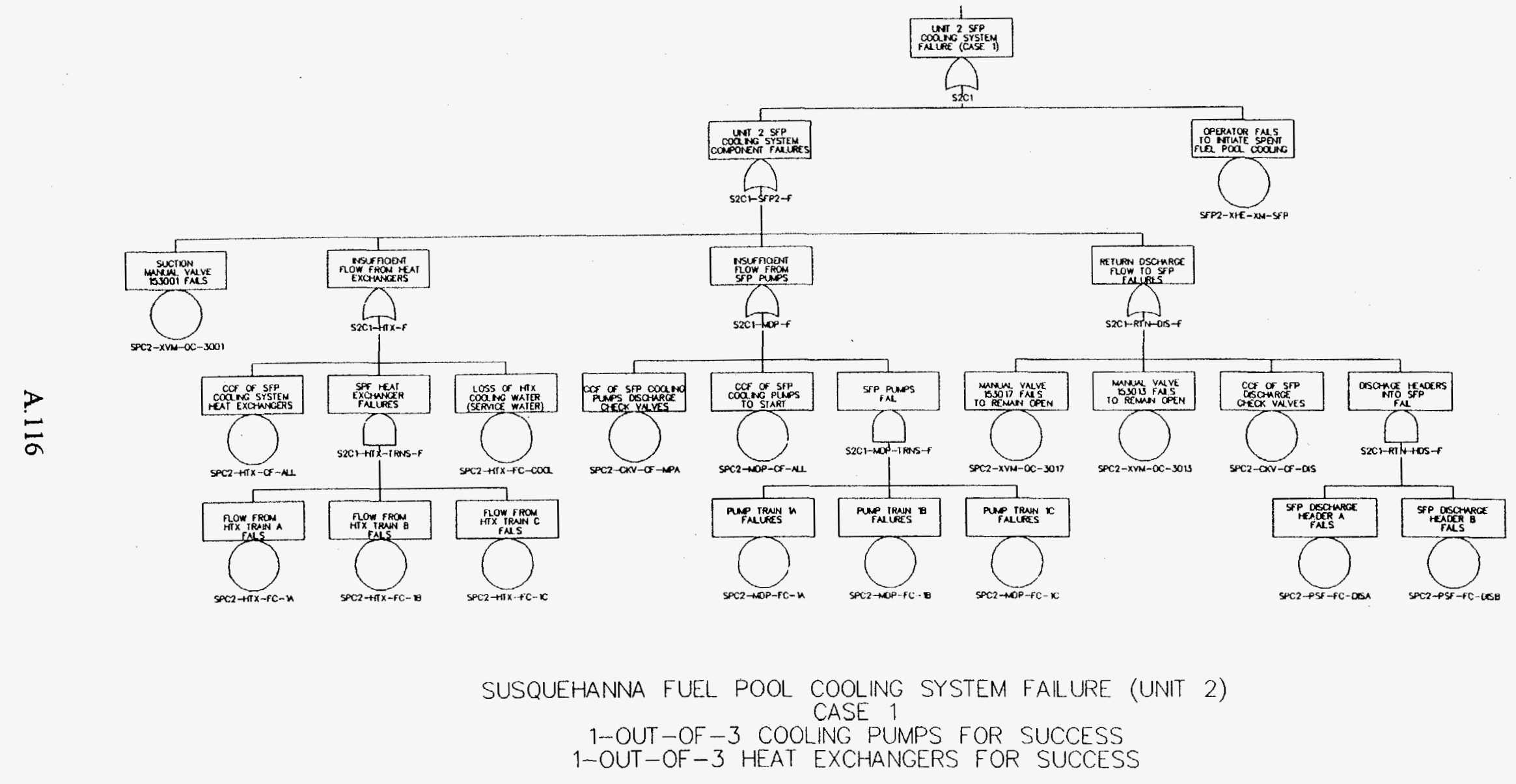




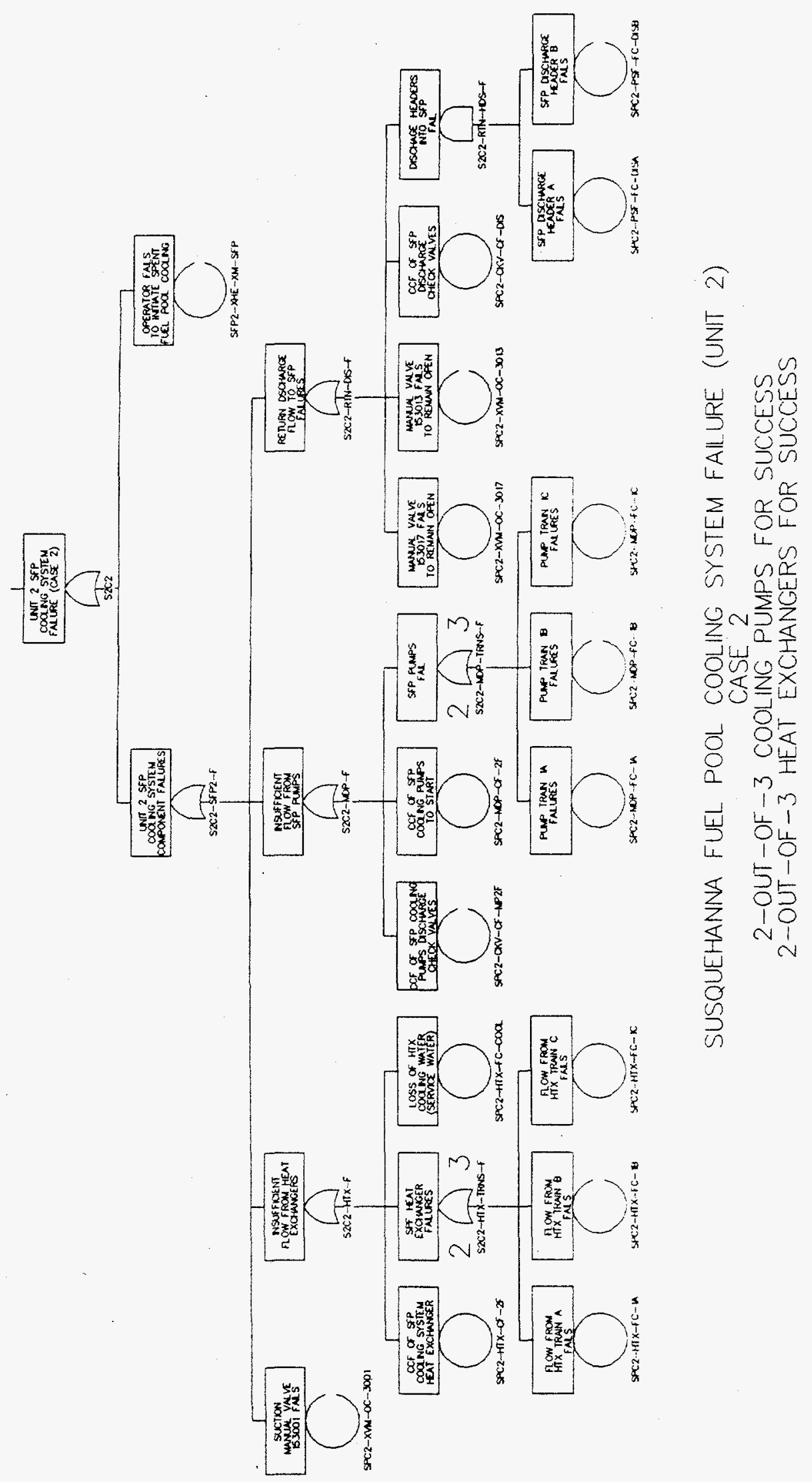

A. 117 


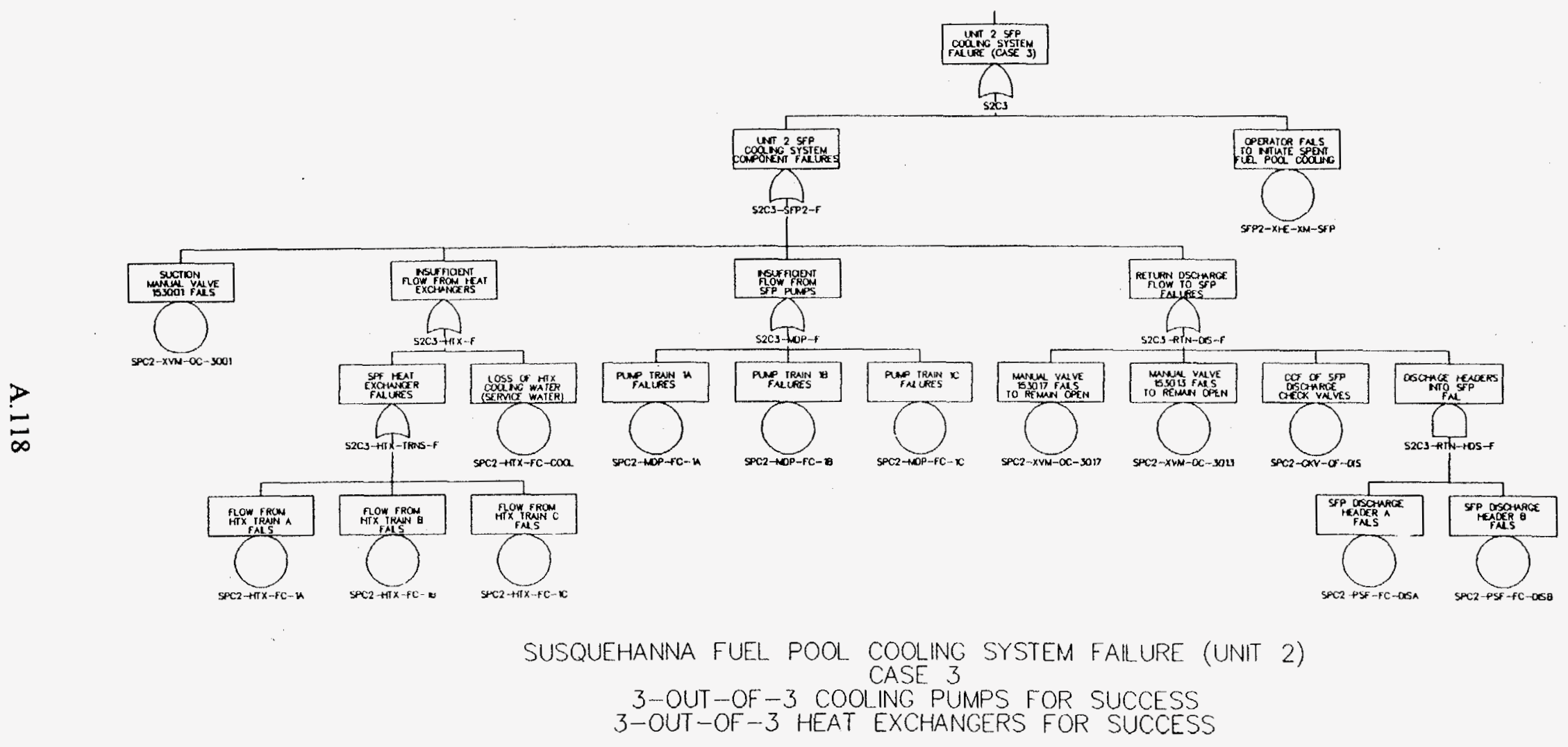




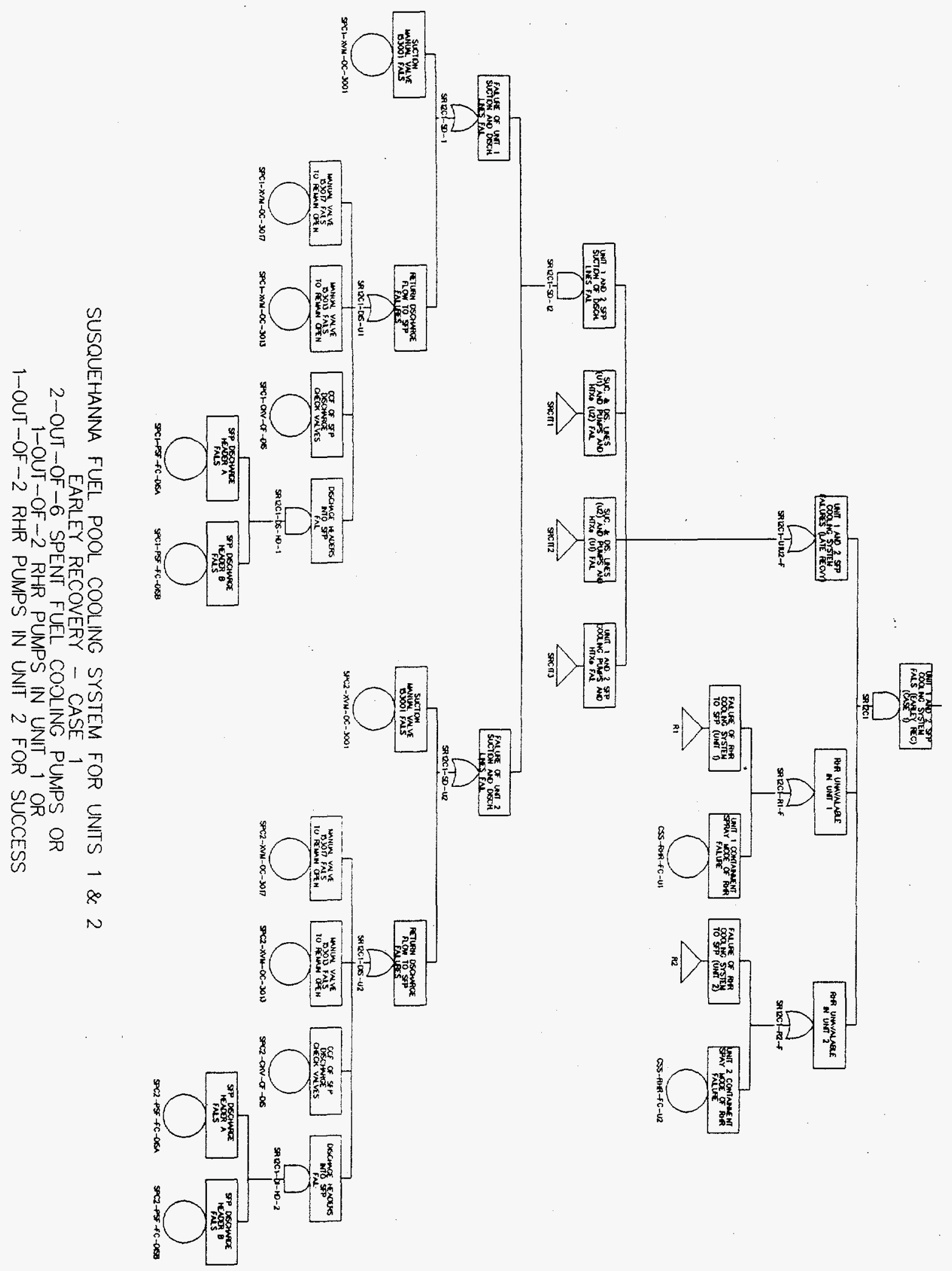




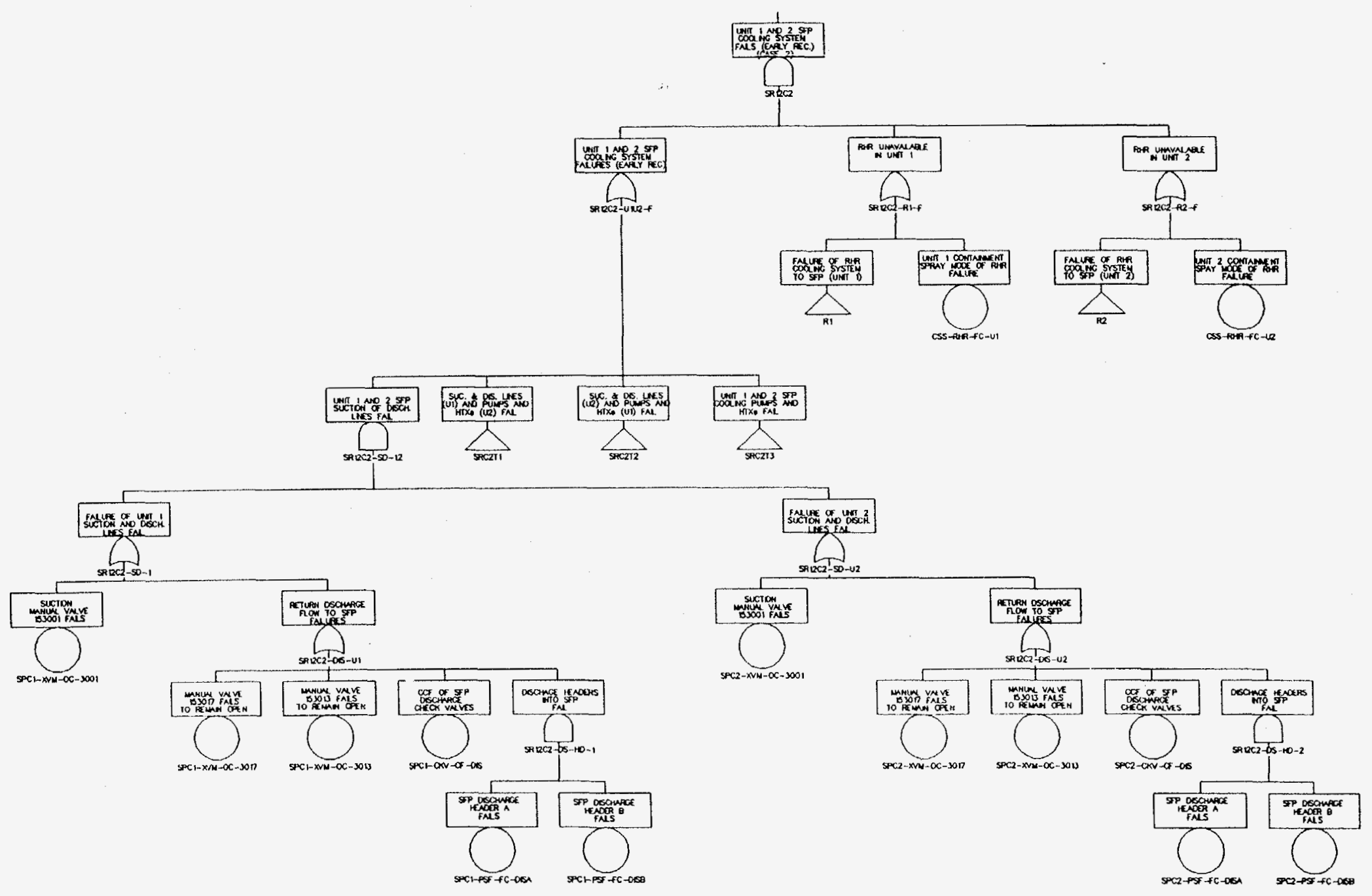

SUSQUEHANNA FUEL POOL COOLING SYSTEM FOR UNITS 1 \& 2

EARLY RECOVERY - CASE 2

3-OUT-OF-6 SPENT FUEL COOLING PL'MPS OR

1 1-OUT-OF-2. RHR PUMPS IN UNIT 1 OR

$1-O U T-O F-2$ RHR PUMPS IN UNIT 1 FOR SUCCESS 


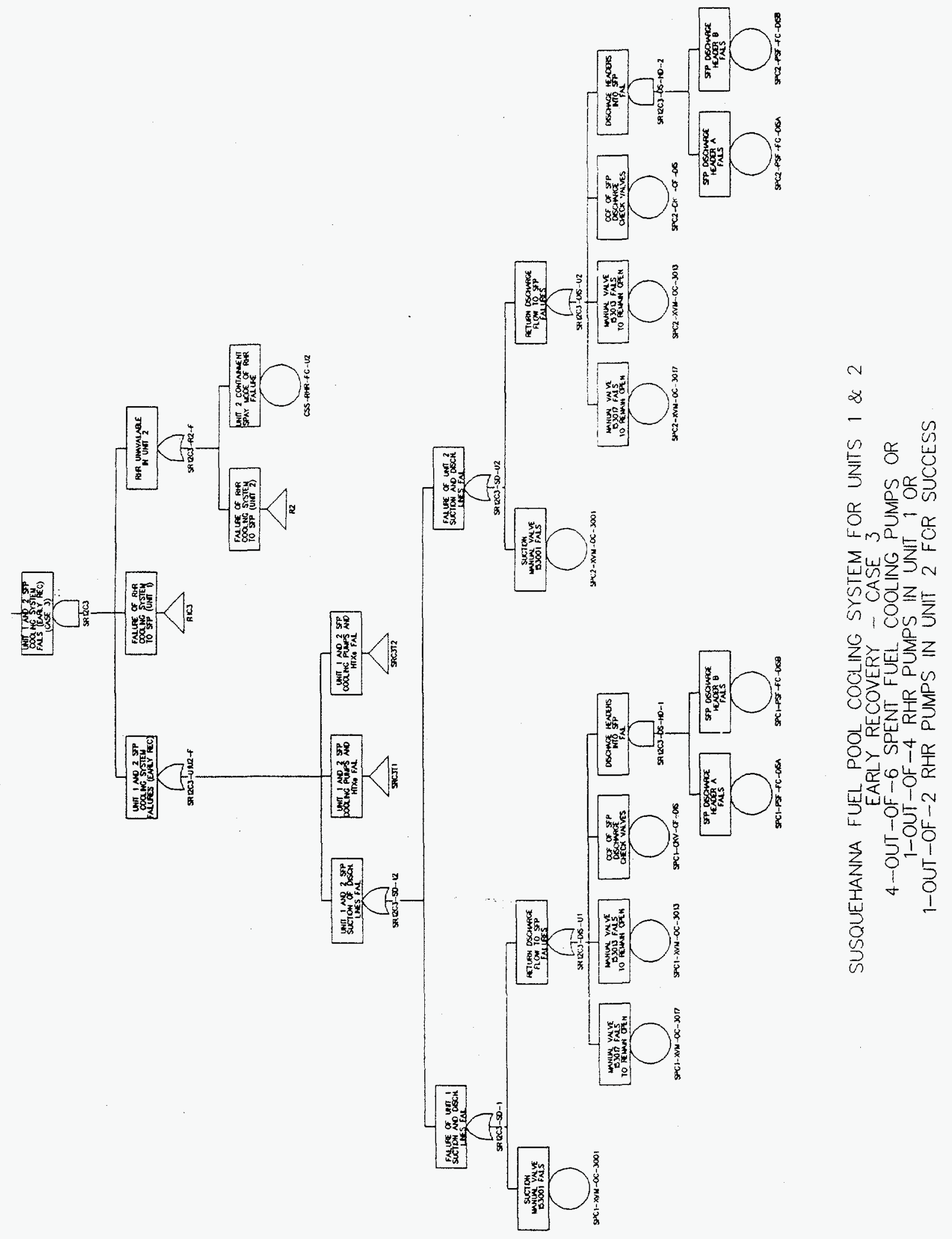




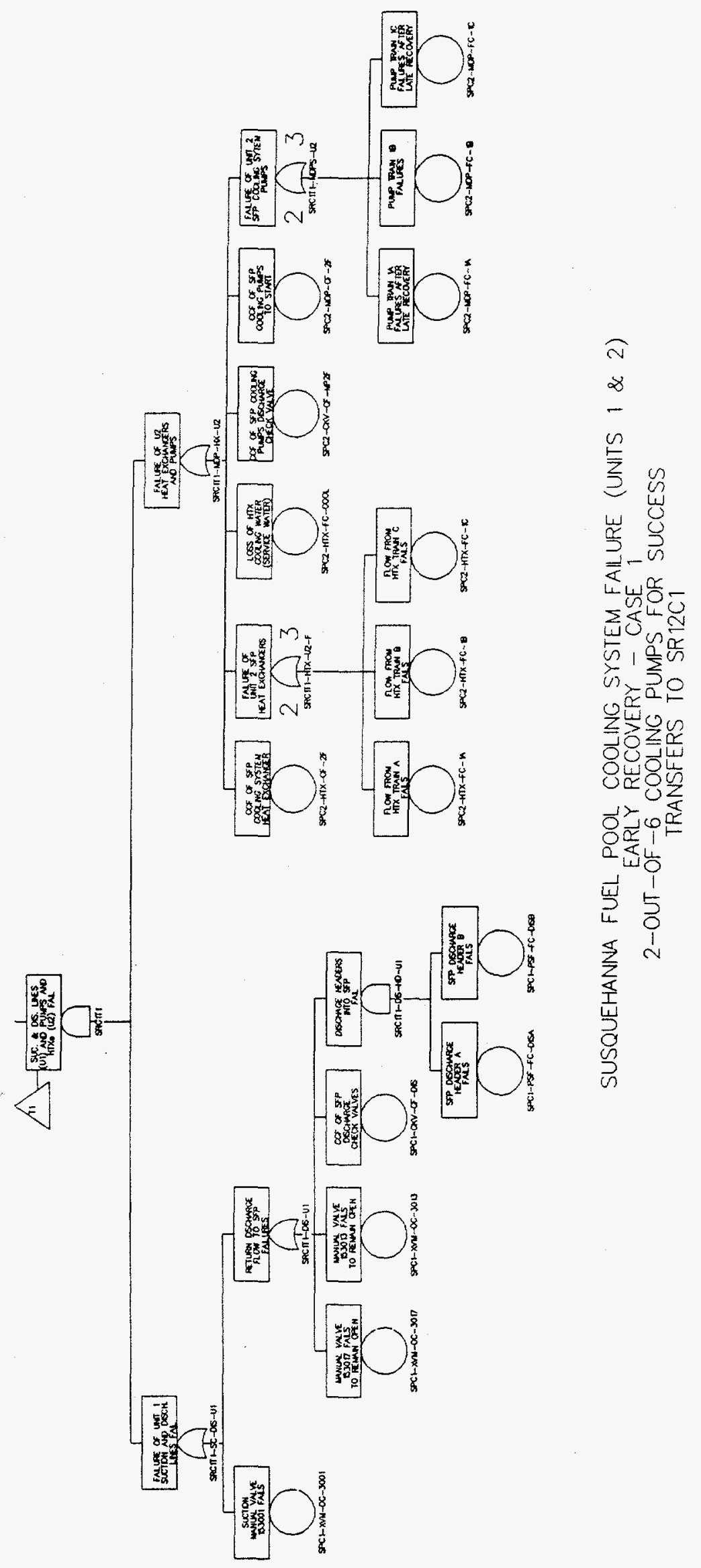

A. 122 


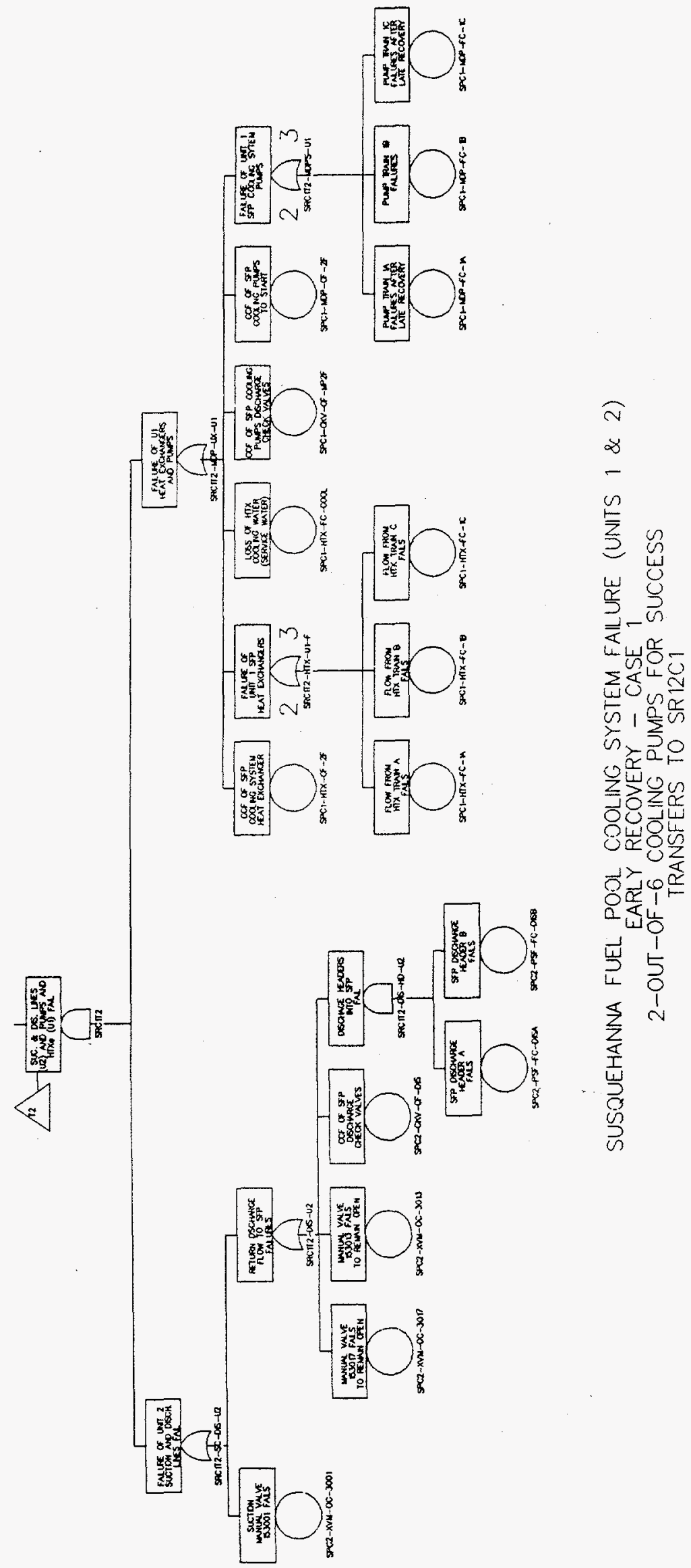

A. 123 


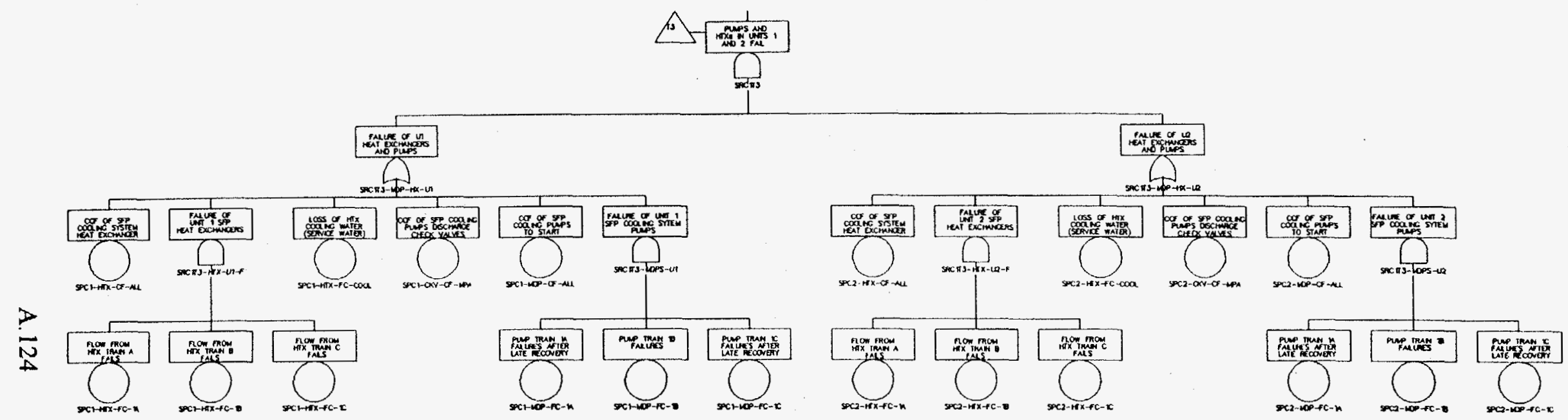

SUSQUEHANNA FUEL POOL COOLING SYSTEM FALLURE (UNITS 1 \& 2) 2-OUT EARLY RECOVERY - CASE

-6 COOLING PUMPS FOR SUCCESS

TRANSFERS TO SR $12 \mathrm{C} 1$ 


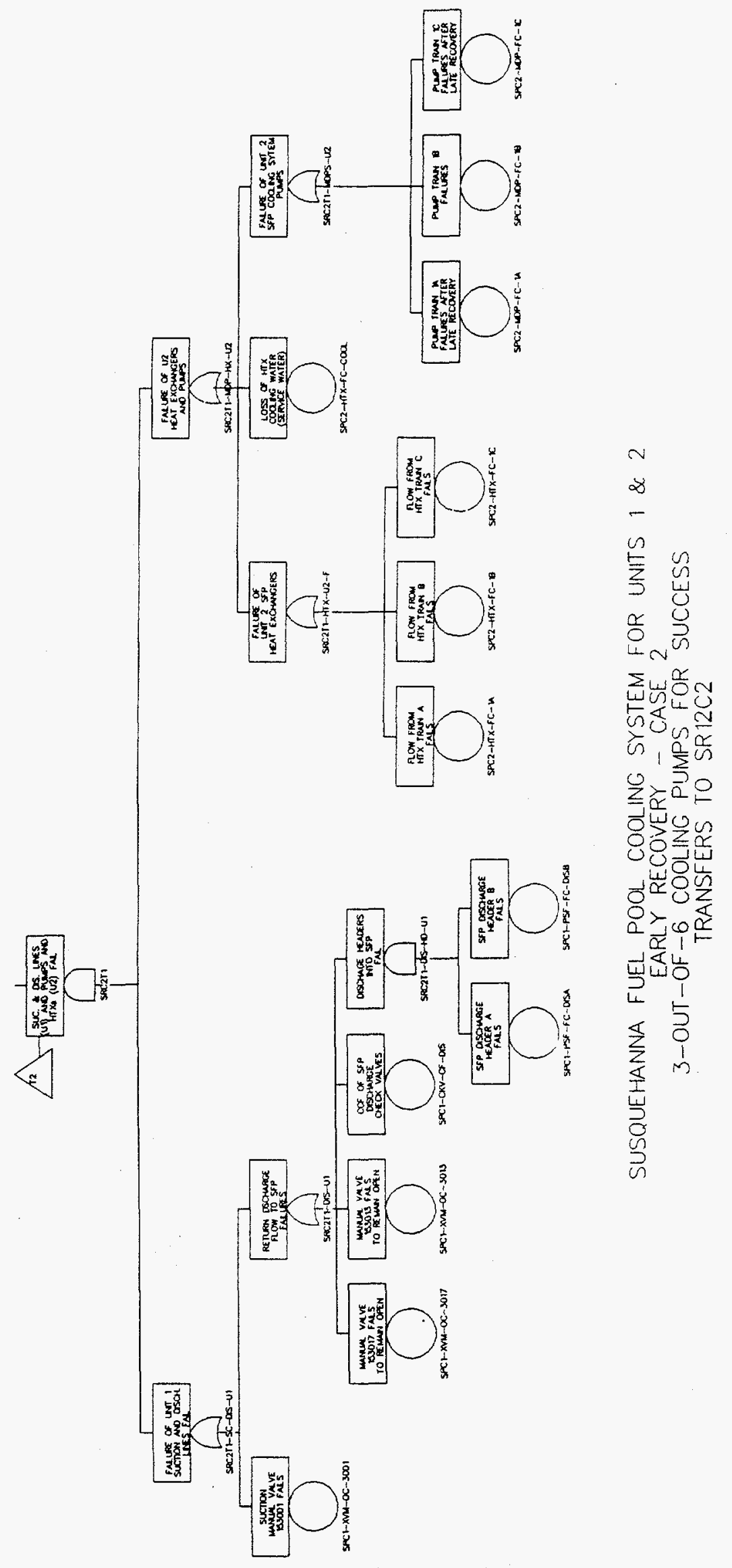

A. 125 


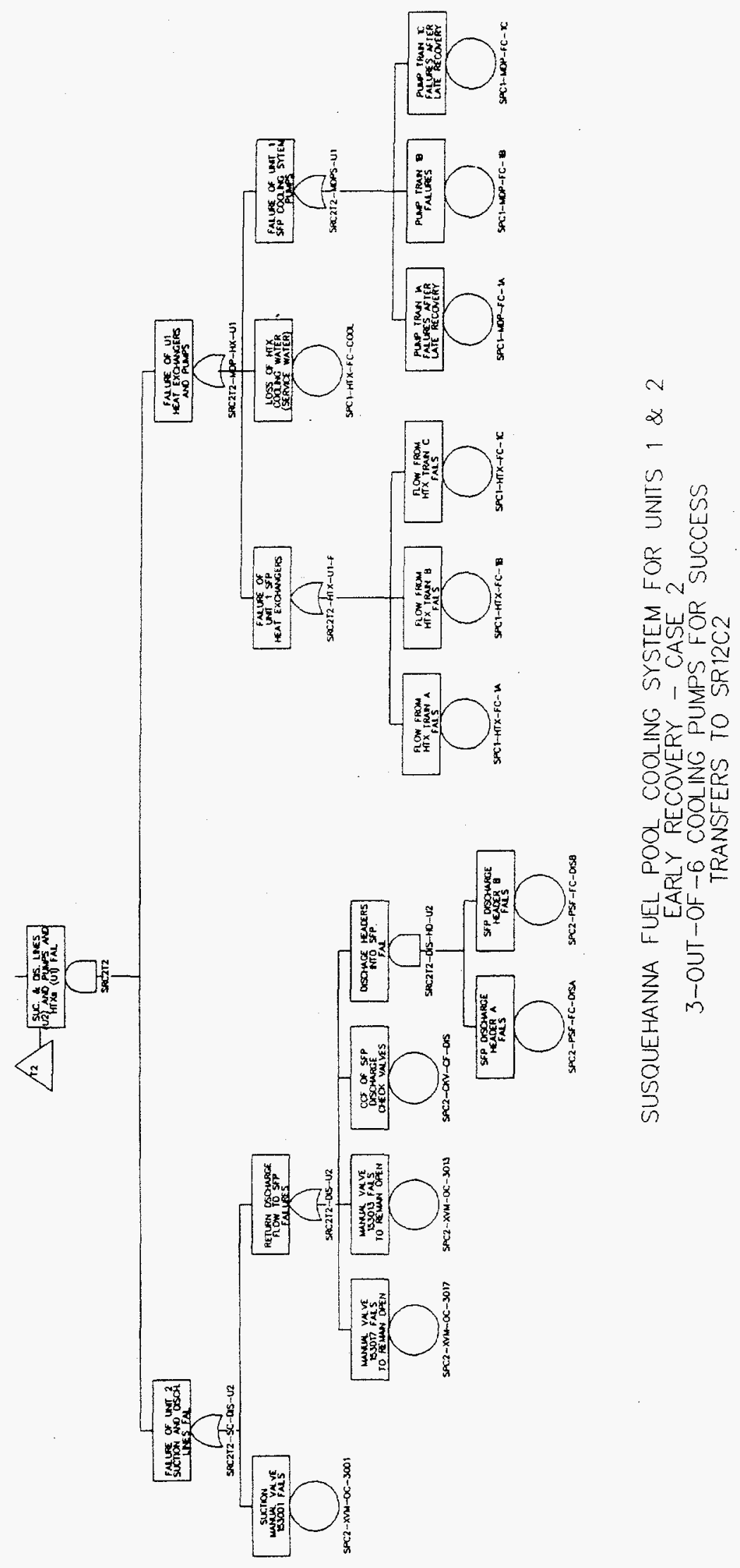

A. 126 


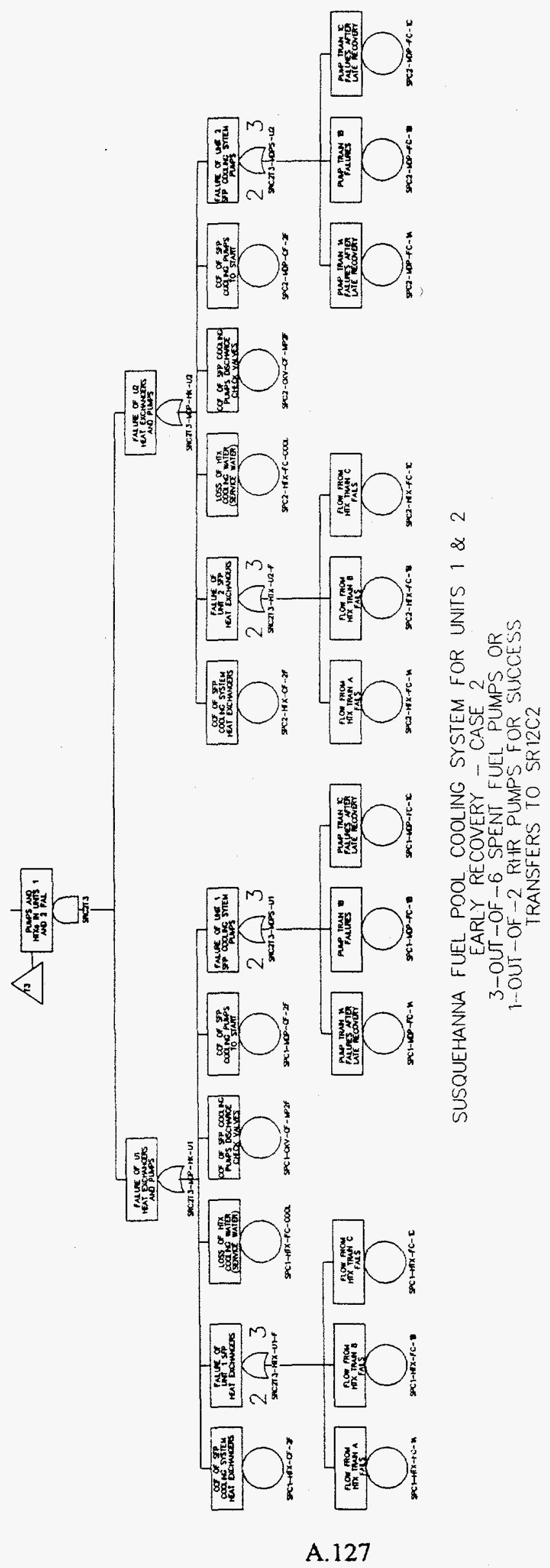




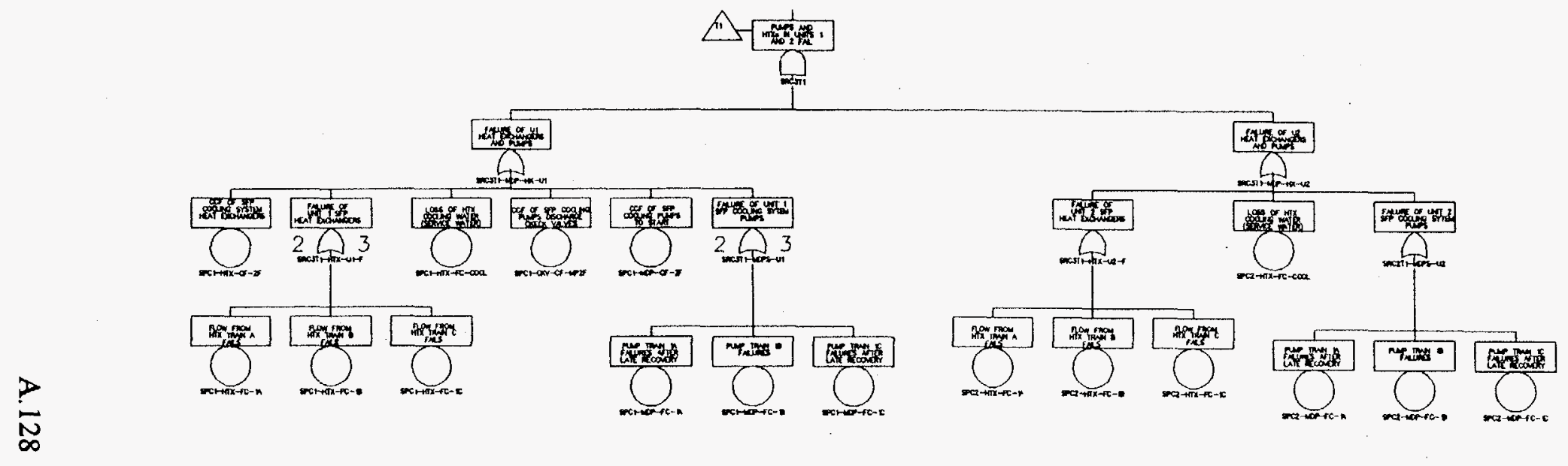

SUSQUEHANNA FUEL POO COOLING SYSTEM FOR UNITS 1 \& 2

4-OUT-OF-6 SPENT FUEL COOLING PUMPS OR
1-OUT-OF 2 RHR PUMPS FOR SUCCESS

TRANSFERS TO SR $12 \mathrm{C} 3$ 


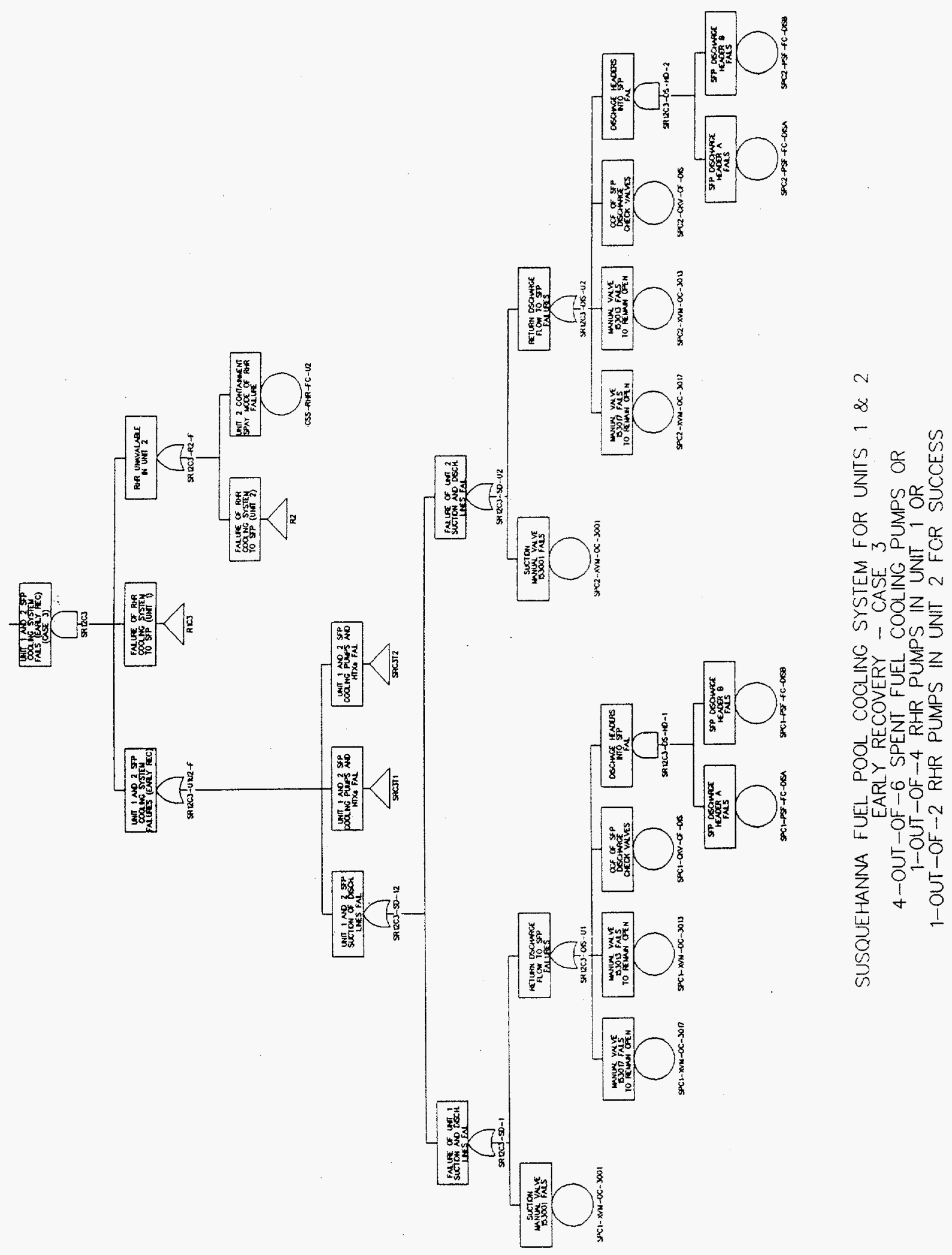



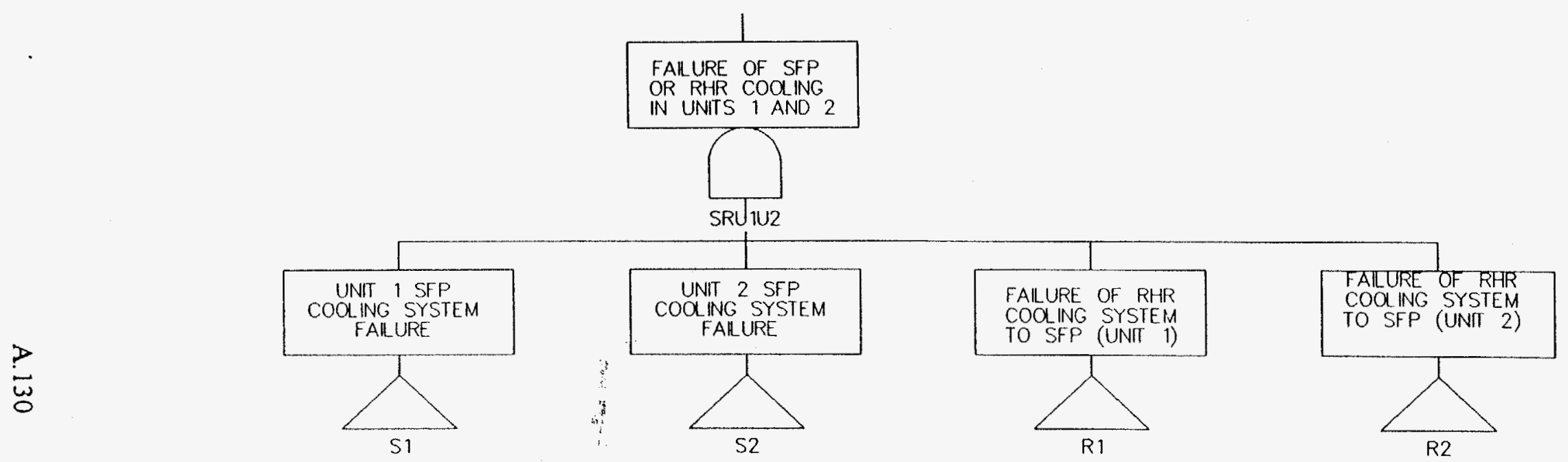

SPENT FUEL POOL COOLING SYSTEMS

FOR UNITS 1 AND 2

SUCCESS REQUIRES AT LEAST ONE SUCCESSFUL SYSTEM FROM EITHER UNIT 


\section{A.7. References}

A.1 K.D. Russell, et al., Systems Analysis Programs for Hands-on Integrated Reliability Evaluations (SAPHIRE), Version 5.0: Technical Reference Manual, NUREG/CR-6116, July 1994.

A.2 T.V. Vo, T.R. Blackburn, T.M. Mitts, H.K. Phan, Risk Analysis for Spent Fuel Pool Cooling at Susquehanna Electric Power Station (Draft Report), Pacific Northwest Laboratory, prepared for the U.S. Nuclear Regulatory Commission Office of Nuclear Reactor Regulation under Contract DE-AC06-76RLO 1830, October 1994.

A.3 U.S. Nuclear Regulatory Commission, Regulatory Analysis for the Resolution of Generic Issue 82, "Beyond Design Basis Accidents in Spent Fuel Pools", NUREG-1353, 1989.

A.4 J.W. Minarick, "Revised LOOP Recovery and PWR Seal LOCA Models," ORNL/NRC/LTR-89/11, technical letter report prepared for the U.S. Nuclear Regulatory Commission, August 1989.

A.5 J.A. Schroeder, Simplified Plant Risk Model for Susquehanna $I \& 2$ (ASP BWR C), Rev. 2, prepared for the U.S. Nuclear Regulatory Commission under JCN W6467-5, 1995.

A.6 J. Darby, et al, Evaluation of Potential Severe Accidents During Low Power and Shutdown Operations at Grand Gulf, Unit 1, NUREG/CR-6143, 1994.

A.7 T.L. Chu, et al, Evaluation of Potential Severe Accidents During Low Power and Shutdown Operations at Grand Gulf, Unit 1, NUREG/CR-6144, 1994.

A.8 P. Sobel, Revised Livermore Seismic Hazard Estimates for 69 Nuclear Power Plant Sites East of the Rocky Mountains, Draft Report for Comment, NUREG-1488, 1993. 
Appendix B

Event Quantification 


\section{APPENDIX B - EVENT QUANTIFICATION}

\section{B.1 Basic Event Probabilities}

The fault trees used in this study are super-component based. The unavailability of a given super-component is approximated as the sum of the unavailabilities of the components contained in the super-component definition. The base component unavailabilities, in turn, are the same generic values used in the ASP models [B.1,B.2]. The basic events and associated probabilities used in this study (including a breakdown into components where relevant) are listed in Table B.1.

In some cases, the basic event probabilities (e.g., for the relative frequency of SFPC system leaks versus SFP boundary leaks) are derived. The estimation process used for each of these values is presented in Section B.3 below.

\section{B.2 Initiating Event Frequencies}

\section{B.2.1 Loss of SFPC System}

Over the time period 1987 through June 1996, the AEOD data base ${ }^{1}$ includes 53 LOSPC events (see Table 5.5). Of these, 21 occurred during operation and 31 occurred during refueling. (The plant status for the one remaining event has not been determined.) Noting that the total number of reactor years for this time period is $1005 \mathrm{ry}$, and assuming 2-month refueling outages,

$$
\begin{aligned}
& \lambda_{\operatorname{LOSFP}}(\text { Operation }) \approx \frac{21}{\left[\frac{16}{18} \cdot 1005 \mathrm{ry}\right]}=2.4 \times 10^{-2} / \mathrm{ry} \\
& \lambda_{\text {LOSFP }}(\text { Re fueling }) \approx \frac{21}{\left[\frac{2}{18} \cdot 1005 \mathrm{ry}\right]}=2.8 \times 10^{-1} / \mathrm{ry}
\end{aligned}
$$

\section{B.2.2 Loss of Offsite Power}

According to Ref. B.3, the frequency of not recovering power by time $t$ can be modeled using a mixture of exponential distributions:

$$
\lambda(t)=\sum_{i} \lambda_{0 i} e^{-\alpha_{i t} t^{4}}
$$

For Susquehanna, $\mathrm{i}=\mathrm{I1}, \mathrm{G} 1 \mathrm{R} 2, \mathrm{~S} 2 \mathrm{R} 2, \mathrm{SS} 3$ per Table 2 in the above reference. The numerical values for the parameters are listed in Table B.2. (Note that G1R2 corresponds to G5 and S2R2

\footnotetext{
${ }^{1}$ This study employs the June 13, 1996 version of the database; changes to the database, e.g., additional entries, can affect the conclusions drawn.
} 
corresponds to SR7 in the reference.) The frequency of loss of offsite power (LOOP) is determined by setting $\mathrm{t}=0$; the result is $\lambda_{\text {LOOP }}=0.08 / \mathrm{yr}^{2}$

\section{B.2.3 L.oss of Inventory}

Table 5.4 provides a breakdown of loss of inventory events contained in the AEOD database. A categorization of the piping-associated SFP leaks by size and plant status is shown in Table B.3. In that table, 1) the values in parentheses are for the entire database and the numbers outside of the parentheses are for the period $1987-6 / 96 ; 2$ ) the values in the right-hand column don't add up because the severity of 1 event was not determined, and 3) a "medium" leak is assumed to contribute 0.5 to the count for small leaks and 0.5 to the count for large leaks.

A similar breakdown of seal-associated SFP leaks by size and plant status is shown in Table B.4. Note that in both tables, the counts of non-refueling leakage events could be low (because the leak events are not necessarily reportable).

The evidence is too weak to prove that the frequency of SFP leaks is dependent on the size of the leak or on the plant status (refueling vs. non-refueling). On the other hand, it might be assumed $a$ priori that there is such a dependence because: i) mechanisms that lead to small leaks appear to be more likely than mechanisms that lead to large ones; and ii) there is increased activity around the SFP during refueling, which leads to an increased possibility for error. Assuming that the loss of inventory initiating event frequency is dependent on leak size and plant status, the following estimates are used: ${ }^{3}$

$$
\begin{aligned}
& \lambda_{\text {LINV }}(\text { Small Leak, Operation }) \approx \frac{(5+0)}{\left[\frac{16}{18} \cdot 1005 \mathrm{ry}\right]}=5 \times 10^{-3} / \mathrm{ry} \\
& \lambda_{\text {LINV }}(\text { Large Leak, Operation }) \approx \frac{(2+0)}{\left[\frac{16}{18} \cdot 1005 \mathrm{ry}\right]}=2 \times 10^{-3} / \mathrm{ry} \\
& \lambda_{\text {LINV }}(\text { Small Leak, Refueling }) \approx \frac{(2.5+1)}{\left[\frac{2}{18} \cdot 1005 \mathrm{ry}\right]}=3 \times 10^{-2} / \mathrm{ry} \\
& \lambda_{\text {LINV }}(\text { Large Leak, Refueling }) \approx \frac{(1.5+1)}{\left[\frac{2}{18} \cdot 1005 \mathrm{ry}\right]}=2 \times 10^{-2} / \mathrm{ry}
\end{aligned}
$$

\footnotetext{
${ }^{2}$ The model of Ref. B.3 is applicable to a single unit. In this analysis, it is used to represent the frequency of LOOP for two units as well, despite the large contribution of plant-centered LOOPs ( $i=I 1$ ). This conservative, simplified treatment is equivalent to assuming that the conditional probability of a LOOP at the second unit is virtually unity, given the occurrence of LOOP at the first unit.

${ }^{3}$ These estimates are based on an earlier categorization of events; a leak now considered to be "small" was categorized as being "large." Changes in the estimates to reflect the categorization shown in Table B.4 will not significantly affect the results of this study.
} 


\section{B.2.4 Loss of Primary Coolant}

The frequency of LOCA during operation is obtained from Ref. B.4; the value of $1.5 \times 10^{-2} / \mathrm{ry}$ is appropriate for small LOCAs.

For LOCAs during refueling, Refs. B.5 (NUREG/CR-6143, the Grand Gulf shutdown risk study) and B.6 (NUREG/CR-6144, the Surry shutdown risk study) define the following nonpipe break events:

H LOCA = recoverable diversion of RCS coolant

$\mathrm{J}$ LOCA $=$ LOCA in connected system (e.g., RHR)

$\mathrm{K}$ LOCA $=$ maintenance-induced LOCA

Ref. B. 5 indicates that $4 \mathrm{~J}$ LOCAs have been observed in 375 boiling water reactor (BWR) years. Ref. B.6 provides the following frequency estimates for J and K LOCAs:
J LOCA:
$8 \mathrm{E}-3 / \mathrm{yr}$
K LOCA:
$3 \mathrm{E}-3 / \mathrm{yr}$

Noting that the above estimates are annualized, the following estimate for the frequency of a LOCA during refueling is derived. (Note also that H LOCAs are not treated in this study, due to their easy recoverability, and due to the large amount of time generally available for the accidents being analyzed.)

$$
\begin{aligned}
& \lambda_{\mathrm{J}-\text { LOCA }}(\text { Refueling Outage }) \approx \frac{4}{\left[\frac{2}{18} \cdot 375 \mathrm{ry}\right]}=9.6 \times 10^{-2} / \mathrm{ry} \\
& \begin{aligned}
\lambda_{\mathrm{K}-\text { LOCA }}(\text { Refueling Outage }) & \approx 3 \times 10^{-3} \cdot \frac{18}{2}=2.7 \times 10^{-2} / \mathrm{ry} \\
\lambda_{\text {LOCA }}(\text { Refueling Outage }) & =\lambda_{\mathrm{J}-\text { LOCA }}(\text { Refueling Outage })+\lambda_{\mathrm{K}-\text { LOCA }}(\text { Refueling Outage }) \\
& =0.12 / \text { ry }
\end{aligned}
\end{aligned}
$$

\section{B.2.5 Earthquake}

According to Ref. B.7, the discrete frequency-magnitude distribution for earthquakes at the Susquehanna site is as shown in Table B.5. Summing the frequencies of earthquakes with peak ground acceleration (PGA) between $0.2 \mathrm{~g}$ and $0.6 \mathrm{~g}$ leads to an initiating event frequency estimate of $1.2 \times 10^{-4} / \mathrm{ry}$. Earthquakes with PGA below $0.2 \mathrm{~g}$ are assumed to have a negligible impact on the plant; earthquakes with PGA above $0.6 \mathrm{~g}$ are assumed to be direct core damage contributors (i.e., they are likely to cause severe damage, regardless of what happens to the spent fuel pool). 


\section{B.3 Derived Basic Event Probabilities}

Except for the human error probabilities (which are discussed in Appendix C), most of the basic event probabilities listed in Section B.1 are generic values. This section documents the deriviations of the following non-generic basic event probabilities and split fractions ${ }^{4}$ : a) the conditional frequency of failure to recover offsite power in 4 hours, b) the fraction of loss of inventory events involving the spent fuel pool cooling system, c) the fraction of events involving a complicated recovery, and d) the fraction of complicated events leading directly to core damage.

\section{B.3.1 Offsite Power Recovery}

The conditional frequency of failing to recover offsite power in time t, given a loss of offsite power event, is computed using the following equation.

$$
\operatorname{Fr}\{\text { Nonrecovery by } \mathrm{t} \mid \mathrm{LOOP}\}=\frac{\sum_{\mathrm{i}} \lambda_{0 \mathrm{i}} \mathrm{e}^{-\alpha_{\mathrm{i}} \mathrm{\beta}_{\mathrm{i}}}}{\sum_{\mathrm{i}} \lambda_{0 \mathrm{i}}}
$$

Using Table B. 2 and evaluating the equation at $t=4$ hours, the nonrecovery frequency is 0.045 .

\section{B.3.2 Loss of Inventory Events Involving SFPC System}

The loss of inventory event trees shown in Appendix A distinguish between losses originating from the SFPC system (e.g., valve misalignments) and those originating from the SFP boundary (e.g., pneumatic seal failures). The relative frequencies of these two classes are estimated using the 1987 - 6/96 data shown in Tables B.3 and B.4.

$$
\begin{aligned}
& \operatorname{Fr}\{\text { SFPC System } \mid \text { Small Leak, Operation }\} \approx \frac{5}{5+1} \approx 0.8 \\
& \operatorname{Fr}\{\text { SFPC System | Large Leak, Operation }\} \approx \frac{2}{2+1} \approx 0.7 \\
& \operatorname{Fr}\{\text { SFPC System } \mid \text { Small Leak, Refueling }\} \approx \frac{3.5}{3.5+1} \approx 0.8 \\
& \operatorname{Fr}\{\text { SFPC System | Large Leak, Refueling }\} \approx \frac{0.5}{0.5+1} \approx 0.3
\end{aligned}
$$

Note that in the case of the estimates for leaks during operation, no seal failures are included in the database for the time period of interest. The crude estimates developed are conservative with respect to the occurrence of seal failures. Note also that the associated basic event probabilities in Table B.1 are the complements of the above estimates.

\footnotetext{
${ }^{4}$ A split fraction is the conditional frequency of taking the upper path at a given event tree branching point, given the sequence of events leading up to that branching point. In this model, split fractions are treated as basic events in trivial (single element) fault trees.
} 


\section{B.3.3 Complicated Scenarios}

In this study, it is recognized that complications in responding to a plant-wide event (e.g., a LOOP) can inhibit the operators from devoting sufficient resources to spent fuel pool problems until late in the scenario. This section describes the simple model used to quantify the likelihood of a complicated scenario. The likelihood that operators will not respond promptly, given a complicated scenario, is addressed in Appendix C.

a) Operationalized definition

The scenario is "complicated" when one or more of the following occur:

- Offsite power is unavailable early (including recovery), unless all emergency diesel generators (EDGs) are available

- One or more safety relief valves (SRVs) fail open or closed

- High Pressure Core Injection (HPCI) is unavailable

- RHR is unavailable

- A large seismic event (PGA $\geq 0.2 \mathrm{~g})$ occurs

These conditions are based on a consideration of key safety functions. The operators are likely to be in difficulty if they have problems with: i) primary system pressure, temperature, or level control; ii) suppression pool temperature or containment pressure control; iii) establishing shutdown cooling.

b) Scenarios which are "complicated" by definition

- Loss of offsite power, some EDGs available, failure of early offsite power recovery

- $\quad$ Loss of offsite power, no EDGs available (station blackout - SBO)

- All seismic scenarios

c) Scenarios for which split fractions must be computed

- Loss of offsite power

- Primary LOCA

d) Model

- $\quad$ LOOP (non-SBO)

The scenario is complicated if either RHR, HPCI, or an SRV fails. Note that some power is available.

$$
\mathrm{P}\{\text { Complicated }\}=\mathrm{P}\{\mathrm{RHR}\}+\mathrm{P}\{\mathrm{HPCI}\}+\mathrm{P}\{\mathrm{SRV}\}
$$




\section{- LOCA}

The scenario is complicated if a LOOP occurs or RHR or HPCI fails.

$\mathrm{P}\{$ Complicated $\}=\mathrm{P}\{\mathrm{LOOP}\}+\mathrm{P}\{\mathrm{RHR}\}+\mathrm{P}\{\mathrm{HPCI}\}$

e) Quantification

Using the Accident Sequence Precursor model for Susquehanna [B.4], the following failure probabilities are computed:

\begin{tabular}{|c|c|}
\hline Failure & Probability \\
\hline Offsite Power & $2.7 \mathrm{E}-3^{a}$ \\
\hline RHR & $4.1 \mathrm{E}-4$ \\
\hline HPCI & $2.7 \mathrm{E}-2$ \\
\hline SRV & $3.2 \mathrm{E}-2$ \\
\hline
\end{tabular}

${ }^{2}$ Based on: i) a consequential LOOP frequency 10 times higher than the base frequency, and ii) a time window of 24 hours.

The resulting split fractions are then as follows.

$\mathrm{P}\{$ Complicated $\mid \mathrm{LOOP}\}=5.9 \mathrm{E}-2$

$\mathrm{P}\{$ ComplicatedILOCA $\}=3.0 \mathrm{E}-2$

\section{B.3.4 Core Damage Given a Complicated Scenario}

If a scenario is complicated, there is a reasonable chance that core damage may occur, regardless of what happens to the spent fuel pool. This section describes the simple model used to quantify the likelihood of this occurrence.

a) Scenarios for which split fractions must be computed

- Loss of offsite power, complicated recovery

- Primary LOCA, Case 1, complicated recovery

- $\quad$ Primary LOCA, Cases 2 and 3

- $\quad$ Seismic event (PGA $\geq 0.2 \mathrm{~g}$ ), complicated recovery

Note that the split fractions need to be quantified conditional on the recovery being complicated, i.e., on one or more of the defining conditions for a complicated scenario being true. 
b) Approach

If:

- the conditional core damage probability (CCDP) given an accident scenario,

- the conditional probability of core damage given that the scenario is not complicated, and

- the probability that the scenario is complicated scenario are known,

the conditional probability of core damage given a complicated scenario can be computed. In the following equation, the overbars denote a complemented event. Thus, for example, $\mathrm{P}\{\overline{\text { Complicated }}\}$ is the probability that the scenario is not complicated.

$$
\begin{aligned}
& \mathrm{P}\{\mathrm{CD}\}= \mathrm{P}\{\mathrm{CD} \mid \text { Complicated }\} \cdot \mathrm{P}\{\text { Complicated }\} \\
&+\mathrm{P}\{\mathrm{CD} \mid \overline{\text { Complicated }}\} \cdot \mathrm{P}\{\overline{\text { Complicated }}\} \\
& \therefore \mathrm{P}\{\mathrm{CD} \mid \mathrm{Complicated}\}= \\
& \\
& \frac{\mathrm{P}\{\mathrm{CD}\}-\mathrm{P}\{\mathrm{CD} \mid \overline{\text { Complicated }}\} \cdot \mathrm{P}\{\overline{\text { Complicated }}\}}{\mathrm{P}\{\text { Complicated }\}}
\end{aligned}
$$

c) Quantification

Using the Accident Sequence Precursor model for Susquehanna [B.4], the following scenario-dependent probabilities are computed.

\begin{tabular}{|c|c|c|c|c|c|}
\hline Scenario & $\mathrm{P}\{\mathrm{CD}\}$ & $\mathrm{P}\{$ Complicated $\}$ & $\mathrm{P}\{\overline{\text { Complicated }}\}$ & $\mathrm{P}\{\mathrm{CD} \mid \overline{\text { Complicated }}\}$ & $\mathrm{P}\{\mathrm{CD} \mid$ Complicated $\}$ \\
\hline LOOP & $4.40 \mathrm{E}-05$ & $5.90 \mathrm{E}-02$ & $9.41 \mathrm{E}-01$ & $3.00 \mathrm{E}-06$ & $6.98 \mathrm{E}-04$ \\
\hline PLOCA & $5.80 \mathrm{E}-06$ & $3.00 \mathrm{E}-02$ & $9.70 \mathrm{E}-01$ & $0.00 \mathrm{E}+00$ & $1.93 \mathrm{E}-04$ \\
\hline Seismic & $1.05 \mathrm{E}-02$ & $1.00 \mathrm{E}+00$ & $0.00 \mathrm{E}+00$ & $0.00 \mathrm{E}+00$ & $1.05 \mathrm{E}-02$ \\
\hline
\end{tabular}

Notes:

1) For LOOP scenarios, the only path to core damage given that RHR, SRVs, HPCI are all successful is station blackout.

2) Seismic events are assumed to be complicated by definition

3) $\mathrm{P}\{\mathrm{CD} \mid \mathrm{EQE}\}$ is computed using information from the NUREG-1150 seismic analysis for Peach Bottom [B.9] because the results of the seismic assessment for Susquehanna were not available. The Peach Bottom conditional probabilities of core damage given each of the three earthquake acceleration levels between $0.2 \mathrm{~g}$ and $0.6 \mathrm{~g}$ are used as follows. (Note that the $\mathrm{g}_{\mathrm{i}}$ in the second equation stands for the ith acceleration level, $\mathrm{i}=1,2$, or 3 .) 


$$
\begin{aligned}
& P\{C D \mid E Q E\} \cdot P\{E Q E\}=P\{C D \mid 0.23 g\} \cdot P\{0.23 g\}+P\{C D \mid 0.37 g\} \cdot P\{0.37 g\} \\
& +\mathrm{P}\{\mathrm{CD} \mid 0.53 \mathrm{~g}\} \cdot \mathrm{P}\{0.53 \mathrm{~g}\} \\
& P\{C D \mid E Q E\}=\frac{\sum_{i=1,2,3} P\left\{C D \mid g_{i}\right\} P\left\{g_{i}\right\}}{\sum_{i=1,2,3} P\left\{g_{i}\right\}}
\end{aligned}
$$

\begin{tabular}{|c|c|c|c|}
\hline$g$ & $P\{g][B .7]$ & $P\{C D \mid g][B .9]$ & $P\{C D \mid g\}^{*} P(g)$ \\
\hline 0.23 & $1.02 \mathrm{E}-04$ & $1.76 \mathrm{E}-04$ & $1.80 \mathrm{E}-08$ \\
\hline 0.37 & $1.34 \mathrm{E}-05$ & $2.39 \mathrm{E}-02$ & $3.20 \mathrm{E}-07$ \\
\hline 0.53 & $3.52 \mathrm{E}-06$ & $2.59 \mathrm{E}-01$ & $9.12 \mathrm{E}-07$ \\
\hline TOTALS & $1.19 \mathrm{E}-04$ & & $1.25 \mathrm{E}-06$ \\
\hline
\end{tabular}

\section{B.4 References}

B.1 M.T. Drouin, F.T. Harper, and A.L. Camp, Analysis of Core Damage Frequency from Internal Events: Methodology Guidelines, NUREG/CR-4550, Vol. 1, 1987.

B.2 A. Mosleh, Procedure for Analysis of Common-Cause Failures in Probabilistic Safety Analysis, NUREG/CR-5801, 1993.

B.3 J.W. Minarick, "Revised LOOP Recovery and PWR Seal LOCA Models," ORNL/NRC/LTR-89/11, technical letter report prepared for the U.S. Nuclear Regulatory Commission, August 1989.

B.4 J.A. Schroeder, Simplified Plant Risk Model for Susquehanna $1 \& 2$ (ASP BWR C), Rev. 2, prepared for the U.S. Nuclear Regulatory Commission under JCN W6467-5, 1995.

B.5 J. Darby, et al, Evaluation of Potential Severe Accidents During Low Power and Shutdown Operations at Grand Gulf, Unit 1, NUREG/CR-6143, 1994.

B.6 T.L. Chu, et al, Evaluation of Potential Severe Accidents During Low Power and Shutdown Operations at Grand Gulf, Unit 1, NUREG/CR-6144, 1994.

B.7 P. Sobel, Revised Livermore Seismic Hazard Estimates for 69 Nuclear Power Plant Sites East of the Rocky Mountains, Draft Report for Comment, NUREG-1488, 1993.

B.8 G.M. Grant, et al, Emergency Diesel Generator Power System Reliability, 1987-1993, INEL-95/0035, 1996.

B.9 J.A. Lambright, et al, Analysis of Core Damage Frequency: Peach Bottom, Unit 2, External Events, NUREG/CR-4550, Vol. 4, Rev. 1, Part 3, December 1990. 
Table B.1 - Basic Event Data (Page 1 of 11)

\begin{tabular}{|c|c|c|c|c|}
\hline \multirow{2}{*}{$\begin{array}{c}\text { BASIC EVENT NAME } \\
\checkmark\end{array}$} & \multicolumn{3}{|l|}{ COMPONENT DATA } & \multirow{2}{*}{$\begin{array}{l}\text { BASIC } \\
\text { EVENT } \\
\text { PROB. }\end{array}$} \\
\hline & COMPONENT NAME & FAILURE MODE & FAILURE PROB & \\
\hline ALT-XHE-XM-SFP & Operator Action & $\begin{array}{l}\text { Operator fails to establish } \\
\text { alternate cooling early }\end{array}$ & $1.0 \mathrm{E}-2$ & $1.0 \mathrm{E}-2$ \\
\hline ALT-XHE-XM-SFPL & Operator Action & $\begin{array}{l}\text { Operator fails to establish } \\
\text { alternate cooling late }\end{array}$ & $8.0 \mathrm{E}-2$ & $8.0 \mathrm{E}-2$ \\
\hline ALT-XHE-XM-SFPP & Operator Action & $\begin{array}{l}\text { Operator fails to establish } \\
\text { alternate cooling during LOOP }\end{array}$ & $3.0 \mathrm{E}-2$ & $3.0 \mathrm{E}-2$ \\
\hline CSS-RHR-FC-U1 & Core Spray Injection Unit 1 & Fails to operate & $4.0 \mathrm{E}-4$ & $4.0 \mathrm{E}-4$ \\
\hline CSS-RHR-FC-U1 & Core Spray Injection Unit 2 & Fails to operate & $4.0 \mathrm{E}-4$ & 4.0E-4 \\
\hline EPS-DGN-CF-ALL & Diesel generators & CCF to start & $1.44 \mathrm{E}-3$ & $1.44 \mathrm{E}-3$ \\
\hline EPS-DGN-FC-1A & Diesel generator $1 \mathrm{~A}$ & Fails to start/run & $1.1 \mathrm{E}-1$ & $1.1 \mathrm{E}-1$ \\
\hline EPS-DGN-FC-1ARE & Diesel generator $1 \mathrm{~A}$ & Fails to start/run (refueling) & $1.8 \mathrm{E}-1$ & $1.8 \mathrm{E}-1$ \\
\hline EPS-DGN-FC-1B & Diesel generator $1 \mathrm{~B}$ & Fails to start/run & $1.1 \mathrm{E}-1$ & $1.1 \mathrm{E}-1$ \\
\hline EPS-DGN-FC-1BRE & Diesel generator $1 \mathrm{~B}$ & Fails to start/run (refueling) & $1.8 \mathrm{E}-1$ & $1.8 \mathrm{E}-1$ \\
\hline EPS-DGN-FC-2A & Diesel generator $2 \mathrm{~A}$ & Fails to start/run & $1.1 \mathrm{E}-1$ & $1.1 \mathrm{E}-1$ \\
\hline EPS-DGN-FC-2ARE & Diesel generator $2 \mathrm{~A}$ & Fails to startrun (refueling) & $1.8 \mathrm{E}-1$ & $1.8 \mathrm{E}-1$ \\
\hline EPS-DGN-FC-2B & Diesel generator $2 \mathrm{~B}$ & Fails to start/run & $1.1 \mathrm{E}-1$ & $1.1 \mathrm{E}-1$ \\
\hline EPS-DGN-FC-2BRE & Diesel generator $2 \mathrm{~B}$ & Faails to start/run (refueling) & $1.8 \mathrm{E}-1$ & $1.8 \mathrm{E}-1$ \\
\hline EPS-XHE-NOREC & Operator Action & Fails to recover emergency power & $3.0 \mathrm{E}-2$ & $3.0 \mathrm{E}-2$ \\
\hline EPWR-XHE-EA-REC & Human Action & Fails to recover offsite power within $4 \mathrm{hrs}$ & $4.5 \mathrm{E}-2$ & $4.5 \mathrm{E}-2$ \\
\hline ESA-TRIP & Flag Event & SFP Trips with ESF Actuation & TRUE & TRUE \\
\hline FVPWR-FC-SFP & \begin{tabular}{|l} 
Flag Event \\
\end{tabular} & Vital Power Available & TRUE & TRUE \\
\hline GOPEN-AIR-FC & Gate air system & Fails to shut off or deflate & $1.0 \mathrm{E}-6$ & $1.0 \mathrm{E}-6$ \\
\hline GOPEN-FC-CRN1 & Crane 1 & Fails to operate & $6.0 \mathrm{E}-3$ & $6.0 \mathrm{E}-3$ \\
\hline GOPEN-FC-CRN2 & Crane 2 & Fails to operate & $6.0 \mathrm{E}-3$ & $6.0 \mathrm{E}-3$ \\
\hline GOPEN-GAT-RL-CRN & Gate 1 & Fails to release from crane & $1.0 \mathrm{E}-4$ & $1.0 \mathrm{E}-4$ \\
\hline GOPEN-GATE-FC-1 & Gate 1 & Fails to remove & $1.0 \mathrm{E}-4$ & $1.0 \mathrm{E}-4$ \\
\hline GOPEN-GATE-FC-2 & Gate 2 & Fails to remove & $1.0 \mathrm{E}-4$ & $1.0 \mathrm{E}-4$ \\
\hline GOPEN-XHE-XA-INT & Operator Action & Fails to open gate & $7.0 \mathrm{E}-3$ & $7.0 \mathrm{E}-3$ \\
\hline GOPEN-XVM-CO-CP & Cast Pit manual valve & Fails open & $5.5 \mathrm{E}-7$ & $5.5 \mathrm{E}-7$ \\
\hline
\end{tabular}


Table B.1 - Basic Event Data (Page 2 of 11)

\begin{tabular}{|c|c|c|c|}
\hline \multirow{2}{*}{ BASIC EVENT NAME } & \multicolumn{2}{|l|}{ COMPONENT DATA } & \multirow{2}{*}{$\begin{array}{l}\text { BASIC } \\
\text { EVENT } \\
\text { PROB. }\end{array}$} \\
\hline & COMPONENT NAME & FAILURE MODE & \\
\hline LMKUP-XHE-XA-SFP & Operator Action & Fails to align Makeup Systems (Late) & $1.1 \mathrm{E}-2$ \\
\hline LPWR-XHE-LA-REC & Operator Action & Fails to recover power (Late) & 0.5 \\
\hline MKP-XHA-XA-CLGIS & Operator Action & $\begin{array}{l}\text { Fails to align Makeup Systems } \\
\text { (Unit is critical, LINVC, isolated) }\end{array}$ & $5.0 \mathrm{E}-4$ \\
\hline$\overline{\text { MKP-XHA-XA-CLGNI }}$ & Operator Action & $\begin{array}{l}\text { Fails to align Makeup Systems } \\
\text { (Unit is critical, LINVC, SFPC system, not isolated) }\end{array}$ & $2.5 \mathrm{E}-3$ \\
\hline MKP-XHA-XA-CLNIB & Operator Action & $\begin{array}{l}\text { Fails to align Makeup Systems } \\
\text { (Unit is critical, LINVC, SFP boundary, not isolated) }\end{array}$ & $1.8 \mathrm{E}-2$ \\
\hline MKP-XIE-XA-CSMIS & Operator Action & $\begin{array}{l}\text { Fails to align Makeup Systems } \\
\text { (Unit is critical, LINCS, isolated) }\end{array}$ & $5.0 \mathrm{E}-4$ \\
\hline MKP-XHE-XA-CSMNI & Operator Action & $\begin{array}{l}\text { Fails to align Makeup Systems } \\
\text { (Unit is critical, LINCS, not isolated) }\end{array}$ & $1.0 \mathrm{E}-3$ \\
\hline MKP-XHE-XA-RLGIS & Operator Action & $\begin{array}{l}\text { Fails to align Makeup Systems or ECCS Systems } 5.0 \mathrm{E}-4 \\
\text { (Unit is refueling, LINVR, isolated) }\end{array}$ & $5.0 \mathrm{E}-4$ \\
\hline MKP-XHE-XA-RLGNI & Operator Action & $\begin{array}{l}\text { Fails to align Makeup Systems or ECCS Systems } 2.5 \mathrm{E}-3 \\
\text { (Unit is refueling, LINVR, SFPC system, not isolated) }\end{array}$ & $2.5 \mathrm{E}-3$ \\
\hline MKP-XHL-XA-RL_NIB & Operator Action & $\begin{array}{l}\text { Fails to align Makeup Systems or ECCS Systems } 1.8 \mathrm{E}-2 \\
\text { (Unit is refueling, LINVR, SFP boundary, not isolated) }\end{array}$ & $1.8 \mathrm{E}-2$ \\
\hline MKP-XHE-XA-RSMIS & Operator Action & $\begin{array}{l}\text { Fails to align Makeup Systems or ECCS Systems } 5.0 \mathrm{E}-4 \\
\text { (Unit is refueling, LINRS, isolated) }\end{array}$ & $5.0 \mathrm{E}-4$ \\
\hline MKP-XHE-XA-RSMNI & Operator Action & $\begin{array}{l}\text { Fails to align Makeup Systems or ECCS Systems } \\
\text { (Unit is refueling, LINRS, not isolated) }\end{array}$ & $1.0 \mathrm{E}-3$ \\
\hline MUES-XHE-XA-LSFP & Operator Action & Fails to align Makeup or ECCS Systems (late) & $1.1 \mathrm{E}-2$ \\
\hline MUES-XHE-XA-SFP & Operator Action & Fails to align Makeup or ECCS Systems & $7.0 \mathrm{E}-3$ \\
\hline NCD-CORE-DM-12 & Core Damage & All diesels available & $6.98 \mathrm{E}-4$ \\
\hline NCD-CORE-DM-DGAL & Core Damage & All diesels available & $6.98 \mathrm{E}-4$ \\
\hline NCD-CORE-DM-DGPR & Core Damage & Partial diesels available & $6.98 \mathrm{E}-4$ \\
\hline NCD-CORE-DM-PL & Core Damage & During Primary LOCA & $1.93 \mathrm{E}-4$ \\
\hline NCD-CORE-DM-PR & Core Damage & Primary LOCA during refueling & $1.93 \mathrm{E}-4$ \\
\hline NCD-CORE-DM-SBO & Core Damage & During SBO & $6.98 \mathrm{E}-4$ \\
\hline
\end{tabular}


Table B.1 - Basic Event Data (Page 3 of 11)

\begin{tabular}{|c|c|c|c|c|}
\hline \multirow{2}{*}{$\begin{array}{c}\text { BASIC EVENT NAME } \\
y\end{array}$} & \multicolumn{3}{|l|}{ COMPONENT DATA } & \multirow{2}{*}{$\begin{array}{l}\text { BASIC } \\
\text { EVENT } \\
\text { PROB. }\end{array}$} \\
\hline & COMPONENT NAME & FAILURE MODE & FAILURE PROB & \\
\hline R1-XHE-XM-RHR & Operator Action & Fails to iniate RHR Assist Mode (unit 1) & $7.0 \mathrm{E}-2$ & $7.0 \mathrm{E}-2$ \\
\hline R2-XHE-XM-RHR & Operator Action & Fails to iniate RHR Assist Mode (unit 2) & $7.0 \mathrm{E}-2$ & $7.0 \mathrm{E}-2$ \\
\hline RHR1-CKV-CF-AC & Check valves 151 F031A and 151 F031C & CCF to open/remain open & $2.78 \mathrm{E}-5$ & $2.78 \mathrm{E}-5$ \\
\hline RHR1-CKV-CF-BD & Check valves 151 F031B and 151 F031D & CCF to open/remain open & $2.78 \mathrm{E}-5$ & $2.78 \mathrm{E}-5$ \\
\hline RHR1-HTX-CF-AB & RHR heat exchangers $1 \mathrm{~A}$ and $1 \mathrm{~B}$ & CCF to operate & $1.37 \mathrm{E}-5$ & $1.37 \mathrm{E}-5$ \\
\hline RHR1-HTX-FC-1A & $\begin{array}{l}\text { RHR heat exchanger } 1 \mathrm{~A} \\
\text { Manual valve HV } 151 \mathrm{~F} 047 \mathrm{~A} \\
\text { Manual valve HV } 151 \mathrm{~F} 003 \mathrm{~A} \\
\text { Relief valve PSV } 151 \mathrm{~F} 066 \mathrm{~A} \\
\text { Manual valve HV } 151 \mathrm{~F} 048 \mathrm{~B} \\
\end{array}$ & $\begin{array}{l}\text { Plugs } \\
\text { Plugs } \\
\text { Plugs } \\
\text { Fails open } \\
\text { Ruptures/leaks } \\
\end{array}$ & $\begin{array}{l}1.37 \mathrm{E}-4 \\
4.0 \mathrm{E}-5 \\
4.0 \mathrm{E}-5 \\
1.0 \mathrm{E}-5 \\
4.0 \mathrm{E}-5 \\
\end{array}$ & $2.67 \mathrm{E}-4$ \\
\hline RHR1-HTX-FC-1B & $\begin{array}{l}\text { RHR heat exchanger 1B } \\
\text { Manual valve HV } 151 \text { F047B } \\
\text { Manual valve HV } 151 \text { F003B } \\
\text { Relief valve PSV } 151 \text { F066B } \\
\text { Manual valve HV } 151 \text { F048B } \\
\end{array}$ & $\begin{array}{l}\text { Plugs } \\
\text { Plugs } \\
\text { Plugs } \\
\text { Fails open } \\
\text { Ruptures/leaks } \\
\end{array}$ & $\begin{array}{l}1.37 \mathrm{E}-4 \\
4.0 \mathrm{E}-5 \\
4.0 \mathrm{E}-5 \\
1.0 \mathrm{E}-5 \\
4.0 \mathrm{E}-5 \\
\end{array}$ & $2.67 \mathrm{E}-4$ \\
\hline RHR1-HTX-FC-COOL & RHR HTX cooling system & Fails to operate & $2.4 \mathrm{E}-4$ & $2.4 \mathrm{E}-4$ \\
\hline RHR1-MDP-CF-AC & RHR pumps $1 \mathrm{~A}$ and $1 \mathrm{C}$ & CCF to start & $4.5 \mathrm{E}-5$ & $4.5 \mathrm{E}-5$ \\
\hline RHR1-MDP-CF-BD & RHR pumps $1 \mathrm{~B}$ and $1 \mathrm{D}$ & CCF to start & $4.5 \mathrm{E}-5$ & $4.5 \mathrm{E}-5$ \\
\hline RHRL-MDP-FC-1A & $\begin{array}{l}\text { RHR motor driven pump 1A } \\
\text { RHR motor driven pump 1A } \\
\text { Manual valve HV 151 F006A } \\
\text { Check valve 151 F031A } \\
\text { Manual valve 151 F034A } \\
\end{array}$ & $\begin{array}{l}\text { Fails to start } \\
\text { Fails to run } \\
\text { Fails to open/remain open } \\
\text { Fails to open/remain open } \\
\text { Fails to remain open } \\
\end{array}$ & $\begin{array}{l}3.0 \mathrm{E}-3 \\
7.2 \mathrm{E}-4 \\
1.4 \mathrm{E}-4 \\
1.0 \mathrm{E}-4 \\
4.0 \mathrm{E}-5 \\
\end{array}$ & $4.0 \mathrm{E}-3$ \\
\hline RHR1-MDP-FC-1B & $\begin{array}{l}\text { RHR motor driven pump 1B } \\
\text { RHR motor driven pump 1B } \\
\text { Manual valve HV 151 F006B } \\
\text { Check valve 151 F031B } \\
\text { Manual valve 151 F034B } \\
\end{array}$ & $\begin{array}{l}\text { Fails to start } \\
\text { Fails to run } \\
\text { Fails to open } \\
\text { Fails to open/remain open } \\
\text { Fails to remain open } \\
\end{array}$ & $\begin{array}{l}3.0 \mathrm{E}-3 \\
7.2 \mathrm{E}-4 \\
1.4 \mathrm{E}-4 \\
1.0 \mathrm{E}-4 \\
4.0 \mathrm{E}-5 \\
\end{array}$ & $4.0 \mathrm{E}-3$ \\
\hline
\end{tabular}


Table B.1 - Basic Event Data (Page 4 of 11)

\begin{tabular}{|c|c|c|c|c|}
\hline \multirow{2}{*}{$\begin{array}{c}\text { BASIC EVENT NAME } \\
y\end{array}$} & \multicolumn{3}{|l|}{ COMPONENT DATA } & \multirow{2}{*}{$\begin{array}{l}\text { BASIC } \\
\text { EVENT } \\
\text { PROB. }\end{array}$} \\
\hline & COMPONENT NAME & FAILURE MODE & FAILURE PROB & \\
\hline RHR1-MDP-FC-1C & $\begin{array}{l}\text { RHR motor driven pump 1C } \\
\text { RHR motor driven pump 1C } \\
\text { Manual valve HV } 151 \text { F006C } \\
\text { Check valve } 151 \text { F031C } \\
\text { Manual valve } 151 \text { F034C } \\
\end{array}$ & $\begin{array}{l}\text { Fails to start } \\
\text { Fails to run } \\
\text { Fails to open } \\
\text { Fails to open/remain open } \\
\text { Fails to remain open } \\
\end{array}$ & $\begin{array}{l}3.0 \mathrm{E}-3 \\
7.2 \mathrm{E}-4 \\
1.4 \mathrm{E}-4 \\
1.0 \mathrm{E}-4 \\
4.0 \mathrm{E}-5 \\
\end{array}$ & $4.0 \mathrm{E}-3$ \\
\hline RHR1-MDP-FC-1D & $\begin{array}{l}\text { RHR motor driven pump 1D } \\
\text { RHR motor driven pump 1D } \\
\text { Manual valve HV } 151 \mathrm{~F} 006 \mathrm{D} \\
\text { Check valve } 151 \mathrm{~F} 031 \mathrm{D} \\
\text { Manual valve } 151 \mathrm{~F} 034 \mathrm{D} \\
\end{array}$ & $\begin{array}{l}\text { Fails to start } \\
\text { Fails to run } \\
\text { Fails to open } \\
\text { Fails to open/remain open } \\
\text { Fails to remain open } \\
\end{array}$ & $\begin{array}{l}3.0 \mathrm{E}-3 \\
7.2 \mathrm{E}-4 \\
1.4 \mathrm{E}-5 \\
1.0 \mathrm{E}-4 \\
4.0 \mathrm{E}-5 \\
\end{array}$ & $4.0 \mathrm{E}-3$ \\
\hline RHR1-PSF-CC-DISA & $\begin{array}{l}\text { Manual valve } 153070 \mathrm{~A} \\
\text { Check valve } 153071 \mathrm{~A}\end{array}$ & $\begin{array}{l}\text { Fails to open/remain open } \\
\text { Fails to open/remain open }\end{array}$ & $\begin{array}{l}1.4 \mathrm{E}-4 \\
1.0 \mathrm{E}-4 \\
\end{array}$ & $2.4 \mathrm{E}-4$ \\
\hline RHR1-PSF-CC-DISB & $\begin{array}{l}\text { Manual valve } 153070 \mathrm{~B} \\
\text { Check valve } 153071 \mathrm{~B} \\
\end{array}$ & $\begin{array}{l}\text { Fails to open/remain open } \\
\text { Fails to open/remain open }\end{array}$ & $\begin{array}{l}1.4 \mathrm{E}-4 \\
1.0 \mathrm{E}-4 \\
\end{array}$ & $2.4 \mathrm{E}-4$ \\
\hline RHR1-TRNS-UA-TM & RHR trains $A$ and $B$ & Unavailable due to Test/Maintenance & $1.3 \mathrm{E}-1$ & $1.3 \mathrm{E}-1$ \\
\hline RHR1-XVM-CC-010A & Manual valve $151 \mathrm{~F} 010 \mathrm{~A}$ & Fails to open/remain open & $1.4 \mathrm{E}-4$ & $1.4 \mathrm{E}-4$ \\
\hline RHR1-XVM-CC-010B & Manual valve $151 \mathrm{~F} 010 \mathrm{~B}$ & Fails to open/remain open & $1.4 \mathrm{E}-4$ & $1.4 \mathrm{E}-4$ \\
\hline RHR1-XVM-CC-1070 & Manual valve 151070 & Fails to open/remain open & $1.4 \mathrm{E}-4$ & $1.4 \mathrm{E}-4$ \\
\hline RHR1-XVM-CC-SUC & $\begin{array}{l}\text { Manual valve } 153021 \\
\text { Manual valve } 153060 \\
\end{array}$ & $\begin{array}{l}\text { Fails to open/remain open } \\
\text { Fails to open/remain open }\end{array}$ & $\begin{array}{l}1.4 \mathrm{E}-4 \\
1.4 \mathrm{E}-4 \\
\end{array}$ & $2.8 \mathrm{E}-4$ \\
\hline RHR1-XVM-OO-017A & Manual valve HV 151 F017A & Fails to close & $1.0 \mathrm{E}-4$ & $1.0 \mathrm{E}-4$ \\
\hline RHR1-XVM-OO-017B & Manual valve HV 151 F017B & Fails to close & $1.0 \mathrm{E}-4$ & $1.0 \mathrm{E}-4$ \\
\hline RHR1-XVM-OO-4A & Manual valve HV 151 F004A & Fails to close & $1.0 \mathrm{E}-4$ & $1.0 \mathrm{E}-4$ \\
\hline RHR1-XVM-OO-4B & Manual valve HV $151 \mathrm{~F} 004 \mathrm{~B}$ & Fails to close & $1.0 \mathrm{E}-4$ & $1.0 \mathrm{E}-4$ \\
\hline RHR1-XVM-OO-4C & Manual valve HV $151 \mathrm{~F} 004 \mathrm{C}$ & Fails to close & $1.0 \mathrm{E}-4$ & $1.0 \mathrm{E}-4$ \\
\hline RHR1-XVM-OO-4D & Manual valve HV $151 \mathrm{~F} 004 \mathrm{D}$ & Fails to close & $1.0 \mathrm{E}-4$ & $1.0 \mathrm{E}-4$ \\
\hline RHR1-XVM-OO-SFP1 & Manual valve 153001 & Fails to close & $1.0 \mathrm{E}-4$ & $1.0 \mathrm{E}-4$ \\
\hline RHR2-CKV-CF-AC & Check valves $151 \mathrm{~F} 031 \mathrm{~A}$ and $151 \mathrm{~F} 031 \mathrm{C}$ & CCF to open/remain open & $2.78 \mathrm{E}-5$ & $2.78 \mathrm{E}-5$ \\
\hline RHR2-HTX-CF-AB & RHR heat exchangers $1 \mathrm{~A}$ and $1 \mathrm{~B}$ & CCF to operate & $1.37 \mathrm{E}-5$ & $1.37 \mathrm{E}-5$ \\
\hline
\end{tabular}


Table B.1 - Basic Event Data (Page 5 of 11)

\begin{tabular}{|c|c|c|c|c|}
\hline \multirow{2}{*}{$\begin{array}{l}\text { BASIC EVENT NAME } \\
\vdots\end{array}$} & \multicolumn{3}{|l|}{ COMPONENT DATA } & \multirow{2}{*}{$\begin{array}{l}\text { BASIC } \\
\text { EVENT } \\
\text { PROB. }\end{array}$} \\
\hline & COMPONENT NAME & FAILURE MODE & FAILURE PROB & \\
\hline RHR2-HTX-FC-1A & $\begin{array}{l}\text { RHR heat exchanger 1A } \\
\text { Manual valve HV } 151 \mathrm{~F} 047 \mathrm{~A} \\
\text { Manual valve HV } 151 \mathrm{~F} 003 \mathrm{~A} \\
\text { Relief valve PSV } 151 \mathrm{~F} 066 \mathrm{~A} \\
\text { Manual valve HV } 151 \mathrm{~F} 048 \mathrm{~B}\end{array}$ & $\begin{array}{l}\text { Plugs } \\
\text { Plugs } \\
\text { Plugs } \\
\text { Fails open } \\
\text { Ruptures/leaks } \\
\end{array}$ & $\begin{array}{l}1.37 \mathrm{E}-4 \\
4.0 \mathrm{E}-5 \\
4.0 \mathrm{E}-5 \\
1.0 \mathrm{E}-5 \\
4.0 \mathrm{E}-5 \\
\end{array}$ & $2.67 \mathrm{E}-4$ \\
\hline RHR2-HTX-FC-COOL & RHR HTX cooling system & Fails to operate & $2.4 \mathrm{E}-4$ & $2.4 \mathrm{E}-4$ \\
\hline RHR2-MDP-CF-AC & RHR pumps $1 \mathrm{~A}$ and $1 \mathrm{C}$ & CCF to start & $4.5 \mathrm{E}-5$ & $4.5 \mathrm{E}-5$ \\
\hline RHR2-MDP-FC-1A & $\begin{array}{l}\text { RHR motor driven pump 1A } \\
\text { RHR motor driven pump 1A } \\
\text { Manual valve HV 151 F006A } \\
\text { Check valve } 151 \text { F031A } \\
\text { Manual valve } 151 \text { F034A } \\
\end{array}$ & $\begin{array}{l}\text { Fails to start } \\
\text { Fails to run } \\
\text { Fails to open/remain open } \\
\text { Fails to open/remain open } \\
\text { Fails to remain open } \\
\end{array}$ & $\begin{array}{l}3.0 \mathrm{E}-3 \\
7.2 \mathrm{E}-4 \\
1.4 \mathrm{E}-4 \\
1.0 \mathrm{E}-4 \\
4.0 \mathrm{E}-5 \\
\end{array}$ & $4.0 \mathrm{E}-3$ \\
\hline RHR2-MDP-FC-1C & $\begin{array}{l}\text { RHR motor driven pump 1C } \\
\text { RHR motor driven pump 1C } \\
\text { Manual valve HV } 151 \text { F006C } \\
\text { Check valve } 151 \text { F031C } \\
\text { Manual valve } 151 \text { F034C }\end{array}$ & $\begin{array}{l}\text { Fails to start } \\
\text { Fails to run } \\
\text { Fails to open } \\
\text { Fails to open/remain open } \\
\text { Fails to remain open } \\
\end{array}$ & $\begin{array}{l}3.0 \mathrm{E}-3 \\
7.2 \mathrm{E}-4 \\
1.4 \mathrm{E}-4 \\
1.0 \mathrm{E}-4 \\
4.0 \mathrm{E}-5 \\
\end{array}$ & $4.0 \mathrm{E}-3$ \\
\hline RHR2-PSF-CC-DISA & $\begin{array}{l}\text { Manual valve } 153070 \mathrm{~A} \\
\text { Check valve } 153071 \mathrm{~A}\end{array}$ & $\begin{array}{l}\text { Fails to open/remain open } \\
\text { Fails to open/remain open }\end{array}$ & $\begin{array}{l}1.4 \mathrm{E}-4 \\
1.0 \mathrm{E}-4 \\
\end{array}$ & $2.4 \mathrm{E}-4$ \\
\hline RHR2-PSF-CC-DISB & $\begin{array}{l}\text { Manual valve } 153070 \mathrm{~B} \\
\text { Check valve } 153071 \mathrm{~B}\end{array}$ & $\begin{array}{l}\text { Fails to open/remain open } \\
\text { Fails to open/remain open }\end{array}$ & $\begin{array}{l}1.4 \mathrm{E}-4 \\
1.0 \mathrm{E}-4 \\
\end{array}$ & $2.4 \mathrm{E}-4$ \\
\hline RHR2-TRNS-UA-TM & RHR trains $A$ and $B$ & Unavailable due to Test/Maintenance & $3.0 \mathrm{E}-3$ & $3.0 \mathrm{E}-3$ \\
\hline RHR2.XVM-CC-1070 & Manual valve 151070 & Fails to open/remain open & $1.4 \mathrm{E}-4$ & $1.4 \mathrm{E}-4$ \\
\hline RHR2-XVM-CC-SUC & $\begin{array}{l}\text { Manual valve } 153021 \\
\text { Manual valve } 153060 \\
\end{array}$ & $\begin{array}{l}\text { Fails to open/remain open } \\
\text { Fails to open/remain open }\end{array}$ & $\begin{array}{l}1.4 \mathrm{E}-4 \\
1.4 \mathrm{E}-4 \\
\end{array}$ & $2.8 \mathrm{E}-4$ \\
\hline RHR2-XVM-00-017A & Manual valve HV $151 \mathrm{~F} 017 \mathrm{~A}$ & Fails to close & $1.0 \mathrm{E}-4$ & $1.0 \mathrm{E}-4$ \\
\hline RHR2-XVM-OO-4A & Manual valve HV 151 F004A & Fails to close & $1.0 \mathrm{E}-4$ & $1.0 \mathrm{E}-4$ \\
\hline RHR2-XVM-OO-4C & Manual valve HV $151 \mathrm{~F} 004 \mathrm{C}$ & Fails to close & $1.0 \mathrm{E}-4$ & $1.0 \mathrm{E}-4$ \\
\hline RHR2-XVM-OO-SFP1 & Manual valve 153001 & Fails to close & $1.0 \mathrm{E}-4$ & $1.0 \mathrm{E}-4$ \\
\hline SFP-LEAK-AUTOISO & SFP Isolation & Automatic Isolation & $6.0 \mathrm{E}-6$ & $6.0 \mathrm{E}-6$ \\
\hline
\end{tabular}


Table B.1 - Basic Event Data (Page 6 of 11)

\begin{tabular}{|c|c|c|c|c|}
\hline \multirow{2}{*}{$\begin{array}{c}\text { BASIC EVENT NAME } \\
-\end{array}$} & \multicolumn{3}{|l|}{$\overline{\text { COMPONENT DATA }}$} & \multirow{2}{*}{$\begin{array}{l}\text { BASIC } \\
\text { EVENI } \\
\text { PROB. }\end{array}$} \\
\hline & COMPONENT NAME & FAILURE MODE & FAILURE PROB & \\
\hline SFP-MKUP-ALT-F & System Failure & Alternate SFP Makup System fails & $1.0 \mathrm{E}-2$ & $1.0 \mathrm{E}-2$ \\
\hline SFP-MKUP-ECCS-F & System Failure & ECCS Systems fail to provide water & $1.0 \mathrm{E}-1$ & $1.0 \mathrm{E}-1$ \\
\hline SFP-MKUP-REG-F & System Failure & Regular SFP Makup System fails & $1.0 \mathrm{E}-1$ & $1.0 \mathrm{E}-1$ \\
\hline SFP-MKUP-U2-F & System Failure & Unit 2 makup system fail to provide water & $5.0 \mathrm{E}-2$ & $5.0 \mathrm{E}-2$ \\
\hline SFP-OP-GATE & Flag Event & SFPs are connectable & TRUE & TRUE \\
\hline SFP-OPEN-GATE & Gate Status & $\begin{array}{l}\text { Open gate status of transfer gate } \\
\text { between pools }\end{array}$ & $1.0 \mathrm{E}-1$ & $1.0 \mathrm{E}-1$ \\
\hline SFP-XHE-ISO-LK & Operator Action & $\begin{array}{l}\text { Fails to isolate leak during } \\
\text { Primary LOCA }\end{array}$ & $7.0 \mathrm{E}-3$ & $7.0 \mathrm{E}-3$ \\
\hline SFP-XHE-MANISO-E & Operator Action & $\begin{array}{l}\text { Fails to isolate small SFP boundary } \\
\text { leak (early) }\end{array}$ & $7.0 \mathrm{E}-3$ & $7.0 \mathrm{E}-3$ \\
\hline SFP-XHE-MANIOS-L & Operator Action & $\begin{array}{l}\text { Fails to isolate small SFP boundary } \\
\text { leak (late) }\end{array}$ & $8.0 \mathrm{E}-2$ & $8.0 \mathrm{E}-2$ \\
\hline SFP-XHE-XA-ECCS & Operator Action & Fails to align ECCS & $1.0 \mathrm{E}-3$ & $1.0 \mathrm{E}-3$ \\
\hline SFP-XHE-XE-LINVC & Operator Action & $\begin{array}{l}\text { Fails to restore SFP (Loss of Inventory) } \\
\text { Unit is critical }\end{array}$ & 7.0E-2 & $7.0 \mathrm{E}-2$ \\
\hline SFP-XIIE-XE-LINVR & Operator Action & $\begin{array}{l}\text { Fails to restore SFP (Loss of Inventory) } \\
\text { Unit is refueling }\end{array}$ & $4.0 \mathrm{E}-3$ & $4.0 \mathrm{E}-3$ \\
\hline SFP-XHE-XE-LP & Operator Action & $\begin{array}{l}\text { Fails to restore SFP Cooling } \\
\text { during loss of power }\end{array}$ & $7.0 \mathrm{E}-2$ & $7.0 \mathrm{E}-2$ \\
\hline SFP-XHE-XE-PLC & Operator Action & $\begin{array}{l}\text { Fails to restore SFP Cooling } \\
\text { during Primary LOCA (Unit is critical) }\end{array}$ & $7.0 \mathrm{E}-2$ & $7.0 \mathrm{E}-2$ \\
\hline SFP-XHE-XE-PLR & Operator Action & $\begin{array}{l}\text { Fails to restore SFP Cooling } \\
\text { during Primary LOCA (Unit is refueling) }\end{array}$ & $4.0 \mathrm{E}-3$ & $4.0 \mathrm{E}-3$ \\
\hline SFP-XHE-XE-UC & Operator Action & $\begin{array}{l}\text { Fails to restore SFP Cooling } \\
\text { (unit is critical) }\end{array}$ & $4.0 \mathrm{E}-2$ & $4.0 \mathrm{E}-2$ \\
\hline
\end{tabular}


Table B.1 - Basic Event Data (Page 7 of 11)

\begin{tabular}{|c|c|c|c|c|}
\hline \multirow{2}{*}{$\begin{array}{c}\text { BASIC EVENT NAME } \\
\gamma\end{array}$} & \multicolumn{3}{|l|}{ COMPONENT DATA } & \multirow{2}{*}{$\begin{array}{l}\text { BASIC } \\
\text { EVENT } \\
\text { PROB. }\end{array}$} \\
\hline & COMPONENT NAME & FALLURE MODE & FAILURE PROB & \\
\hline SFP-XHE-XE-UR & Operator Action & $\begin{array}{l}\text { Fails to restore SFP Cooling } \\
\text { (unit is refueling) }\end{array}$ & $4.0 \mathrm{E}-2$ & $4.0 \mathrm{E}-2$ \\
\hline SFP1-XHE-XM-LSFP & Operator Action & $\begin{array}{l}\text { Fails to iniate SFP Cooling } \\
\text { after late recovery (unit 1) }\end{array}$ & $8.0 \mathrm{E}-2$ & $8.0 \mathrm{E}-2$ \\
\hline SFPI-XHE-XM-SFP & Operator Action & $\begin{array}{l}\text { Fails to iniate SFP Cooling } \\
\text { (early, unit 1) }\end{array}$ & $7.0 \mathrm{E}-3$ & $7.0 \mathrm{E}-3$ \\
\hline SFP2-XHE-XM-LSFP & Operator Action & $\begin{array}{l}\text { Fails to iniate SFP Cooling } \\
\text { after late recovery (unit 2) }\end{array}$ & $8.0 \mathrm{E}-2$ & $8.0 \mathrm{E}-2$ \\
\hline SFP2-XHE-XM-SFP & Operator Action & $\begin{array}{l}\text { Fails to initate SFP Cooling } \\
\text { (early, unit } 2 \text { ) }\end{array}$ & $3.0 \mathrm{E}-2$ & $3.0 \mathrm{E}-2$ \\
\hline SFPS-XHE-XM-LSFP & Operator Action & $\begin{array}{l}\text { Fails to initate SFP Cooling } \\
\text { (late, unit } 1 \text { and } 2 \text { ) }\end{array}$ & $1.1 \mathrm{E}-2$ & $1.1 \mathrm{E}-2$ \\
\hline SPC1-CKV-CF-2F & SFP heat exchanger dis. chk valves & CCF to open/remain open & $1.87 \mathrm{E}-5$ & $1.87 \mathrm{E}-5$ \\
\hline SPC1-CKV-CF-DIS & SFP discharge check valves & CCF to open/remain open & $2.67 \mathrm{E}-5$ & $2.67 \mathrm{E}-5$ \\
\hline SPC1-CKV-CF-MP2F & SFP pump discharge check valves & CCF (2-of-3) to open/remain open & $3.16 \mathrm{E}-5$ & $3.16 \mathrm{E}-5$ \\
\hline SPC1-CKV-CF-MPA & SFP pump discharge check valves & CCF (all 3) to open/remain open & $1.69 \mathrm{E}-5$ & $1.69 \mathrm{E}-5$ \\
\hline SPC1-1ITX-CF-2F & SFP heat exchangers & CCF (2-of-3) HTXs & $1.87 \mathrm{E}-5$ & $1.87 \mathrm{E}-5$ \\
\hline SPC1-HTX-CF-ALL & SFP heat exchangers & CCF (all 3) HTXs & $3.7 \mathrm{E}-6$ & $3.7 \mathrm{E}-6$ \\
\hline SPC1-HTX-FC-1A & $\begin{array}{l}\text { Manual valve } 153002 \mathrm{~A} \\
\text { Heat exchanger } 1 \mathrm{~A} \\
\text { Manual valve } 153004 \mathrm{~A} \\
\end{array}$ & $\begin{array}{l}\text { Plugs } \\
\text { Plugs } \\
\text { Plugs } \\
\end{array}$ & $\begin{array}{l}4.0 \mathrm{E}-5 \\
1.37 \mathrm{E}-5 \\
4.0 \mathrm{E}-5 \\
\end{array}$ & $2.17 \mathrm{E}-5$ \\
\hline SPC1-HTX-FC-1B & $\begin{array}{l}\text { Manual valve } 153002 \mathrm{~B} \\
\text { Heat exchanger } 1 \mathrm{~B} \\
\text { Manual valve } 153004 \mathrm{~B}\end{array}$ & $\begin{array}{l}\text { Plugs } \\
\text { Plugs } \\
\text { Plugs } \\
\end{array}$ & $\begin{array}{l}4.0 \mathrm{E}-5 \\
1.37 \mathrm{E}-5 \\
4.0 \mathrm{E}-5 \\
\end{array}$ & $2.17 \mathrm{E}-5$ \\
\hline SPC1-HTX-FC-1C & $\begin{array}{l}\text { Manual valve } 153002 \mathrm{C} \\
\text { Heat exchanger } 1 \mathrm{C} \\
\text { Manual valve } 153004 \mathrm{C}\end{array}$ & $\begin{array}{l}\text { Plugs } \\
\text { Plugs } \\
\text { Plugs } \\
\end{array}$ & $\begin{array}{l}4.0 \mathrm{E}-5 \\
1.37 \mathrm{E}-5 \\
4.0 \mathrm{E}-5 \\
\end{array}$ & $2.17 \mathrm{E}-5$ \\
\hline SPC1-HTX-FC-COOL & SFP HTX cooling system & Fails to operate & $2.4 \mathrm{E}-4$ & $2.4 \mathrm{E}-4$ \\
\hline SPC1-MDP-CF-2F & SFP MDP (early) & CCF to start/run (2-of-3) & $5.86 \mathrm{E}-4$ & $5.86 \mathrm{E}-4$ \\
\hline
\end{tabular}


Table B.1 - Basic Event Data (Page 8 of 11)

\begin{tabular}{|c|c|c|c|c|}
\hline \multirow{2}{*}{$\begin{array}{l}\text { BASIC EVENT NAME } \\
y\end{array}$} & \multicolumn{3}{|l|}{ COMPONENT DATA } & \multirow{2}{*}{$\begin{array}{l}\text { BASIC } \\
\text { EVENI } \\
\text { PROB. }\end{array}$} \\
\hline & COMPONENT NAME & FAILURE MODE & FAILURE PRUB & \\
\hline $\begin{array}{l}\text { SPC1-MDP-CF-ALL } \\
\text { SPC1-MDP-CF-L2F }\end{array}$ & $\begin{array}{l}\text { SFP MDP (early) } \\
\text { SFP MDP (late) }\end{array}$ & $\begin{array}{l}\text { CCF to start/run (all 3) } \\
\text { CCF to start/run (2-of-3) }\end{array}$ & $\begin{array}{r}2.72 \mathrm{E}-4 \\
5.86 \mathrm{E}-4 \\
\end{array}$ & $\begin{array}{l}2.72 \mathrm{E}-4 \\
5.86 \mathrm{E}-4 \\
\end{array}$ \\
\hline SPC1-MDP-CF-LALL & SFP MDP (late) & CCF to start/run (all 3) & $2.72 \mathrm{E}-4$ & $2.72 \mathrm{E}-4$ \\
\hline SPC1-MDP-FC-1A & $\begin{array}{l}\text { Manual valve } 153006 \mathrm{~A} \\
\text { Motor driven pump } 1 \mathrm{~A} \\
\text { Check valve } 153009 \mathrm{~A} \\
\text { Manual valve } 153010 \mathrm{~A} \\
\end{array}$ & $\begin{array}{l}\text { Fails to remain open } \\
\text { Fails to start/run } \\
\text { Fails to open/remain open } \\
\text { Fails to remain open } \\
\end{array}$ & $\begin{array}{l}4.0 \mathrm{E}-5 \\
3.7 \mathrm{E}-3 \\
1.0 \mathrm{E}-4 \\
4.0 \mathrm{E}-5 \\
\end{array}$ & $3.88 \mathrm{E}-3$ \\
\hline SPC1-MDP-FC-1AL (late) & $\begin{array}{l}\text { Manual valve } 153006 \mathrm{~A} \\
\text { Motor driven pump 1A } \\
\text { Check valve } 153009 \mathrm{~A} \\
\text { Manual valve } 153010 \mathrm{~A} \\
\end{array}$ & $\begin{array}{l}\text { Fails to remain open } \\
\text { Fails to start/run } \\
\text { Fails to open/remain open } \\
\text { Fails to remain open } \\
\end{array}$ & $\begin{array}{l}4.0 \mathrm{E}-5 \\
3.7 \mathrm{E}-3 \\
1.0 \mathrm{E}-4 \\
4.0 \mathrm{E}-5 \\
\end{array}$ & $3.88 \mathrm{E}-3$ \\
\hline SPC1-MDP-FC-1B & $\begin{array}{l}\text { Manual valve } 153006 \mathrm{~B} \\
\text { Motor driven pump 1B } \\
\text { Check valve } 153009 \mathrm{~B} \\
\text { Manual valve } 153010 \mathrm{~B} \\
\end{array}$ & $\begin{array}{l}\text { Fails to remain open } \\
\text { Fails to start/run } \\
\text { Fails to open/remain open } \\
\text { Fails to remain open } \\
\end{array}$ & $\begin{array}{l}4.0 \mathrm{E}-5 \\
3.7 \mathrm{E}-3 \\
1.0 \mathrm{E}-4 \\
4.0 \mathrm{E}-5 \\
\end{array}$ & $3.88 \mathrm{E}-3$ \\
\hline SPC1-MDP-FC-1BL (late) & $\begin{array}{l}\text { Manual valve 153006B } \\
\text { Motor driven pump 1B } \\
\text { Check valve } 153009 \mathrm{~B} \\
\text { Manual valve } 153010 \mathrm{~B} \\
\end{array}$ & $\begin{array}{l}\text { Fails to remain open } \\
\text { Fails to start/run } \\
\text { Fails to open/remain open } \\
\text { Fails to remain open } \\
\end{array}$ & $\begin{array}{l}4.0 \mathrm{E}-5 \\
3.7 \mathrm{E}-3 \\
1.0 \mathrm{E}-4 \\
4.0 \mathrm{E}-5\end{array}$ & $3.88 \mathrm{E}-3$ \\
\hline SPC1-MDP-FC-1C & $\begin{array}{l}\text { Manual valve } 153006 \mathrm{C} \\
\text { Motor driven pump 1C } \\
\text { Check valve } 153009 \mathrm{C} \\
\text { Manual valve } 153010 \mathrm{C} \\
\end{array}$ & $\begin{array}{l}\text { Fails to remain open } \\
\text { Fails to start/run } \\
\text { Fails to open/remain open } \\
\text { Fails to remain open } \\
\end{array}$ & $\begin{array}{l}4.0 \mathrm{E}-5 \\
3.7 \mathrm{E}-3 \\
1.0 \mathrm{E}-4 \\
4.0 \mathrm{E}-5 \\
\end{array}$ & $3.88 \mathrm{E}-3$ \\
\hline SPC1-MDP-FC-1CL (late) & $\begin{array}{l}\text { Manual valve } 153006 \mathrm{C} \\
\text { Motor driven pump 1C } \\
\text { Check valve } 153009 \mathrm{C} \\
\text { Manual valve } 153010 \mathrm{C} \\
\end{array}$ & $\begin{array}{l}\text { Fails to remain open } \\
\text { Fails to start/run } \\
\text { Fails to open/remain open } \\
\text { Fails to remain open } \\
\end{array}$ & $\begin{array}{l}4.0 \mathrm{E}-5 \\
3.7 \mathrm{E}-3 \\
1.0 \mathrm{E}-4 \\
4.0 \mathrm{E}-5 \\
\end{array}$ & $3.88 \mathrm{E}-3$ \\
\hline SPC1-PSF-FC-DISA & $\begin{array}{l}\text { Manual valve } 153018 \mathrm{~A} \\
\text { Check valve } 153019 \mathrm{~A}\end{array}$ & $\begin{array}{l}\text { Plugs } \\
\text { Fails to open/remain open }\end{array}$ & $\begin{array}{l}4.0 \mathrm{E}-5 \\
1.0 \mathrm{E}-4 \\
\end{array}$ & $1.4 \mathrm{E}-4$ \\
\hline SPC1-PSF-FC-DISB & $\begin{array}{l}\text { Manual valve } 153018 \mathrm{~B} \\
\text { Check valve } 153019 \mathrm{~B}\end{array}$ & $\begin{array}{l}\text { Plugs } \\
\text { Fails to open/remain open }\end{array}$ & $\begin{array}{l}4.0 \mathrm{E}-5 \\
1.0 \mathrm{E}-4 \\
\end{array}$ & $1.4 \mathrm{E}-4$ \\
\hline
\end{tabular}


Table B.1 - Basic Event Data (Page 9 of 11)

\begin{tabular}{|c|c|c|c|c|}
\hline \multirow{2}{*}{$\begin{array}{c}\text { BASIC EVENT NAME } \\
y\end{array}$} & \multicolumn{3}{|l|}{ COMPONENT DATA } & \multirow{2}{*}{$\begin{array}{l}\text { BASIC } \\
\text { EVENT } \\
\text { PROB. }\end{array}$} \\
\hline & COMPONENT NAME & FAILURE MODE & FAILURE PROB & \\
\hline SPC1-XVM-OC-3001 & Manual valve 153001 & Plugs & $4.0 \mathrm{E}-5$ & $4.0 \mathrm{E}-5$ \\
\hline SPC1-XVM-OC-3013 & Manual valve 153013 & Fails to remain open/Plugs & 4.0E-5 & $4.0 \mathrm{E}-5$ \\
\hline SPC1-XVM-OC-3017 & Manual valve 153017 & Fails to remain open/Plugs & $4.0 \mathrm{E}-5$ & $4.0 \mathrm{E}-5$ \\
\hline SPC2-CKV-CF-DIS & SFP discharge check valves & CCF to open/remain open & $2.67 \mathrm{E}-5$ & $2.67 \mathrm{E}-5$ \\
\hline SPC2-CKV-CF-MP2F & SFP pump discharge check valves & CCF (2-of-3) to open/remain open & $3.16 \mathrm{E}-5$ & $3.16 \mathrm{E}-5$ \\
\hline SPC2-CKV-CF-MPA & SFP pump discharge check valves & CCF (all 3) to open/remain open & $1.69 \mathrm{E}-5$ & $1.69 \mathrm{E}-5$ \\
\hline SPC2-HTX-CF-2F & SFP heat exchangers & CCF (2-of-3) HTXs & $1.87 \mathrm{E}-5$ & $1.87 \mathrm{E}-5$ \\
\hline SPC2-HTX-CF-ALL & SFP heat exchangers & CCF (all 3) HTXs & $3.7 \mathrm{E}-6$ & $3.7 \mathrm{E}-6$ \\
\hline SPC2-HTX-FC-1A & $\begin{array}{l}\text { Manual valve } 153002 \mathrm{~A} \\
\text { Heat exchanger } 1 \mathrm{~A} \\
\text { Manual valve } 153004 \mathrm{~A} \\
\end{array}$ & $\begin{array}{l}\text { Plugs } \\
\text { Plugs } \\
\text { Plugs } \\
\end{array}$ & $\begin{array}{l}4.0 \mathrm{E}-5 \\
1.37 \mathrm{E}-5 \\
4.0 \mathrm{E}-5\end{array}$ & $2.17 \mathrm{E}-5$ \\
\hline SPC2-HTX-FC-1B & $\begin{array}{l}\text { Manual valve } 153002 \mathrm{~B} \\
\text { Heat exchanger 1B } \\
\text { Manual valve 153004B } \\
\end{array}$ & $\begin{array}{l}\text { Plugs } \\
\text { Plugs } \\
\text { Plugs } \\
\end{array}$ & $\begin{array}{l}4.0 \mathrm{E}-5 \\
1.37 \mathrm{E}-5 \\
4.0 \mathrm{E}-5 \\
\end{array}$ & $2.17 \mathrm{E}-5$ \\
\hline SPC2-HTX-FC-1C & $\begin{array}{l}\text { Manual valve } 153002 \mathrm{C} \\
\text { Heat exchanger } 1 \mathrm{C} \\
\text { Manual valve } 153004 \mathrm{C} \\
\end{array}$ & $\begin{array}{l}\text { Plugs } \\
\text { Plugs } \\
\text { Plugs } \\
\end{array}$ & $\begin{array}{l}4.0 \mathrm{E}-5 \\
1.37 \mathrm{E}-5 \\
4.0 \mathrm{E}-5 \\
\end{array}$ & $2.17 \mathrm{E}-5$ \\
\hline SPC2-H7X-FC-COOL & SFP HTX cooling system & Fails to operate & $2.4 \mathrm{E}-4$ & $2.4 \mathrm{E}-4$ \\
\hline SPC2-MDP-CF-2F & SFP MDP (early) & CCF to start/run (2-of-3) & $5.86 \mathrm{E}-4$ & $5.86 \mathrm{E}-4$ \\
\hline SPC2-MDP-CF-ALL & SFP MDP (early) & CCF to start/run (all 3) & $2.72 \mathrm{E}-4$ & $2.72 \mathrm{E}-4$ \\
\hline SPC2-MDP-CF-L2F & SFP MDP (late) & CCF to start/run (2-of-3) & $5.86 \mathrm{E}-4$ & $5.86 \mathrm{E}-4$ \\
\hline SPC2-MDP-CF-LALL & SFP MDP (late) & CCF to start/run (all 3) & $2.72 \mathrm{E}-4$ & $2.72 \mathrm{E}-4$ \\
\hline SPC2-MDP-FC-1A & $\begin{array}{l}\text { Manual valve } 153006 \mathrm{~A} \\
\text { Motor driven pump } 1 \mathrm{~A} \\
\text { Check valve } 153009 \mathrm{~A} \\
\text { Manual valve } 153010 \mathrm{~A}\end{array}$ & $\begin{array}{l}\text { Fails to remain open } \\
\text { Fails to start/run } \\
\text { Fails to open/remain open } \\
\text { Fails to remain open }\end{array}$ & $\begin{array}{l}4.0 \mathrm{E}-5 \\
3.7 \mathrm{E}-3 \\
1.0 \mathrm{E}-4 \\
4.0 \mathrm{E}-5 \\
\end{array}$ & $3.88 \mathrm{E}-3$ \\
\hline SPC2-MDP-FC-1AL (late) & $\begin{array}{l}\text { Manual valve } 153006 \mathrm{~A} \\
\text { Motor driven pump } 1 \mathrm{~A} \\
\text { Check valve } 153009 \mathrm{~A} \\
\text { Manual valve } 153010 \mathrm{~A} \\
\end{array}$ & $\begin{array}{l}\text { Fails to remain open } \\
\text { Fails to start/run } \\
\text { Fails to open/remain open } \\
\text { Fails to remain open }\end{array}$ & $\begin{array}{l}4.0 \mathrm{E}-5 \\
3.7 \mathrm{E}-3 \\
1.0 \mathrm{E}-4 \\
4.0 \mathrm{E}-5\end{array}$ & $3.88 \mathrm{E}-3$ \\
\hline
\end{tabular}


Table B.1 - Basic Event Data (Page 10 of 11)

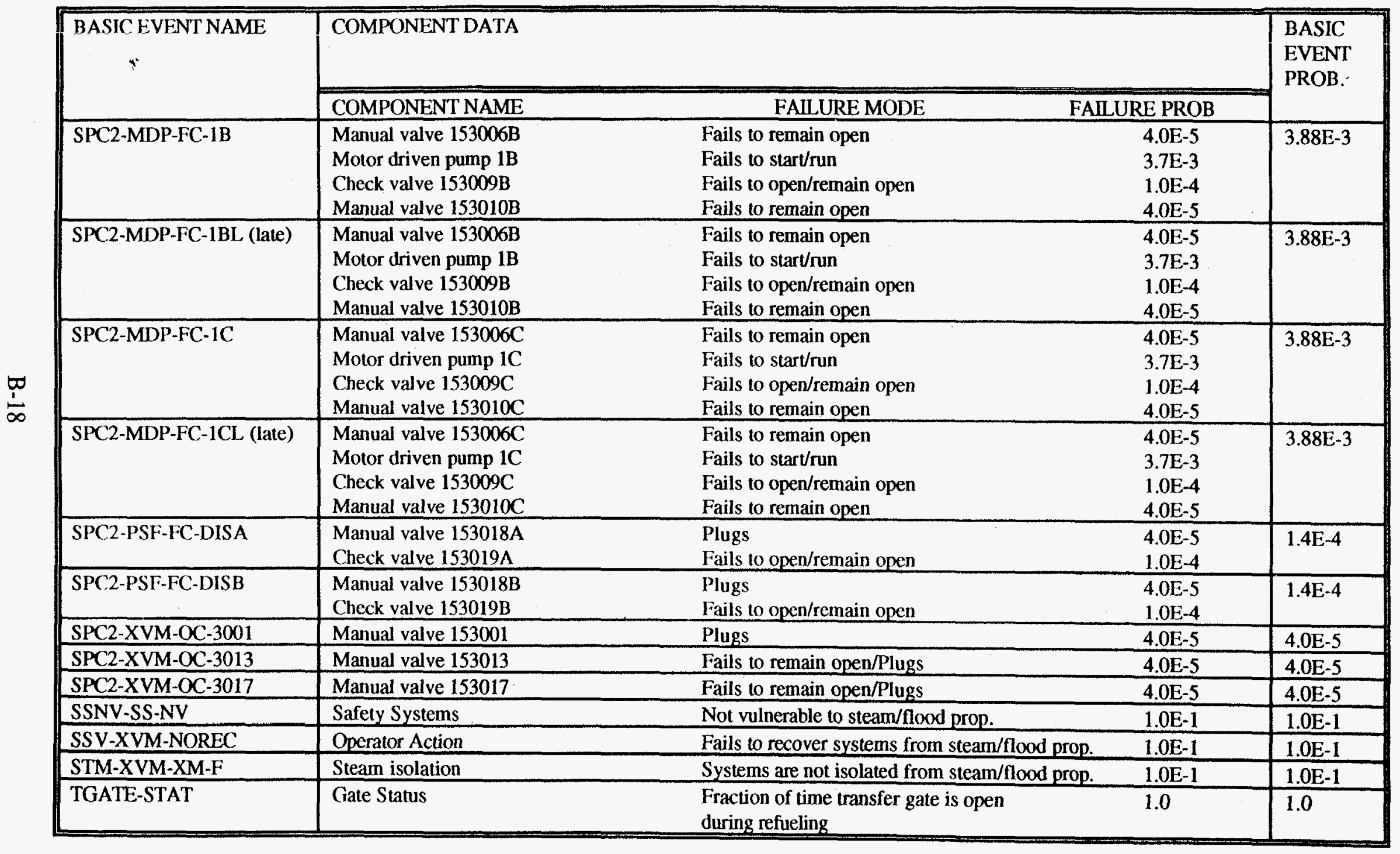


Table B.1 - Basic Event Data (Page 11 of 11)

\begin{tabular}{|c|c|c|c|c|}
\hline \multirow{2}{*}{ BASIC EVENT NAME } & \multicolumn{3}{|l|}{ COMPONENT DATA } & \multirow{2}{*}{$\begin{array}{l}\text { BASIC } \\
\text { EVENT } \\
\text { PROB. }\end{array}$} \\
\hline & COMPONENT NAME & FAILURE MODE & FAILURE PROB & \\
\hline UNREC-XHE-RECV-1 & \multicolumn{2}{|c|}{ Complicated Recovery of Core Cooling, LOOP, EP recovered early } & $5.9 \mathrm{E}-2$ & $5.9 \mathrm{E}-2$ \\
\hline UNREC-XHE-RECV-2 & \multicolumn{2}{|c|}{$\begin{array}{l}\text { Complicated Recovery of Core Cooling, LOOP, EP not recovered } \\
\text { Complicated Recovery of Core Cooling during Primary }\end{array}$} & $5.9 \mathrm{E}-2$ & $5.9 \mathrm{E}-2$ \\
\hline UNREC-XHE-RECV-P & \multicolumn{2}{|c|}{ Complicated Recovery of Core Cooling during Primary LOCA } & $3.0 \mathrm{E}-2$ & $3.0 \mathrm{E}-2$ \\
\hline LKSMR & Leak fraction & $\begin{array}{l}\text { Fraction of small eaks in SFP boundary } \\
\text { (operation and refueling) }\end{array}$ & $2.0 \mathrm{E}-1$ & $2.0 \mathrm{E}-1$ \\
\hline LKLGC & Leak fraction & $\begin{array}{l}\text { Fraction of large leaks in SFP boundary } \\
\text { (operation) }\end{array}$ & $3.0 \mathrm{E}-1$ & $3.0 \mathrm{E}-1$ \\
\hline LKLGR & Leak fraction & $\begin{array}{l}\text { Fraction of large leaks in SFP boundary } \\
\text { (refueling) }\end{array}$ & $7.0 \mathrm{E}-1$ & $7.0 \mathrm{E}-1$ \\
\hline MISLLGE & Operator Action & $\begin{array}{l}\text { Fails to isolate large SFP boundary } \\
\text { leak (early) }\end{array}$ & $1.8 \mathrm{E}-1$ & $1.8 \mathrm{E}-1$ \\
\hline MISLLGL & Operator Action & $\begin{array}{l}\text { Fails to isolate large SFP boundary } \\
\text { leak (late) }\end{array}$ & 8.0E-1 & $8.0 \mathrm{E}-1$ \\
\hline MISLSPCE & Operator Action & $\begin{array}{l}\text { Fails to isolate SFPC system } \\
\text { leak (refueling) }\end{array}$ & $8.0 \mathrm{E}-2$ & $8.0 \mathrm{E}-2$ \\
\hline MISISSPHIN & Operator Action & $\begin{array}{l}\text { Fails to isolate SFPC system } \\
\text { leak (critical) }\end{array}$ & $8.0 \mathrm{E}-2$ & $8.0 \mathrm{E}-2$ \\
\hline
\end{tabular}


Table B.2 - LOOP Model Parameters for Susquehanna

\begin{tabular}{|c|c|c|c|}
\hline $\mathrm{i}$ & $\lambda_{0}$ & $\alpha$ & $\beta$ \\
\hline $\mathrm{I} 1$ & 0.0797 & 3.3136 & 0.7837 \\
\hline $\mathrm{G} 1 \mathrm{R} 2$ & 0.01 & 1.4697 & 0.9899 \\
\hline S2R2 & 0.005 & 0.1985 & 0.9759 \\
\hline SS3 & 0.002 & 0 & 0 \\
\hline
\end{tabular}

Table B.3 - Breakdown of Piping-Associated SFP Leaks

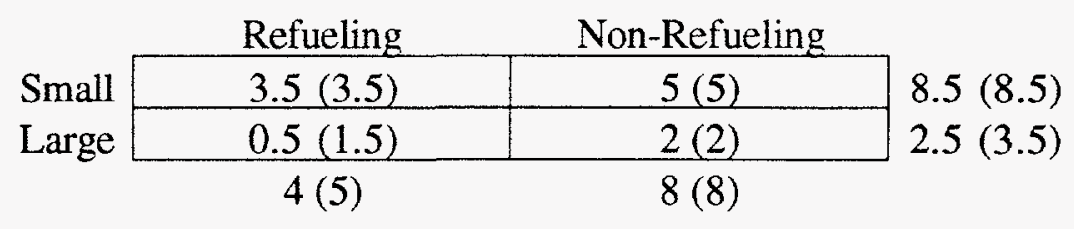

Table B.4 - Breakdown of Seal-Associated SFP Leaks

\begin{tabular}{l|c|c|}
\multicolumn{2}{c}{ Refueling } & \multicolumn{1}{c}{ Non-Refueling } \\
\cline { 2 - 3 } Small & $1(2)$ & $0(1)$ \\
\cline { 2 - 2 } Large & $1(3)$
\end{tabular}

Table B.5 - Frequency-Magnitude Relationship for Earthquakes at the Susquehanna Site

\begin{tabular}{|c|c|}
\hline g level & Mean Frequency $(/ \mathrm{yr})$ \\
\hline 0.15 & $1.47 \mathrm{E}-04$ \\
\hline 0.26 & $5.29 \mathrm{E}-05$ \\
\hline 0.31 & $3.49 \mathrm{E}-05$ \\
\hline 0.41 & $1.71 \mathrm{E}-05$ \\
\hline 0.51 & $9.28 \mathrm{E}-06$ \\
\hline 0.66 & $4.26 \mathrm{E}-06$ \\
\hline 0.82 & $2.19 \mathrm{E}-06$ \\
\hline 1.02 & $1.02 \mathrm{E}-06$ \\
\hline
\end{tabular}


Appendix C

Human Reliability Analysis 


\section{APPENDIX C - HUMAN RELIABILITY ANALYSIS}

\section{C.1 Approach}

In keeping with the simple modeling approach used in other parts of the analysis, a simple human reliability analysis (HRA) technique is employed. This technique, documented in Ref. C.1, is a worksheet-based approach developed for the Accident Sequence Precursor (ASP) program. A sample worksheet for a single action is shown in Figure C.1. The worksheet requires the analyst to evaluate performance shaping factors (PSFs) relevant to a given action and then to modify base human error probabilities (HEPs) based on the evaluation.

The likelihood of failure of subsequent actions is treated using a second worksheet (see Figure C.2). This worksheet addresses issues that could increase the dependency between actions. This study treats multiple unit actions (e.g., failure of operators at Unit 2 to restore spent fuel pool makeup using Unit 2 systems, given that operators at Unit 1 have failed using the Unit 1 systems) using the worksheet. In general, the result is that there is a moderate level of dependency between actions.

The base HEPS and modification factors used in this procedure are derived from the widely used Technique for Human Error Prediction (THERP) [C.2] methodology. Thus, the approach does not represent a fundamentally different approach to dealing with human errors; rather it is a consistent psychology- and human factors-based compilation which allows relatively quick (if sometimes conservative) estimates of HEPs under a wide variety of conditions.

\section{C.2 Performance Shaping Factors}

There are six performance shaping factors required by the ASP HRA technique and used in this analysis. The performance shaping factors are:

1. Complexity, stress, and workload

2. Experience/training

3. Procedures

4. Ergonomics

5. Fitness for Duty

6. Crew dynamics.

The first four PSFs are of special interest to this study, due to the nature of the spent fuel pool accident scenarios hypothesized. 
Plant:

Scenario:

Sequence Number:

Cutset:

Task Error Description:

Brocessing Besponse

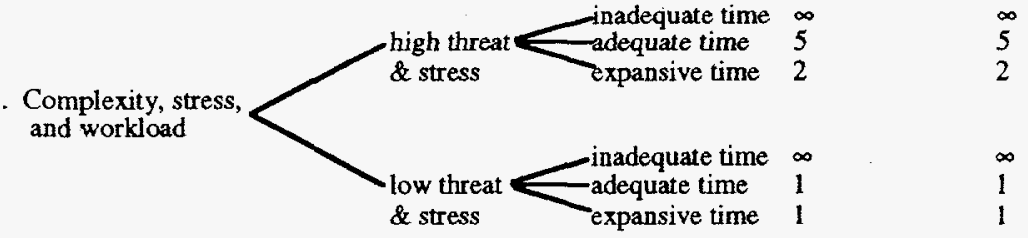

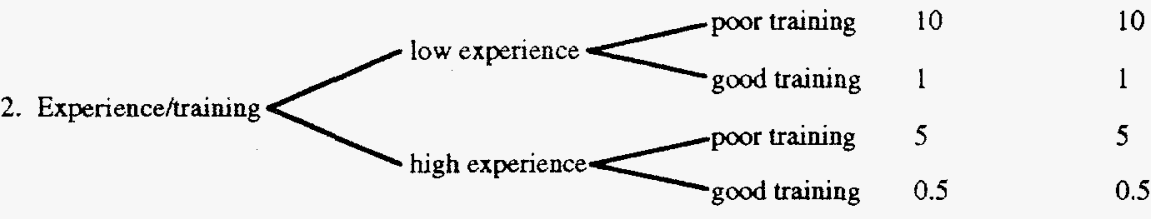

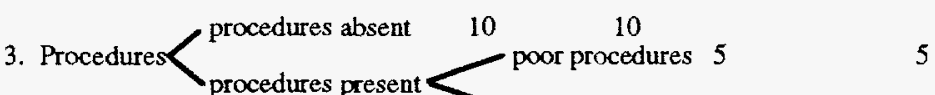

procedures present $<$ good procedures 1

4. Ergonomics

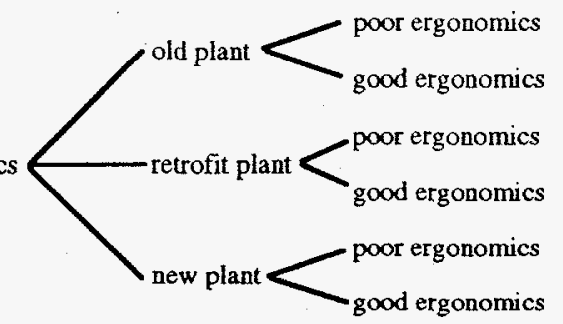

$\begin{array}{ll}5 & 5 \\ 1 & 1 \\ 3 & 3 \\ 0.7 & 0.7 \\ 2 & 2 \\ 0.4 & 0.4\end{array}$

5. Fitness for duty $\begin{array}{lll}\text { unfit } & 25 & 25 \\ \text { fit } & 1 & 1\end{array}$

6. Crew dynamics $\begin{array}{lll}\text { poor crew dynamics } & 10 & 10 \\ \text { good crew dynamics } & 1 & 1\end{array}$.

$\begin{array}{cccc} & \begin{array}{c}\text { Complexity, Experience/ Procedures Ergonomics } \\ \text { stress, and }\end{array} & \begin{array}{c}\text { Fitmess } \\ \text { training }\end{array} & \text { for } \\ \text { Work } & \text { dynamics } \\ \text { Task Portion } & \text { workload } & & \text { dury }\end{array}$

$\mathbf{x}$

$\mathbf{x}$

$\mathrm{x}$

$x$

$\boldsymbol{x}$

Processing Failure Probability

Response:

$10 \mathrm{E}-3 x$

$\mathbf{x}$

$x$

$\mathbf{x}$

$x$

$\mathbf{x}$

Response Failure Probability

Task Failure Probability

Without Formal Dependence

Figure C.1 - ASP HRA Worksheet (Sheet 1 of 2) 
DEPENDENCY CONDITION TABLE

\begin{tabular}{|c|c|c|c|c|c|c|c|}
\hline $\begin{array}{c}\text { Condition } \\
\text { Number }\end{array}$ & $\begin{array}{c}\text { Crew } \\
\text { (same or } \\
\text { different) }\end{array}$ & $\begin{array}{l}\text { System } \\
\text { (same or } \\
\text { different) }\end{array}$ & $\begin{array}{l}\text { Location } \\
\text { (same or } \\
\text { different) }\end{array}$ & $\begin{array}{c}\text { Time } \\
\text { (close in } \\
\text { time or not } \\
\text { close in } \\
\text { time }\end{array}$ & $\begin{array}{c}\text { Cues } \\
\text { (additional } \\
\text { or not } \\
\text { additional) }\end{array}$ & Dependency & $\begin{array}{l}\text { Number of } \\
\text { Human Action } \\
\text { Failures }\end{array}$ \\
\hline 1 & s & $s$ & $\mathrm{~s}$ & c & - & complete & \multirow{4}{*}{ error is the } \\
\hline 2 & $s$ & $s$ & $s$ & $\mathrm{nc}$ & na & high & \\
\hline 3 & $s$ & s & s & $\mathrm{nc}$ & a & moderate & \\
\hline 4 & $\mathrm{~s}$ & $s$ & d & $\mathrm{c}$ & - & high & \\
\hline 5 & $\mathrm{~s}$ & $s$ & d & $\mathrm{nc}$ & na & moderate & \multirow[t]{2}{*}{ third error } \\
\hline 6 & $s$ & $s$ & d & $\mathrm{nc}$ & $\mathrm{a}$ & low & \\
\hline 7 & $\mathrm{~s}$ & $\mathrm{~d}$ & $s$ & $c$ & - & moderate & \multirow[t]{2}{*}{ in the } \\
\hline 8 & $\mathrm{~s}$ & $\mathrm{~d}$ & s & $\mathrm{nc}$ & na & low & \\
\hline 9 & $s$ & $\mathrm{~d}$ & $s$ & $\mathrm{nc}$ & $\mathrm{a}$ & low & \multirow[t]{2}{*}{ sequence } \\
\hline 10 & $s$ & d & d & c & - & moderate & \\
\hline 11 & $s$ & d & d & nc & na & low & \multirow[t]{2}{*}{ then the } \\
\hline 12 & $s$ & $d$ & d & $\mathrm{nc}$ & $\mathrm{a}$ & low & \\
\hline 13 & d & $\mathrm{s}$ & $\mathrm{s}$ & $\mathrm{c}$ & - & moderate & \multirow[t]{2}{*}{ dependency } \\
\hline 14 & d & $s$ & $s$ & $\mathrm{nc}$ & na & low & \\
\hline 15 & d & $s$ & s & $\mathrm{nc}$ & $\mathrm{a}$ & zero & \multirow[t]{2}{*}{ is moderate, } \\
\hline 16 & d & $s$ & $\mathrm{~d}$ & $\mathrm{c}$ & - & zero & \\
\hline 17 & d & $s$ & d & $\mathrm{nc}$ & na & zero & \multirow[t]{2}{*}{ if $i t$ is the } \\
\hline 18 & d & $s$ & d & $\mathrm{nc}$ & a & zero & \\
\hline 19 & d & $d$ & $s$ & c & - & low & \multirow[t]{2}{*}{ fourth error } \\
\hline 20 & d & $\mathrm{d}$ & $\mathrm{s}$ & nc & na & zero & \\
\hline 21 & d & d & $s$ & $\mathrm{nc}$ & a & zero & \multirow[t]{2}{*}{ dependency } \\
\hline 22 & d & d & d & $\mathrm{c}$ & - & zero & \\
\hline 23 & d & d & d & $\mathrm{nc}$ & na & zero & \multirow[t]{2}{*}{ is high } \\
\hline 24 & $d$ & $\mathrm{~d}$ & $\mathrm{~d}$ & $\mathrm{nc}$ & $\mathrm{a}$ & zero & \\
\hline
\end{tabular}

Using N=Task Failure Probability Without Formal Dependence (calculated on previous page):

For Complete Dependence the probability of failure is 1 .

For High Dependence the probability of failure is $(1+\mathrm{N}) / 2$

For Moderate Dependence the probability of failure is $(1+6 \mathrm{~N}) / 7$

For Low Dependence the probability of failure is $(1+19 \mathrm{~N}) / 20$

For Zero Dependence the probability of failure is $\mathrm{N}$
$\left(1+\underline{-}^{*}\right.$
)$)$
Task Failure Probability With
Formal Dependence

Figure C.2 - ASP HRA Worksheet (page 2 of 2) 
1. Complexity stress, and workload. For this PSF several different conditions would exist for the hypothesized scenarios. For example, actions modeled such as placing RHR in a spent fuel pool assist cooling mode can be fairly complex and time consuming. That is, operators are engaged in multiple tasks which require a good deal of time to complete. In addition, variations in scenario timing occur due to different decay heat loads that can affect the time available, size of leaks etc., in turn affecting workload and the operators' stress. The number of personnel available in refueling vs. non fueling conditions can also be a factor.

2. Experience/training. For this PSF we needed to consider the interaction of the operators' training on events of this type, with the novelty of the particular scenario. For example, in some cases, operators have literally never taken the actions described. Whatever historical evidence existed was brought into consideration for this factor. Also, the procedures we reviewed were of a generic nature rather than a step-by-step prescription.

3. Procedures. This PSF is particularly important because procedures may not be well developed for some spent fuel pool scenarios as they have not received as much attention as direct core damage scenarios. Thus a distinction was made between those actions covered by either the plant EOPs or plant NOPs, and those covered by the non-specific Fuel Pool cooling procedures we had reviewed.

4. Ergonomics. This PSF is important in several ways. First, some of the needed accident mitigation equipment may not be accessible during the scenario (e.g., elevated radiation levels near the pool during a severe draining event). Another important ergonomics issue concerns the human-machine interface, as this affects how operators are informed of spent fuel pool conditions and how they manipulate components in response to their indications. Also, many actions are required outside of the control where typically the Human Machine Interface (HMI) is not as cleanly designed and controlled as in the reactor control room. The number and type of manual actions, and leak location also play a role.

$5 \& 6$. Fitness for Duty and Crew dynamics. Due to the generic aspect of this analysis these factors were assumed to have no impact.

\section{C.3 Key Assumptions}

A number of assumptions were made to facilitate the analysis. These assumptions were made to assure consistencies across the human actions in the scenarios.

1. Operators all have good training

2. Procedures are generic

3. Ergonomics inside the control room are good

4. Ergonomics outside the control room are poor (as defined by the ASP HRA worksheet)

5. Operators are fit for duty

6. Crew dynamics are good

These assumptions were then modified based upon the factors of event timing, type of leak, scenario complexity, reactor state, need for manual actions outside the control room, 
environmental concerns, and the possibility for second checks and recovery. Each of these issues were considered in completing the ASP quantification form. In general the kinds of considerations made for these factors are listed in Table C.1 below.

We also attempted to consider the known operating experience. Operating experience played a role in checking the reasonableness of the human error probabilities, as well as understanding how the factors in Table C.1 above might impact performance.

Table C. 2 below shows the final results of the human reliability analysis. For each human error basic event, the failure mode, a description of what factors were considered in the quantification, and the resulting HEP are listed. Section C. 4 of this appendix contains the ASP HRA worksheets for each of the human error. The worksheets occur in the approximate order of Table C.2.

Table C.1 - Factors and Considerations Influencing Human Error Probabilities

\begin{tabular}{|l|l|}
\hline Factor & Considerations/Assumptions \\
\hline Event timing & Affected by leak size, location \\
\hline Type of leak & $\begin{array}{l}\text { Large leaks are more easily detected, but } \\
\text { give less time to act. Seal leaks are more } \\
\text { easily detected than spent fuel pool cooling } \\
\text { system leaks. }\end{array}$ \\
\hline Scenario complexity & $\begin{array}{l}\text { A non-isolated leak will increase event } \\
\text { complexity and stress. }\end{array}$ \\
\hline Reactor state & $\begin{array}{l}\text { If the reactor is refueling personnel are more } \\
\text { likely to be around increasing chance of } \\
\text { detection of problems outside the control } \\
\text { room. However extra personnel and } \\
\text { workload can decrease vigilance }\end{array}$ \\
\hline Actions outside control room & $\begin{array}{l}\text { Generally ergonomics are less favorable in } \\
\text { the plant }\end{array}$ \\
\hline Environmental factors & $\begin{array}{l}\text { Radiation, high temperature, high humidity } \\
\text { can negatively impact performance }\end{array}$ \\
\hline Second checks and recovery & $\begin{array}{l}\text { Second unit can serve as possible source of } \\
\text { recovery }\end{array}$ \\
\hline
\end{tabular}


Table C. 2 - Results of the Human Reliability Analysis (HRA) (page 1 of 4)

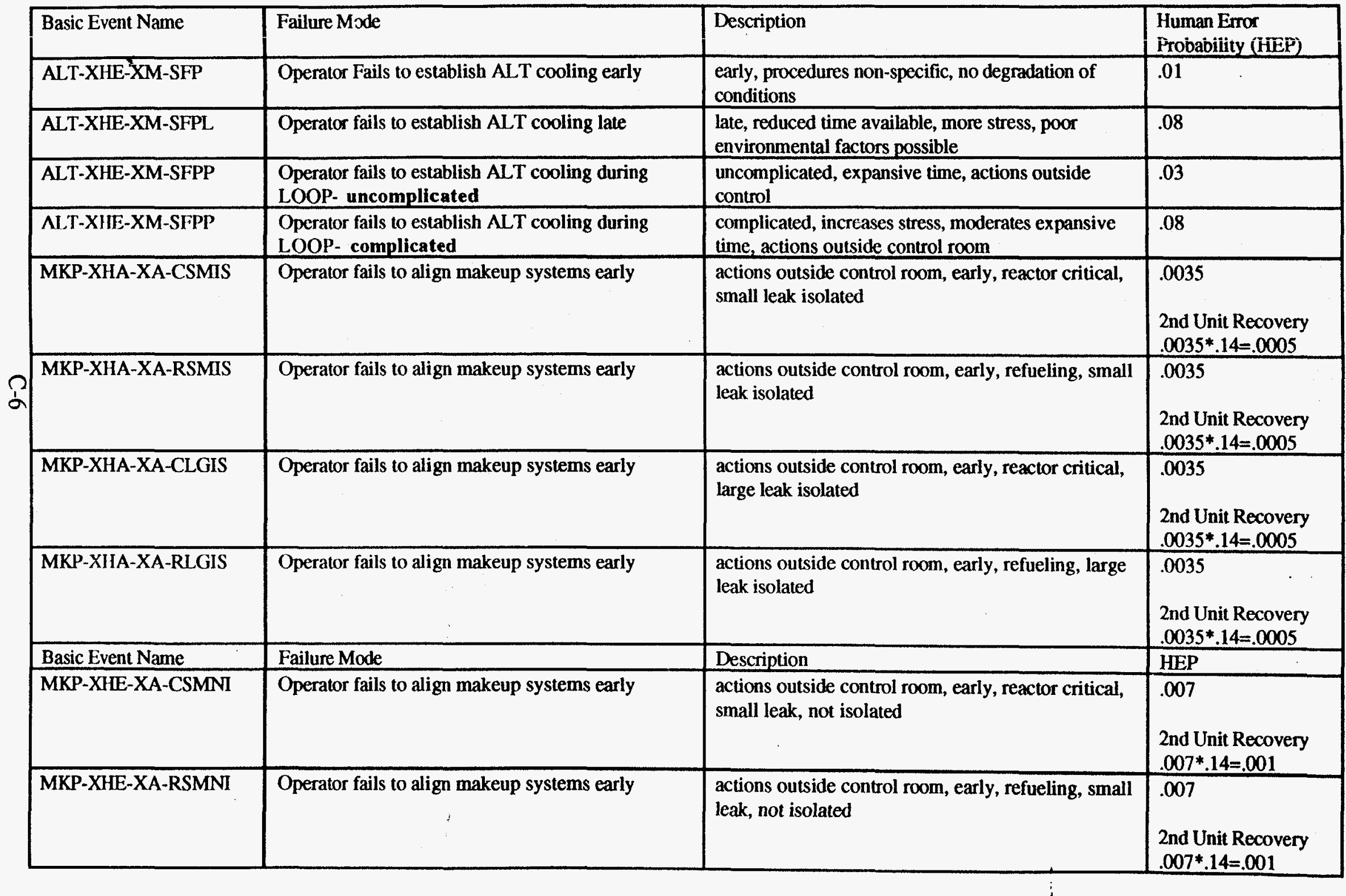


Table C.2 - Results of the Human Reliability Analysis (HRA) (page 2 of 4)

\begin{tabular}{|c|c|c|c|}
\hline Basic Event Name & Failure Mode & Description & \begin{tabular}{|l|} 
Human Error \\
Probability (HEP) \\
\end{tabular} \\
\hline MKP-XHA-XA-CLGNI & Operator fails to align makeup systems early & $\begin{array}{l}\text { actions outside control room, early, reactor critical, } \\
\text { large leak, not isolated }\end{array}$ & $\begin{array}{l}.018 \\
\text { 2nd Unit Recovery } \\
.018 * .14=.0025 \\
\end{array}$ \\
\hline MKP-XHA-XA-CLNIB & Operator fails to align makeup systems early & $\begin{array}{l}\text { actions outside control room, early, reactor critical, } \\
\text { large leak- boundary, not isolated }\end{array}$ & .018 \\
\hline MKP-XHE-XA-RLGNI & Operator fails to align makeup systems early & $\begin{array}{l}\text { actions outside control room, early, refueling, large } \\
\text { leak, not isolated }\end{array}$ & $\begin{array}{l}.018 \\
\text { 2nd Unit Recovery } \\
.018^{*} .14=.0025\end{array}$ \\
\hline MKP-XHE-XA-RLNIB & Operator fails to align makeup systems early & $\begin{array}{l}\text { actions outside control room, early, refueling, large } \\
\text { leak-boundary, not isolated }\end{array}$ & .018 \\
\hline EPS-XHE-NOREC & Operator fails to recover emergency power & actions outside control room & .03 \\
\hline GOPEN-XHE-XA-INT & Operators fail to open gate & early, actions outside control room & .007 \\
\hline LMKUP-XHE-XA-SFP & Operator fails to align makeup systems late & late, reduces time, more stress & $\begin{array}{l}.08 \\
\text { 2nd Unit Recovery } \\
.08 * .14=.011\end{array}$ \\
\hline
\end{tabular}


Table C.2 - Results of the Human Reliability Analysis (HRA) (page 3 of 4)

\begin{tabular}{|l|l|l|l|}
\hline Basic Event Name & Failure Mode & Description & HEP \\
\hline MUES-XHE-XA-SFP & Operator fails to align makeup or ECCS systems early & early & .007 \\
\hline MUES-XHE-XA-LSFP & Operator fails to align makeup or ECCS systems late & late, reduces time, more stress & $\begin{array}{l}.08 \\
2 n d \\
.08 * .14=.011\end{array}$ \\
\hline SFP-XHE-XE-UC & Operator fails to restore SFP Cooling System & decision only, reactor critical, leak location & .035 \\
\hline SFP-XIIE-XE-UR & Operator fails to restore SFP Cooling System & decision only, reactor refueling, leak location & .035 \\
\hline SFP-XHE-XE-LP & Operator fails to restore SFP Cooling System & decision only, loss of power, leak location & .07 \\
\hline SFP-XHE-XE-LINVR & Operator fails to restore SFP Cooling System & $\begin{array}{l}\text { decision only, reactor refueling, greater } \\
\text { number of staff in plant, leak location }\end{array}$ & .0035 \\
\hline SFP-XHE-XE-LINVC & Operator fails to restore SFP Cooling System & $\begin{array}{l}\text { decision only, reactor critical, leak location } \\
\text { decision only, reactor refueling, greater } \\
\text { number of staff in plant, leak location }\end{array}$ & .07 \\
\hline SFP-XHE-XE-PLR & Operator fails to restore SFP Cooling System & 0035 \\
\hline ofecision only, reactor critical, leak location & .07 \\
\hline SFP-XHE-XE-PLC & Operator fails to restore SFP Cooling System & $\begin{array}{l}\text { early, uncomplicated, actions never } \\
\text { performed, manual actions outside control } \\
\text { room }\end{array}$ & .07 \\
\hline R1-XHE-XM-RHR & $\begin{array}{l}\text { Operator fails to initiate RHR mode of SFP cooling- } \\
\text { Unit 1 }\end{array}$ & $\begin{array}{l}\text { Oprly, uncomplicated, actions never } \\
\text { performed, manual actions outside control } \\
\text { room }\end{array}$ & $\begin{array}{l}.07 \\
\text { potential environmental factors }\end{array}$ \\
\hline SF2-XHE-XM-RHR & Unit 2 & & .05 \\
\hline
\end{tabular}


Table C. 2 - Results of the Human Reliability Analysis (HRA) (page 4 of 4)

\begin{tabular}{|c|c|c|c|}
\hline Basic Event Name & Failure Mode & Description & HEP \\
\hline MISLSPHN & Operator fails to isolate SFP boundary leak, early & $\begin{array}{l}\text { early, pipe leak, reactor critical, non-specific } \\
\text { procedures, actions outside control room }\end{array}$ & .008 \\
\hline MISLSPCE & Operator fails to isolate SFP boundary leak, early & $\begin{array}{l}\text { early, pipe leak, refueling, non-specific } \\
\text { procedures, actions outside control room }\end{array}$ & .008 \\
\hline MISLLGE & Operator fails to isolate SFP boundary leak, early & $\begin{array}{l}\text { early, large seal leak (reducing time } \\
\text { available), difficult to mitigate, procedures } \\
\text { non-specific, actions outside control room }\end{array}$ & .18 \\
\hline MISLI.GL & Operator fails to isolate SFP boundary leak, late & $\begin{array}{l}\text { late, large leak, procedures non-specific, poor } \\
\text { environmental factors possible, actions } \\
\text { outside control room }\end{array}$ & .8 \\
\hline SFP-XHE-MANISO-E & Operator fails to isolate SFP, early & $\begin{array}{l}\text { early, small seal leak, non-specific } \\
\text { procedures, actions outside control room }\end{array}$ & .007 \\
\hline SFP-XHE-MANISO-L & Operator fails to isolate SFP boundary Leak, late & $\begin{array}{l}\text { late, non-specific procedures, poor } \\
\text { environmental factors possible, outside } \\
\text { control room }\end{array}$ & .08 \\
\hline SFP-XHE-XA-ECCS & Operator fails to align ECCS systems & well trained action & .001 \\
\hline $\begin{array}{l}\text { SFP1-XHE-XM-SFP (Unit } \\
\text { 1) } \\
\text { SFP2-XIHE-XM-SFP (Unit } \\
\text { 2) }\end{array}$ & Operator fails to initiate SFP cooling- early & early, actions outside control room & .007 \\
\hline $\begin{array}{l}\text { SFPI-XHE-XM- } \\
\text { LSIPP(Unit 1) } \\
\text { SFP2-XIE-XM-LSFP } \\
\text { (Unit 2) }\end{array}$ & $\begin{array}{l}\text { Operator fails to initiate SFP cooling after late } \\
\text { recovery }\end{array}$ & late, actions outside control room & .08 \\
\hline
\end{tabular}




\section{C.4 HRA Worksheets}

The worksheets used to generate the results shown in Table C.2 are shown in the following pages. 
Plant:

Scenario:

Sequence Number:

Task Error Description: Operator Fails to Establish ALT Cooling Early

1. Complexity, stress, and workload

\section{Processing}

Response

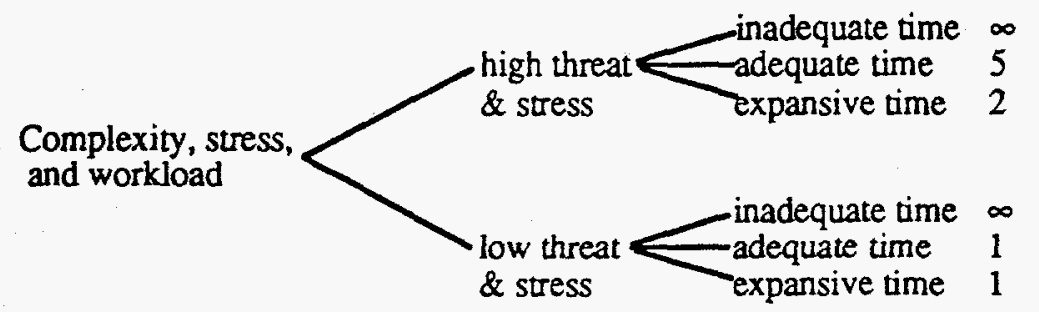

$\infty$
5
2

2. Experience/training

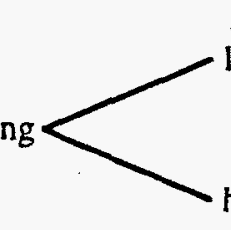
low

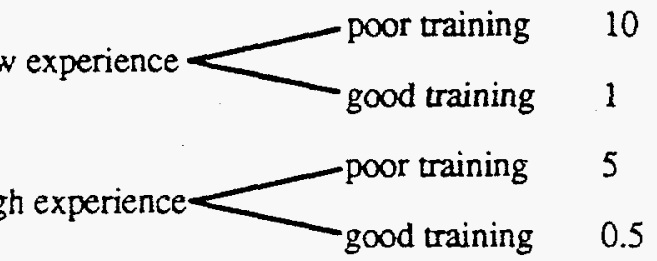

3. Procedures procedures absent $10_{\text {procedures present }}^{10} \begin{gathered}10 \\ \text { poor procedures } 5 \\ \text { good procedures } 1\end{gathered}$

4. Ergonomics
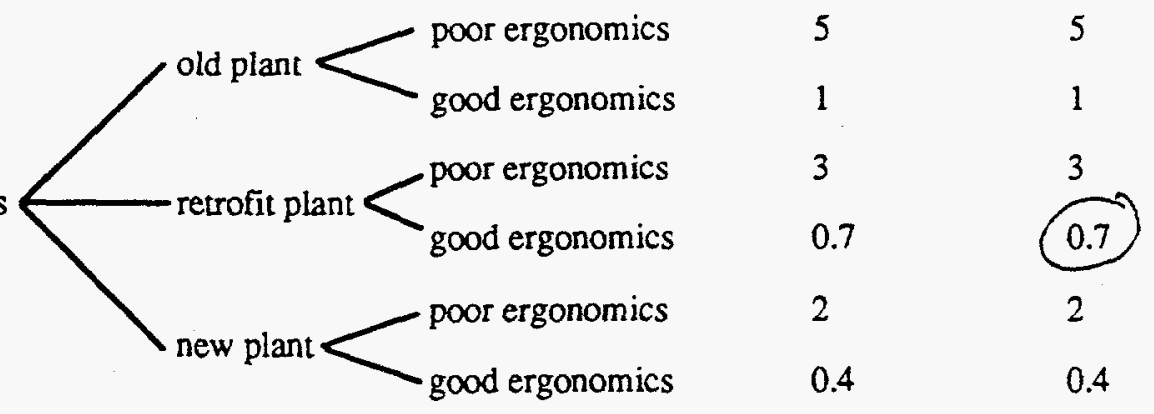

5. Fitness for duty< unfit 25

25

6. Crew dynamics

10

10

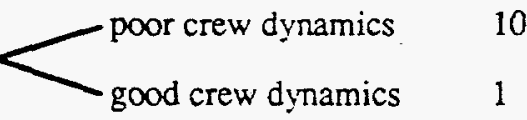

(1)

Task Portion

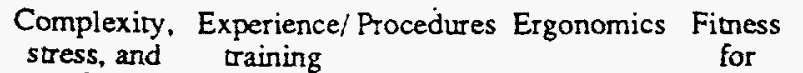

Processing: $10 \mathrm{E}-2 \mathrm{x}$ $\mathbf{x}$ $\mathrm{X}$ X $\mathrm{x}$ $\mathrm{X}$ Processing Failure Probability

Response: $10 \mathrm{E}-3$ $x+1 \times-5$ $x-7 \times 1 \quad x$ $=$ +.01 Response Failure Probability 
Plant: Scenario:

Sequence Number:

Task Error Description: Operator Fails to Estab]ish ALI Cooling Late

1. Complexity, stress, and workload

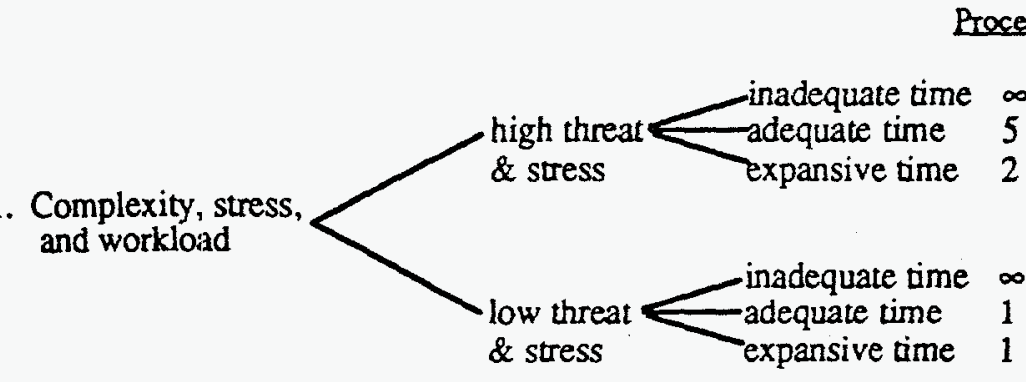

Processing

Response

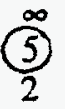

2. Experience/training

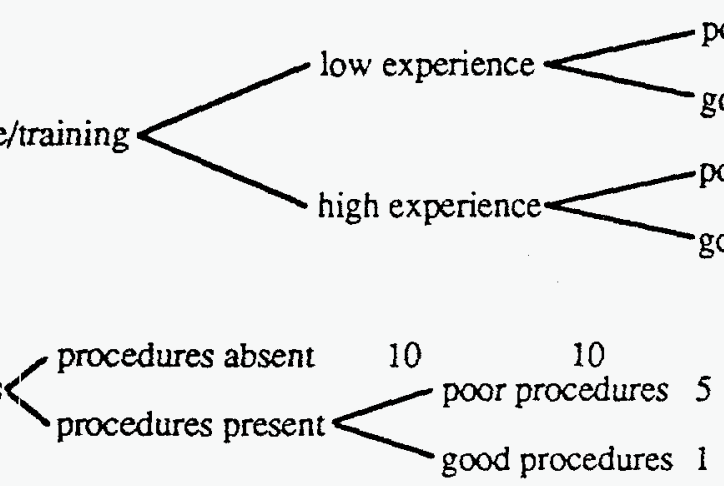

3. Procedure

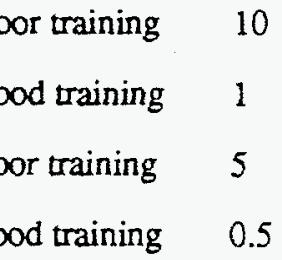

procedures present $\longrightarrow$ good procedures 1

4. Ergonomics

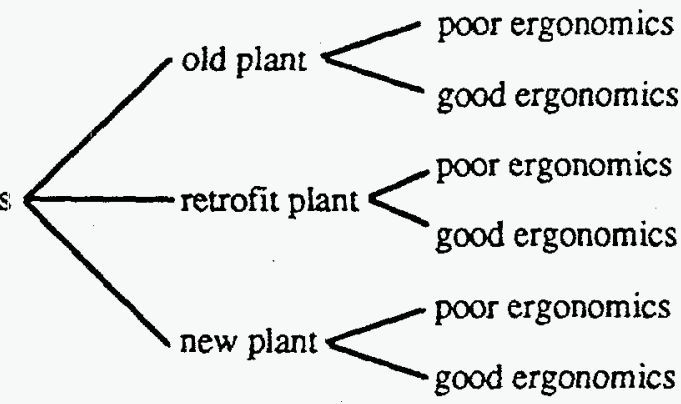

5

1

3

0.7

2

0.4
5

1

0.7

2

0.4

5. Fitness for duty< unfit $\frac{25}{\text { fit }} \quad 1$

25

6. Crew dynamics

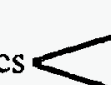

poor crew dynamics

10

10

good crew dynamics

1

Complexity, Experience/Ptocedures Ergonomics stress, and
workload

Task Portion training

Processing: $10 \mathrm{E}-2 \mathrm{x}$ $x$ $x$ $x$ $x$ $\mathrm{x}$

Response: $10 \mathrm{E}-3 \times 5$ $x+1-x$ $x-5$ $\mathrm{x}$ $x$ $x+1$ $=$ +.075 Response Failure Probability 
Plant: Scenario: Sequence Number:

Task Error Description: Operator Fails to Establish ALT Cooling During LOOD. uncomplicated

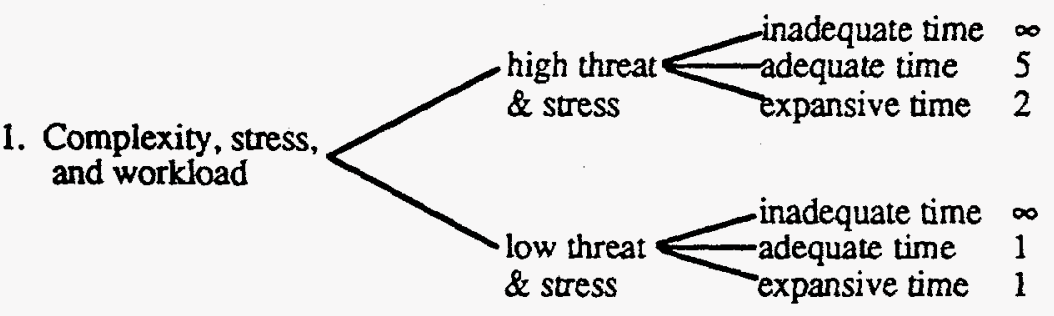

Complexity, stress,
and workJoad

Processing

2. Experience/training

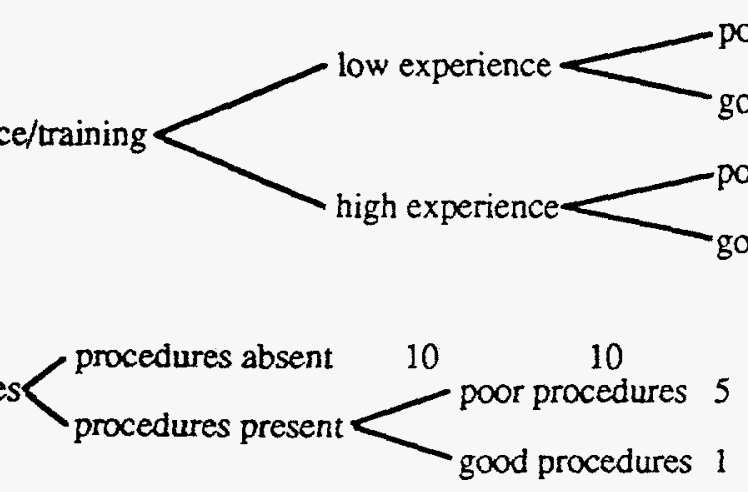

3. Procedures

\section{Response}

$\infty$

5

(2)

$\infty$

1

1

4. Ergonomics

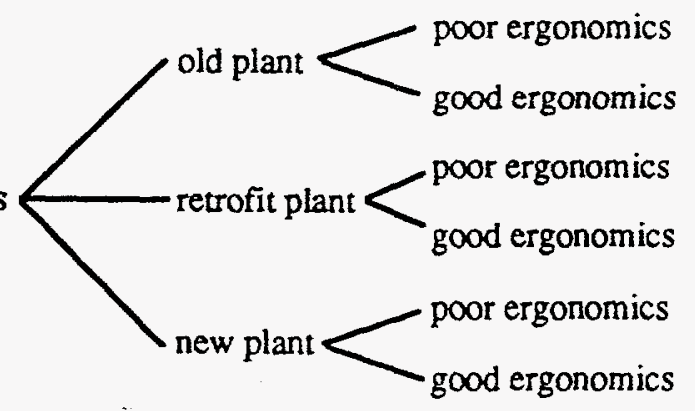

5

1

3

0.7

2

0.4

5. Fimess for duty<smiles>CCCCCCC</smiles>

6. Crew dynamics

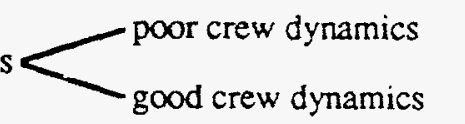

Task Portion yorkload $x$ $\mathrm{x}$ $x$ x Processing Failure Probability Response: $10 \mathrm{E}-3$ $x$ $\times 5$ $\mathrm{x}$ $x$ $x$ 


\section{ASP HUMAN ERROR WORKSHEET (Page 1 of 2) ALT-XHE-XM-SFPP}

Plant:

Scenario:

Sequence Number:

Task Error Description:_Operator Fails to Establish ALT cooling during L 100P, complicated Processing

Response

1. Complexity, stress,
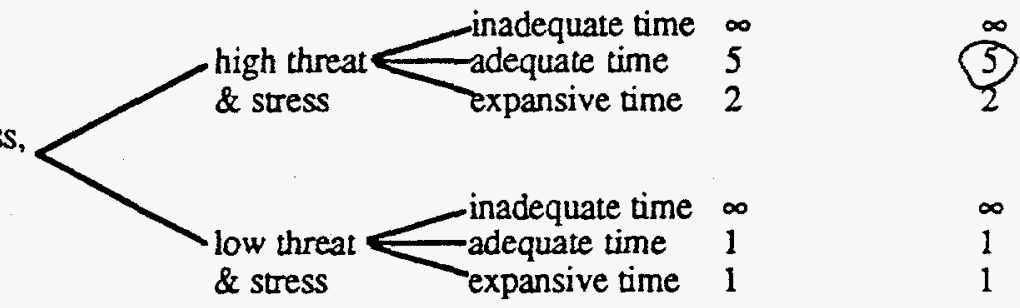

3. Experience/training ${ }_{\text {high experience }<\text { procedures absent }}^{10}$ poor procedures 5

10

10

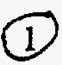

5

0.5

4. Ergonomics

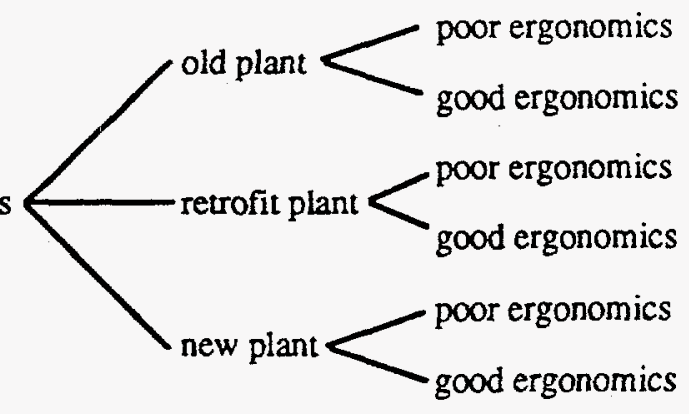

5. Fitness for duty

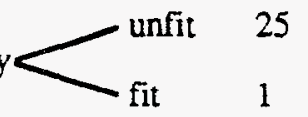

25

6. Crew dynamics

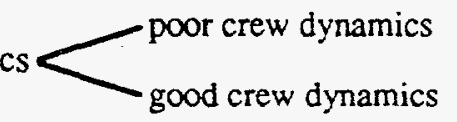

10

1
5

1

3

0.7

2

0.4

10

(1)

$$
\begin{aligned}
& \text { Complexity. Experience/Procedures Ergonomics Finness Crew } \\
& \text { stress, and training for dynamics }
\end{aligned}
$$

Task Portion

Processing: $10 \mathrm{E}-2 \times$ $x$ $x+x$ $x$ Processing Failure Probability Response: $10 E-3 \times 5 \times 1$ $\mathrm{x}$ +.075 Response Failure Probability 
Plant:

Scenario:

Sequence Number:

Task Error Description: Operator Fails to Align Makeup Systems Early-small leak isolated, Processing

Response large leak isolated.

1. Complexity, stress,

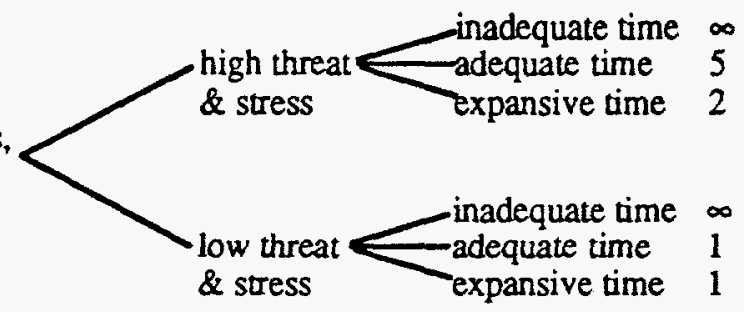

$\infty$

5 and workload $\begin{array}{ll}\text { adequate time } & 1 \\ \text { expansive time } & 1\end{array}$

2. Experience/training
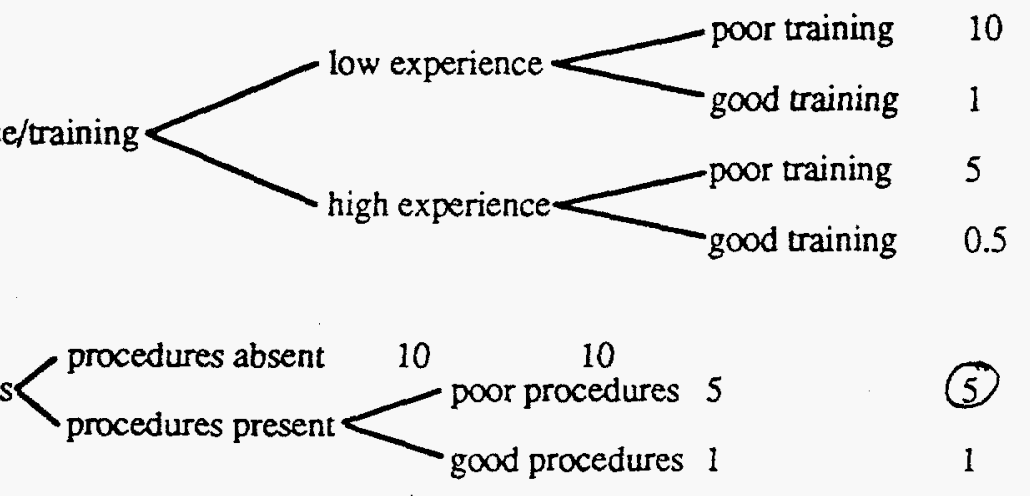

3. Procedures

4. Ergonomics

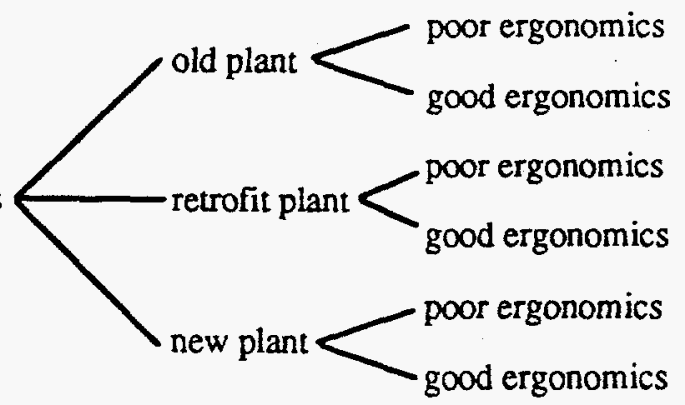

5. Fitness for duty $<_{\text {fit }}{ }_{1}$ unfit ${ }_{1} 25$

6. Crew dynamics

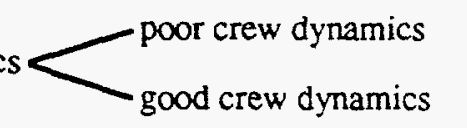

Task Portion stress, and dury

Processing Failure Probability +.0035 Response Failure Probability Task Failure Probability C-15 
Plant:

Scenario:

Sequence Number:

Task Error Description: Operator fails to align makeup system early-small leak not isolated Processing Response

1. Complexity, stress, and workload
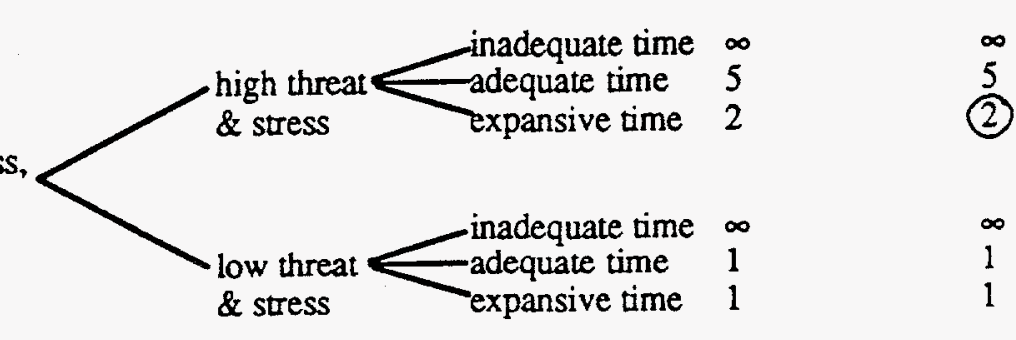

2. Experience/training
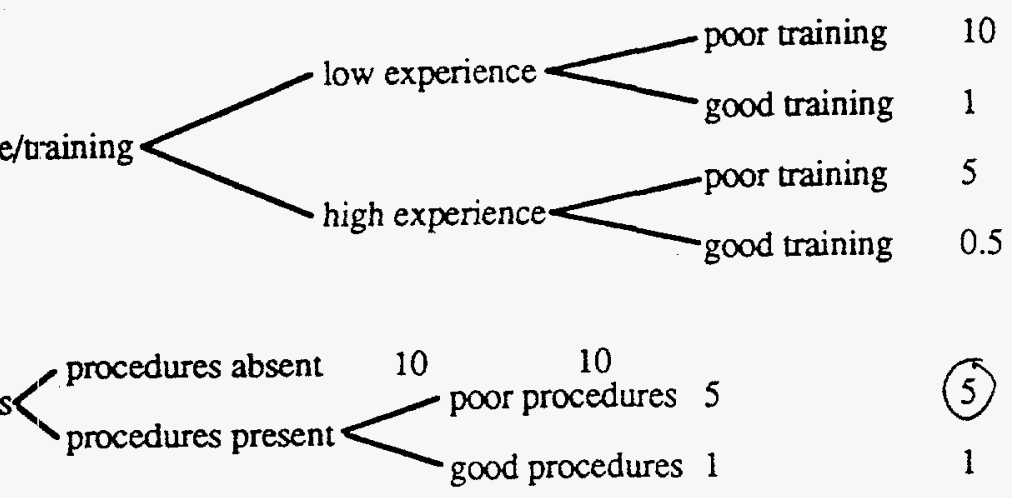

3. Procedures

4. Ergonomics

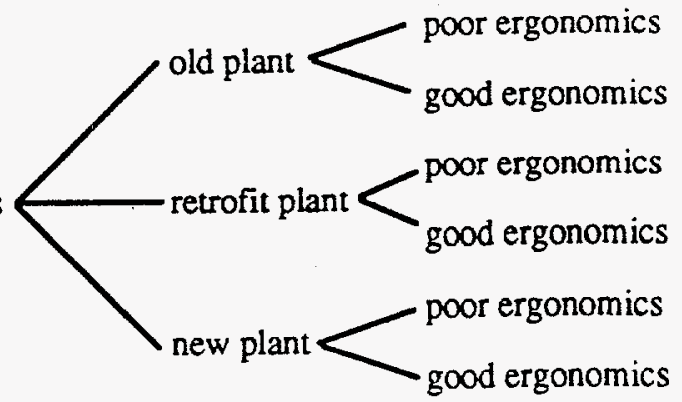

5. Fitness for duty< unfit 25.
6. Crew dynamic

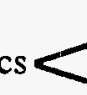

poor crew dynamics

good crew dynamics

10

10

(1) Complexity, Experience/Procedures Ergonomics
$\begin{aligned} & \text { Fimess } \\ & \text { stress, and }\end{aligned}$ frew
workload
;

Task Portion

$\begin{array}{ll}5 & 5 \\ 1 & 1 \\ 3 & 3 \\ 0.7 & 0.7 \\ 2 & 2 \\ 0.4 & 0.4\end{array}$

Processing: $10 \mathrm{E}-2 \mathrm{x}$ $\mathbf{x}$ $\mathbf{X}$

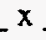
x $x$ Processing Failure Probability

Response: $10 \mathrm{E}-3 \times 2$ $x+1$ $x+5$ 1 $x+1$ $\mathrm{x}$ 
Plant: Scenario: Sequence Number: MKP-XHE-XA-RLNIB

Task Error Description: Operator fails to align makeup system early-large leak. not isolated

1. Complexity, stress, and workload

\section{Processing}

\section{Response}
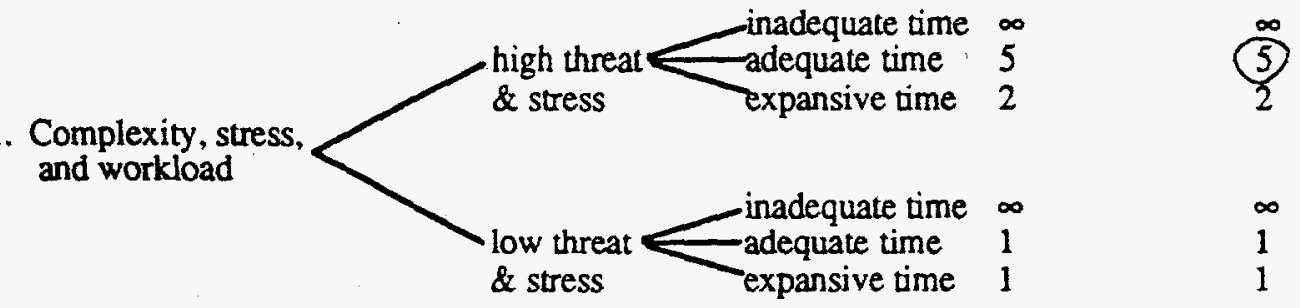

2. Experience/training

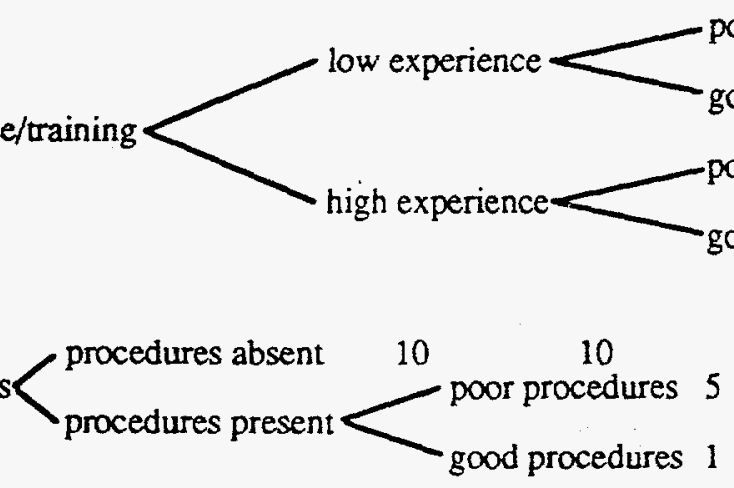

3. Procedures

4. Ergonomics
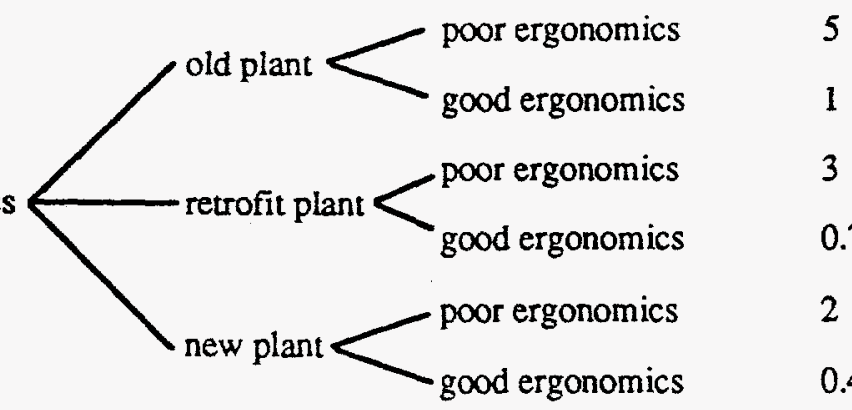

5. Fimess for duty $<_{\text {fit }}$ unfit $\frac{25}{1}$

25

6. Crew dynamics

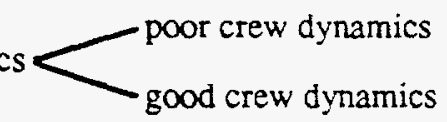

10

1

Task Portion workload $x$ $x$ Processing Failure Probability

Processing: $10 \mathrm{E}-2 \mathrm{x}$ $x$ $x$ $x$ Response: $10 \mathrm{E}-3 \times 5 \times 1 \times 1 \times 1 \times 1 \times 1 \times 1 \times 18$ Response Failure Probability 
Plant:

Scenario:

Sequence Number:

Task Error Description: Operator Fails to Recover Emergency Power

Processing

Response

1. Complexity, stress,

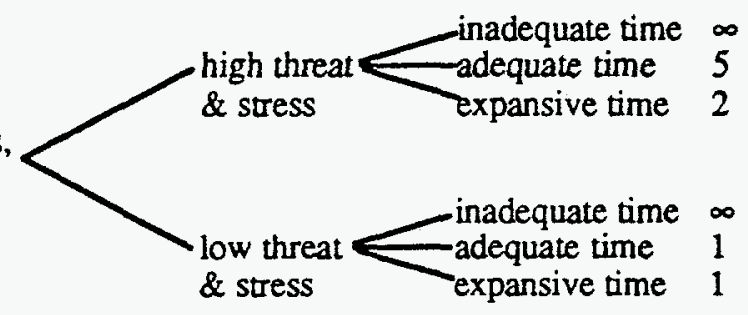

$\stackrel{\infty}{5}$ and workload

expansive time 1

1

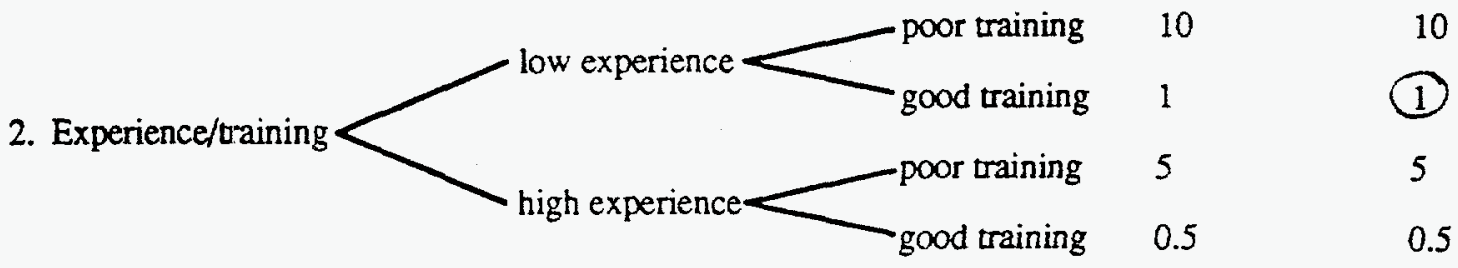

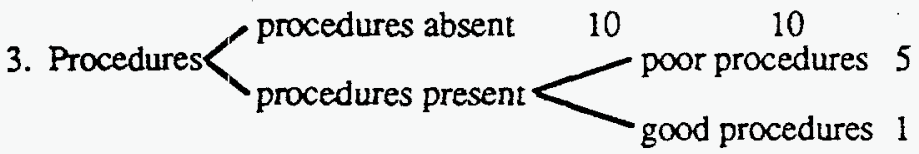

4. Ergonomics

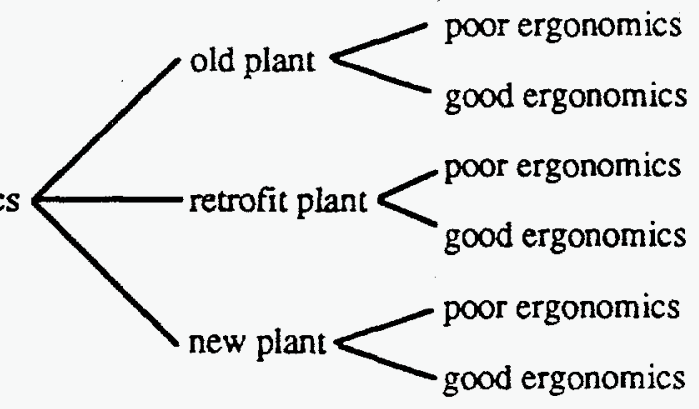

5

5

1

3

0.7

2

2

0.4

0.4

5. Fitness for duty< unfit 25

25

6. Crew dynamics

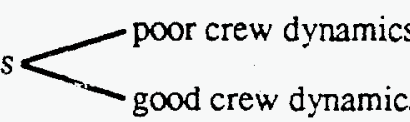

10

10

1

(1)

Complexity, Experience/Procedures Ergonomics
$\begin{aligned} & \text { Fitness } \\ & \text { stress, and }\end{aligned}$ for
workload
training

Task Portion $\mathrm{x}$ $x$ $x$ $x$ Processing Failure Probability

Response:

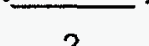
x 1 $\times$ $x$ $\mathrm{x}$ x 1 $=$ 
Plant: Scenario: Sequence Number:

Task Error Description: Operator Fails to Open Gate, early

Processing

Response

1. Complexity, stress,
and workload $\underset{\text { expansive time }}{\text { high threat }} \begin{aligned} & \text { inadequate time } \\ & \text { \& stress }\end{aligned}$

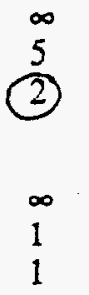

Experienceftraining

low experience

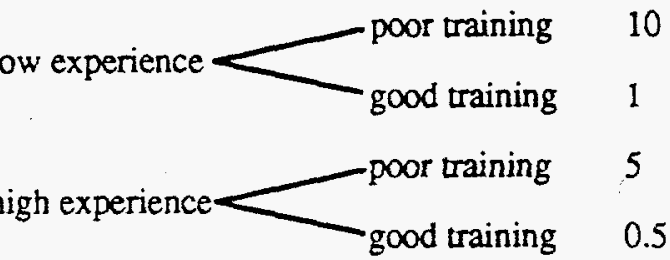

10

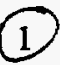

5

0.5

0.5

3. Procedures

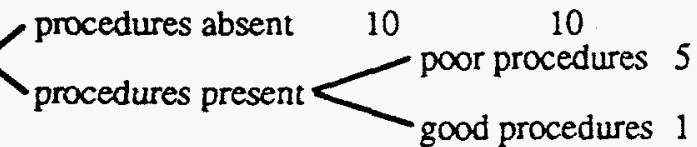

4. Ergonomics
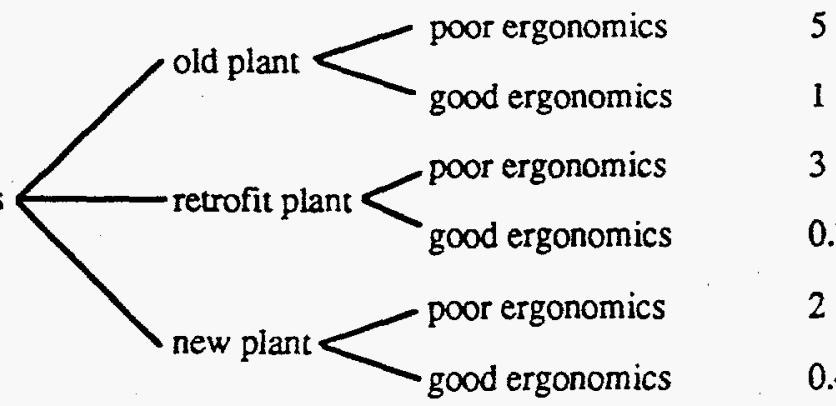

5

1

3

0.7

3

2

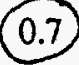

0.4

2

0.4

5. Finess for duty< unfit 25

25

6. Crew dynamics $<$ - poor crew dynamics 10

Complexity, Experience/Procedures Ergonomics $\begin{gathered}\text { Fimess } \\ \text { for } \\ \text { stress, and drew } \\ \text { workload } \\ j\end{gathered}$
training

Task Portion $\mathbf{x}$ $\mathrm{x}$ $x$ $x$ $x$ Processing Failure Probability

Processing: $10 \mathrm{E}-2 \times$ $x+5$ $x-1=$ +.007 Response Failure Probability 
Plant: Scenario: Sequence Number:

Task Error Description: Operator Eails to Align Makeup Systems, late

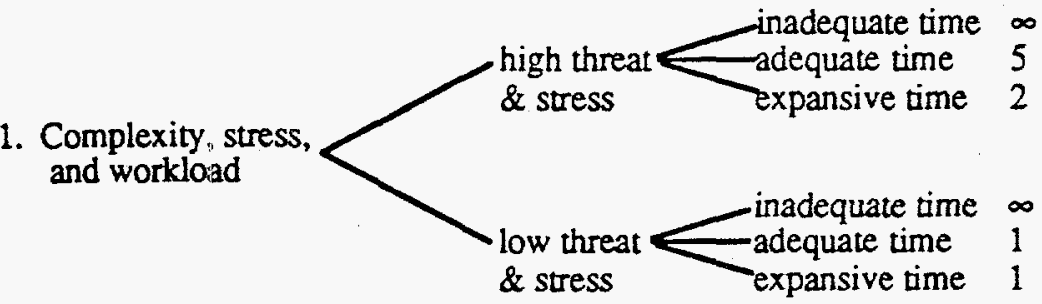

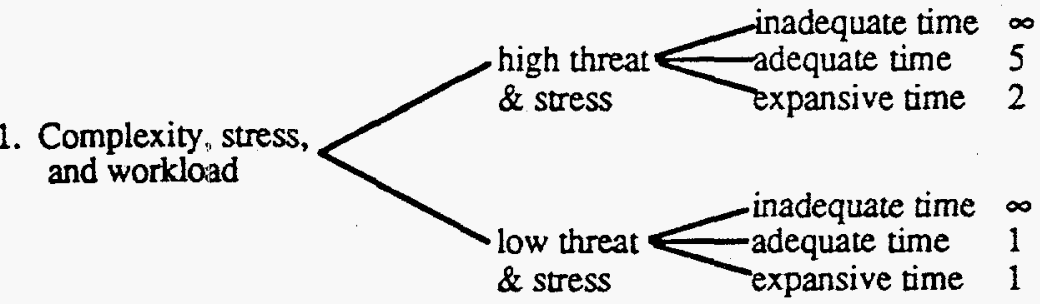

\section{Processing}

2. Experience/training $\underbrace{-\operatorname{low} \text { poor training }}_{\text {high experience }} 10$

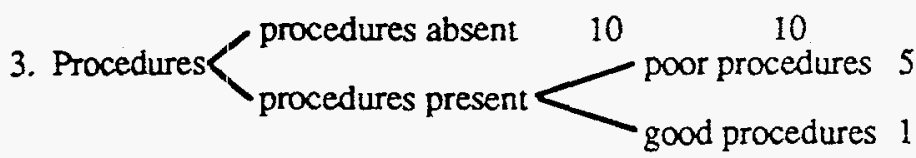

4. Ergonomics

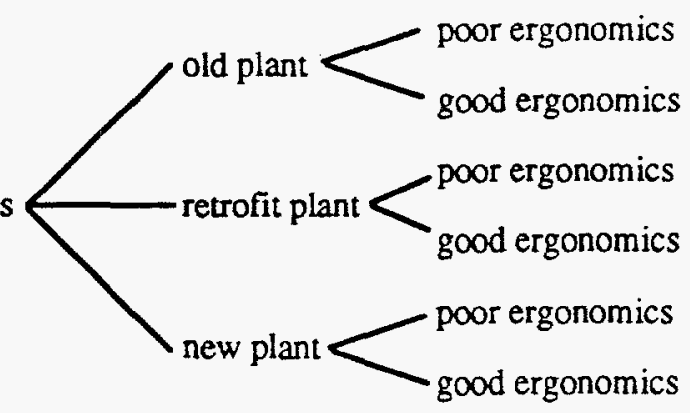

5. Fimess for duty< unfit ${ }_{\text {fit }}^{25}$

25

6. Crew dynamics<smiles>CCCCCCCCCOC(=O)OOC(=O)OCC</smiles>

10

10

(1)
Response

$\frac{\infty}{2}$

1
10

(1)

5

0.5

$\begin{array}{ll}5 & 5 \\ 1 & 1 \\ 3 & 3 \\ 0.7 & 0.7 \\ 2 & 2 \\ 0.4 & 0.4\end{array}$
Complexity, Experience/ Procedures Ergonomics
ftress, and $\begin{gathered}\text { Fimess } \\ \text { training }\end{gathered}$
$\begin{gathered}\text { for } \\ \text { workload }\end{gathered}$

Task Portion $\mathbf{x}$ $x$ Processing Failure Probability

Processing: $10 \mathrm{E}-2 \mathrm{x}$ X $x$ $x$ $x=$ +.075 Response Failure Probability Response: $10 \mathrm{E}-3$ $x+5 \times 3$ 
Plant:

Scenario:

Sequence Number:

Task Error Description: Operator Fails to Align Makeup or ECCS Systems, early

Brocessing

\section{Respense}

1. Complexity, stress,
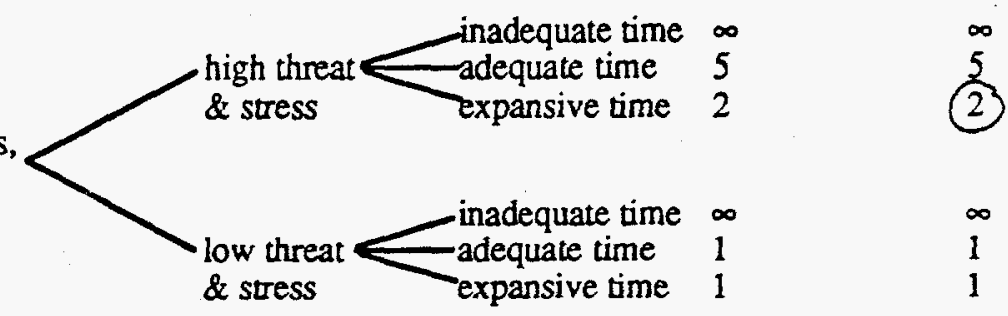
and workload

$\begin{array}{ll}\infty & \infty \\ 5 & 5\end{array}$

and workload

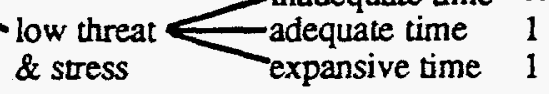

10

2. Experience/training

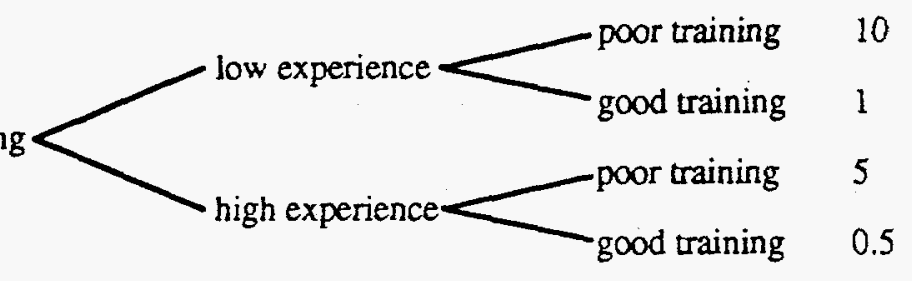

3. Procedures

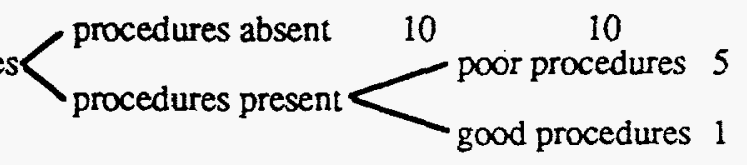

4. Ergonomics

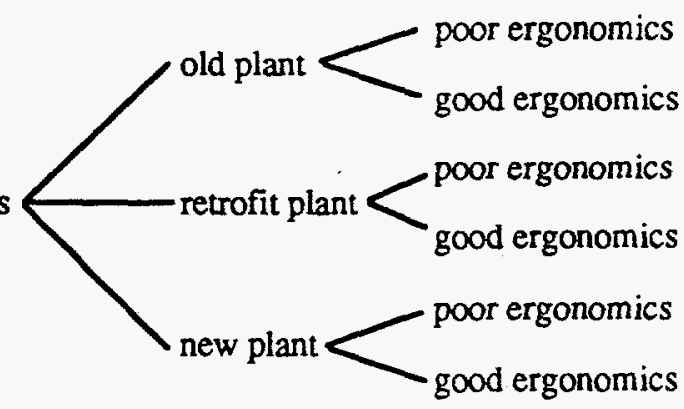

5
1
3
0.7
2
0.4

$$
5
$$

1

3

0.7

2

5. Fitness for duty< unfit 25

25

6. Crew dynamics

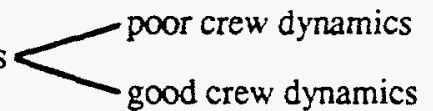

10

10

1

(1)

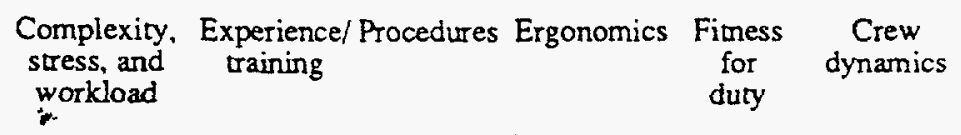

Task Portion stress, and training

Processing: $10 \mathrm{E}-2 \mathrm{x}$ X $x$ X $x$ Processing Failure Probability Response: $10 \mathrm{E}-3 x$ X $-x$ $x-1=$ 
Plant:

Scenario:

Sequence Number:

Task Error Description:_Operator Fails to Align Makeup or ECCS Systems, late

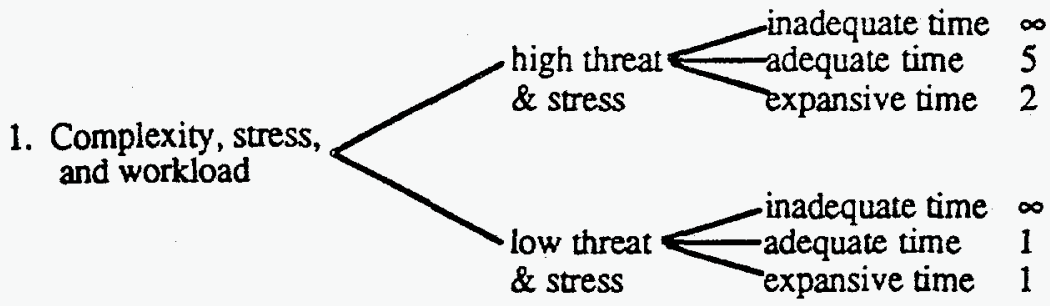

1. Complexity, stress,
and workload

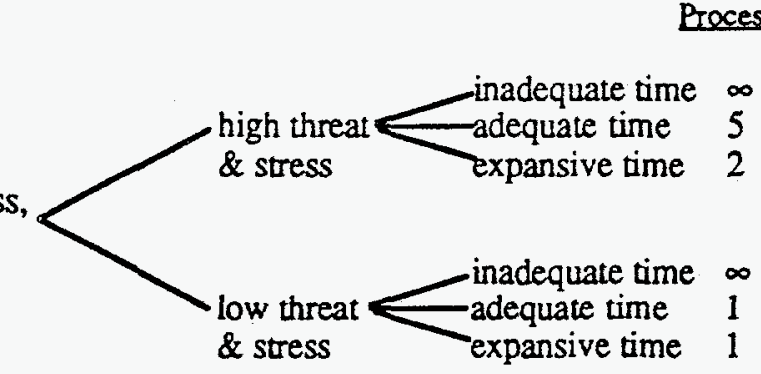

Brocessing

Response

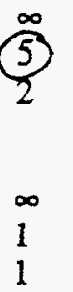

2. Experience/training 10

3. Procedures<

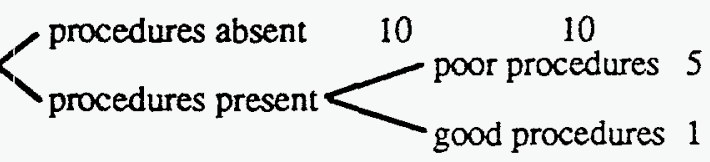

4. Ergonomics

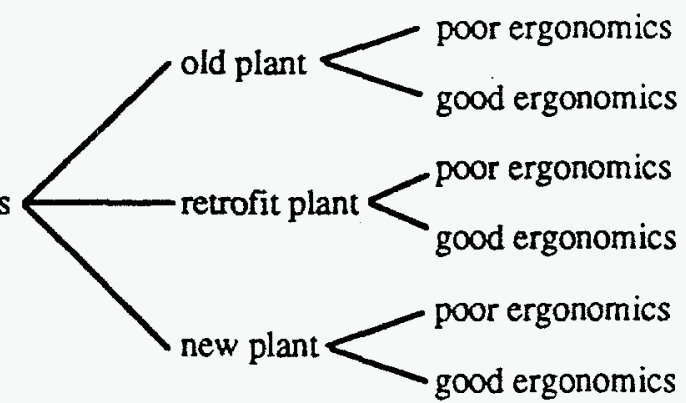

5

5

1

1

3

0.7

0.7

2

2

0.4

0.4

5. Fitness for duty< unfit 25

25

(1)

6. Crew dynamics

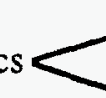
poor crew dynamics good crew dynamics

10

10

1

Task Portion Complexity, Experience/Procedures Ergonomics
stress, and training workload

Processing: $10 \mathrm{E}-2 \mathrm{x}$ $\mathrm{X}$ $x$ $x$ $\mathrm{X}$ x Processing Failure Probability

Response: $10 E-3 \times 5$ $x+1-5$ $\mathrm{x}$ $\mathrm{x}$ +.075 Response Failure Probability 
Plant:

Scenario:

Sequence Number:

Task Error Description: Operator Fails to Restore SEP Cooling System Decision

Brocessing Response

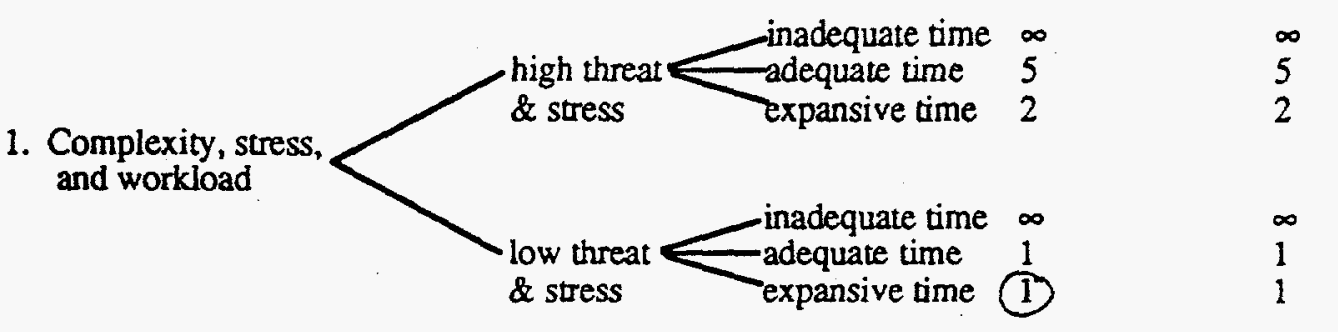

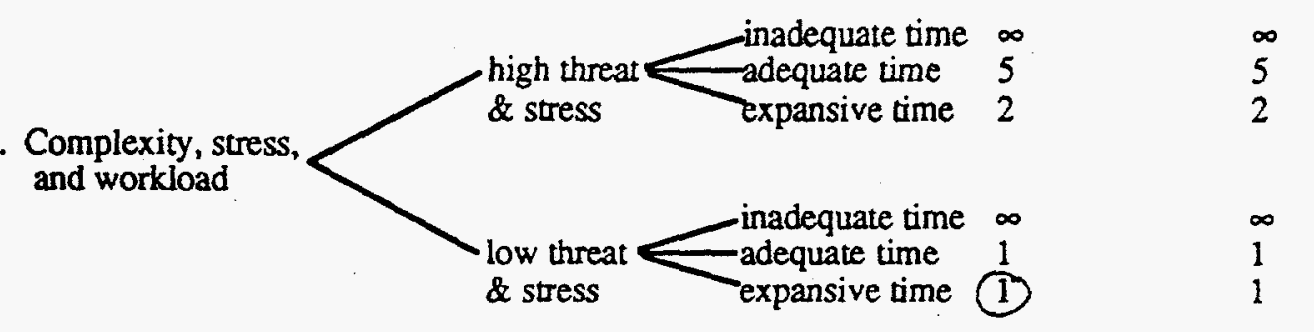

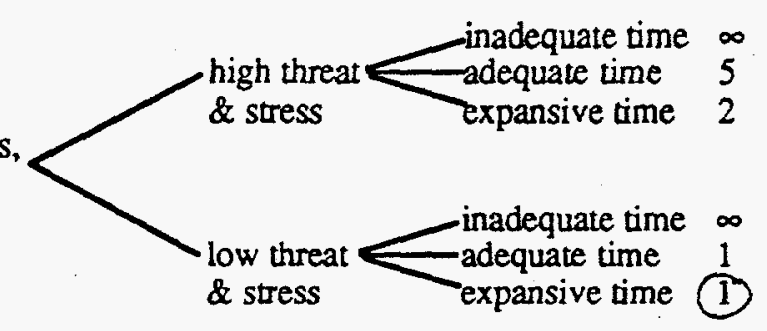

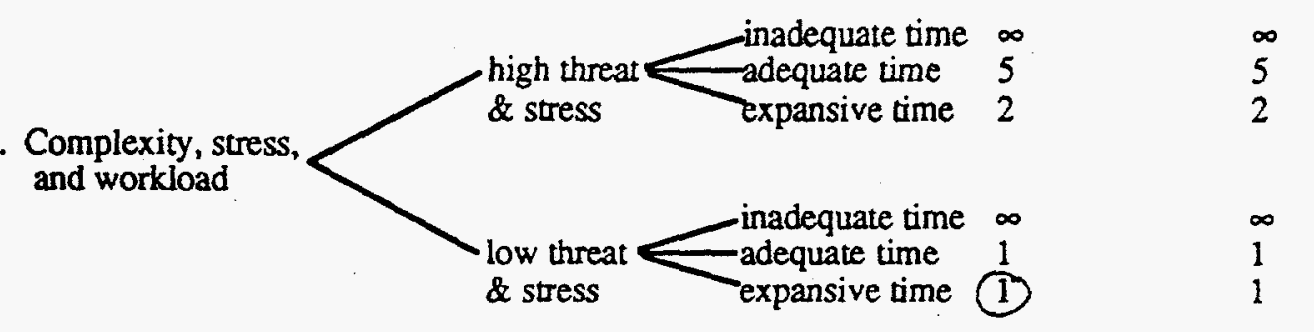

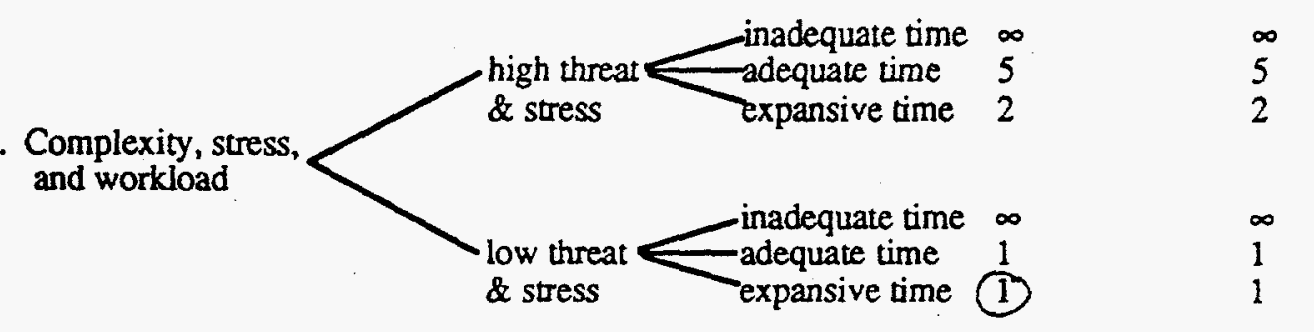

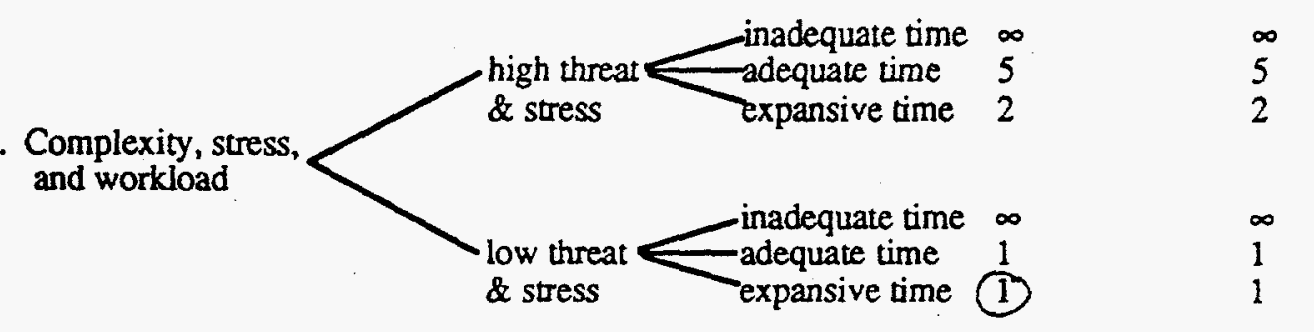

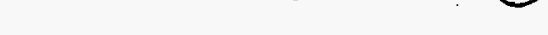

(1)

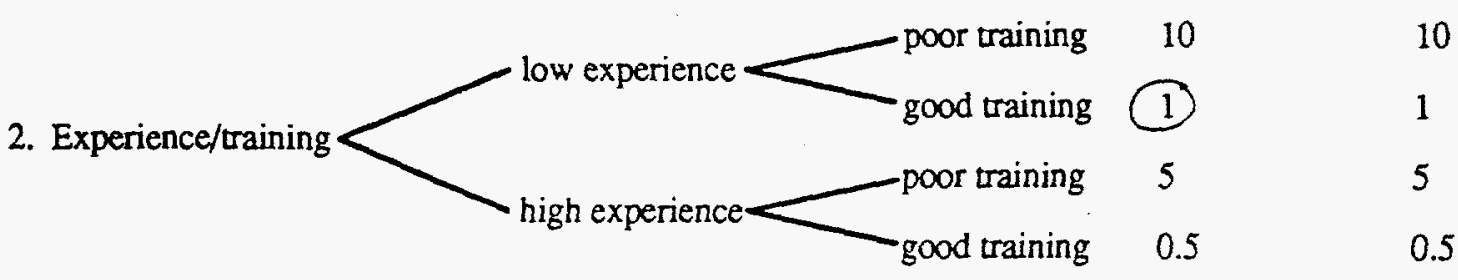

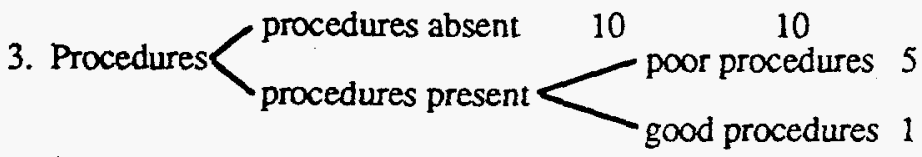

4. Ergonomics 2 ooor ergonomics

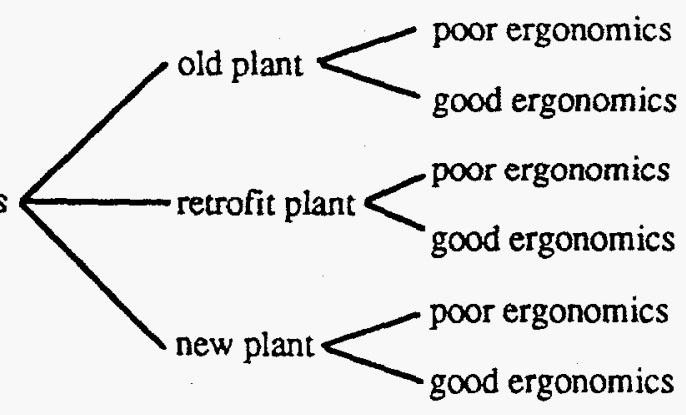

5

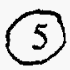

$5-5$

1

3

(0.7) $\quad 0.7$

22

$\begin{array}{ll}0.4 & 0.4\end{array}$

5. Finess for duty $\sum_{\text {fit }}^{\text {unfit }} \quad \begin{array}{ll}25 & 25 \\ \text { (1) } & 1\end{array}$

6. Crew dynamics $<_{\text {good crew dynamics }}^{\text {poor crew dynamics }} 10$ (1) 10

Task Portion

Complexity. Experience/Procedures Ergonomics Fimess Crew
stress, and
braining stress, and training for
workload

Processing: $10 \mathrm{E}-2 \times 1 \times 1 \times 1 \times 1 \times 1 \times 1=$

Response: $10 \mathrm{E}-3 x$ $\mathrm{X}$ $x$ $\mathrm{x}$ $\mathbf{x}$ x $=$ .035 Processing Failure Probability Response Failure Probability 
Plant: Scenario:

Sequence Number:

Task Error Description: Operator Fails to Restore SFP Cooling System Decision

1. Complexity, stress, and workload

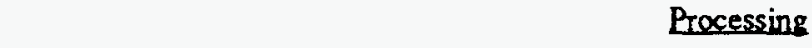

Processing

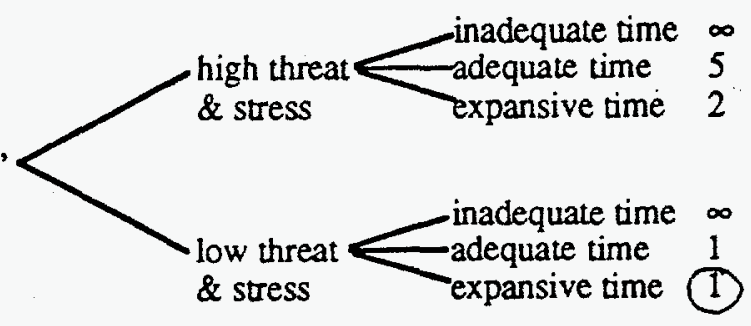

2. Experience/training

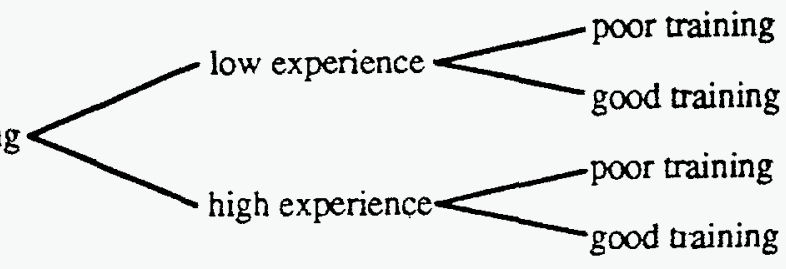

10

3. Procedures

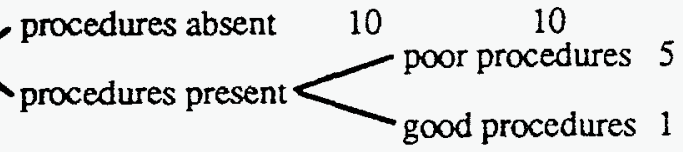

4. Ergonomics

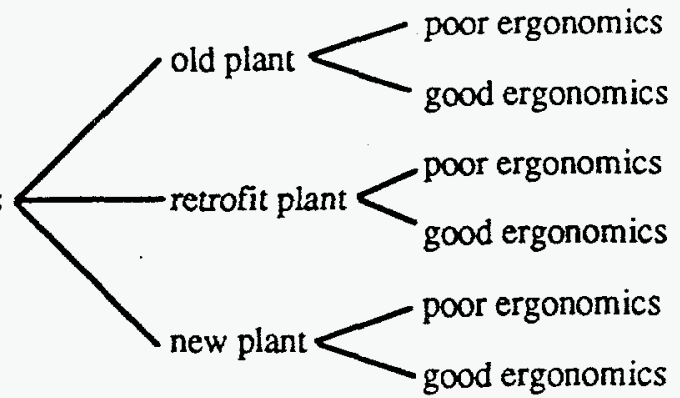

5

1

3

0.7

2

0.4
Response

$\infty$

5

2

1
$10 \quad 10$

(1) 1

55

0.5

(5)

1
5. Fitness for duty $\longrightarrow_{\text {fit }}^{\text {unfit }}$

6. Crew dynamics

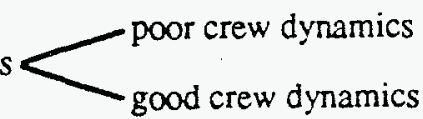

10

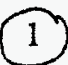

10

1

Task Portion

$$
\begin{aligned}
& \text { Complexity, Experience/ Procedures Ergonomics } \\
& \begin{array}{c}
\text { Fitness } \\
\text { stress, and } \\
\text { workload }
\end{array}
\end{aligned}
$$

io

Processing: $10 \mathrm{E}-2 \mathrm{x}$

Response: $10 \mathrm{E}-3 \mathrm{x}$ $\mathrm{x}$ $x$ $x$ $x$ $\mathrm{x}$ $1=$ .035 Processing Failure Probability $\mathrm{x}$ $x$ $=$ $+$ Response Failure Probability 
Plant:

Scenario:

Sequence Number:

Task Error Description: Operator Fails to Restore SFP Cooling System, Decision

Brocessing

Besponse

1. Complexity, stress,

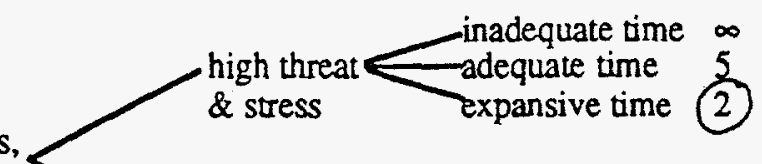

$\infty$
5
2
and workload

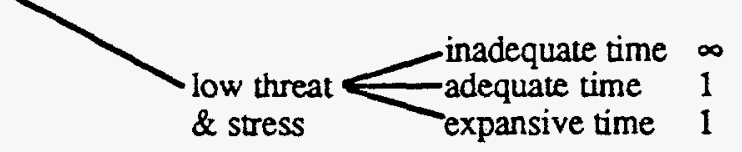

2. Experience/training

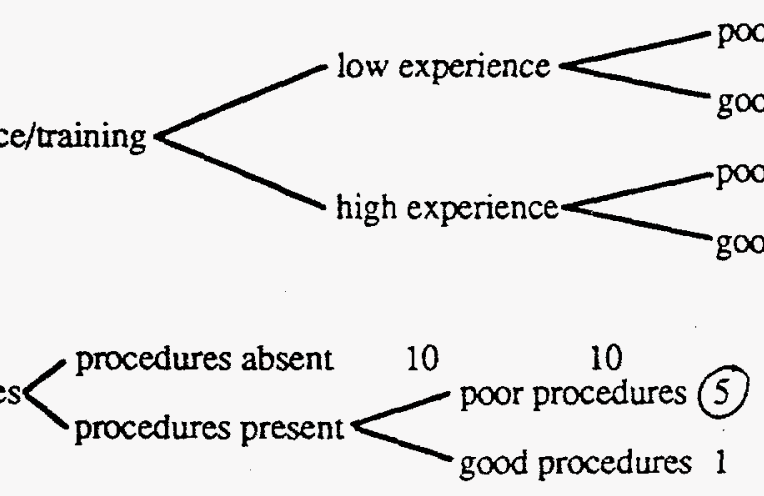

3. Procedures

4. Ergonomics

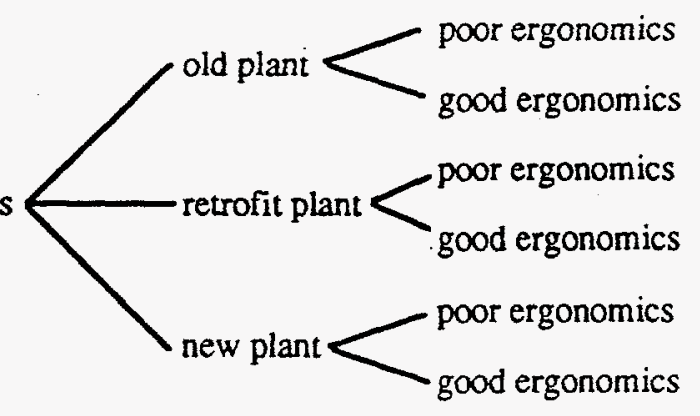

5

1 . 1

3

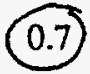

0.7

2

2

0.4

0.4

5. Fitness for duty< unfit 25

25

6. Crew dynamics $<_{\text {good crew dynamics }}^{\text {poor crew dynamics }}$

10

10

1

Task Portion

$\begin{array}{ccc}\text { Complexity, Experience/Procedures Ergonomics } & \begin{array}{c}\text { Fitness } \\ \text { stress, and } \\ \text { workload }\end{array} & \begin{array}{c}\text { Crew } \\ \text { training }\end{array} \\ \text { dury } & \text { dynamics }\end{array}$

Processing: $10 \mathrm{E}-2 \times \frac{2}{2} \times 1 \times \frac{1}{1} \times 1.1 \times 1=$ .07 Processing Failure Probability Response: $10 \mathrm{E}-3 \mathrm{x}$ $\mathrm{x}$ $x$ $\mathrm{x}$ $\mathrm{x}$ $\mathrm{x}$ Response Failure Probability 
Plant: Scenario:

Sequence Number:

Task Error Description: Operator Fails to Restore SFP Cooling System

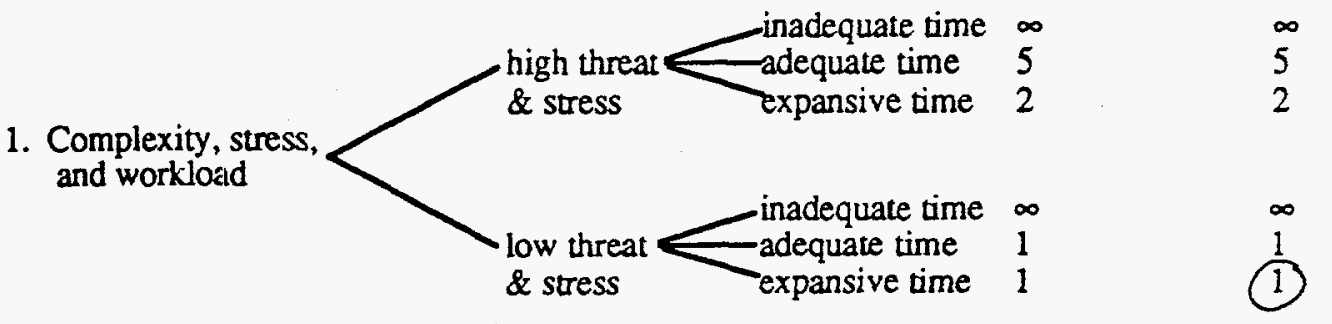

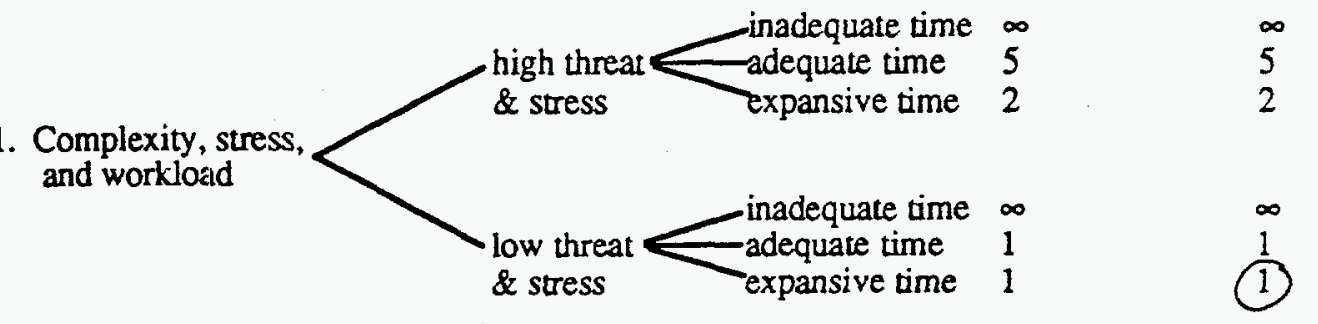

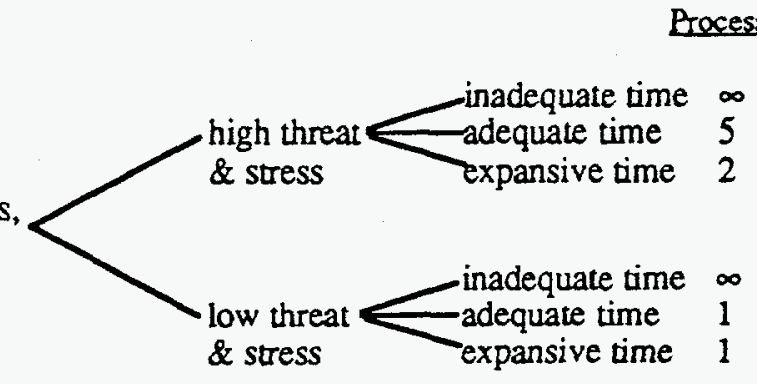

Brocessing

Response

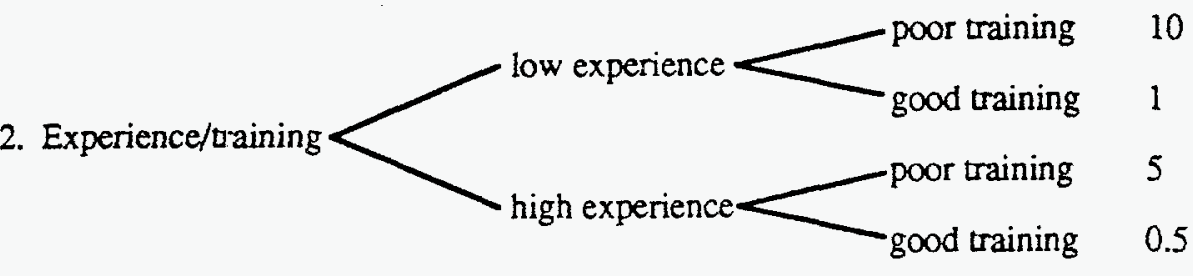

3. Procedures<

procedures absent 10

$10 \quad 10$

procedures present

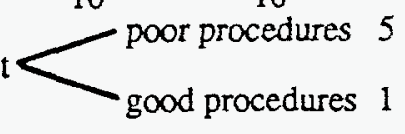

4. Ergonomics

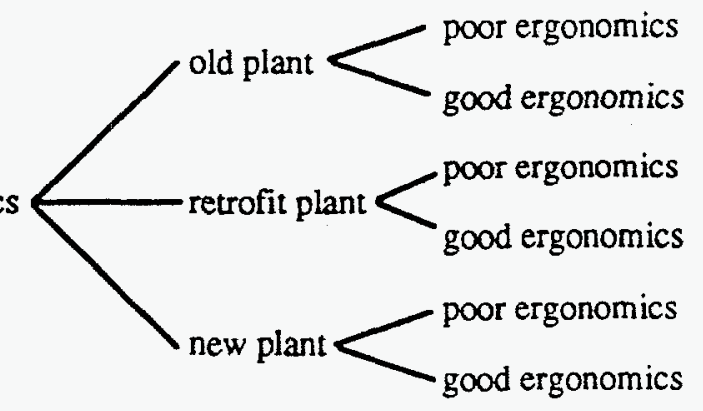

5

5. Fitness for duty< unfit ${ }^{25}$

6. Crew dynamics

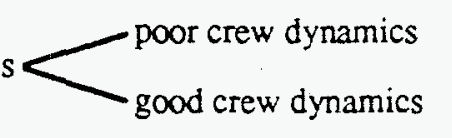

10

10

1

Task Portion

Complexity, Experience/Procedures Ergonomics stress, and training workload

Processing: $10 \mathrm{E}-2 \times$ $\mathrm{x}$

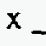
X Processing Failure Probability Response: $10 \mathrm{E}-3 \times 1 \times 1 \times 5 \times .7 \times 1 \times 1=$ +.0035 Response Failure Probability 
Plant:

Scenario:

Sequence Number:

Task Error Description: Operator Fails to Restore SFP Cooling System

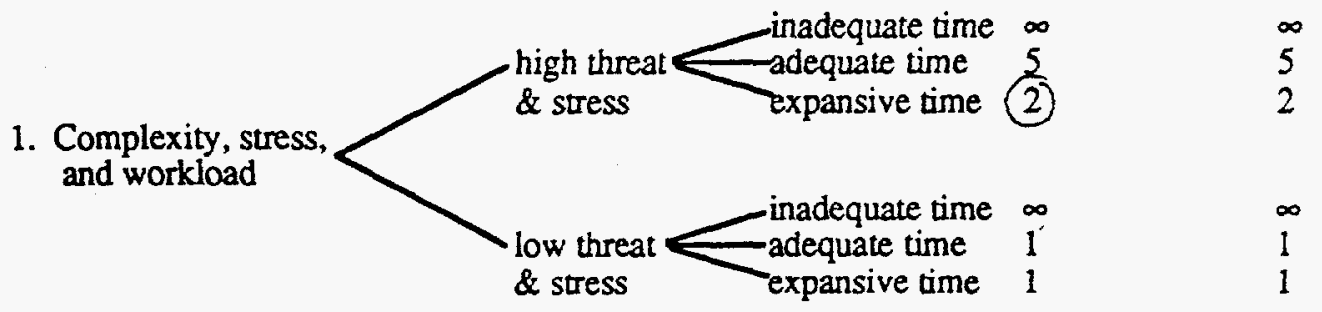

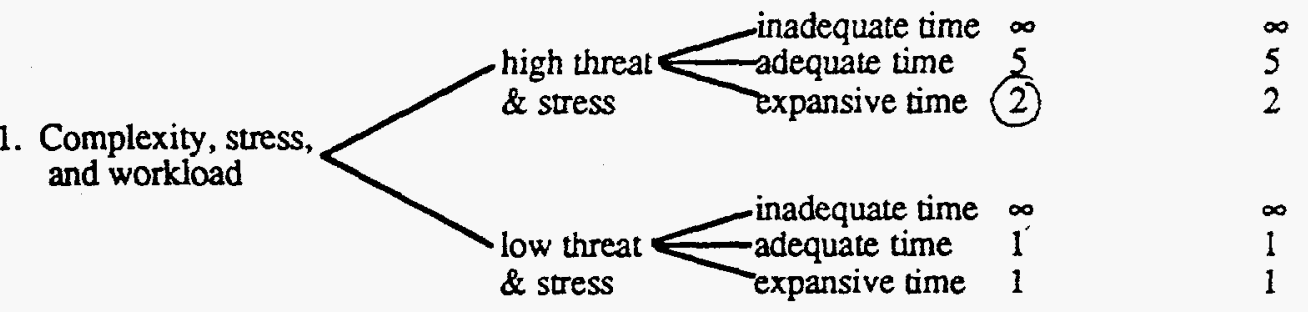

Processing

Response

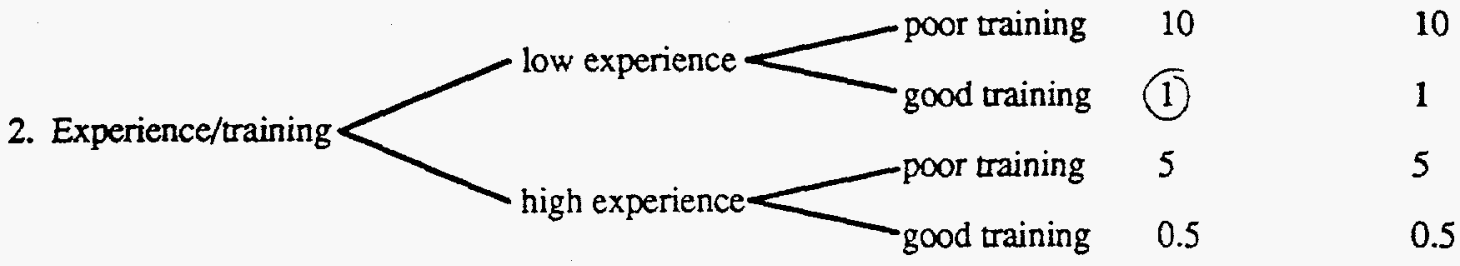

3. Procedures procedures absent $10 \quad 10$ 10

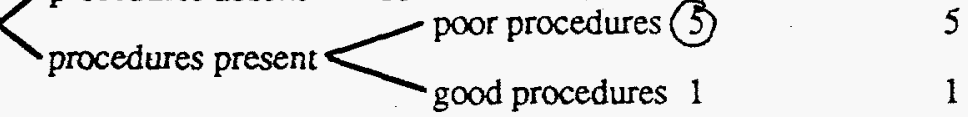

4. Ergonomics

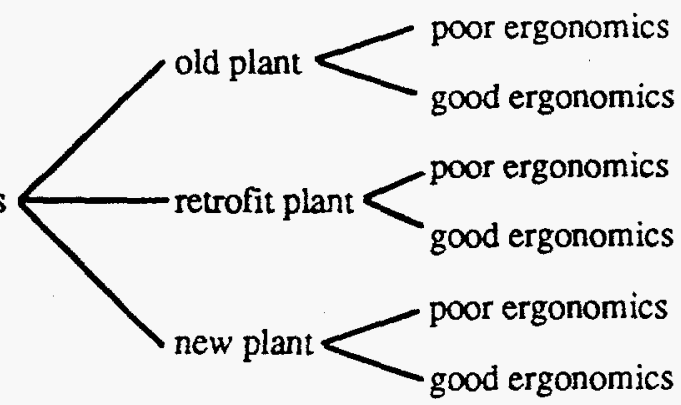

5

5

1

$3 \quad 3$

$0.7 \quad 0.7$

2

2

0.4

0.4

5. Fitness for duty

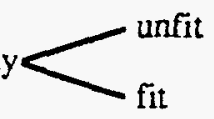

25

1

6. Crew dynamic

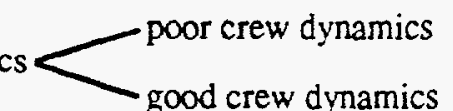

10

10

(1)

1

Complexity. Experience/Procedures Ergonomics
stress, and
workload

Task Portion workload $x$ x $\mathrm{x}$ $=$

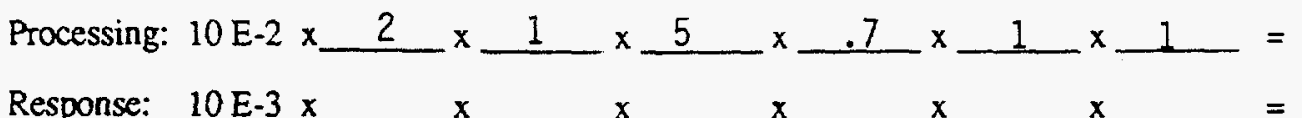

.07 Processing Failure Probability

$+$ Response Failure Probability

Task Failure Probability Without Formal Dependence 
Plant:

Scenario:

Sequence Number:

Task Error Description: Operator Fails to Restore SFP Cooling System

Brocessing

Response

1. Complexity, stress,

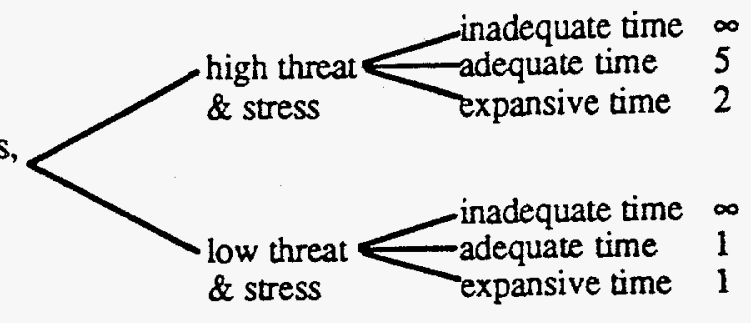

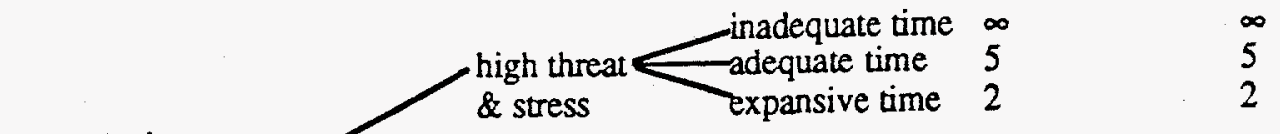
and workload

expansive time 1

$\stackrel{1}{1}$

2. Experience/training

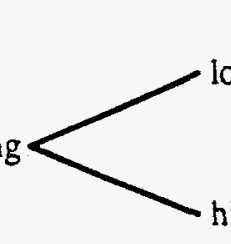

low experience

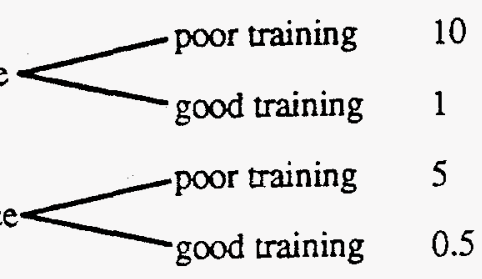

10

10

(1)

5

high experience $\longrightarrow_{\text {good training }} 0.5$

0.5

3. Procedures

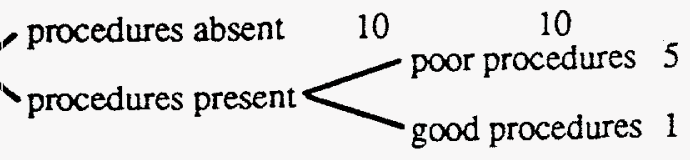

4. Ergonomics

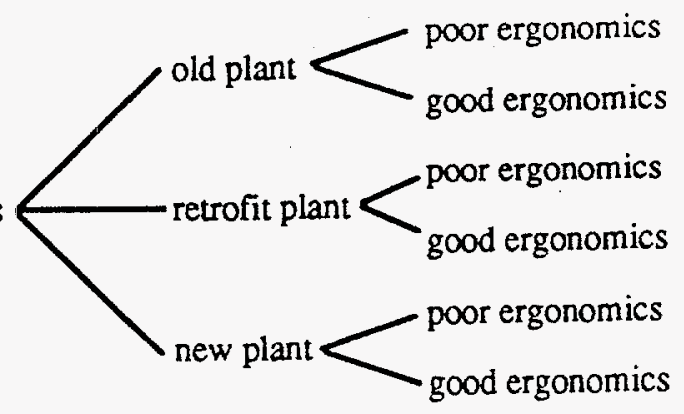

5
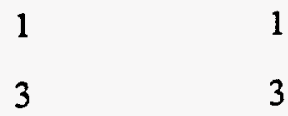

0.7

5. Fitness for duty<smiles>CCCCCCC</smiles>

25

6. Crew dynamics

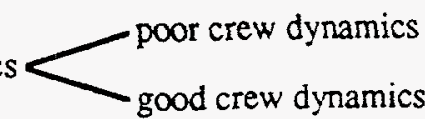

10

10

1

Task Portion

$$
\begin{aligned}
& \text { Complexity, } \\
& \text { stress, and } \\
& \text { workload } \\
& \text {; }
\end{aligned}
$$

Processing: $10 \mathrm{E}-2 x$ X $x$ $x$ X x

Response: $10 \mathrm{E}-3$ $\mathrm{x}$ $5 \times$ +.0035 Response Failure Probability 
Plant:

Scenario:

Sequence Number:

Task Error Description: Operator Fails to Restore SEP Cooling System

Processing

1. Complexity, stress and workload

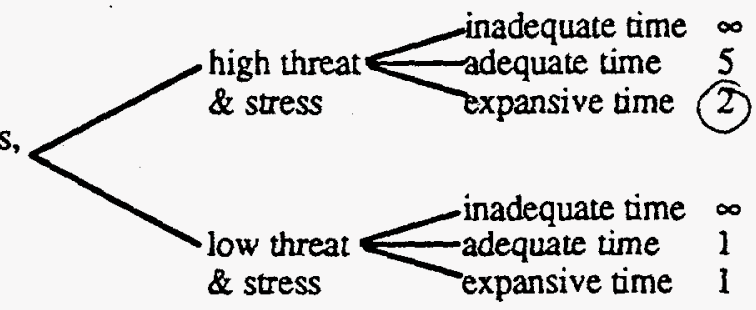

2. Experience/training

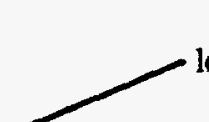

low experience

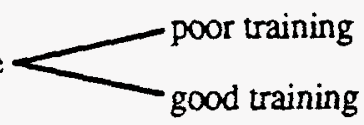

high experience

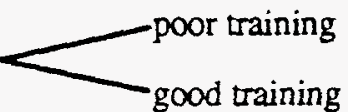

10

3. Procedures

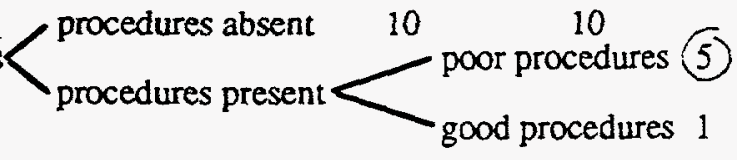

4. Ergonomics

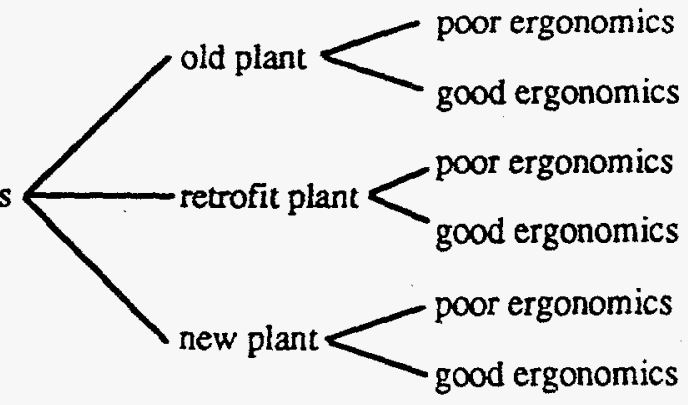

5

1

3

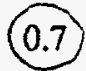

2

0.4
Response

$\infty$

5

2

1
10

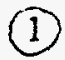

5

0.5

5

1

5. Fitness for duty unfit 25

(1) 1

6. Crew dynamics $\longrightarrow$ poor crew dynamics

$10 \quad 10$

(1) 1

Task Portion

Complexity. Experience/Procedures Ergonomics stress, and training

Processing: $10 \mathrm{E}-2$ workload

Fitness
for

Crew

dynamics

Response: $10 \mathrm{E}-3 \mathrm{x}$ $x$ $\mathbf{x}$ $5 \times$ $7 x$ $1 \times 1=$ .07 Processing Failure Probability X $x$ $x$ $=$

$+$

C-29
10

1

5

0.5 
Plant:

Scenario:

Sequence Number:

Task Error Description: Operator FAils to Initiate RHR Mode of SFP Cooling, early. uncomplicat Processing Response

1. Complexity, stress, and workload

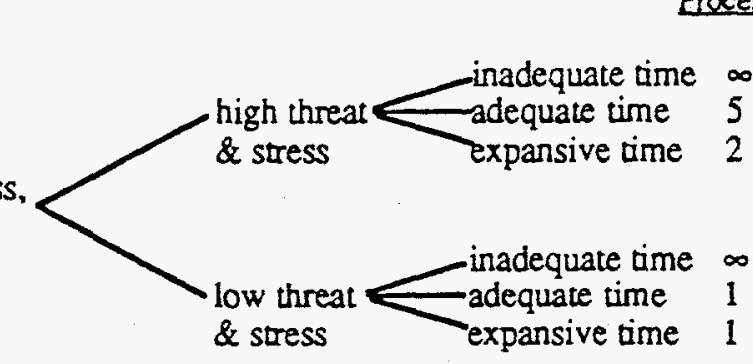

$\begin{array}{ll}\infty & \infty \\ 5 & 5 \\ 2 & 2 \\ 1 & \infty \\ 1 & 1 \\ 1 & 1\end{array}$

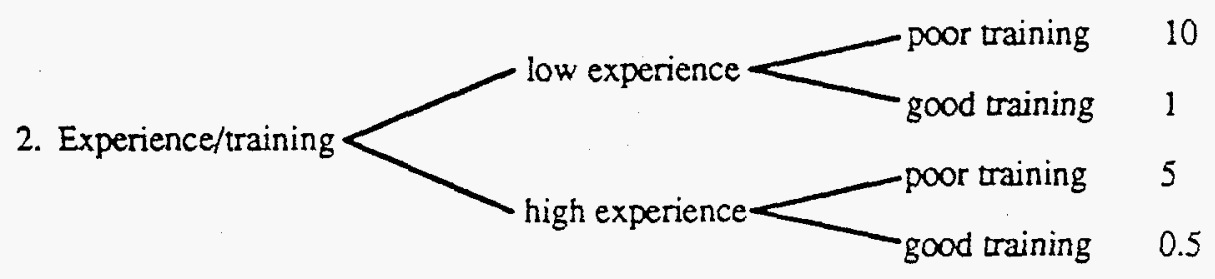

3. Procedures

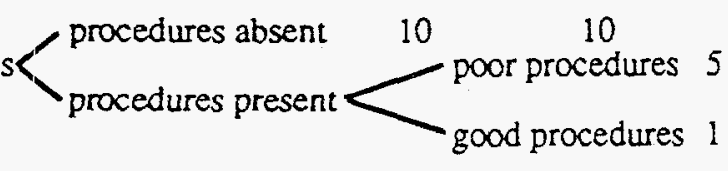

4. Ergonomics

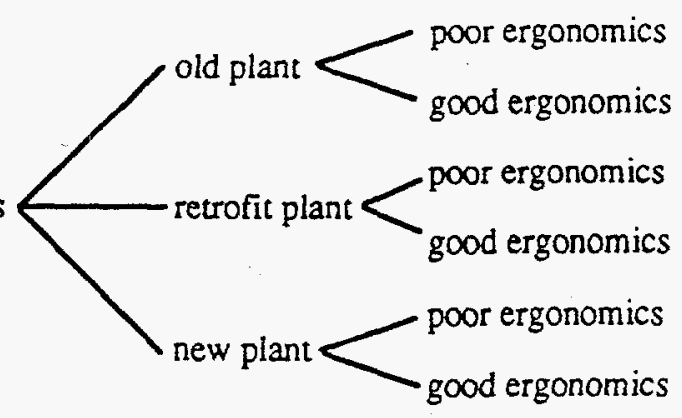

5

\section{1}

3

0.7

2

0.4

5

1

3

(0.7)

2

0.4

5. Fitness for duty $<_{\text {fit }}^{\text {unfit }}{ }_{1}^{25}$

25

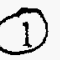

6. Crew dynannics

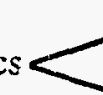
-poor crew dynamics

10

10

-good crew dynamics

1

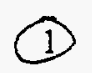
Complexity, Experience/ Procedures Ergonomics Finess
stress, and $\begin{gathered}\text { Crew } \\ \text { training }\end{gathered}$
forkload

Task Portion

Processing: $10 \mathrm{E}-2 \times$ $x$ $x$ x $x$ x $=$ Processing Failure Probability

Response: $10 \mathrm{E}-3$ $x+10$ $5 x$ $x+.7 \times$ ${ }^{x}-1$ $=\quad+.07$ Response Failure Probability 
Plant: Scenario:

Sequence Number:

Task Error Description: Operator Fails to Initiate RHR Mode of SFP Cooling, early, uncomplicater

1. Complexity, stress, and workload

\section{Processing}

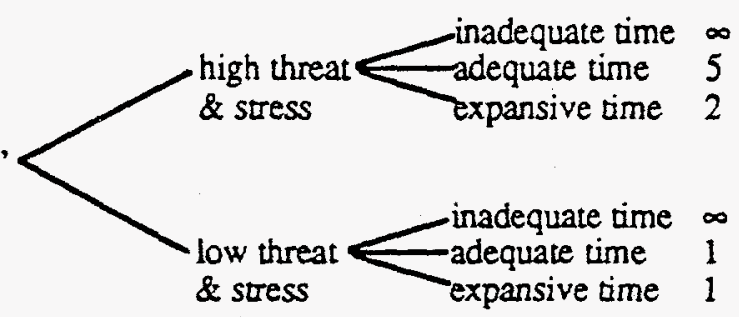

2. Experience/training
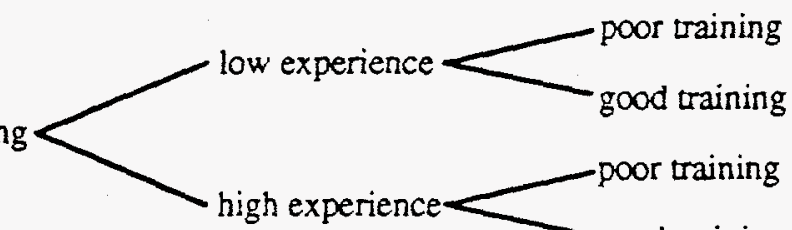
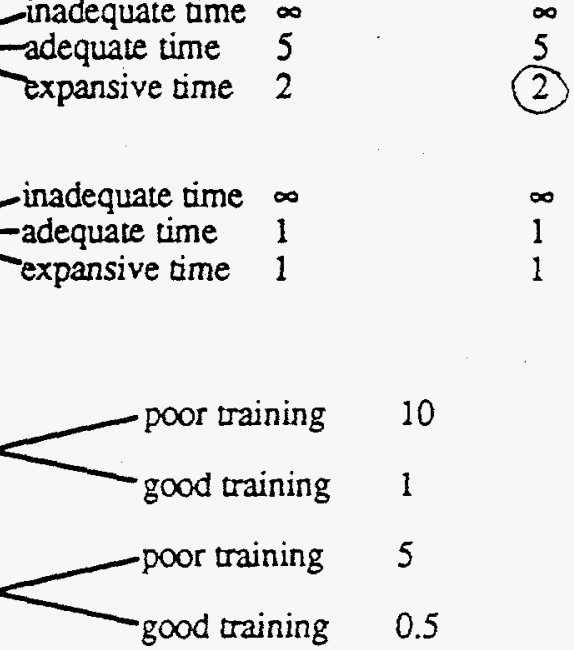

$\infty$

1

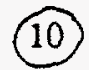

4. Ergonomics

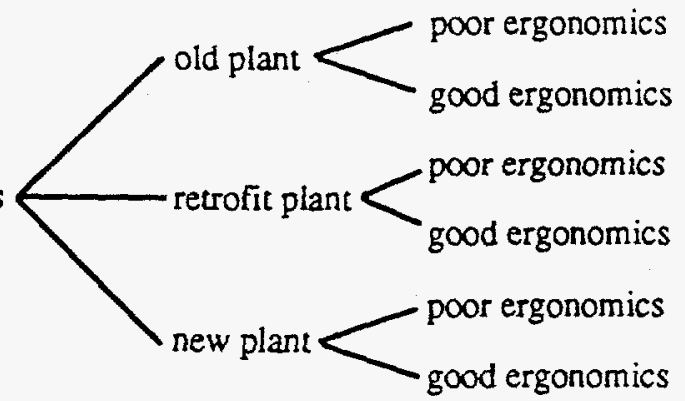

5

1

3

0.7

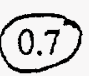

2

0.4

5. Fimess for duty $<_{\text {fit }}$ unfit $\quad 25$

25

6. Crew dynamics

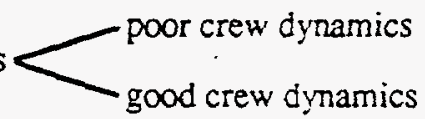

10

10

1

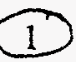
Complexity, Experience/Procedures Ergonomics $\begin{gathered}\text { Finness } \\ \text { for } \\ \text { stress, and dynamics } \\ \text { training } \\ \text { duty }\end{gathered}$

Task Portion

Processing Failure Probability

$+.07 \quad$ Response Failure Probability

Processing: $10 \mathrm{E}-2 \mathrm{x}$ $x$ $x$ $x$ $x$ $x$ 
Plant: Scenario:

Sequence Number:

Task Error Description: Operator Fails to I solate Leak During Primary LocA

1. Complexity, stress, and workload

Processing

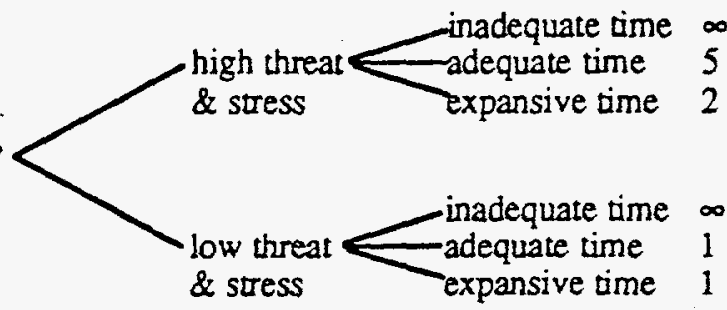

2. Experience/raining

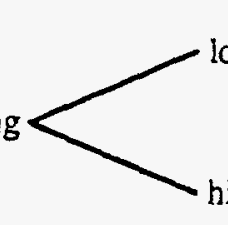

low experience

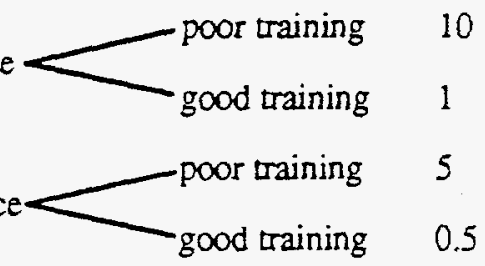

Response

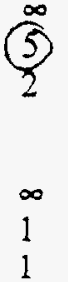

3. Procedures procedures absent

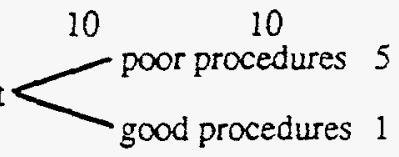

4. Ergonomics

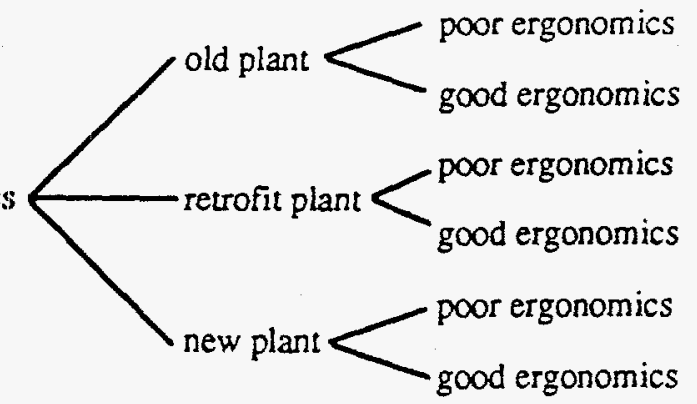

\section{5}

5

1

3

0.7

0.7

$2 \quad 2$

0.4

0.4

10

5

0.5

5. Fitness for duty $<_{\text {fit }}$ unfit 25

25

6. Crew dynamics

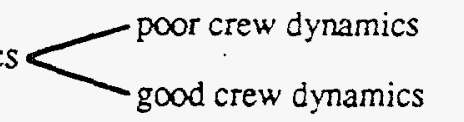

10

10

1

Complexity, Experience/ Procedures Ergonomics stress, and

Task Portion syorkload training

Fimess

for
duty

Processing: $10 \mathrm{E}-2 \mathrm{x}$ $\mathrm{x}$ $x$ X $\mathrm{x}$ Processing Failure Probability

Response: $10 E-3 \times$ $x$ $x+1-3$ $x$ +.045 Response Failure Probability 


\section{ASP HUMAN ERROR WORKSHEET (Page 1 of 2) $\begin{gathered}\text { MISLSPHN } \\ \text { MISLSPCE }\end{gathered}$}

Plant:

Scenario:

Sequence Number:

Task Error Description: Operator Fails to Isolate SFP Boundary Leak Early-critical, refueling Brocessing

Response

pipe leak

1. Complexity, stress,

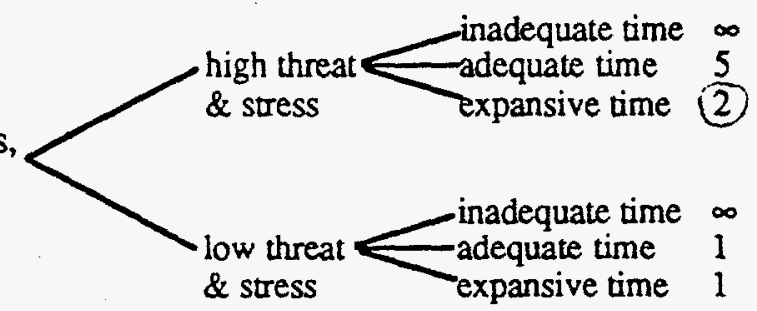

$\frac{\infty}{2}$ and workload expansive time 1

$\infty$
1
1

2. Experience/training

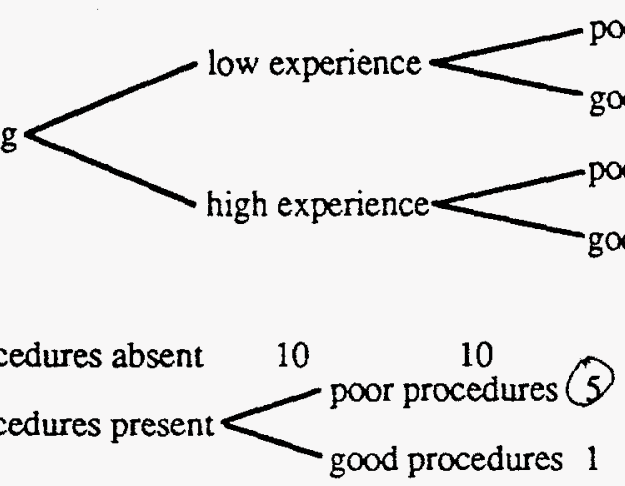

10

3. Procedures $\begin{aligned} & \text { procedures absent } 10 \\ & \text { procedures present }\end{aligned} \underbrace{10}_{\text {good procedures } 1}$

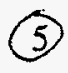

4. Ergonomics

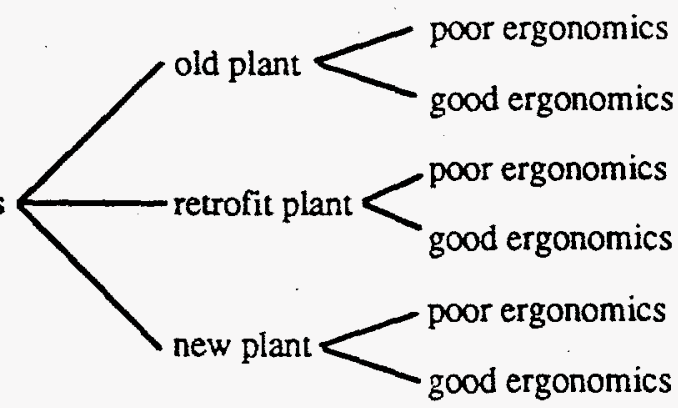

5. Fimess for duty $<25$ 1 25

6. Crew dynamics

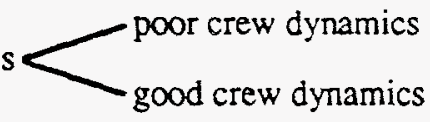

10

1
10

5

1

3

(0.7)

2

0.4

(1)

Task Portion Complexity, Experience/Ptocedures Ergonomics
stress, and training
yorkload Fimess
for
duty dynamics

Processing: $10 \mathrm{E}-2 \times 2$

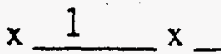
$\times$ $\times 1=$ $.07 \quad$ Processing Failure Probability Response: $10 \mathrm{E}-3 \times$ $\times 1+5$ $x$ $\mathrm{x}$ $=$ +.007 Response Failure Probability 
Plant:

Scenario:

Sequence Number:

Task Error Description: Operator Fails to Isolate SFP Boundary Leak Early, large seal leak Brocessing Response

1. Complexity, stress, and workload

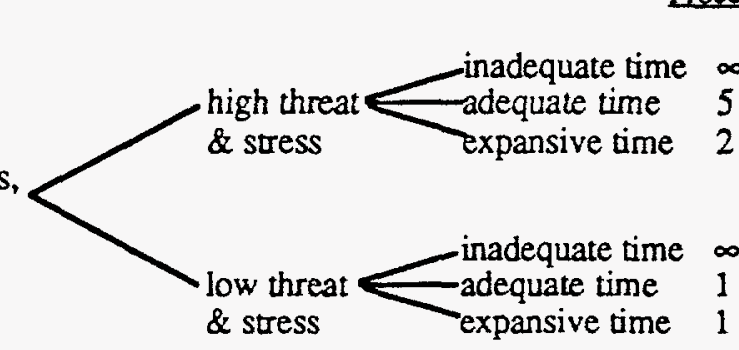

$\stackrel{5}{5}_{2}^{\infty}$

2. Experience/training

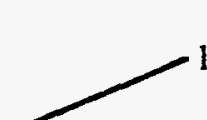

low experience

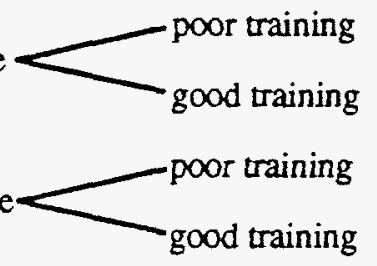

10

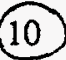

1

5

0.5

3. Procedures

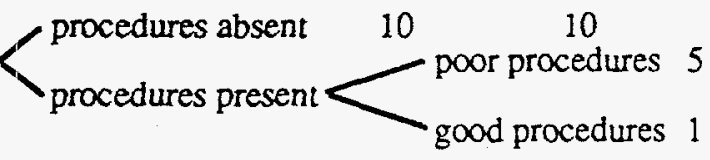

4. Ergonomics

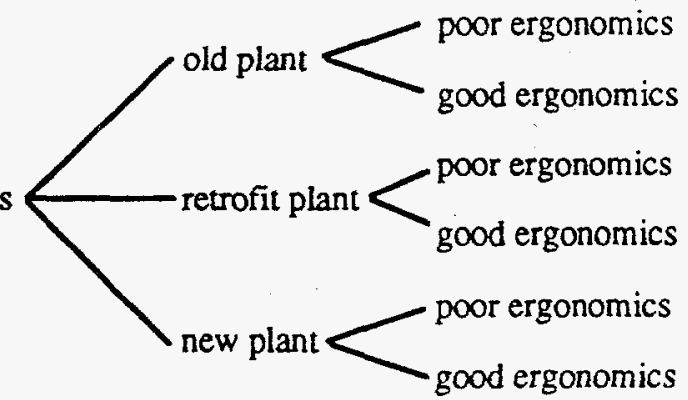

5. Fitness for duty $<$ unfit 25

6. Crew dynamics<smiles>CCCCCCCOC(=O)OOC(=O)OCCCC</smiles>

10

1

5

1

3

0.7

2

0.4

25

10

(1)

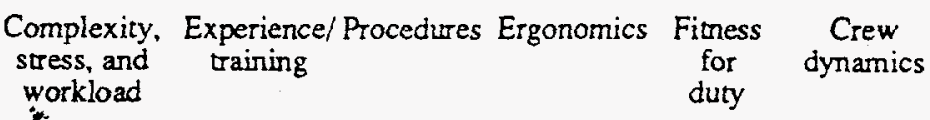

Task Portion x X $x$ $=$ Processing Failure Probability

Response: $10 E-3 \times 5$ $x+x$ $x$ $\times 1 \times 1=$ $+.18$ Response Failure Probability 
Plant:

Scenario:

Sequence Number:

Task Error Description: Operator Fails to Isolate SFP Boundary Leak Late. large leak Processing Response

1. Complexity, stress and workload
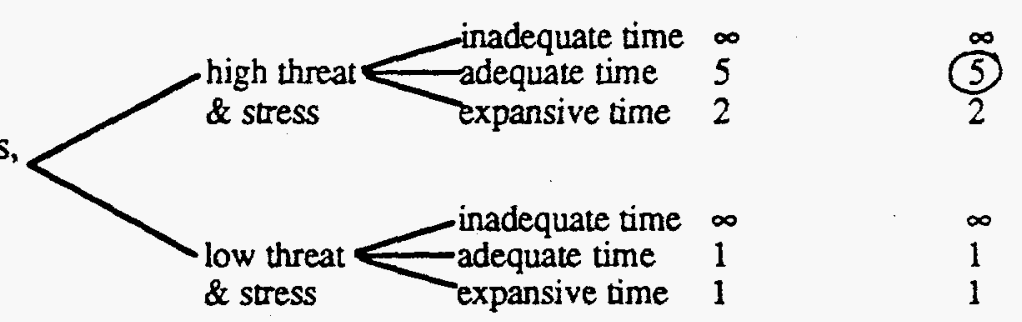

2. Experience/training

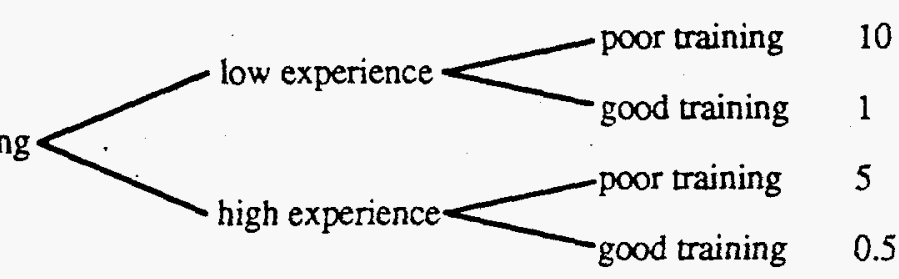

3. Procedures procedures absent

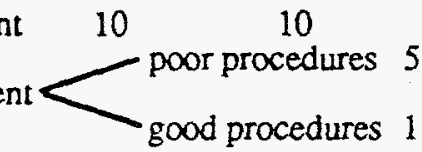

4. Ergonomics

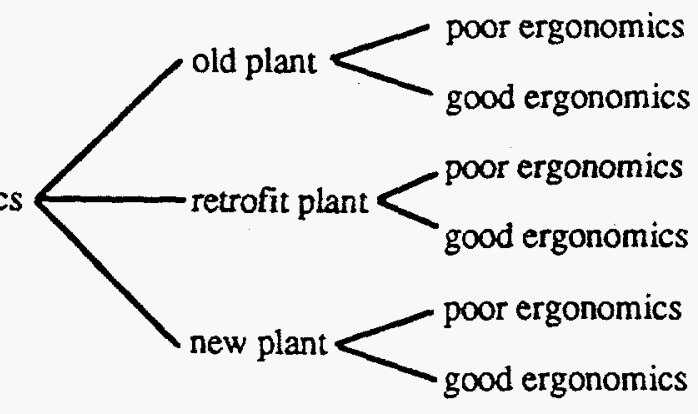

5

5

1

3

0.7

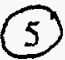

1

4. Ergonomics

25

5. Fitness for duty< unfit $\underbrace{25}_{\text {fit }}$

6. Crew dynamic

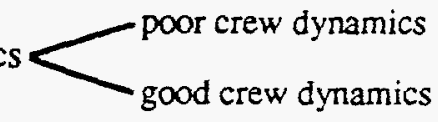

10

10

1

(1)

Complexity, Experience/Procedures Ergonomics
stress, and
training
workload

Task Portion workload $x$ $\mathbf{x}$ $\mathrm{x}$ $x$ Processing Failure Probability

Response: $10 \mathrm{E}-3$ X $x$ $x$ $\mathrm{x}$ $=$ Response Failure Probability 
Plant: Scenario:

Sequence Number:

Task Error Description: Operator Fails to Isolate SFP Boundary Leak Early, small seal leak Brocessing Response

1. Complexity, stress, and workload

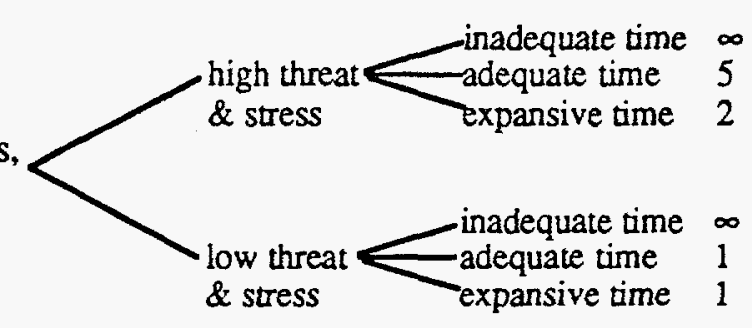

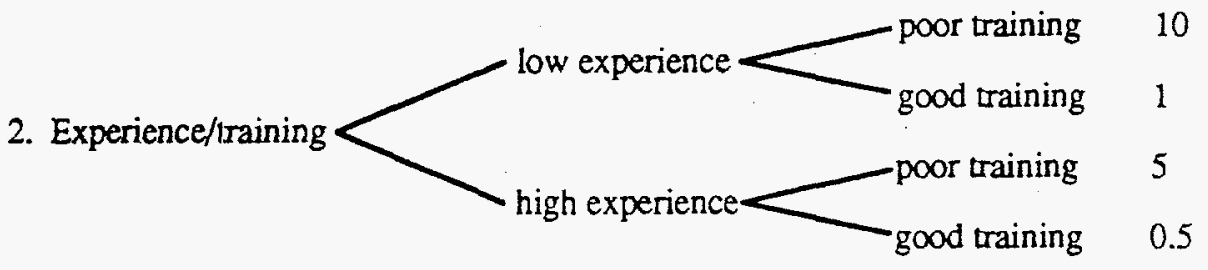
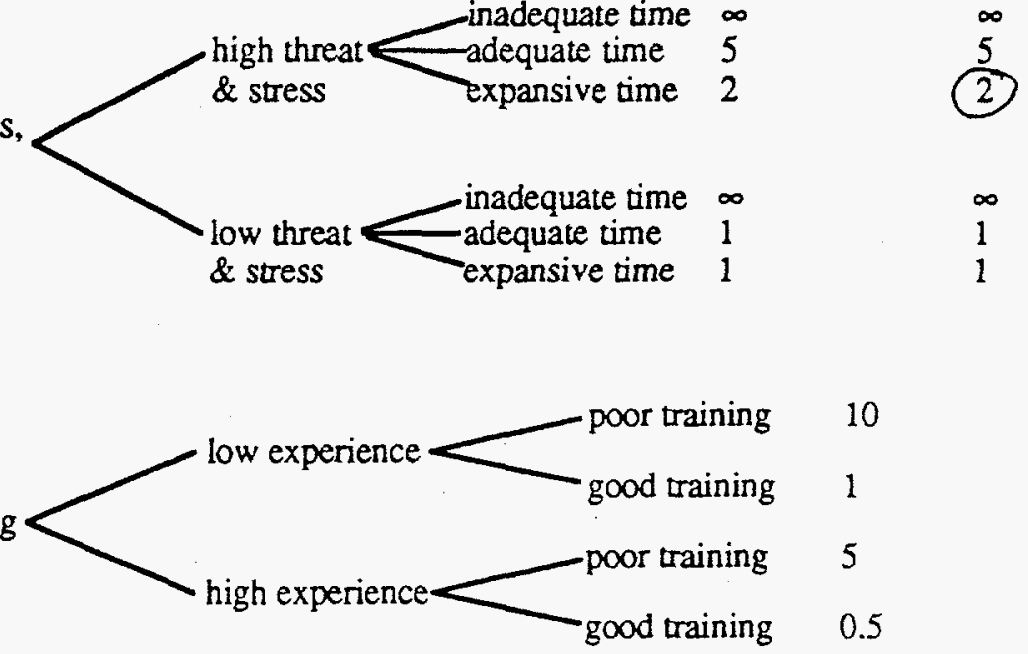
10

3. Procedures

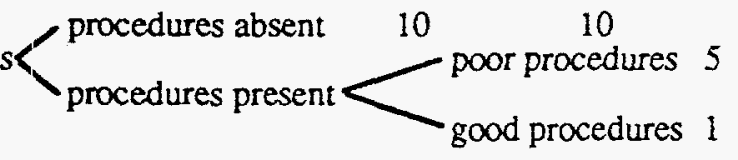

4. Ergonomics

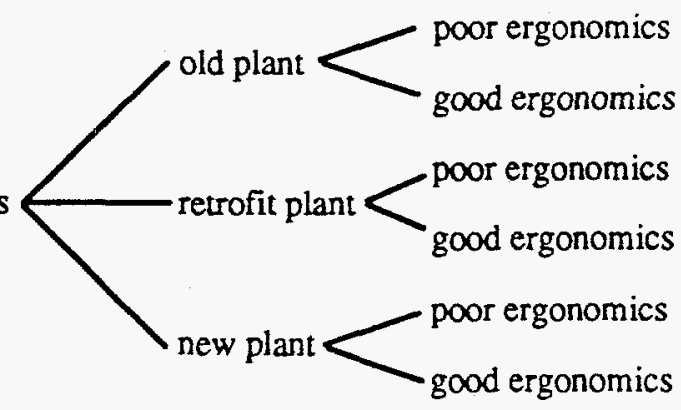

5

5. Fitness for duty $\sum_{\text {fit }}^{\text {unfit }}{ }_{1}^{25}$

6. Crew dynamics<smiles>C1C[AsH2]C1</smiles>
poor crew dynamics

Task Portion workload

Processing: $10 \mathrm{E}-2 \mathrm{x}$ $x$ $\mathrm{x}$ $x$ $x$ $x$ Processing Failure Probability

Response: $10 \mathrm{E}-3 \times$ $x$ $x$ $x+1$ $=$ $+.007$ Response Failure Probability 
Plant:

Scenario:

Sequence Number:

Task Error Description: Operator Fails to Isolate SFP Boundary Leak Late.small leak

Processing

Response

1. Complexity, stress,

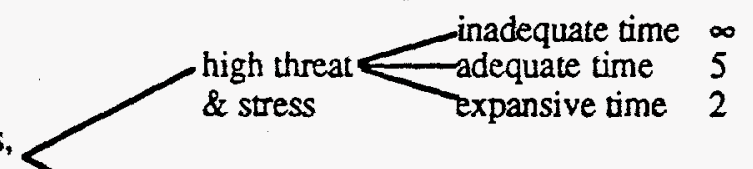
and workload

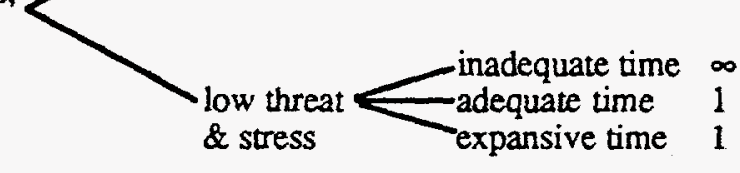

$\infty$
$\frac{5}{2}$
$\infty$
1
1

2. Experience/training

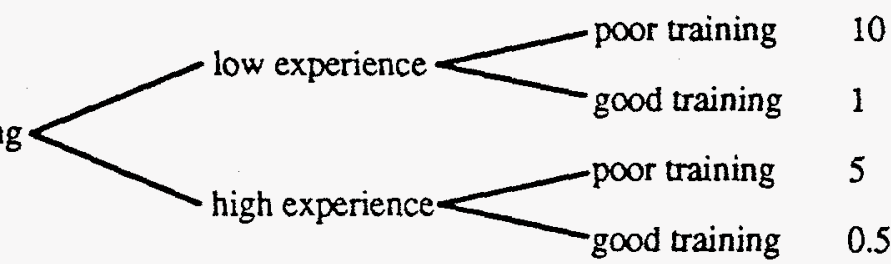

3. Procedures

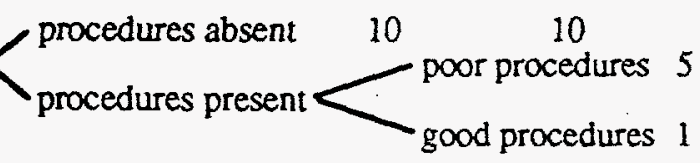

4. Ergonomics

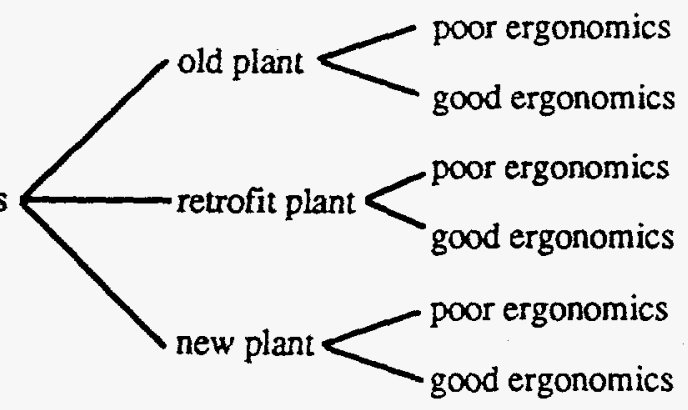

5

5

1

3

0.7

2

2

0.4

0.4

5. Fitness for duty $<_{\text {fit }}$ unfit ${ }_{1}^{25}$

25

6. Crew dynamics

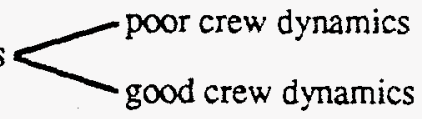

10

10

1

(1)

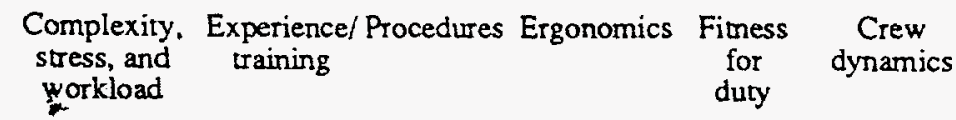

Task Portion $x$ $x$ $x$ Processing Failure Probability

Processing: $10 \mathrm{E}-2 \mathrm{x}$ $x$ $x$ $x+1$ $x+1=$ 
Plant:

Scenario:

Sequence Number:

Task Error Description: Operator Fails to Align ECCS Systems

Brocessing

Response

1. Complexity, stress,
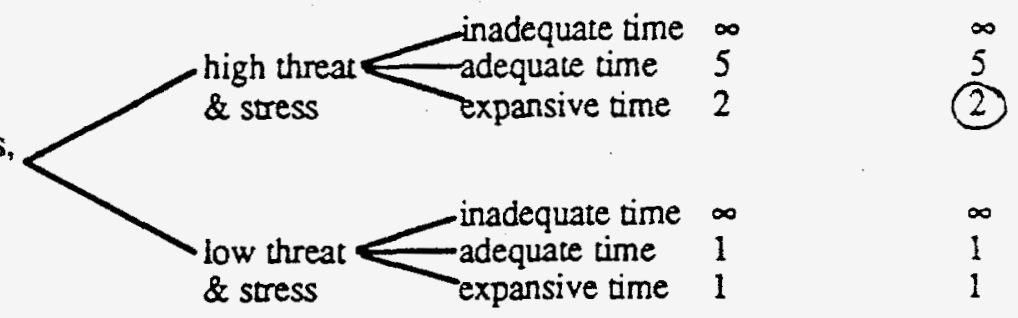
and workload

2. Experience/training

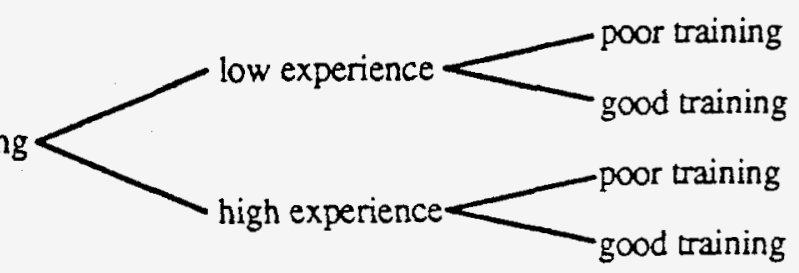

10

1

5

0.5

10

3. Procedures

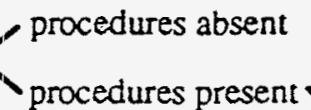

10

10

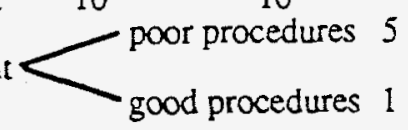

4. Ergonomics
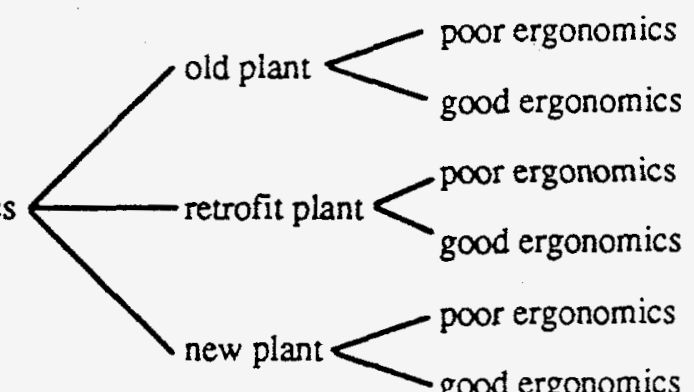

5

1

3

0.7

5. Fitness for duty< unfit $\underbrace{}_{\text {fit }} 25$

25

6. Crew dynamics<smiles>CCCCCCCCOC(=O)OCc1ccccc1</smiles>

10

10

1

(1)

Task Porion

Complexity, stress, and yorkload training

Processing: $10 \mathrm{E}-2 \mathrm{x}$ $x$ $x$ x ${ }^{x}$

Response: $10 \mathrm{E}-3$ $\mathrm{x}$ ${ }^{x}$ $x$ 
Plant:

Scenario:

Sequence Number:

Task Error Description:

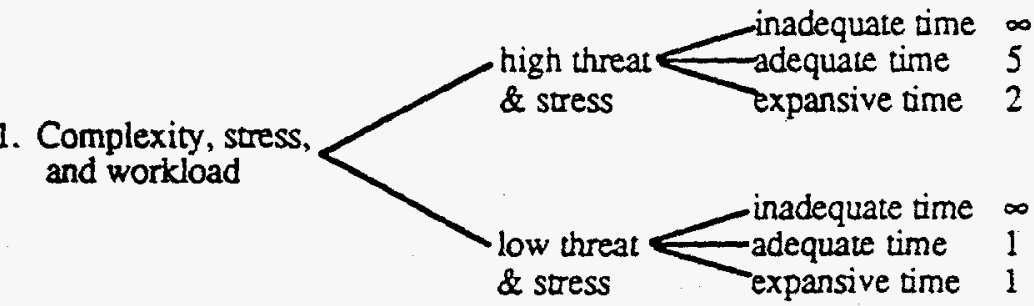

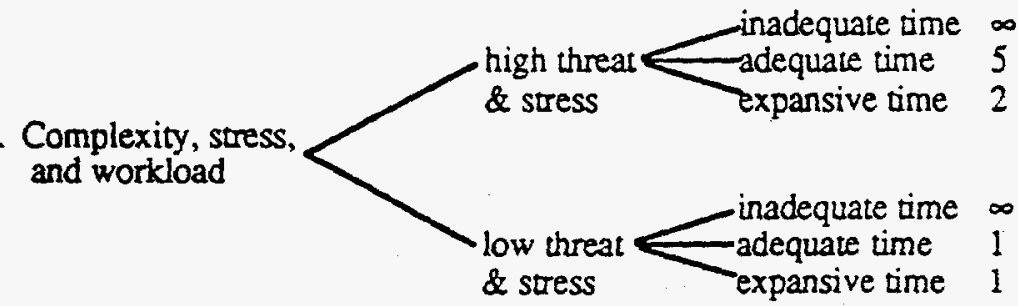

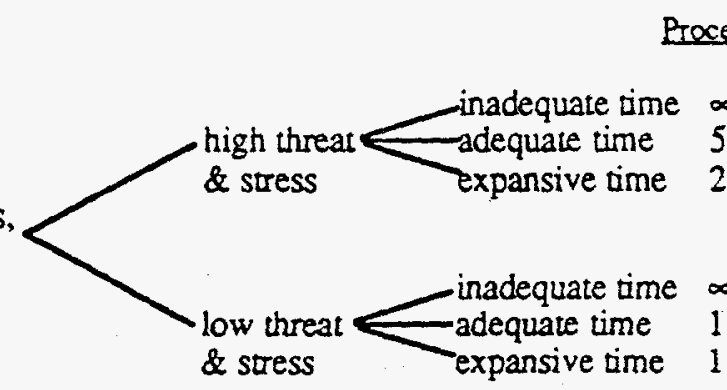

Processing

\section{Response}

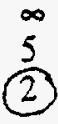

1

3. Procedures

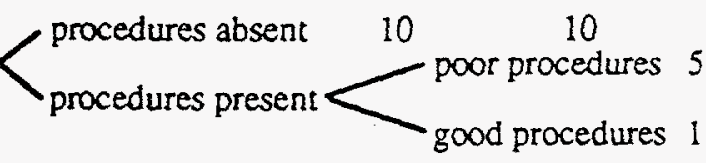

10

2. Experience/training

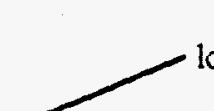

low experience

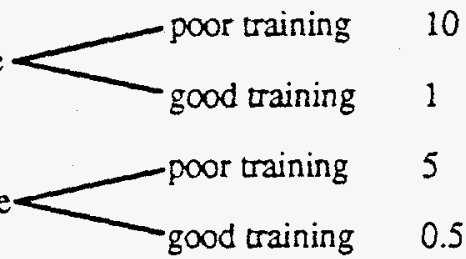

4. Ergonomics

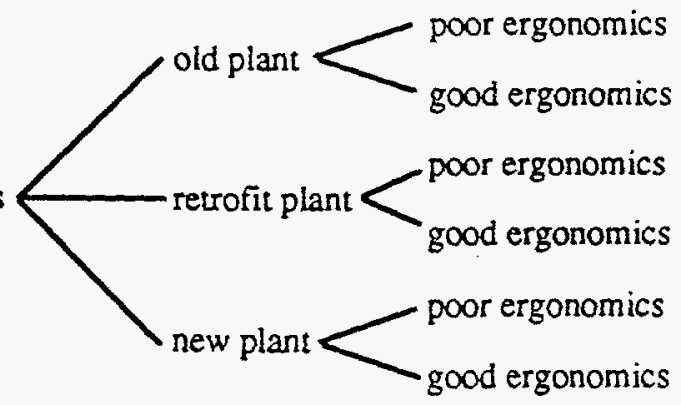

5

5

1

1

3

0.7

3

2

5. Fimess for duty $<_{\text {fit }}{ }_{1}^{\text {unfit }}{ }^{25}$

6. Crew dynamics

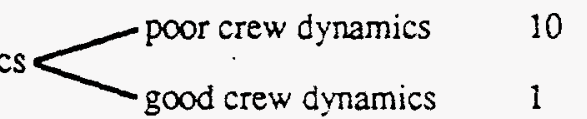

Task Portion

iworkload

Processing: $10 \mathrm{E}-2 \times$ $x$ $x$ $\mathrm{x}$ $\mathrm{x}$ $x$

Processing Failure Probability

Response: $10 \mathrm{E}-3$ $x$ $x$ $\times .7 \times$ $x$ $=$ 


\section{ASP HUMAN ERROR WORKSHEET (Page 1 of 2) SFP1-XHE-XM-LSFP

Plant:

Scenario:

Sequence Number:

Task Error Description: Operator Fails to Initiate SFP Cooling after Late Recovery

1. Complexity, stress,
and workload
\& stress
\& stress

Complexity, stress,
and workload

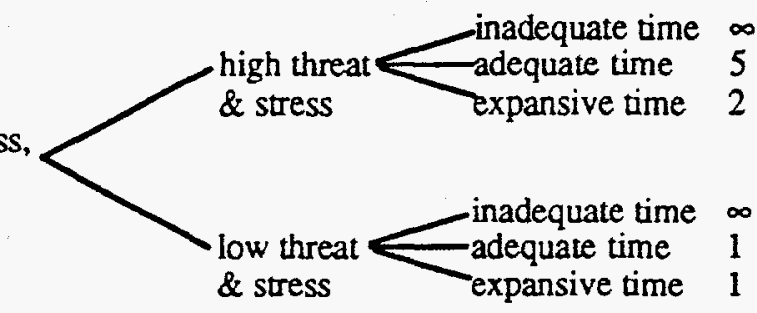

Processing

Response

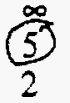

2. Experience/training

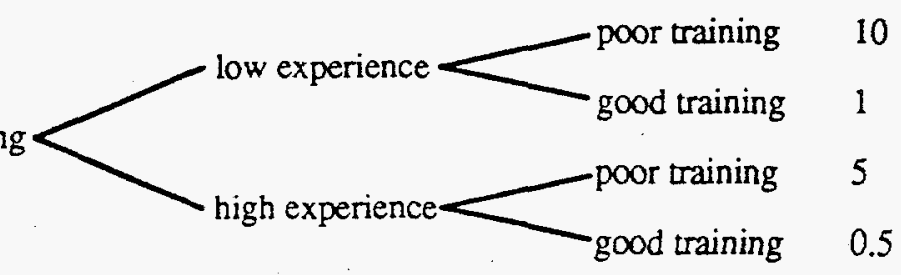

3. Procedures

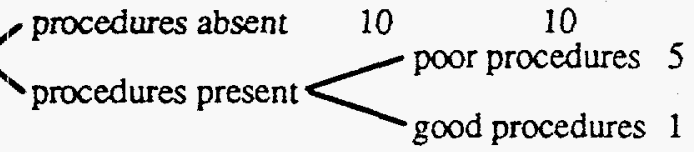

4. Ergonomics

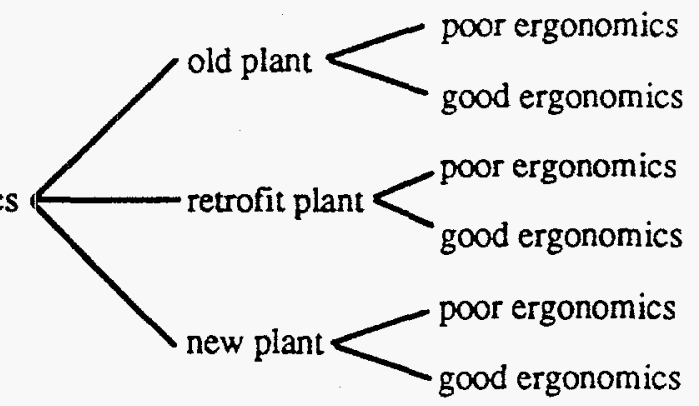

5

\section{1}

3

0.7

2

0.4

25

(1)

5. Fitness for duty< unfit $\underbrace{}_{\text {fit }} 25$

(1)

6. Crew dynamics

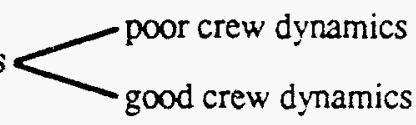

10

10

1

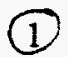
Complexity, Experience/ Procedures Ergonomics
$\begin{aligned} & \text { Fimess } \\ & \text { stress, and } \\ & \text { workload }\end{aligned}$

Task Portion $\mathrm{x}$ $\mathrm{x}$ $\mathrm{x}$ $=$ Processing: $10 \mathrm{E}-2 x$ X $x$ $x-1=1=$

Response: 10 E-3 x 5 $x+1 \times-5 \times 3$ $=$

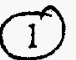
5
0.5
Processing Failure Probability +.075 Response Failure Probability 


\section{C.5 References}

C.1 H.S. Blackman and J.C. Byers, ASP Human Reliability Methodology Development, draft report prepared for the U.S. Department of Energy under DOE Idaho Operations Office Contract DE-AC07-94ID13223, Idaho National Engineering Laboratory, 1995.

C.2 A.D. Swain, Handbook of Human Reliability Analysis with Emphasis on Nuclear Power Plant Applications, NUREG/CR-1278, 1983. 


\section{APPENDIX D}

Key Assumptions 


\section{APPENDIX D - KEY ASSUMPTIONS}

\section{D.1 General Assumptions}

1) For those initiating events which affect more than the SFPC system (i.e., LOOP, seismic, PLOCA), if the plant recovery/stabilization is complicated, either there will be no early attempts to recover SFPC or such attempts will be ineffective. This assumes that the effective focus of the operators will be on safeguarding the core.

2) If there is no early attempt to restore cooling to the spent fuel pool, the RHR supplemental cooling assist mode cannot be used. This is based on the length of time necessary to initiate this cooling method (the pool will have already reached near boiling conditions in a late cooling restoration attempt), and the possibility of a harsh environment inhibiting any local actions.

3) If the operators' early attempts to restore cooling using the SFPC system fails, no late restoration of SFPC is modeled. This treats the possibility that the reason for the early failure still applies to later attempts.

4) During normal operation, two of the three SFPC pumps and two heat exchangers are operating.

5) If the pool cross-connect is open in a dual unit plant, the previously operating configuration of either units' SFPC system is adequate to prevent boiling in both units. For example, if Unit 1 loses SFPC with the pool cross-connect open, whatever combination of Unit 2 pump(s) that remained running will be adequate to prevent boiling in the Unit 1 pool. This assumption applies to Cases 1 and 2 .

6) Once the spent fuel pool reaches near boiling conditions, the pool can not be crossconnected. This based on the possibility of a harsh environment prohibiting the action.

7) Top event ALT-C (alternate cooling) represents boiling/makeup cooling. In this case spent fuel is not assumed to be vulnerable but safety system(s) could be vulnerable.

8) A single pump RHR train in SFP cooling assist mode can provide cooling to both units if the pool cross-connect is open (in a dual unit plant).

10) If the pool cross-connect is closed, operators would first attempt to establish the cross connection prior to aligning RHR in the spent fuel pool cooling assist mode.

11) No cooling water systems can be cross-connected between the two units via piping connections, except Service Water. The only cross-connect of cooling systems is through the SFP cross-connect. 
12) If restoration of cooling to the SFP is late (i.e., the pool is near boiling or already boiling), it is possible that reactor safety systems may be affected by the steam before cooling is restored.

13) Once reactor safety systems are affected by the effects of a boiling spent fuel pool, no chance of system restoration exists unless the steaming effects are first mitigated. This does not necessarily have to involve cooling the pool; redirection or venting of the steam from the reactor building is also possible.

14) In the case of reactor scram concurrent with loss of the SFPC system, the RHR train is modeled to be available for SFP cooling only if the operator establishes alternate shutdown cooling mode using a core spray injection system. No RHR train can be aligned in the spent fuel pool cooling assist mode if it is being used in the normal shutdown cooling mode.

15) Since there are several direct and indirect alarms and indications when boiling initiates, the unavailability of these alarms and indicators is not modeled.

16) The probability of direct core damage (i.e., core damage not caused by spent fuel pool steaming or flooding) is assumed to be negligible in the case of an uncomplicated recovery.

17) The SFPC system is powered from a non-safety bus. It will automatically trip on LOOP or on an engineered safeguards feature (ESF) actuation signal.

\section{D.2 Loss of SFPC (LOSFP) Modeling Assumptions}

1) The loss of the SFPC system does not cause a plant transient or reactor scram.

2) For Cases 1 and 2, one RHR train (two pumps) is assumed to be unavailable for use in spent fuel pool cooling.

\section{D.3 Loss of Offsite Power (LOOP) Modeling Assumptions}

1) The pool cross-connect cannot be opened without offsite power. (The overhead crane necessary for gate removal is powered from non-diesel backed buses.)

2) Two-unit plants can cross-connect vital power sources and share emergency diesel generator (EDG) power.

3) Unless all EDGs are available or offsite power is recovered within 4 hours, neither unit's RHR system is modeled on the basis that recovery would be complicated.

4) Availability of only a partial set of EDGs causes operator distraction and will inhibit early restoration of SFPC. 
5) SFPC systems which are powered from non-diesel backed buses cannot be powered without offsite power. In other words, credit is not taken for any ability to cross-tie vital and non-vital buses.

6) Loss of all EDGs (SBO) followed by an early recovery of offsite power is assumed to be a complicated recovery.

7) Early recovery of power is assumed to mean recovery of power within 4 hrs. After that, if all EDGs fail, the core cannot be cooled (DC power will last only for 4 hours).

8) Late recovery of power is assumed to mean recovery of power within $20 \mathrm{hrs}$. After that, the pool coolant will be near boiling in many cases.

\section{D.4 Loss of Coolant Accident in Primary System (PLOCA) Modeling Assumptions}

1) Upon a PLOCA, the SFPC system pumps trip on ESF actuation.

2) RHR is not available for spent fuel pool cooling assist mode for Case 1. This assumes that both trains of RHR are needed to cool the primary system.

3) The transfer gate between the reactor cavity and the spent fuel pool is always assumed to be open during refueling.

4) While in refueling mode, the operator must isolate the break and must establish the level using the ECCS prior to restoring spent fuel pool cooling.

5) In Cases 2 and 3, the transfer gate cannot be put back in place once a PLOCA event has been initiated.

6) While in Case 1, the operator will establish cooling on the primary side before restoring the spent fuel pool cooling.

7) Failure to isolate the break is assumed to result in a boiloff. Makeup systems are assumed not to be able to keep up with the loss from the break.

\section{D.5 Loss of Spent Fuel Pool Inventory Modeling Assumptions}

1) Two leak sites are modeled: the SFPC system (e.g., pipe break) and the spent fuel pool boundary.

2) Only leaks in the SFPC system with flow rates greater than the normal makeup rate are analyzed.

3) If a siphon breaker fails to isolate a leak in the SFPC system, the operator must isolate the break manually, otherwise leakage is assumed to continue until the level in the spent fuel 
pool drops below the end of the inlet piping and automatic siphon breaking ("isolation") occurs.

4) Failure to isolate a spent fuel pool boundary leak is assumed to result eventually in pool boiling (the leak rate greatly exceeds the makeup rate). Also, the boiloff timing is not affected by the makeup rate.

5) If the operator fails to respond relatively early to a spent fuel pool boundary leak, late recovery is not possible.

6) Early isolation of a leak is assumed to lead to a non-consequential flooding event.

\section{D.6 Seismic Event Modeling Assumptions}

1) Three levels of peak ground acceleration are considered. These ranges are as follows:

$$
\begin{aligned}
& \mathrm{PGA}<0.2 \mathrm{~g} \\
& 0.2 \mathrm{~g} \leq \mathrm{PGA} \leq 0.6 \mathrm{~g} \\
& \mathrm{PGA}>0.6 \mathrm{~g}
\end{aligned}
$$

Earthquakes with PGA $<0.1 \mathrm{~g}$ are assumed to result in a recoverable loss of offsite power and negligible component/structural damage. In this study, their effects are assumed to be included in the LOOP analysis. Earthquakes with PGA $>0.6 \mathrm{~g}$ are assumed to cause failure of the spent fuel pool structure. (The high confidence of low probability of failure capacity - HCLPF - for spent fuel pool structural damage was estimated to be $0.5 \mathrm{~g}$ for a representative BWR and $0.65 \mathrm{~g}$ for a representative PWR $[2,19]$.)

2) If the spent fuel pool structure is damaged by an earthquake (i.e., PGA $>0.6 \mathrm{~g}$ ), pool boiloff (of the remaining inventory) is assumed. 